\title{
Radionuclide Migration at the Rio Blanco Site, A Nuclear-stimulated Low-permeability Natural Gas Reservoir
}

\author{
Prepared by \\ Clay A. Cooper, Ming Ye, Jenny Chapman, and Craig Shirley \\ submitted to \\ Environmental Management Program \\ Nevada Site Office \\ National Nuclear Security Administration \\ U.S. Department of Energy \\ Las Vegas, Nevada
}

September 2005

Publication No. 45215 
Reference herein to any specific commercial product, process, or service by trade name, trademark, manufacturer, or otherwise, does not necessarily constitute or imply its endorsement, recommendation, or favoring by the United States Government or any agency thereof or its contractors or subcontractors.

Available for sale to the public, in paper, from:

\author{
U.S. Department of Commerce \\ National Technical Information Service \\ 5285 Port Royal Rd. S/D \\ Springfield, VA 22161-0002 \\ phone: 800.553.6847 \\ fax: 703.605.6900 \\ email: order@ntis.gov \\ online ordering: http://www.osti.gov/ordering.htm
}

Available electronically at http://www.doe.osti/bridge

Available for a processing fee to the U.S. Department of Energy and its contractors, in paper, from: U.S. Department of Energy

Office of Scientific and Technical Information

P.O. Box 62

Oak Ridge, TN 37831-0062

phone: 865.576.8401

fax: 865.576.5728

email: reports@adonis.osti.gov 


\title{
Radionuclide Migration at the Rio Blanco Site, A Nuclear-stimulated Low-permeability Natural Gas Reservoir
}

\author{
Prepared by \\ Clay A. Cooper, Ming Ye, Jenny Chapman, and Craig Shirley \\ Division of Hydrologic Sciences \\ Desert Research Institute \\ Nevada System of Higher Education \\ Publication No. 45215 \\ Submitted to \\ Environmental Management Program \\ Nevada Site Office \\ National Nuclear Security Administration \\ U.S. Department of Energy \\ Las Vegas, Nevada
}

September 2005

The work upon which this report is based was supported by the U.S. Department of Energy under Contract \#DE-AC52-00NV13609. Approved for public release; further dissemination unlimited. 
THIS PAGE INTENTIONALLY LEFT BLANK 


\section{EXECUTIVE SUMMARY}

The U.S. Department of Energy and its predecessor agencies conducted a program in the 1960s and 1970s that evaluated technology for the nuclear stimulation of lowpermeability gas reservoirs. The third and final project in the program, Project Rio Blanco, was conducted in Rio Blanco County, in northwestern Colorado. In this experiment, three 33-kiloton nuclear explosives were simultaneously detonated in a single emplacement well in the Mesaverde Group and Fort Union Formation, at depths of 1,780, 1,899, and 2,039 m below land surface on May 17, 1973. The objective of this work is to estimate lateral distances that tritium released from the detonations may have traveled in the subsurface and evaluate the possible effect of postulated natural-gas development on radionuclide migration. Other radionuclides were considered in the analysis, but the majority occur in relatively immobile forms (such as nuclear melt glass). Of the radionuclides present in the gas phase, tritium dominates in terms of quantity of radioactivity in the long term and contribution to possible whole body exposure. One simulation is performed for ${ }^{85} \mathrm{Kr}$, the second most abundant gaseous radionuclide produced after tritium.

A geologic model was developed that includes the Mesaverde Group and overlying Fort Union Formation. The upper device was detonated in the lower part of the Fort Union Formation, while the middle and lower devices were detonated in the Mesaverde Group. Both formations are low-permeability shales (permeability $\sim 10^{-17} \mathrm{~m}^{2}$ ), with lenses of slightly higher permeability sandstone spread throughout. The length of some of these lenses is as great as $1,000 \mathrm{~m}$. The formations are hydrostatically pressured; horizontally, the pressure gradient(s) are not well known, as production tests were not run to completion due to the length of time required to reach quasi-steady state. In the vicinity of the emplacement hole, the formations dip approximately $0.19 \mathrm{~m} \mathrm{~m}^{-1}$. Formation fluids (gas and water), however, are not confined to the dipping strata such that fluid interfaces, where they exist, are not dependent upon the direction or location of bedding planes.

The geologic model was incorporated into a conceptual flow and transport model that includes transport of radionuclides (tritiated water and krypton gas) in a two-phase (gas and liquid) system. The conceptual flow and transport model was developed into a numerical model. The model was implemented into the TOUGH2 computer program, which is a nonisothermal, multicomponent flow and transport code capable of modeling flow in three dimensions. Radionuclides released from the cavity were transported in both liquid and gas phases, and were allowed to partition between phases in accordance with Henry's law. Two types of simulations were conducted: one that investigated flow away from the three nuclear cavities in a regional pressure field, and the other that investigated flow from only the middle cavity toward a producing gas well. In addition, a few simulations were conducted that included discrete fractures in the vicinity of the cavities. Results showed fractures to be important when flow-controlling fractures were spaced greater than $20 \mathrm{~m}$ apart. For a greater fracture density, flow through fractures and flow through matrix gas resulted in nearly identical concentrations, indicating that inclusion of discrete fractures in this model may be unnecessary. The reason is that matrix diffusion of tritium in the gas phase acts to make the concentration field more uniform between fractures and matrix.

Two types of models were developed: Type 1, in which methane gas and liquid water with a single radionuclide mixed in both phases migrated within the natural gas reservoir in 
response to chemical gradients (i.e., liquid and gas diffusion), slight regional pressure gradients, and radionuclide decay. In these simulations, transport was modeled away from all three cavity/chimneys. A second type of model was run (Type 2) in which flow and transport was through a narrow interval, $120 \mathrm{~m}$ high, away from a single cavity/chimney toward a producing gas well located outside the current drilling exclusion boundary. Drilling is currently prohibited within $183 \mathrm{~m}(600 \mathrm{ft})$ of the emplacement well. The well was located $291 \mathrm{~m}$ away from the center of the cavity/chimney, such that hydraulic fractures from the production well were assumed to reach the exclusion boundary. The Type 2 simulations were also used to conduct uncertainty analysis using the Monte Carlo method to address parametric uncertainty of porosity and intrinsic permeability.

The Type 1 simulations show that for various combinations of intrinsic permeability and slight regional pressure gradient, the leading edge of the tritium mass fraction (i.e., concentration) field never extends beyond $100 \mathrm{~m}$ from the center of the three cavity/chimneys. These results, however, did not address the impact of a hypothetical nearby gas-producing well. To address this scenario, three-dimensional Type 2 simulations were required.

The three-dimensional simulations modeled flow and transport away from a single cavity/chimney toward a production well. The reservoir properties were those of the Fort Union Formation, as intrinsic permeability is about an order of magnitude greater than for the Mesaverde Group. Several simulations were conducted that investigated sensitivity of permeability, production rate, initial and residual liquid saturation, and tortuosity. For example, a one order-of-magnitude increase in intrinsic permeability had little effect on the transport of tritium, as the Peclet number for gas transport (a relationship between diffusive and advective flow) was much less than one (the highest gas velocities were never greater than $10^{-8} \mathrm{~m} \mathrm{~s}^{-1}$ ). The value of initial and residual liquid (and hence gas) saturation had an effect of diffusing tritium in the gas phase, but the distances varied only by several tens of meters or so. High gas saturation resulted in more spreading and mixing of tritium in the gas phase, and it allowed the center of the tritium "plume" to diffuse more rapidly than for cases where initial gas saturation was low. The choice of tortuosity model had the greatest effect on transport; a relative permeability based model resulted in radionuclide transport distances approximately $100 \mathrm{~m}$ greater than for a saturation-dependent (Millington-Quirk) model. As little research has been conducted on tortuosity in two-phase systems in the past 40 years, a lack of understanding of tortuosity may be the greatest limitation in the models.

Based on the Type 2 simulations with gas production, uncertainty of tritium transport in the gas reservoir was assessed using the Monte Carlo method. Permeability and porosity of the Fort Union Formation were considered as random parameters due to their heterogeneity in the site. Distributions of and the correlation between the two variables were identified based on their on-site core measurements from two boreholes, assuming that the measurements were representative. Five hundred realizations of correlated random fields of the two parameters were generated and used to construct the TOUGH2 input files. Except for these two random parameters, other model parameters remained the same as those of the Type 2 simulations with reference parameters. The stabilization of the statistics of quantities of interest obtained from the 500 realizations was examined empirically and the results suggested that 500 realizations were sufficient to yield meaningful statistics used to quantify tritium transport uncertainty. The 50th percentile represented the prediction of tritium 
transport in an average sense, while the 5 th and 95 th percentiles quantify associated predictive uncertainty caused by the uncertain values of permeability and porosity due to their heterogeneity at the site. The 5th and 95th percentiles were considered superior to the mean and variance of the mass fractions for uncertainty assessment in this project, since there is no evidence that the simulated mass fractions followed normal distributions. Whereas the 50th percentile tritium plume did not approach the production well during the entire simulation period, the 95th percentile tritium plume approached to the production well during and after the pumping period. The breakthrough curves of the 95 th percentile of tritium mass fraction at the pumping well indicated that the tritium concentration could be several orders of magnitude higher than the mass fraction of deterministic Type 2 simulations, suggesting that the uncertainty was not negligible. Nonetheless, the peak mass fraction at the pumping well was close to the environmental background value. Additional uncertainties remain that could not be quantified by the Monte Carlo analysis either due to lack of data (e.g., the lateral gradient) or because they are a conceptual component (e.g., location of pumping well, presence of multiple wells, etc.).

These simulations were conducted with the best information available. No wells have been drilled in the vicinity since the mid-1970s; the study is therefore limited by measurements made in wells during the late 1960s and early to mid-1970s. The greatest limitation is an incomplete understanding of the intrinsic permeability in the reservoir due to the lack of measurements. Geophysical techniques, such as three-dimensional seismic analysis, and/or data from new wells drilled in the area, could be used to define spatial heterogeneity in the flow field, allowing an improved description of the permeability field in the computations. 
THIS PAGE INTENTIONALLY LEFT BLANK 


\section{CONTENTS}

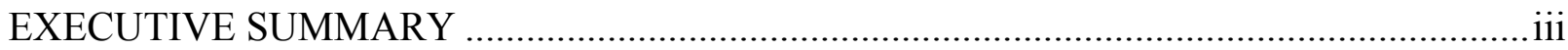

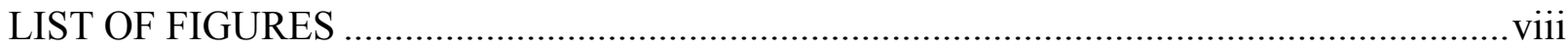

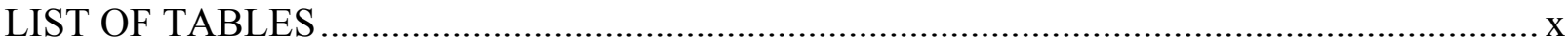

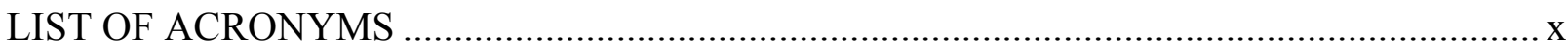

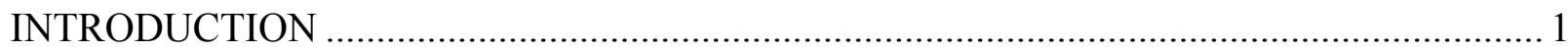

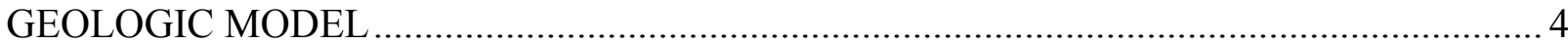

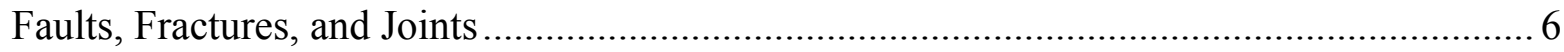

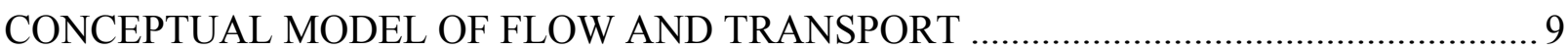

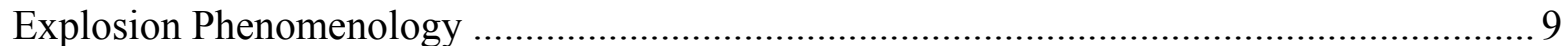

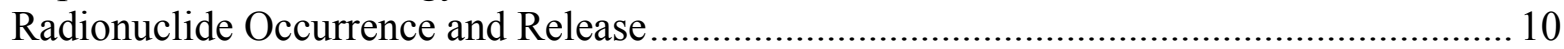

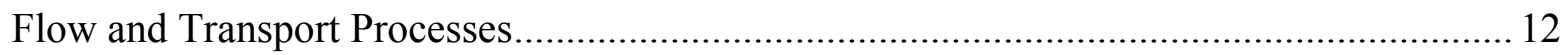

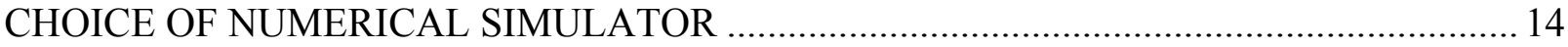

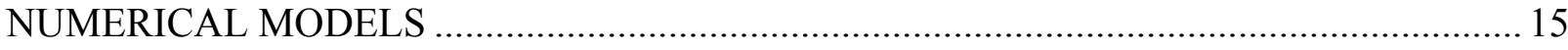

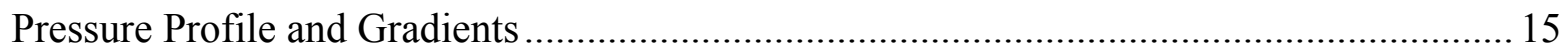

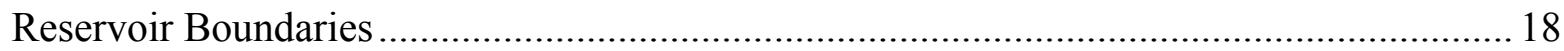

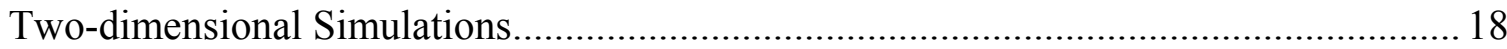

Three-dimensional Simulations with Gas Production...................................................2 20

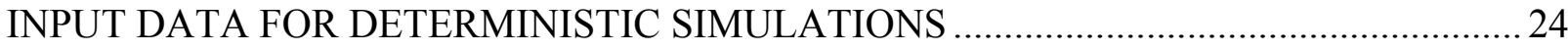

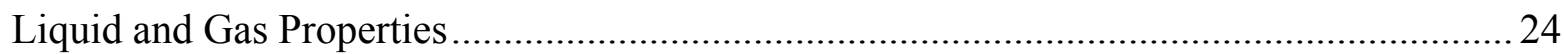

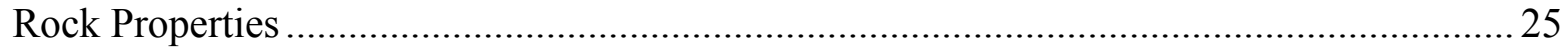

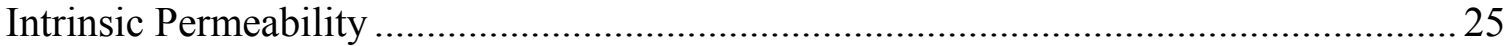

Porosity, Saturation, Matric Potential and Relative Permeability ……………………..... 29

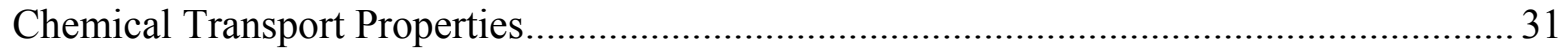

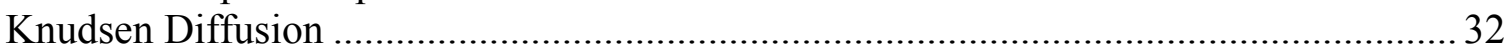

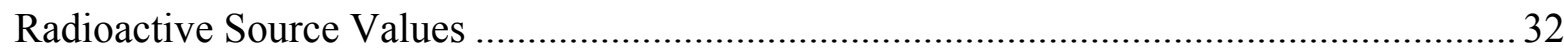

Regulatory Context of Radionuclide Mass Fraction Results .............................................34

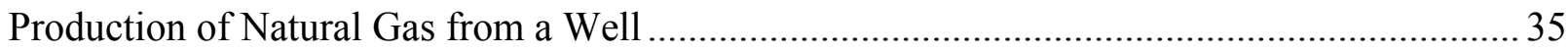

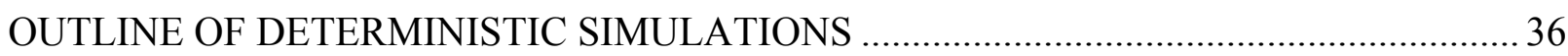

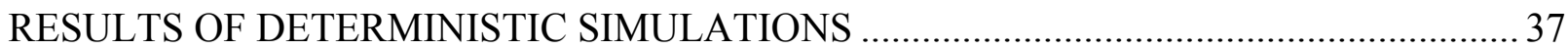

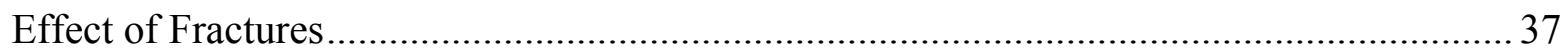

Two-dimensional Transport of Tritiated Water in an Unstressed Gas Reservoir .................. 40

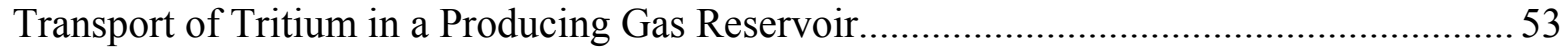

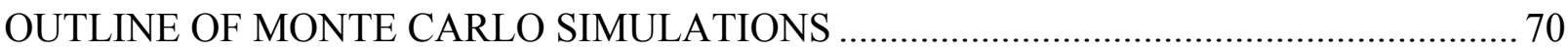

Identification of the Distributions of Permeability and Porosity .......................................... 70

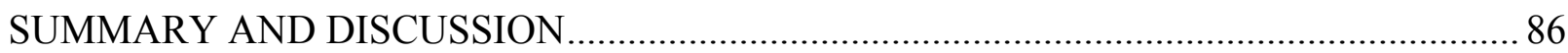

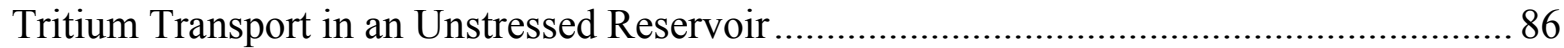

Radionuclide Transport in a Producing Gas Field .............................................................. 87

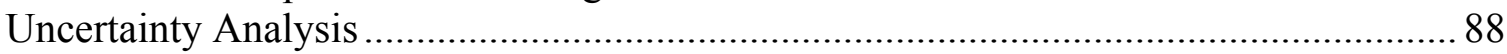

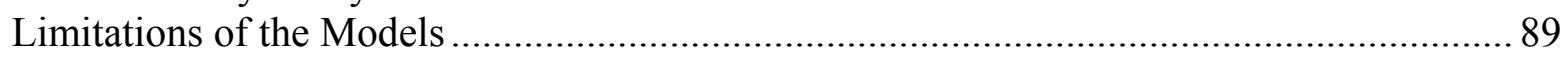

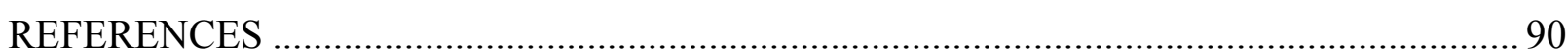


APPENDIX A: WELLS AND LITHOLOGY

APPENDIX B: FRACTURE DATA AND ANALYSIS ………........................................

APPENDIX C: TOUGH2 V2.0 GOVERNING EQUATIONS

\section{LIST OF FIGURES}

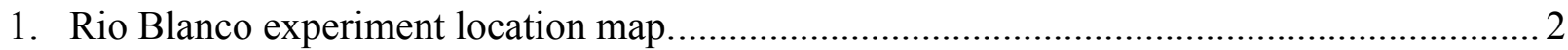

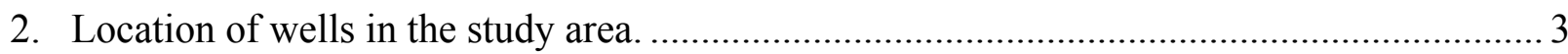

3. Schematic cross section of the Rio Blanco test showing the discontinuous sands of the Fort Union Formation and Mesaverde Group and the concept of connecting those via

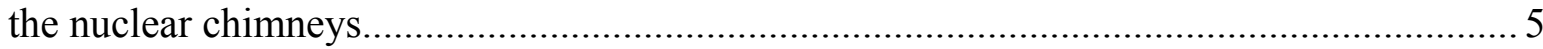

4. Stratigraphy within the vicinity of the emplacement hole, RB-E-01_................................. 7

5. Cross section A-A'

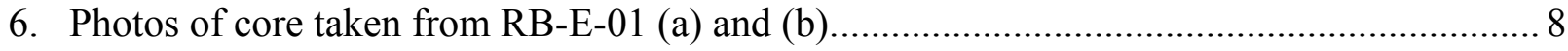

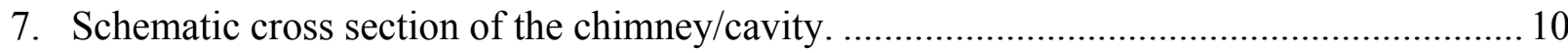

8. Example of a conventional gas reservoir located in an anticline (a) and one located in a low-permeability gas reservoir such as those found in the Piceance Basin (b).................... 13

9. Pressure-depth plot for wells near the detonation point....................................................... 16

10. Hydraulic and transport boundary conditions (a) and computational mesh (b) for the two-dimensional simulations.

11. Saturation and gas velocity profiles resulting from steady-state simulations for combinations of horizontal (upper and lower) boundary conditions in a one-dimensional vertical column.

12. Cross section of relationship between hydrofrac for gas production and nuclear stimulation zone.

13. Model formulation for gas flow and tritium transport to a pumping well (a), and integral finite-difference grid for simulation (b). 22

14. Hydraulic and transport boundary conditions for the three dimensional simulations..........2 23

15. Lognormal probability-probability plot of intrinsic permeability for the Fort Union

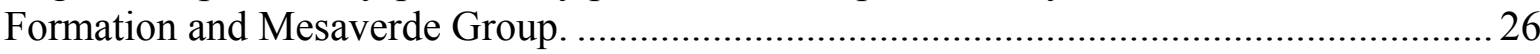

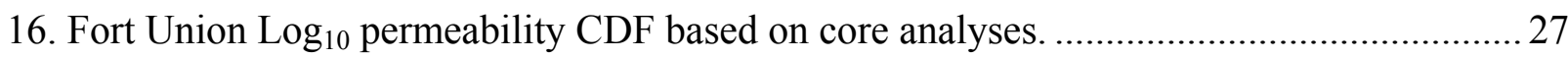

17. Fort Union $\log _{10}$ permeability CDF based on Saraband ${ }^{\odot} \log$ estimates.............................. 27

18. Mesaverde $\log _{10}$ permeability CDF based on core analyses. ............................................... 28

19. Mesaverde $\log _{10}$ permeability CDF based on Saraband ${ }^{\odot} \log$ estimates.............................. 28

20. Moisture retention curve based upon three samples from a plug taken at $1,745.5 \mathrm{~m}$ from

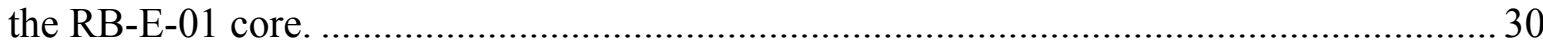

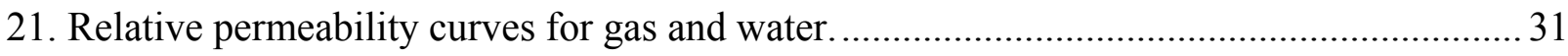

22. Schematic of how fractures are incorporated using the MINC subroutine in TOUGH2 2..... 37

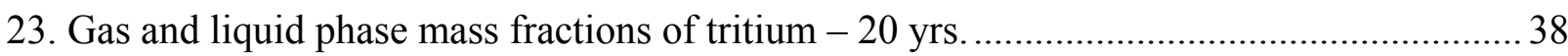


24. One order-of-magnitude increase in fracture permeability - $20 \mathrm{yrs}$

25. Results of a two-dimensional simulation showing $X_{g}{ }^{T H O}$ with the mean properties from Table 3.

26. Results of a two-dimensional simulation showing $X_{g}{ }^{T H O}$ with the k one order of magnitude greater than in the previous "reference" simulation.

27. Results of a two-dimensional simulation showing $X_{g}{ }^{T H O}$ with the mean properties from Table 3 and a slight horizontal pressure gradient of $9.81 \mathrm{~Pa} \mathrm{~m}^{-1}$ (equivalent to $0.001 \mathrm{~m} \mathrm{~m}^{-1}$ of freshwater head) imposed across the domain.....

28. Results of a two-dimensional simulation showing $X_{g}{ }^{K r}$ (krypton mixed in the gas phase). 50

29. Mass fraction of tritium in the gas phase $\left(X_{g}{ }^{T H O}\right.$ ) after (a) 1 month, (b) $1 \mathrm{yr}$, (c) $10 \mathrm{yr}$,

(d) $20 \mathrm{yr}$, (e) $34 \mathrm{yr}$, (f) $45 \mathrm{yr}$, (g) $55 \mathrm{yr}$, (h) $66 \mathrm{yr}$, (i) $100 \mathrm{yr}$, (j) $150 \mathrm{yr}$, (k) $250 \mathrm{yr}$, and

(l) $500 \mathrm{yr}$ for the "reference" simulation with mean properties.

30. Mass fraction of tritium in the liquid phase $\left(X_{l}^{T H O}\right.$ ) after (a) 1 month, (b) $1 \mathrm{yr}$, (c) $10 \mathrm{yr}$,

(d) $20 \mathrm{yr}$, (e) $34 \mathrm{yr}$, (f) $45 \mathrm{yr}$, (g) $55 \mathrm{yr}$, (h) $66 \mathrm{yr}$, (i) $100 \mathrm{yr}$, (j) $150 \mathrm{yr}$, (k) $250 \mathrm{yr}$, and

(l) $500 \mathrm{yr}$ for the "reference" simulation with mean properties.

31. Mass fraction of tritium in the gas phase $\left(X_{g}{ }^{T H O}\right.$ ) after (a) 1 month, (b) $1 \mathrm{yr}$, (c) $10 \mathrm{yr}$,

(d) $20 \mathrm{yr}$, (e) $34 \mathrm{yr}$, (f) $45 \mathrm{yr}$, (g) $55 \mathrm{yr}$, (h) $66 \mathrm{yr}$, (i) $100 \mathrm{yr}$, (j) $150 \mathrm{yr}$, (k) $250 \mathrm{yr}$, and

(l) $500 \mathrm{yr}$ for the condition of permeability, $k=3.4 \times 10^{-15} \mathrm{~m}^{2}$, or one order of magnitude higher than the "reference" case.

32. Mass fraction of tritium in the gas phase $\left(X_{g}{ }^{T H O}\right.$ ) after (a) $34 \mathrm{yr}$, (b) $45 \mathrm{yr}$, (c) $55 \mathrm{yr}$, (d) $66 \mathrm{yr}$, (e) $100 \mathrm{yr}$, (f) $150 \mathrm{yr}$, (g) $250 \mathrm{yr}$, and (h) $500 \mathrm{yr}$ for the conditions similar to the "reference" simulation but with a 25 percent higher rate of gas production.

33. Mass fraction of tritium in the gas phase $\left(X_{g}{ }^{T H O}\right.$ ) after (a) $34 \mathrm{yr}$, (b) $45 \mathrm{yr}$, (c) $55 \mathrm{yr}$,

(d) $66 \mathrm{yr},(\mathrm{e}) 100 \mathrm{yr}$, (f) $150 \mathrm{yr}$, (g) $250 \mathrm{yr}$, and (h) $500 \mathrm{yr}$ for simulations with the initial gas saturation as 0.6 .

34. Mass fraction of tritium in the gas phase $\left(X_{g}{ }^{T H O}\right.$ ) after (a) $34 \mathrm{yr}$, (b) $45 \mathrm{yr}$, (c) $55 \mathrm{yr}$, (d) $66 \mathrm{yr},(\mathrm{e}) 100 \mathrm{yr}$, (f) $150 \mathrm{yr}$, (g) $250 \mathrm{yr}$, and (h) $500 \mathrm{yr}$ for simulations with the initial gas saturation as 0.2 .

35. Mass fraction tritium in the gas phase $\left(X_{g}{ }^{T H O}\right.$, left-hand column, a-d) and mass fraction tritium in the liquid phase $\left(X_{l}^{T H O}\right.$, right-hand column, e-h) for simulation with conditions similar to the "reference" model except that tortuosity has been changed from a Millington-Quirk saturation-based model to a relative permeability based model. 71

36. Histograms of Core and $\log$ data of $\log _{10}$ permeability of the Fort Union Formation. ....... 75

37. Histograms of Core and Log data of porosity (\%) of the Fort Union Formation................ 76

38. Empirical cumulative distribution function (CDF) of (a) permeability of Fort Union Formation obtained from core analysis and its (b) LN, (c) SB, and (d) SU transforms...... 76

39. Empirical cumulative distribution function (CDF) of (a) porosity of the Fort Union Formation obtained from core analysis and its (b) LN, (c) SB, and (d) SU transforms...... 77

40. Correlation between SB transformed permeability and porosity of the Fort Union Formation. 
41. Cumulative distribution functions (CDFs) of measured (dashed) and generated (solid)

(a) $\log$ permeability and (b) porosity.

42. Examination of convergence of Monte Carlo simulations of mass fractions of tritium at

(a) liquid and (b) gas phases at the production well. 81

43. (a) Mean $(\mu)$, (b) upper bound of the 95 percent confidence interval $(\mu+2 \sigma)$, (c) 50th percentile, (d) 75th percentile, (e) 95th percentile, and (f) 99th percentile of mass fraction of tritium in gas phase at 66 years after the detonation (one year after the end of gas production).

44. (a-1) through (1-1) 50th and (a-2) through (1-2) 95th percentiles of mass fraction of tritium in the gas phase after (a) 1 month, (b) $1 \mathrm{yr}$, (c) $10 \mathrm{yr}$, (d) $20 \mathrm{yr}$, (e) $34 \mathrm{yr}$, (f) $45 \mathrm{yr}$, (g) $55 \mathrm{yr}$, (h) $66 \mathrm{yr}$, (i) $100 \mathrm{yr}$, (j) $150 \mathrm{yr}$, (k) $250 \mathrm{yr}$, and (l) $500 \mathrm{yr}$ of detonation.

\section{LIST OF TABLES}

1. Fawn Creek buildup test results (CER Geonuclear, 1970)…............................................... 17

2. Scandard Draw buildup test results (CER Geonuclear, 1970) ……...................................... 17

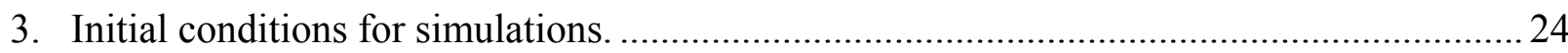

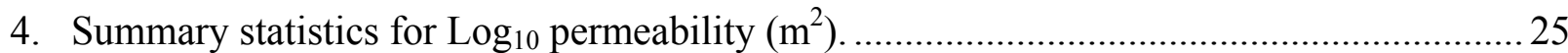

5. Tritium withdrawn from wells RB-E-01 and RB-AR-2 in dry gas (methane) and liquid....33

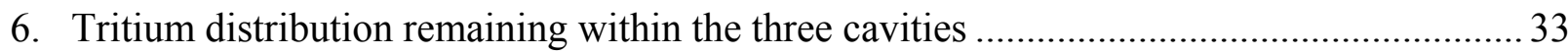

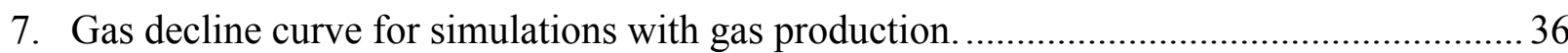

8. Descriptive statistics of porosity measurements of the Fort Union Formation obtained

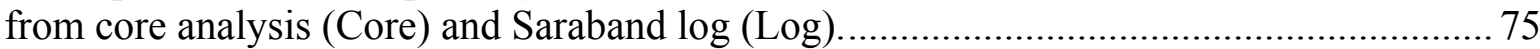

9. Lilliefors statistics of the original and transformed permeability and porosity of the Fort Union Formation.

\section{LIST OF ACRONYMS}

$\mathrm{Ci}$

DOE

$\mathrm{MPa}$

TOUGH

USGS curies

U.S. Department of Energy

megapascals

Transport of Unsaturated Groundwater and Heat

U.S. Geological Survey 


\section{INTRODUCTION}

The U.S. Atomic Energy Commission (predecessor to the U.S. Department of Energy [DOE]) was responsible for nuclear weapons research and development as part of the national defense program during the 1960s and 1970s. In addition to underground testing of nuclear weapons, the commission oversaw a joint program between industry and government to develop technology for nuclear stimulation of low-permeability gas reservoirs. Project Rio Blanco was the third experiment under the program; it was, however, the first experiment in the United States where three nuclear explosives were detonated simultaneously in the same emplacement hole.

Project Rio Blanco is located in west-central Colorado. The three 33-kiloton (kt) nuclear explosives were placed in a 2,134-m-deep well (RB-E-01) at 1,780, 1,899, and 2,039 $\mathrm{m}$ below the land surface and detonated on May 17, 1973. The surface location of the test is $108^{\circ} 21^{\prime} 59^{\prime \prime}$ west longitude and $39^{\circ} 47^{\prime} 35^{\prime \prime}$ north latitude. The objective of the experiment was to produce natural gas from formations not conducive to production by conventional means (e.g., hydraulic and/or acid fracturing). Although the formations were extensively fractured, subsequent drilling and testing indicated that the permeability between the location of the upper and lower nuclear devices had actually decreased, rather than increased. Of several reasons given for this, the most plausible is that the initial values of permeability were overestimated (Toman, 1975), because characterization tests were not run to steady-state due to extremely low formation permeabilities. It may also have been that the

puddle melt associated with the detonation (discussed below) that formed at the bottom of the three chimneys restricted vertical flow.

This report documents a numerical model that describes and estimates the extent of subsurface radionuclide (primarily tritium) transport at Rio Blanco. The model was implemented into the Transport of Unsaturated Groundwater and Heat (TOUGH2) computer program (Pruess et al., 1999). The results provide an estimate of the maximum distance that radionuclides may travel in "unstressed" (a gas reservoir with no production or injection) or "stressed" (a gas reservoir with a production well) conditions using the most reliable data available.

A geologic model and conceptual flow and transport model was presented in an earlier report (Cooper and Chapman, 2001). Key processes contributing to fluid flow and radionuclide transport in nuclear-stimulated gas reservoirs were identified in that report. The results of those analyses were used to further refine the conceptual model and to develop the numerical model discussed in this report.

Figure 1 is a location map of the Rio Blanco experiment. The emplacement hole for the nuclear explosive, RB-E-01, was drilled in 1973 and its location is shown in Figure 2. The simultaneous detonation of the three explosives occurred on May 17, 1973. The first post-detonation re-entry well was drilled into the upper cavity in September 1973. The reentry was through the emplacement hole, and it was not given a separate well name and number. A second re-entry well, RB-AR-2, was drilled into the lower cavity in 1974 (Fenix and Scisson, 1976; U.S. Energy Research and Development Administration, 1975), followed by a formation evaluation well, RB-U-2, drilled as part of the effort to understand why permeabilities were apparently lower after the detonation. Two characterization wells, Fawn 
Creek Government No.1 and Scandard Draw No.1, were production-tested in 1970. Their locations are also shown in Figure 2. An additional evaluation well, RB-U-4, was drilled approximately $190 \mathrm{~m}$ (625 ft) northeast of the emplacement hole (Colorado Department of Health, 1980). This well site was selected so that it would be beyond any predicted fracture zone around the detonations, and is also near the drilling exclusion boundary. Well RB-U-4 was completed in November 1974, tested in December 1974, and tested again during the period from November 1975 until April 1976. The testing showed low-flow capacity from the Fort Union Formation, as was observed in the production testing from the top cavity of the RB-E-01 well.

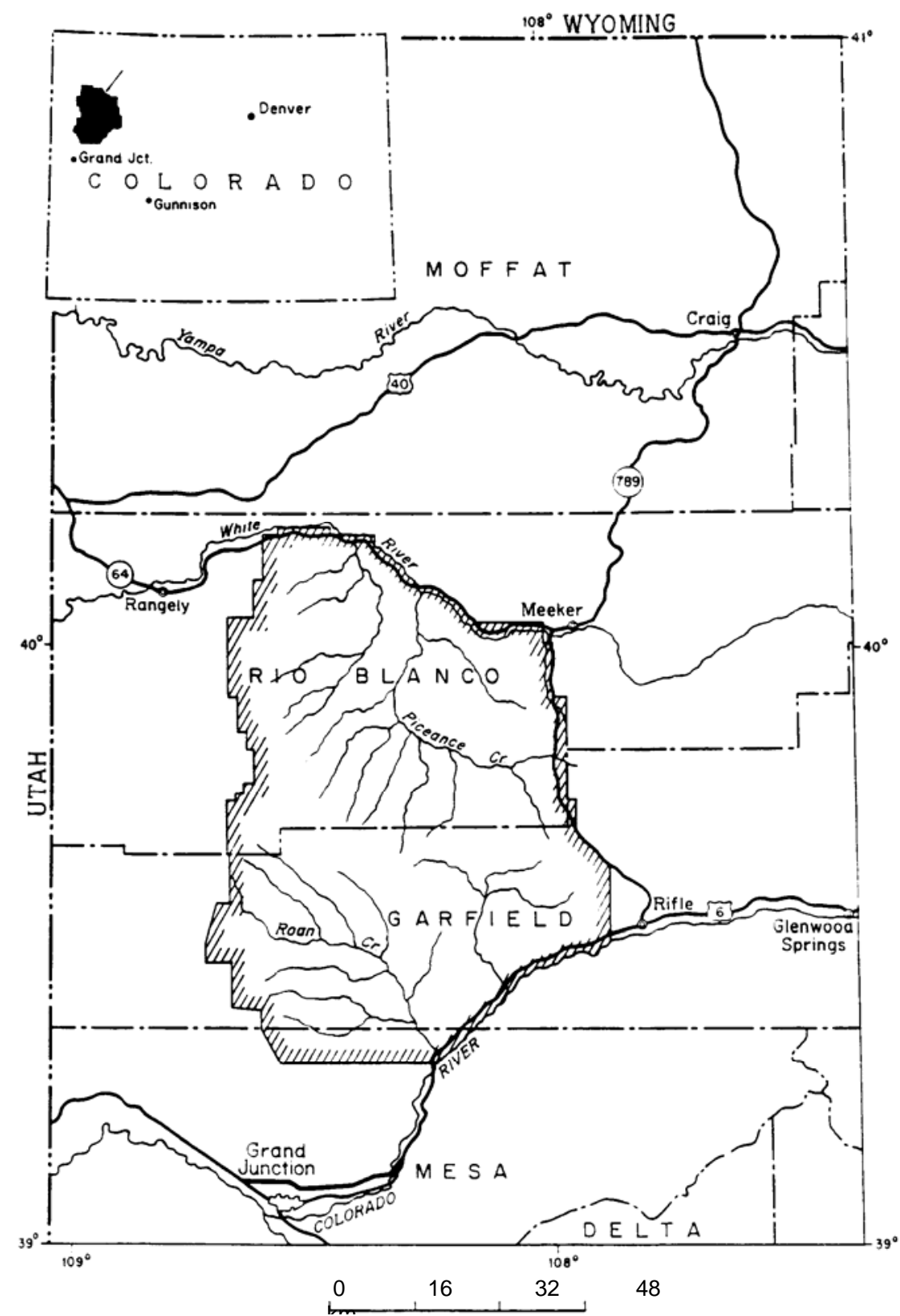

Figure 1. Rio Blanco experiment location map. 

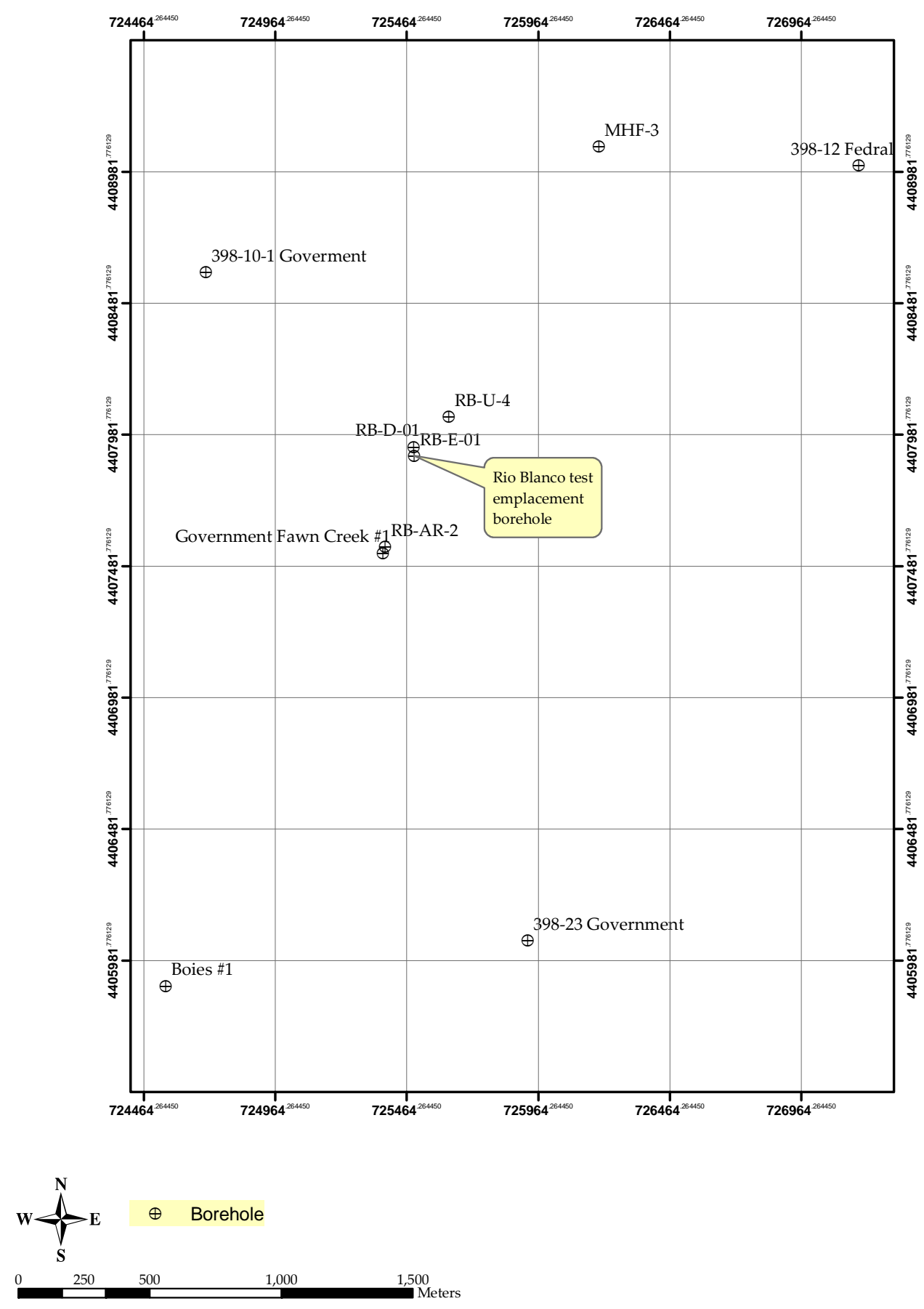

Figure 2. Location of wells in the study area.

Tritiated water produced during production testing at Rio Blanco was injected into nearby well Fawn Creek Government No. 1 within the interval 1,716 to 1,851 m below land surface. The Fawn Creek well was later pumped to remove some of the tritiated water. The final concentration in the well after pumping was $500 \mathrm{pCi} \mathrm{mL}^{-1}$ (pico curies per milliliter). 
Rio Blanco is part of the Long-term Hydrologic Monitoring Program, operated by the U.S. Environmental Protection Agency. The program collects and analyzes samples for radionuclides each year from wells and springs around Rio Blanco. No test-related radionuclides have been detected in the decades this program has operated. Natural gas samples have also been collected from production wells in the area. No test-related radionuclides have been detected in those samples either (Shirley, 2004).

\section{GEOLOGIC MODEL}

The three nuclear devices of the Rio Blanco test were detonated in the Upper Cretaceous Mesaverde Formation or Group (it has since been designated as a Group) in the Piceance Creek Basin of Western Colorado (Hansley and Johnson, 1980). The upper device was detonated in the Ohio Creek member of the Mesaverde, although it was originally reported to have been detonated in the Paleocene Fort Union Formation (CER Geonuclear, 1970). The stratigraphy was revised based upon pollen analyses (Hansley and Johnson, 1980).

The Piceance Creek Basin is a structurally controlled sedimentary basin formed during the Laramide orogeny, from latest Cretaceous through Paleocene time (Johnson, 1989). This same orogeny created the Overthrust Belt, a large geologic structure extending from Montana to New Mexico that has been broken into numerous separate basins and mountain uplifts. Processes associated with development of the Overthrust Belt have resulted in rocks that have been tilted in various directions and exposed to erosion. In many basins, this reassemblage of rocks has resulted in reservoirs with fragmented hydraulic gradients. The extremely low permeability has helped preserve pre-Overthrust fluid pressures; reorganization of those rocks created hydraulic gradients with no relation to the current structure (Masters, 1979). This interplay between uplift, erosion, and low permeability has led to the development of unconventional gas reservoirs in the Piceance Creek Basin, as the gas phase is not always associated with individual strata. Instead, gas is commonly found structurally downdip from water-saturated formations, and it often has no obvious trapping mechanism aside from the low permeability of the reservoir in which it exists (Johnson, 1989).

Within the Mesaverde Group, a second, smaller scale of heterogeneity in permeability exists. This is the scale at which local lenticular, higher permeability gas-producing zones are located. These sandstones are discontinuous, and their permeability is highly spatially variable as the deposits are alluvial. Their locations are also largely unknown as no geophysical imaging was conducted to characterize the reservoir prior to the execution of the nuclear experiment. Figure 3 shows the relationship between heterogeneity and the test locations.

Compounding the problem of the lack of discrete gas/water contacts in any of the fields within the Piceance Basin is that accurate measurements of fluid pressures are largely absent. Most drill-stem tests were not run to completion because the pressure-buildup time was very slow due to the low permeability (Ronald Johnson, U.S. Geological Survey [USGS], personal communication, 2000). The Mesaverde Group is overpressured throughout much of the Piceance Creek Basin, although in the study area it is presumed normally pressured (Johnson, personal communication). Below 3,000 $\mathrm{m}$ in the study area (which is 
below the lowermost test), the formation is thought to be overpressured. Much of this evidence is derived from mud weights used during drilling (Johnson, 1989).

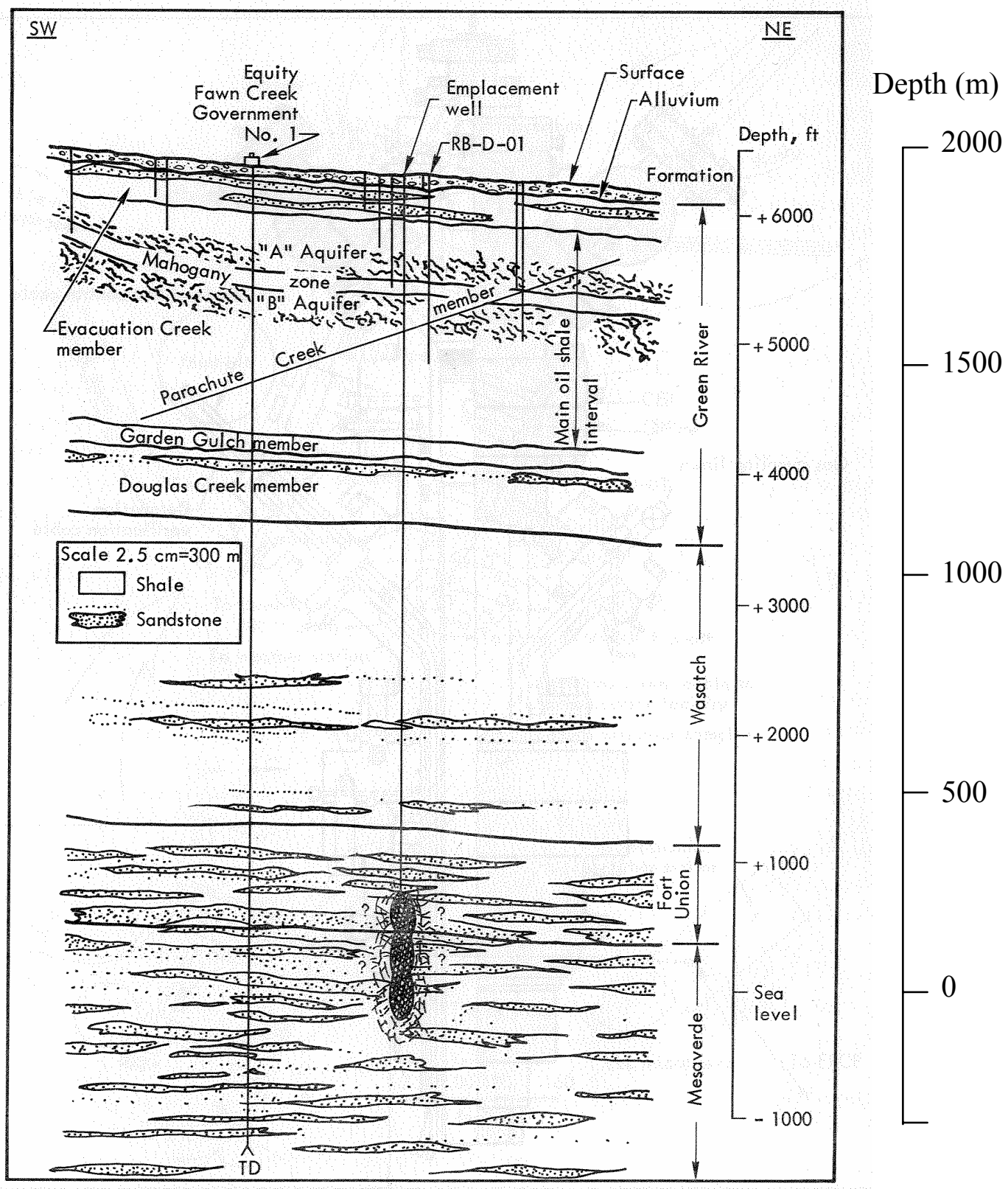

Figure 3. Schematic cross section of the Rio Blanco test showing the discontinuous sands of the Fort Union Formation and Mesaverde Group and the concept of connecting those via the nuclear chimneys (from Woodruff and Guido, 1974). 
Deposition of the Mesaverde Group in the basin mostly predates the Laramide orogeny. The dip of the Mesaverde is not strictly known in the vicinity of the emplacement well. However, the structure of the underlying Jurassic Dakota sandstone is known, and it dips to the northeast at $0.19 \mathrm{~m} / \mathrm{m}$ (Rocky Mountain Map Co., 1999). Because the Mesaverde and Dakota sandstones underwent the same orogeny, and therefore have similar tectonic history and deformation, it is likely that both formations dip at the same angle.

The stratigraphic and lithologic contacts in proximate boreholes were collected from available sources and are presented in Appendix A. The contacts for the Green River, Fort Union Formation, Wasatch Group, and Mesaverde Group were combined with the USGS digital elevation models to create the block model shown in Figure 4. The cross section A-A' (Figure 5) shows that the geology is strataform with a gentle dip to the north. Only two of the boreholes fully penetrate the Mesaverde Formation (Government [Federal] 398-10-1 and Government 398-17-1), so the base elevation of zero meters shown on both the block model and the cross section are for convenience. Variation in thickness of the Mesaverde is discussed below.

The rocks are highly heterogeneous from the centimeter scale (Figure 6a,b) to the scale of tens and hundreds of meters (Figure 6c). Although theoretically possible, incorporating processes from scales ranging from centimeters to kilometers requires physical and chemical couplings not yet fully understood. Even more basic, the details of the spatial variability of porosity and permeability (and associated characteristics such as tortuosity and relative permeability) are unknown in the subsurface within the vicinity of the emplacement hole. Based on outcrop studies, the ratio of length/width/thickness of sandstone lenses is 140/14/1 for channel-fill sand(stones) and 190/80/1 for point-bar sand(stones) (CER Geonuclear, 1970). However, the location and extent of sandstone lenses in the vicinity of the nuclear detonation is conjecture.

\section{Faults, Fractures, and Joints}

A complete analysis of faults, fractures, and joints associated with natural processes (i.e., not related to the nuclear explosions) in the area is described in Appendix B. All of the major faults are located further than several kilometers $(\mathrm{km})$ from the emplacement hole, and were therefore not included in the model. A visual inspection of core samples recovered from the emplacement hole showed little evidence for fractures, and essentially no evidence for fractures that could control flow. Natural fractures were therefore not included in the model, though several simulations were conducted that included fractures implicitly in the models as separate sensitivity studies. The outcome of these simulations is discussed in the Results section. Fractures associated with detonation of the nuclear device, as well as with hydraulic fracturing for possible gas production, were included in all simulations. 


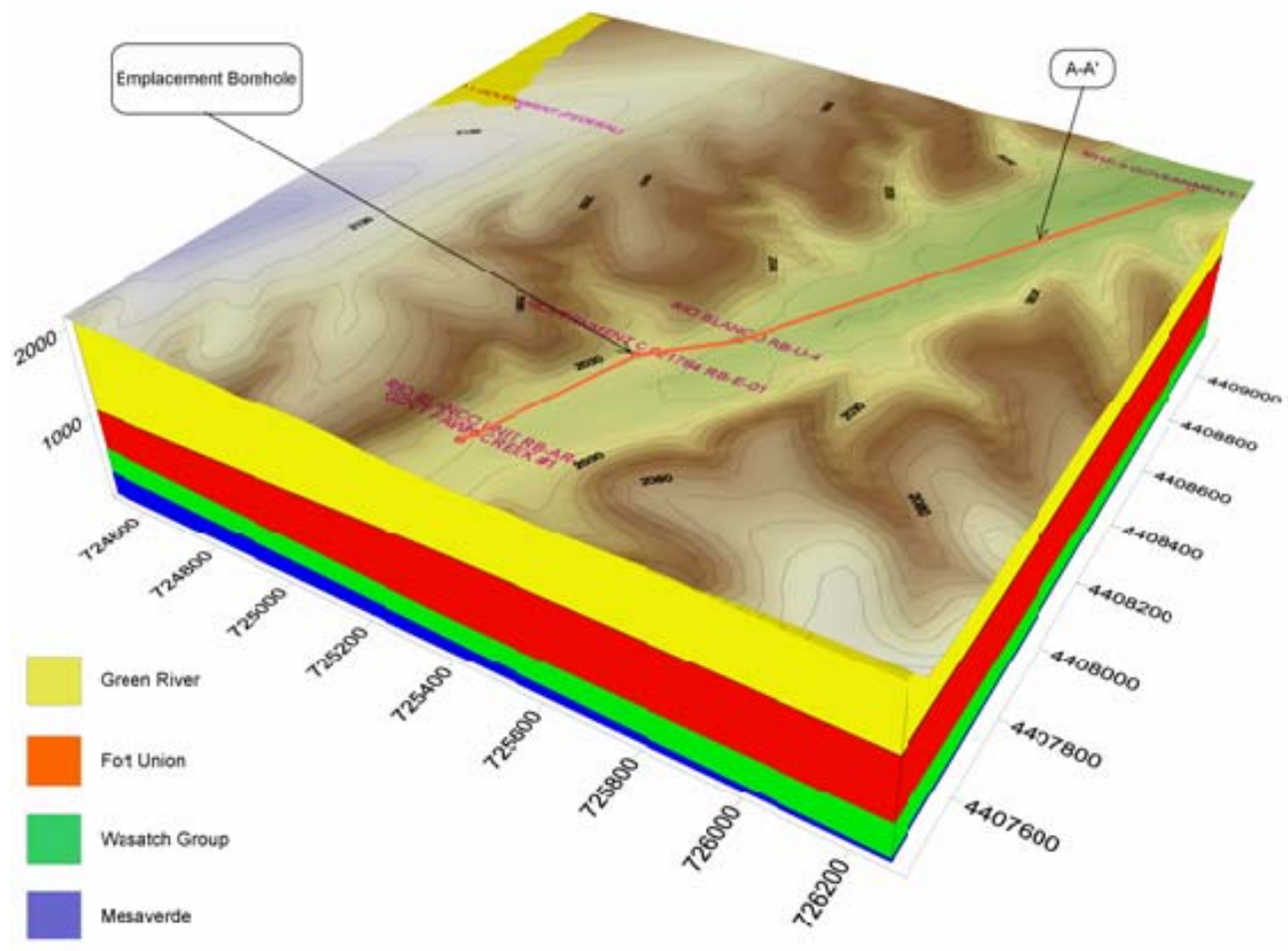

Figure 4. Stratigraphy within the vicinity of the emplacement hole, RB-E-01.

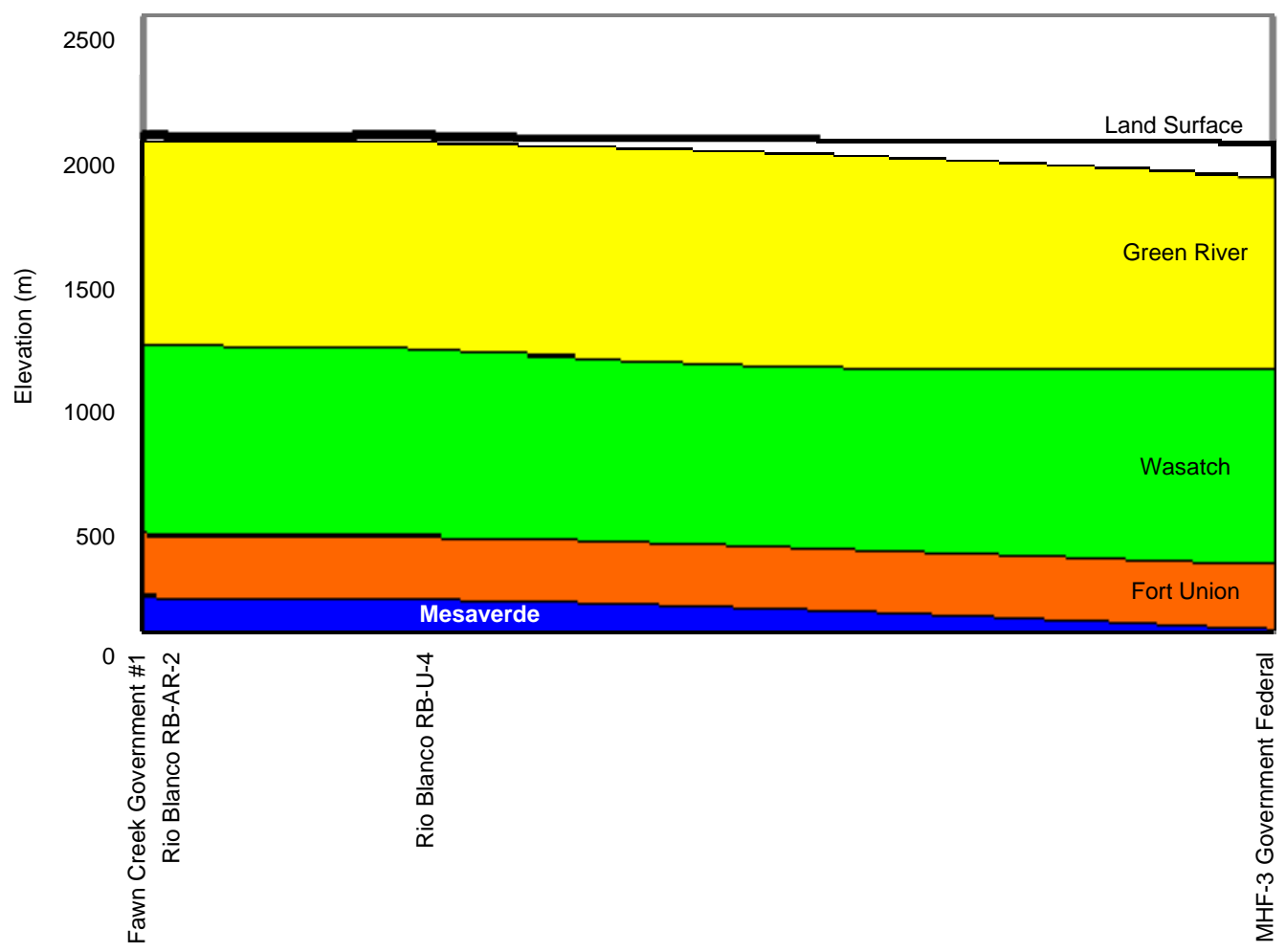

Figure 5. Cross section A-A'. 


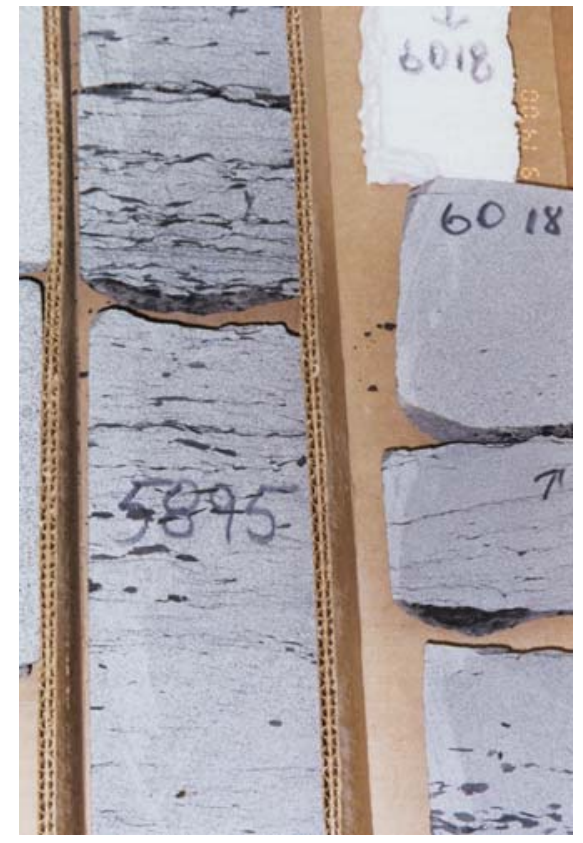

(a)

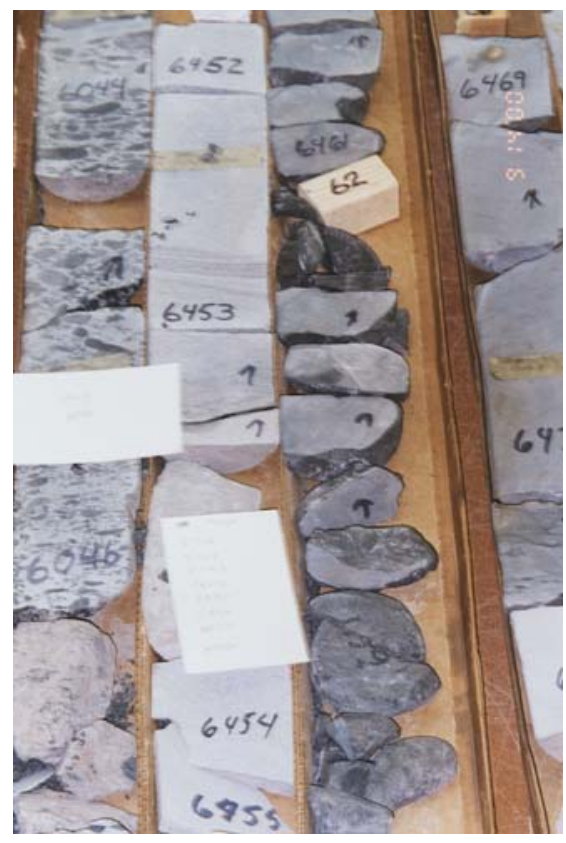

(b)

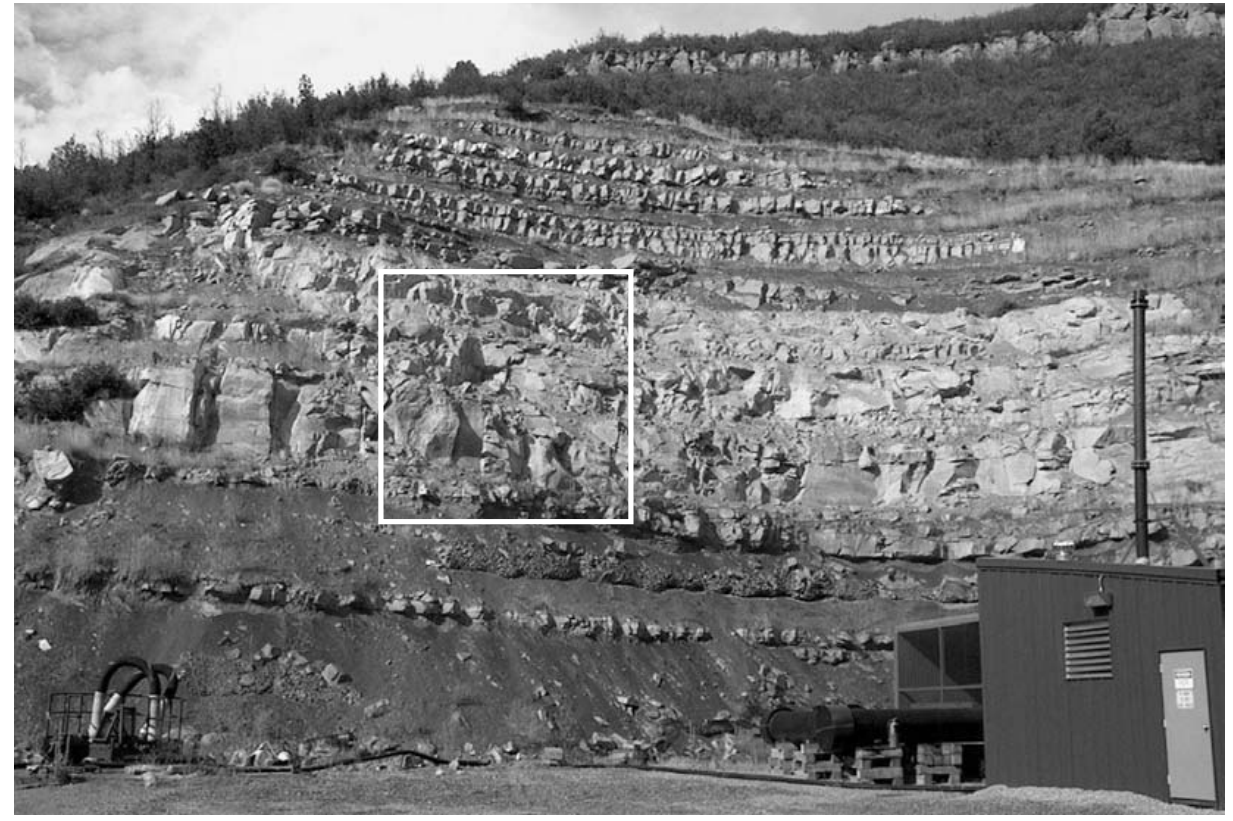

(c)

Figure 6. Photos of core taken from RB-E-01 (a) and (b). The width of each piece is $10 \mathrm{~cm}$ (approximately 4 inches). The numbers are depth in feet below the land surface. The lower photograph (c) is of an outcrop of the Mesaverde Group and shows meter-scale heterogeneity. The white box is approximately $10 \mathrm{~m}^{2}$. The dark rocks in the lower onefourth of the figure are coal beds. Lower photo taken by W. Koontz (from Carroll, 2003). 


\section{CONCEPTUAL MODEL OF FLOW AND TRANSPORT}

\section{Explosion Phenomenology}

The discussion of mechanical effects such as rock fracturing, cavity formation, and pressure history associated with the detonations are from Toman and Tewes (1972), Taylor (1972), Beaver (1972), and Toman (1975). This information is partly derived from models of detonations in other formations that have been scaled to the rock properties at Rio Blanco.

Production tests in the Fawn Creek Government No. 1 well indicated that the formation pressure prior to the detonations was 19.2 MPa (exact depth not given; CER Geonuclear Corp., 1970). The three 33-kt nuclear explosives were simultaneously detonated at 1,780,1,899, and 2,039 $\mathrm{m}$ below the land surface. The formation pressure exceeded the lithostatic pressure within 10 seconds of the blast, causing fracturing of the Mesaverde Group and Fort Union Formation (Toman and Tewes, 1972). The extreme temperatures from the blast vaporized much of the rock, water, and gas, resulting in three underground cavities, each with a volume on the order of $1.3 \times 10^{5} \mathrm{~m}^{3}$ (approximately $10^{9} \mathrm{~kg}$ of rock). Within one minute of the detonation, the formation pressure fell to pre-detonation formation pressure. Molten rock formed a puddle of lava (puddle glass, or melt) several meters deep at the bottom of each cavity. In theory, when the gas pressure could no longer sustain the weight of the roof of the cavity, the roof should have collapsed into the cavity, forming a high-porosity rubble called a chimney. In his analysis of drilling into the upper cavity, Toman (1975) reported that it is uncertain how much (if any) rock collapsed into the cavity. The same uncertainty can be said about the lower two cavities, as there is no documentation suggesting whether or not they collapsed. Within several days of the detonations, the three cavities cooled to below 600 Kelvin $(\mathrm{K})$, and condensation of steam began. At this time, the rate of cooling of the cavity gas sharply decreased. Within one month, most of the steam condensed, causing the formation pressure to drop to 11.1 megapascals (MPa). At this point in time, formation gas flowed into the cavity, resulting in a rise back to the pre-test formation pressure in the cavity/chimney (Toman and Tewes, 1972). Figure 7 is a schematic cross section showing the relationship between the cavity/chimney, test points, and extent of fracturing.

The three cavities each have an estimated radius $\left(R_{c}\right)$ of $21 \mathrm{~m}$. A scale analysis by Toman and Tewes (1972) suggests that for explosives spaced closer than $7 R_{c}$, fractures have a "high probability" of being connected between test points. At Rio Blanco, the upper and lower explosives were both spaced within $7 R_{c}$ of the middle explosive; hence, it was considered highly probable that vertical fracture connectivity existed between all three explosives (although this was not the case, as discussed below). The scale analysis suggested that fractures would extend to $5 R_{c}$ above the uppermost test point and $2 R_{c}$ below the lowest test point. The degree of fracturing (fracture length, aperture, and asperities; network interconnectedness), however, is unknown. For comparison to conditions at the Nevada Test Site, Borg et al. (1976) stated that from the cavity out to $1.3 R_{c}$, the rocks are "highly" crushed. From 2.5 to $4 R_{c}$, the rocks are "pervasively" crushed. Further than 3.5 to $4 R_{c}$, the compressive stress of the shock wave is too small to fracture the rock.

Despite the prediction of hydraulic connection among the three cavities, post-test drilling indicated that no connection existed between the middle and upper cavities (Toman, 1975). Re-entry drilling through the emplacement hole to within either $36 \mathrm{~m}$ or $76 \mathrm{~m}$ of the 
point of the uppermost device was completed six months after the detonation (both numbers are reported in separate locations in the report). Two production tests revealed that there was no communication among the uppermost cavity and the lower ones, as tracer incorporated in the center explosive canister was not detected in the produced gas (Toman, 1975).

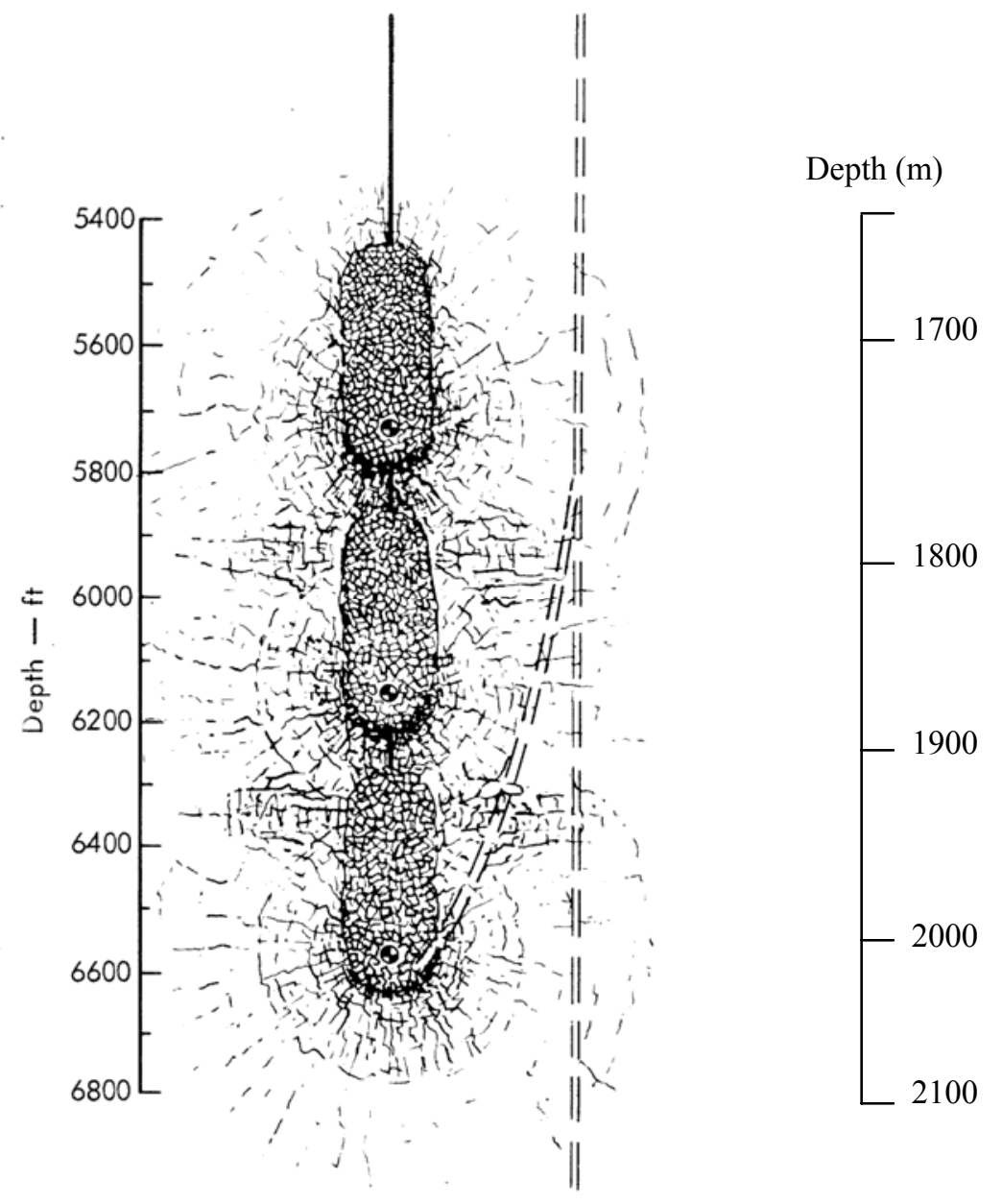

Figure 7. Schematic cross section of the chimney/cavity. The three 33-kt nuclear devices were simultaneously detonated at 1,780,1,899, and 2,039 $\mathrm{m}$ below the land surface. The explosion resulted in the formation of glass around each cavity. Fractures from the detonation extend to approximately $100 \mathrm{~m}$ from the test point. Though this conceptual drawing shows fracture connection between the three chimneys, testing found no connection (from Rubin et al., 1972).

Although the detonation enhanced fracture permeability, no data or models exist that describe permeability enhancement as a function of distance from the detonation. Neither are there data or models that relate explosive yield to fracture orientation or fracture density.

\section{Radionuclide Occurrence and Release}

When a nuclear device is exploded underground, the cavity is initially filled with vaporized material derived from the rock, nuclear fuel, fission products, and construction 
materials associated with the device and emplacement hole. As the cavity cools, radionuclides are distributed into four phases: in the nuclear melt glass, as surface deposits on rubble in the chimney, dissolved in water, or in the gas phase (Borg et al., 1976; IAEA, 1998).

Most of the fission products from the detonations are refractory (having low volatility) and are incorporated into the glass. These will leach very slowly out of the glass as the glass itself slowly dissolves in groundwater. More volatile radionuclides, or those with a gaseous precursor (such as ${ }^{137} \mathrm{Cs}$, which is produced by the decay of ${ }^{137} \mathrm{Xe}$ ), occur both in the melt glass and as more easily dissolved deposits on rock surfaces. Though surface-deposited nuclides are more readily dissolved into groundwater than those in the melt glass, many are reactive and tend to sorb strongly onto mineral surfaces. Several radionuclides are mobile in groundwater, with the most significant being tritium. Other mobile species are ${ }^{85} \mathrm{Kr},{ }^{36} \mathrm{Cl},{ }^{129} \mathrm{I}$, ${ }^{99} \mathrm{Tc}$, and ${ }^{125} \mathrm{Sb}$ (Smith et al., 1995).

At Rio Blanco, the very low intrinsic permeability causes groundwater to be much less mobile than the gas phase. Most of the radioactive isotopes are soluble, and are therefore dissolved in the liquid phase when not present as solids (in the melt glass, as mineral phases, or sorbed onto surfaces). Five radionuclides exist in the gas phase and therefore can potentially move significant distances on the order of several hundred meters. These radionuclides are tritium $\left({ }^{3} \mathrm{H}\right.$ or $\left.\mathrm{T}\right)$, krypton-85 $\left({ }^{85} \mathrm{Kr}\right)$, carbon-14 $\left({ }^{14} \mathrm{C}\right)$, argon-37 $\left({ }^{37} \mathrm{Ar}\right)$, and argon-39 $\left({ }^{39} \mathrm{Ar}\right)$. Investigations at the Gasbuggy nuclear test identified that of these, ${ }^{3} \mathrm{H}$ and ${ }^{85} \mathrm{Kr}$ are responsible for the vast majority of gaseous radioactivity (Holzer, 1970). Tritium was the only radionuclide identified of concern in an assessment of the radiologic implications of commercial utilization of natural gas from a nuclear-stimulated well (Jacobs et al., 1970). Krypton is not retained to any significant extent by the body, so the primary model of exposure is by immersion of the body in contaminated air. The environmental evaluation conducted prior to the Rio Blanco test identified ingestion of tritiated water (after incorporation in foodstuffs, such as milk) to vastly dominate whole body exposure, as compared to immersion exposure to tritium, ${ }^{37} \mathrm{Ar}$, or ${ }^{85} \mathrm{Kr}$, or inhalation or skin absorption of tritiated water, or THO (U.S. AEC, 1971).

Tritium radioactivity released from the three simultaneous detonations was 3,000 Ci (curies), with Toman and Tewes (1972) estimating that 40 percent of this radioactivity was trapped in the melt. The tritium in the melt glass is not readily available for migration, being primarily in bound water dissolved in the nuclear melt glass, with some small portion trapped in vesicles (Borg, 1975). Studies of nuclear tests conducted by the French in Africa report that more than 50 percent of available tritium is captured by melt glass, but recent analyses of contaminant transport from underground tests in Nevada have assumed much less, or even zero, inclusion of tritium in melt. Given the conservative assumption that tritium is present in the liquid or gas phase (allowing transport of larger quantities of radionuclides), the modeling presented here assumes only 5 percent of the tritium produced by the tests is contained within the melt glass, rather than the 40 percent reported by Toman and Tewes (1972).

Because tritium is an isotope of hydrogen (half-life $12.26 \mathrm{yrs}$ ), it is able to form radioactive water and methane $\left(\mathrm{CH}_{4}\right)$ molecules. Water exists in both the gas and liquid phases, while methane exists (under reservoir conditions) in only the gas phase. With respect to tritium, it appears that the pressure and temperature conditions are not sufficient for an isotopic exchange reaction involving hydrogen to occur with methane (Toman, 1975; Frink 
and Wethington, Jr., 1971; Smith, 1975). Some tritiated methane, however, probably formed under the extremely high pressure and temperature conditions associated with the nuclear detonation. In addition, tritium can be present as hydrogen gas (either ${ }^{3} \mathrm{HH}$ or ${ }^{3} \mathrm{H}_{2}$ ), which can be as much as 13 percent of the gas phase (Toman and Tewes, 1972). All of the tritium, therefore, is assumed to be bound in the water molecule (i.e., little tritium exists as either hydrogen gas or tritiated methane).

The radioactivity of ${ }^{85} \mathrm{Kr}$ in the gas phase was calculated to be 2,000 Ci (Toman and Tewes, 1972). Krypton is a noble gas and therefore does not form any compounds; it exists as a component of the gas phase and also as a dissolved gas in the liquid phase. The initial ${ }^{14} \mathrm{C}$ radioactivity was $22.5 \mathrm{Ci}$ (Toman and Tewes, 1972) and exists as either part of the methane molecule or as part of the $\mathrm{CO}_{2}$ gas formed as a product of the nuclear reaction. The other gas-phase fission products are radioactive ${ }^{37} \mathrm{Ar}$ and ${ }^{39} \mathrm{Ar}$. The half-life of ${ }^{37} \mathrm{Ar}$ is only 35 days and has effectively decayed to its nongaseous daughter product in the ensuing 30 years since the detonation. Argon-39 has a much longer half-life (269 years) although fewer than $20 \mathrm{Ci}$ were produced with the explosion.

The focus of this investigation is on the extent to which tritium may be transported in the subsurface, as both tritiated liquid water and tritiated water vapor. The primary objective of the model is to estimate the extent of subsurface radionuclide transport. Except for one simulation in which ${ }^{85} \mathrm{Kr}$ transport was modeled, all of the simulations investigated transport of tritium. If a risk assessment is deemed necessary, transport of ${ }^{85} \mathrm{Kr},{ }^{14} \mathrm{C}$, and ${ }^{39} \mathrm{Ar}$ can be individually calculated so their contributions can be taken into account, though previous assessments suggest their contributions to dose are very small compared to that of tritium (U.S AEC, 1971; Jacobs et al., 1970).

\section{Flow and Transport Processes}

The Mesaverde Group forms a low-permeability, two-phase, fractured gas reservoir with a volumetric gas saturation $\left(S_{g}\right)$ of approximately 0.4 in the project area (CER Geonuclear, 1970). Phase saturation is defined as the volume of a given phase divided by the volume of pores in a unit volume of rock. Thus, the pore space in the Mesaverde contains approximately 40 percent gas and 60 percent liquid. Oil, if present, is disregarded as an active phase; there may, however, be some oil present in the reservoir. In a porous medium, the largest pores are typically filled with the nonwetting fluid (in this case gas) while the smaller pores are filled with the wetting fluid (water). This follows from the Laplace equation, which states that within a pore of radius $r$, the phase pressure $P$ and pore radius are inversely related as

$$
P=\frac{2 \sigma \cos \theta}{r}
$$

Here, $\sigma$ is the surface tension of the wetting fluid and $\theta$ is the contact angle through the wetting phase. If the porous medium is fractured, and the fracture aperture is typically larger than the characteristic pore diameter, the fractures will be filled with the gas-phase fluid (Wang and Narasimhan, 1985; Evans et al., 2001). As discussed above, however, no detectable natural fractures appear to be present in the study area and those that might be present are assumed to be too few and unconnected to contribute significantly to fluid flow. 
Typically, producing gas reservoirs are high-permeability sandstones sealed above and below by low-permeability rocks such as shale, siltstone, or evaporites (Hubbert, 1953; Law and Dickinson, 1985; Lerche and Thomsen, 1994; Dahlberg, 1995). The reservoir fluids are often stratified in the classic textbook manner where gas overlies water or brine with a discrete contact; sometimes a layer of petroleum (a third fluid phase) separates the gas and water. Figure 8a shows a typical hydrocarbon reservoir located within an anticline, trapped by low-permeability shale above. The figure shows that hydrocarbon migration is controlled by the liquid water phase. This is one example of a hydrodynamically and structurally controlled reservoir. If there was no groundwater flow, fluids would be separated by horizontal interfaces, with gas at the top, overlying oil, and then water.

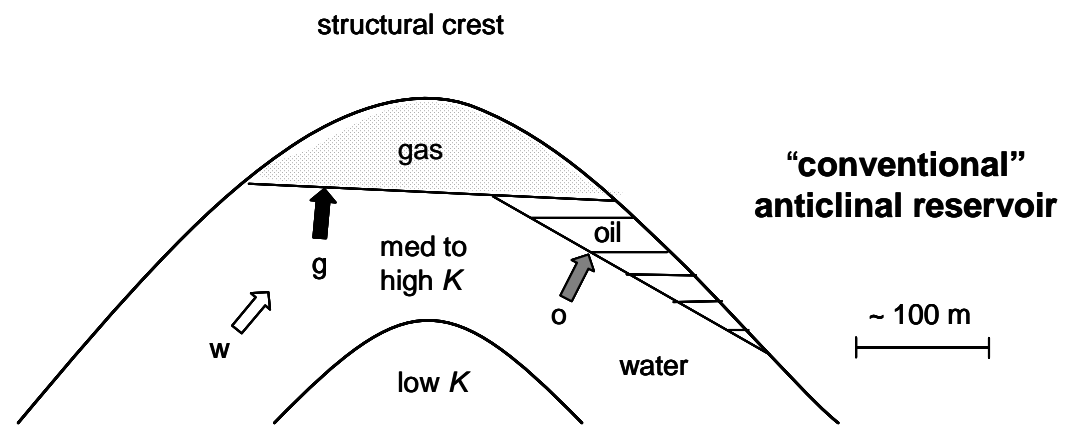

(a)

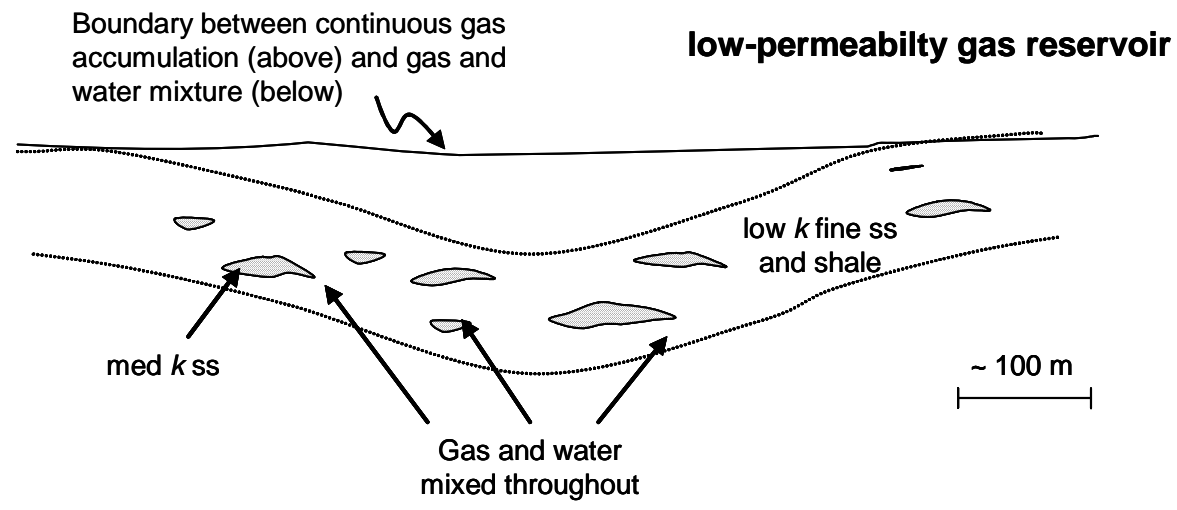

(b)

Figure 8. Example of a conventional gas reservoir located in an anticline (a) and one located in a low-permeability gas reservoir such as those found in the Piceance Basin (b). Both a structural and hydrodynamic trap are shown in (a), where the location of hydrocarbons is dependent upon both the permeability difference between formations and the direction and magnitude of subsurface water flow. In (b), the permeability of the "reservoir" is comparable to that of the trap of conventional reservoirs, i.e., the reservoir is located in what is characteristically considered a trap rock. The rate of production and transport of hydrocarbons is probably faster than the rate of fluid flow such that gas cannot escape at the same rate at which it is produced. 
Many gas fields in the Piceance Basin of western Colorado, such as those located within the Mesaverde Group, are located in very low permeability reservoirs $\left(k<10^{-17} \mathrm{~m}^{2}\right)$ of fine-grained sandstone with porosity less than 10 percent, and commonly less than 2 to 3 percent. These reservoirs are often abnormally pressured (either above or below hydrostatic) and lack discrete stratigraphic or lithologic seals. The gas reservoir is often a zone with gas saturation less than 50 percent such that water and gas coexist at the same elevation with neither phase dominant. That is, in low-permeability gas reservoirs there does not often appear to be a "gas saturated zone," in the sense that there are distinct gas stringers in the reservoir. Instead, a large vertical section of perhaps hundreds of meters may be filled with gas and water. This type of reservoir is depicted in Figure 8b. Additionally, the gas phase transgresses strata and is not confined to individual units because the pressure field does not correspond with orientation or dip of strata. In this case, the pressure field is not structurally controlled as is common with higher permeability gas reservoirs. This interpretation is supported by data presented in CER Geonuclear (1970) and Toman and Tewes (1972).

Sometimes a separate gas phase is located below the water phase, as in synclines (Dahlberg, 1995). The reason is thought to be that groundwater percolation from outcropping reservoir rocks at the land surface balances the buoyant gas lower in the reservoir. This trap/reservoir requires very low permeability, and has been suggested as being common throughout much of the Overthrust belt in Colorado.

Based upon the preliminary simulations of Cooper and Chapman (2001), the dominant transport processes for radionuclides at Rio Blanco are pressure-driven flow of gas, gas diffusion, and exchange between phases. Aqueous phase diffusion is unimportant because diffusion coefficients are four orders of magnitude less than those in the gas phase. Low diffusion coefficients, coupled with low aqueous-phase velocities $\left(<10^{-11} \mathrm{~m}^{2}\right)$, are the reason that dispersion can be ignored in the aqueous phase. Transport in the gas phase is almost always dominated by diffusion instead of mechanical dispersion, because the diffusion coefficient for gases, $D$, is approximately $10^{-5} \mathrm{~m}^{2} \mathrm{~s}^{-1}$. For gas flow through porous media, a maximum velocity could be $10^{-4} \mathrm{~m} \mathrm{~s}^{-1}$ (about $10 \mathrm{~m} \mathrm{day}^{-1}$ ), and a dispersivity $(\alpha)$ value (a characteristic pore diameter) for the Mesaverde or Fort Union sandstones could be $10^{-6} \mathrm{~m}$. The mechanical dispersion coefficient, $D_{h}$, would be $D_{h}=\alpha u \sim 10^{-10} \mathrm{~m}^{2} \mathrm{~s}^{-1}$, which is five orders of magnitude smaller than the molecular diffusion coefficient for a typical gas. Gas dispersion is therefore not considered and is usually only of concern for very highvelocity flow around boreholes.

\section{CHOICE OF NUMERICAL SIMULATOR}

The conceptual model includes flow and transport as coupled processes that must be solved simultaneously to get a realistic understanding of the radionuclide distribution. Nearly all petroleum-oriented simulators solve for the flow field only. In contrast, most transport solvers do not solve for gas as an active phase. Few choices exist for the proper simulation of this subsurface environment.

The Transport of Unsaturated Groundwater and Heat (TOUGH) simulator (Pruess, 1991; Pruess et al., 1999) was used to implement the flow and transport model. TOUGH2 is a DOE-sponsored code that has been used extensively to study heat and mass flow in 
geothermal reservoirs, saturated/unsaturated zones, and oil and gas reservoirs. TOUGH2 can simulate fully coupled, transient, three-dimensional, multiphase, and multicomponent nonisothermal flow. The many applications in which TOUGH2 has been applied are discussed in several workshop reports (Pruess, 1995, 1998). The governing equations solved by TOUGH2 are presented in Appendix C.

\section{NUMERICAL MODELS}

The numerical model is developed in this section, and includes an explanation of the vertical and horizontal pressure gradients within the reservoir, boundary conditions, and initial conditions. A discussion of the distribution of pressures is presented first because of the dependence of pressure gradients and flow processes, which were developed in previous sections. The boundary conditions are discussed next, followed by data used as hydraulic properties and initial conditions in the simulations.

\section{Pressure Profile and Gradients}

Reliable formation pressure data are difficult to obtain for the Mesaverde Group because the shut-in pressure buildups are much too low to be extrapolated to the formation pressures (Johnson, 1989). In the absence of capillary pressure, the formation pressure would be the pressure of either phase - liquid or gas. In the presence of a capillary pressure, the relationship between phase pressures is $P_{c a p}=P_{g}-P_{l}$, where $P$ is pressure and the subscripts refer to "capillary," "gas," and "liquid." The instrument measuring pressure measures a combination of both phases since both phases are present within each pore. No data were found on the initial formation pressure in the emplacement well RB-E-01; however, the initial formation pressure was measured as 19.2 MPa (CER Geonuclear, 1970) in the Fawn Creek Government No. 1 well. This value is consistent with a hydrostatically pressured reservoir. There is some information on the change in formation pressure during the production tests that were conducted subsequent to the detonations. Upon re-entry into the cavity and/or chimney six months after the detonations, the initial bottom hole formation pressure was measured as $14.1 \mathrm{MPa}$ at either $1,704 \mathrm{~m}$ or 1,744 $\mathrm{m}$ below land surface (again, both depths were reported in Toman, 1975). The first drawdown test produced $10^{6} \mathrm{~m}^{3}$ of gas, while the bottom hole pressure dropped to $8.7 \mathrm{MPa}$. A 69-day shut-in period followed, during which time the bottom hole pressure rose to $11.6 \mathrm{MPa}$. A second drawdown test was then begun, lasted 19 days, and produced $1.776 \times 10^{6} \mathrm{~m}^{3}$ of dry gas. The final shut-in pressure at the end of the test was 3.1 MPa. Beyond this time, there are no data on the pressure buildup in the well. Although there are data on pressure transients during the various production tests, no data with respect to the spatial distribution of pressure are known during those tests.

Buildup tests were conducted on two characterization wells: Fawn Creek Government No. 1 and Scandard Draw No. 1. A buildup test is essentially a test where the well is shut in for a period of time until the pre-shut-in pressure is reached, then allowed to flow as the (constant) flow rate and bottomhole pressure (BHP) are monitored. The test is repeated for different flow rates and a plot of pressure squared $\left(P^{2}\right)$ versus a dimensionless time (the time taken to reach an asymptotic pressure) is constructed. Extrapolation of the plot to a specific value of dimensionless time results in the mean pressure in the reservoir at the testing interval. 
This is one type of production test used to determine initial reservoir pressures, and it has been used very successfully on conventional gas reservoirs. In the early 1970s, it was one of the only tests available for unconventional reservoirs; since that time, other tests have been developed. Among the reasons for its poor suitability in low-permeability reservoirs are that the reservoirs are very heterogeneous, are not "infinite," and have high water saturations such that gas is not a continuous phase. Both cores taken from the test hole (RB-E-01) and logs of the hole suggest that none of the conditions required for a successful analysis is present in the sections penetrated by Fawn Creek and Scandard Draw wells.

Figure 9 is a pressure-depth plot of measured pressures from the Fawn Creek, Scandard Draw, and the second re-entry well, RB-AR-2. The data are given in Tables 1 and 2 and are from the CER Geonuclear (1970). This type of plot is often used to correlate stratigraphic zones, and the fluids contained in them, between wells. It is also useful in determining whether a hydraulic (or pneumatic) connection exists between nearby wells. Data that lie along the same gradient are indicative of the density of the fluid (and to some extent the composition, that is, whether it is gas, oil, or water) and whether a hydraulic connection exists between the two points.

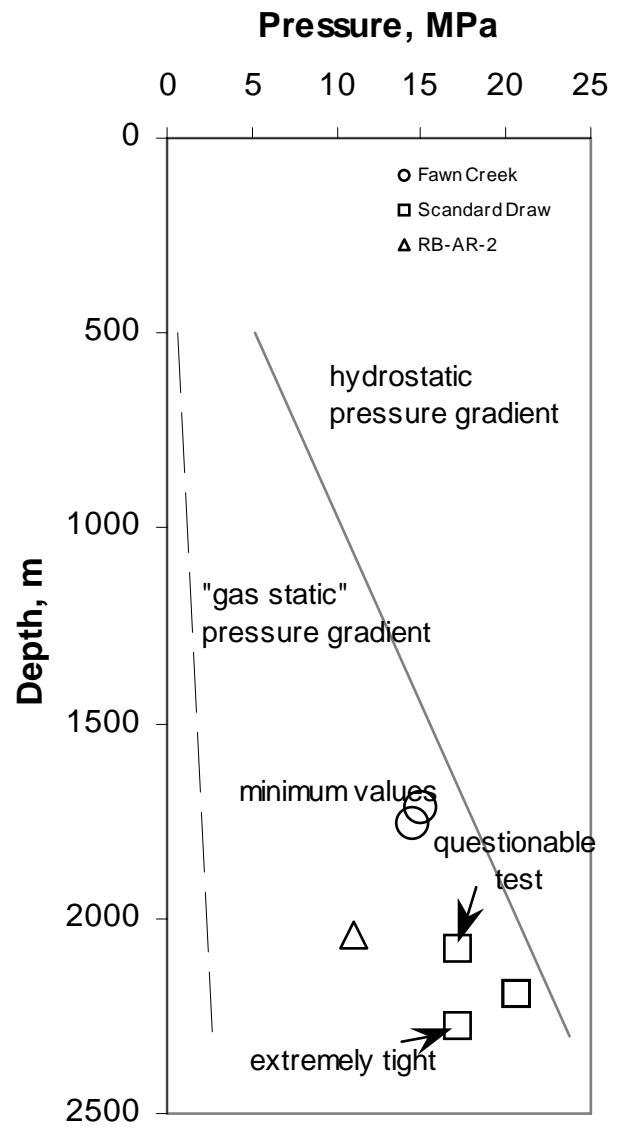

Figure 9. Pressure-depth plot for wells near the detonation point. The solid line depicts hydrostatic pressure gradient; points that lie below the line most likely indicate that the tests were not done to completion, although they can also indicate an underpressured formation. The annotations "extremely tight," "questionable test," and "minimum values" are from the CER Geonuclear (1970) reservoir report. 
Table 1. Fawn Creek buildup test results (CER Geonuclear, 1970).

\begin{tabular}{ccccccc}
\hline Zone & $\begin{array}{c}\text { Buildup } \\
\text { No. }\end{array}$ & $\begin{array}{c}\text { Interval } \\
\text { (ft) }\end{array}$ & $\begin{array}{c}\text { Interval } \\
\text { (m) }\end{array}$ & $\begin{array}{c}\text { Pressure } \\
\text { (psi) }\end{array}$ & $\begin{array}{c}\text { Pressure } \\
\text { (MPa) }\end{array}$ & $\begin{array}{c}\text { Hydrostatic Press. } \\
\text { (MPa) }\end{array}$ \\
\hline 1 & 1 & 5,745 to 5,792 & 1,752 to 1,765 & -- & -- & \\
1 & 2 & 5,745 to 5,792 & 1,752 to 1,765 & -- & -- & 17.26 \\
1 & 3 & 5,745 to 5,792 & 1,752 to 1,765 & $>2095$ & $>14.45$ & \\
2 & 1 & 5,600 to 5,630 & 1,711 to 1,716 & & & 16.8 \\
2 & 2 & 5,600 to 5,630 & 1,711 to 1,716 & $>2150$ & $>14.82$ & \\
\hline
\end{tabular}

--bad test data

Table 2. Scandard Draw buildup test results (CER Geonuclear, 1970).

\begin{tabular}{ccccccc}
\hline Zone & $\begin{array}{c}\text { Buildup } \\
\text { No. }\end{array}$ & $\begin{array}{c}\text { Interval } \\
\text { (ft) }\end{array}$ & $\begin{array}{c}\text { Interval } \\
\text { (m) }\end{array}$ & $\begin{array}{c}\text { Pressure } \\
\text { (psi) }\end{array}$ & $\begin{array}{c}\text { Pressure } \\
\text { (MPa) }\end{array}$ & $\begin{array}{c}\text { Hydrostatic Press. } \\
\text { (MPa) }\end{array}$ \\
\hline 1 & 1 & 7,181 to 7,212 & 2,189 to 2,198 & 2,986 & 20.59 & 21.51 \\
1 & 2 & 7,181 to 7,212 & 2,189 to 2,198 & 2,990 & 20.62 & 21.51 \\
2 & 1 & 6,810 to 6,838 & 2,076 to 2,084 & $2,490^{1}$ & $17.17^{1}$ & 20.40 \\
3 & 1 & 7,454 to 7,476 & 2,272 to 2,279 & $>2,470$ & $>17.03$ & 22.32 \\
\hline
\end{tabular}

questionable test

In the Fawn Creek Government No. 1 well, five tests in two zones were conducted, although none gave satisfactory results (CER Geonuclear, 1970). In the Scandard Draw No. 1 well, four tests were conducted in three zones, and only two tests were considered satisfactory. Although the data are inconclusive, the plot shows that none of the tests was conducted in a gas-saturated part of the reservoir, as any gradient constructed through even the poor data do not suggest a free gas phase (compared to the "gas static" gradient). Supporting this conclusion are the low volumes of gas produced during the tests (on the order of tens of million standard cubic feet per day) and the large volumes of water produced (CER Geonuclear, 1970). Because the data are not reliable, it is difficult to infer if the stratigraphic zones are similar between the two wells, or whether stratigraphic units or geologic structures separate them. The data suggest that the vertical pressure gradient is hydrostatic, as pressures tend to lie along a slope similar to the hydrostatic line in Figure 9 (based upon a brine density of $\left.1,050 \mathrm{~kg} \mathrm{~m}^{-3}\right)$. This supports verbal reports by several geologists working in the area.

Horizontal flow in petroleum reservoirs is typically controlled by producing wells (Gerritsen and Durlofsky, 2005), as the pressure gradient at a well face can greatly exceed the natural gradient within the reservoir. Because of this, reservoir modelers are sometimes not concerned with regional pressure gradients; instead they place importance on gradients imposed by production wells. A document search for regional pressure gradients in the vicinity of the emplacement well resulted in no information. The regional pressure gradient would be controlled by a combination of the structural dip of the formation, location of sources and sinks of subsurface fluids (i.e., outcrops), the nature of the overlying topography, and the time scales of relaxation of pressure associated with erosion at the land surface. The regional pressure gradient, even if known, may not coincide with local horizontal pressure gradients (both magnitude and direction), and is also likely to be dwarfed by local gradients caused by production wells. For this reason, no horizontal pressure gradient was assumed in the simulations and flow was strictly controlled by pressure associated with a production well (consistent with the conclusions of Gerritsen and Durlofsky, 2005), as well as diffusion and dispersion of fluids (discussed below). 


\section{Reservoir Boundaries}

Two-dimensional Simulations

Some simulations modeled flow away from the three-cavities under natural conditions; these were done in two dimensions. For these simulations, four hydraulic and four transport boundary conditions are required, and are shown in Figure 10a. Figure 10b shows the computational mesh for the simulations.

Physically, the upper and lower boundaries are probably both capillary barriers, and were modeled as no flux and prescribed pressure, respectively. The reason is that this combination of boundary conditions reproduces most accurately the liquid saturation profiles reported in the reservoir report (CER Geonuclear, 1970). That report states that the average $S_{l}$ of the rocks throughout the test interval is 0.6. No data, however, exist to suggest values of residual liquid saturation $S_{l r}$ for any rocks. Residual liquid saturation, therefore, was set at 0.6 for all rock types. To maintain a uniform liquid saturation profile, liquid water should not be allowed to flow downward from above, unless it is allowed to exit the lower boundary. A no-flux boundary at the top of the domain restricts flow into or out of the domain, while maintaining the liquid saturation at the set residual value. A prescribed pressure at the bottom allows for vertical flow in and out through the bottom, while maintaining the minimum liquid saturation at the residual value (because a prescribed value of pressure also implies a prescribed value of saturation under conditions of two-phase flow). The saturation profile of a simulation run to steady state in which these two boundary conditions (upper, no flux; lower, prescribed pressure) were applied is shown in Figure 11a. However, if a condition of no flux is located at the bottom, liquid water is allowed to saturate upwards from the bottom boundary (Figure 11b and 11c), provided downward flow of liquid is occurring. A no-flux condition at the top combined with no-flux at the bottom results in a redistribution of liquid in the domain, such that liquid drains downward (maintaining the residual value) and saturating the rocks from the bottom (Figure 11b). Prescribed pressures at both the top and bottom boundaries result in liquid saturations that are maintained at the boundaries (Figure 11c), but this will result in upward flow of the gas phase, under hydrostatic conditions. In contrast to the other three combinations of boundary conditions, two prescribed pressure boundary conditions result in a dynamic (flowing) steady-state condition. Under conditions other than hydrostatic, there will always be vertical flow, the direction dependent upon the direction of the vertical pressure gradient. Finally, a prescribed pressure at the top with a no flux condition at the bottom allows the domain to be completely saturated (Figure 11d) for a downward-acting pressure gradient. If the total pressure gradient were acting upward, the rocks would be drained to residual liquid saturation (not shown).

Pressures on the vertical boundaries up- and downgradient of the flow direction were set such that flow was not allowed to enter the domain upgradient of the three cavities and were fixed to the predetonation pressures at the downgradient boundary. These conditions were set as no flux and prescribed pressure up- and downgradient, respectively. Boundary conditions for radionuclide transport were set to coincide with the corresponding hydraulic boundary condition. That is, no-flux transport boundary conditions were implemented with no-flow hydraulic conditions, while prescribed flux (which was always set as zero) boundary conditions corresponded to no-flow hydraulic boundary conditions. 


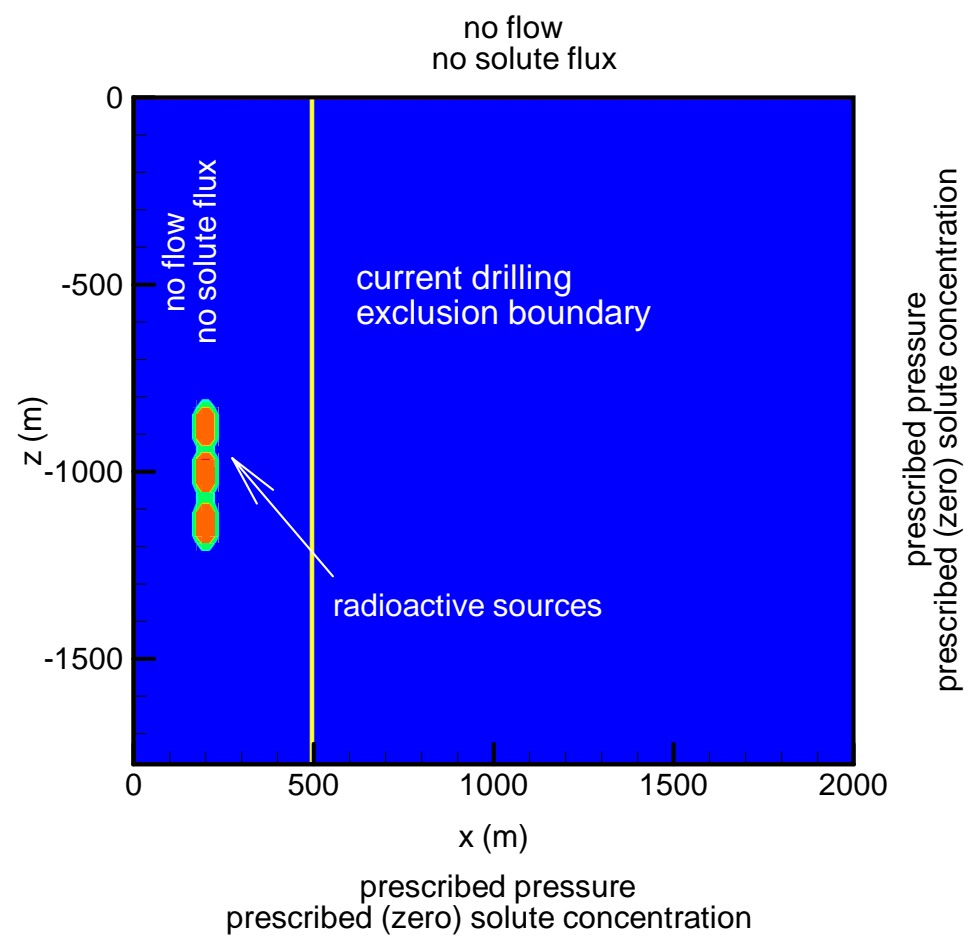

(a)

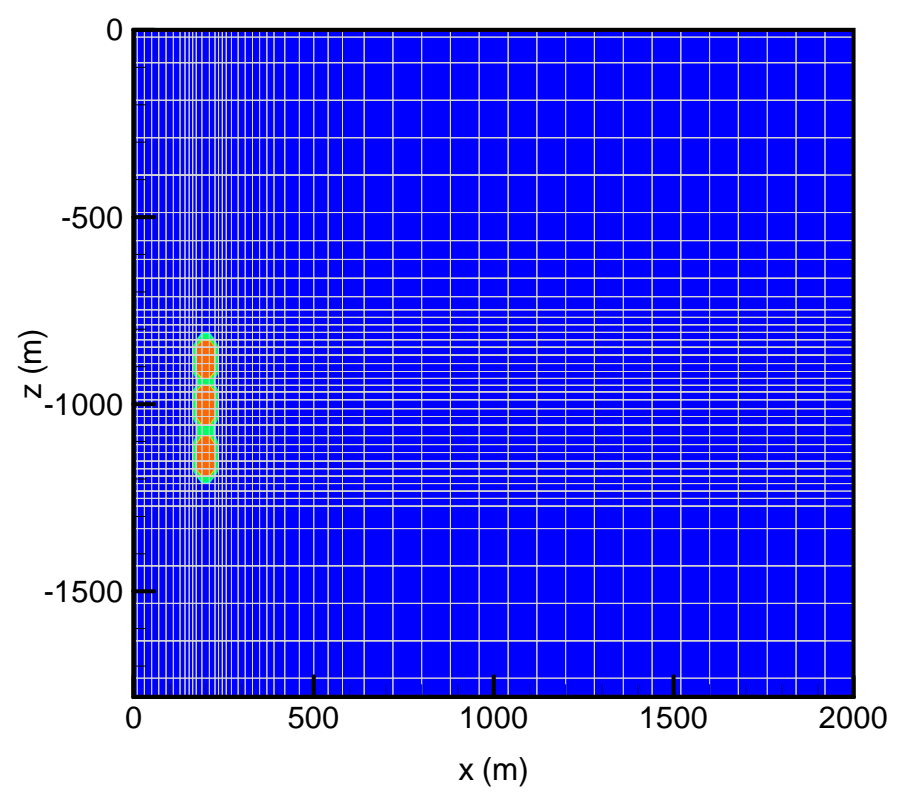

(b)

Figure 10. Hydraulic and transport boundary conditions (a) and computational mesh (b) for the two-dimensional simulations. 

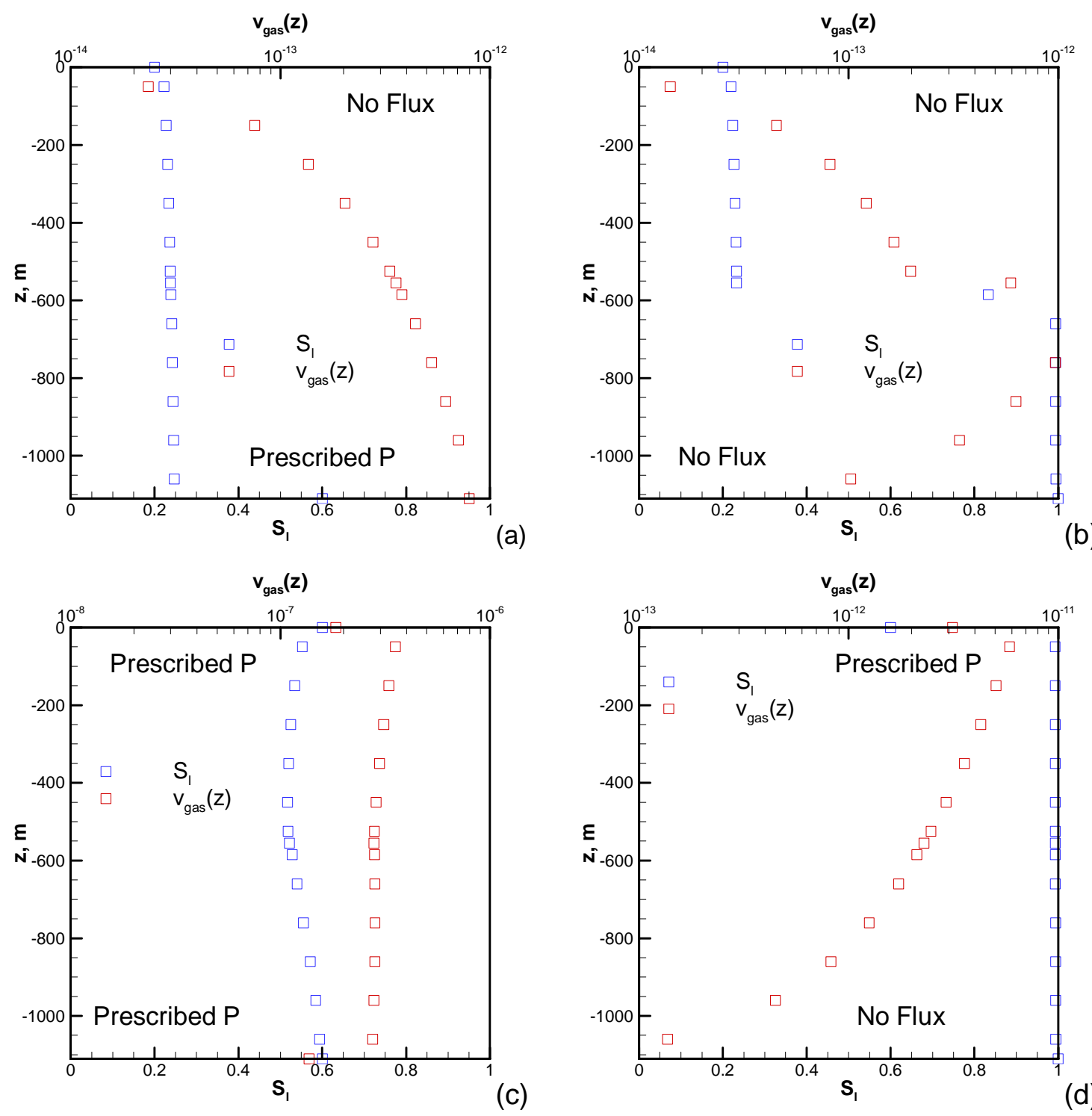

(b)

Figure 11. Saturation and gas velocity profiles resulting from steady-state simulations for combinations of horizontal (upper and lower) boundary conditions in a onedimensional vertical column. The terms "No Flux" and "Prescribed P" are the two types of horizontal hydraulic boundary conditions used in the models. Each simulation was carried out for $10^{6} \mathrm{yr}$. Gas velocities are upward, while liquid phase velocities (not shown) are downward, with absolute values within \pm two orders of magnitude of the gas phase velocities.

\section{Three-dimensional Simulations with Gas Production}

Models which included a producing gas well were run in three-dimensions. The gas production well was placed such that the estimated extent of hydraulic fractures, in the direction toward the nuclear cavity, stopped at the limit of the current drilling exclusion zone $(600 \mathrm{ft}$, or $183 \mathrm{~m})$ required by DOE. The vertical extent of these simulations was $120 \mathrm{~m}$, and included only the second cavity. The production interval in the well is located at the same 
elevation (depth below ground surface) as the middle cavity (Figure 12). The horizontal upper and lower boundaries were assumed to be flow divides that constrained gas and liquid flow within a $120-\mathrm{m}$ vertical section to traveling primarily horizontally toward the well. In other words, the upper and lower boundaries were prescribed (zero) flow. The production well was assumed to be hydraulically fractured such that a high-permeability zone with a radius of $88 \mathrm{~m}$ and height of $68 \mathrm{~m}$ was centered about the well (verbal communication, Presco, Inc., reservoir engineers, April 2004). Figure 13 shows the relationship between the nuclear cavity, the producing well, and the permeability field.

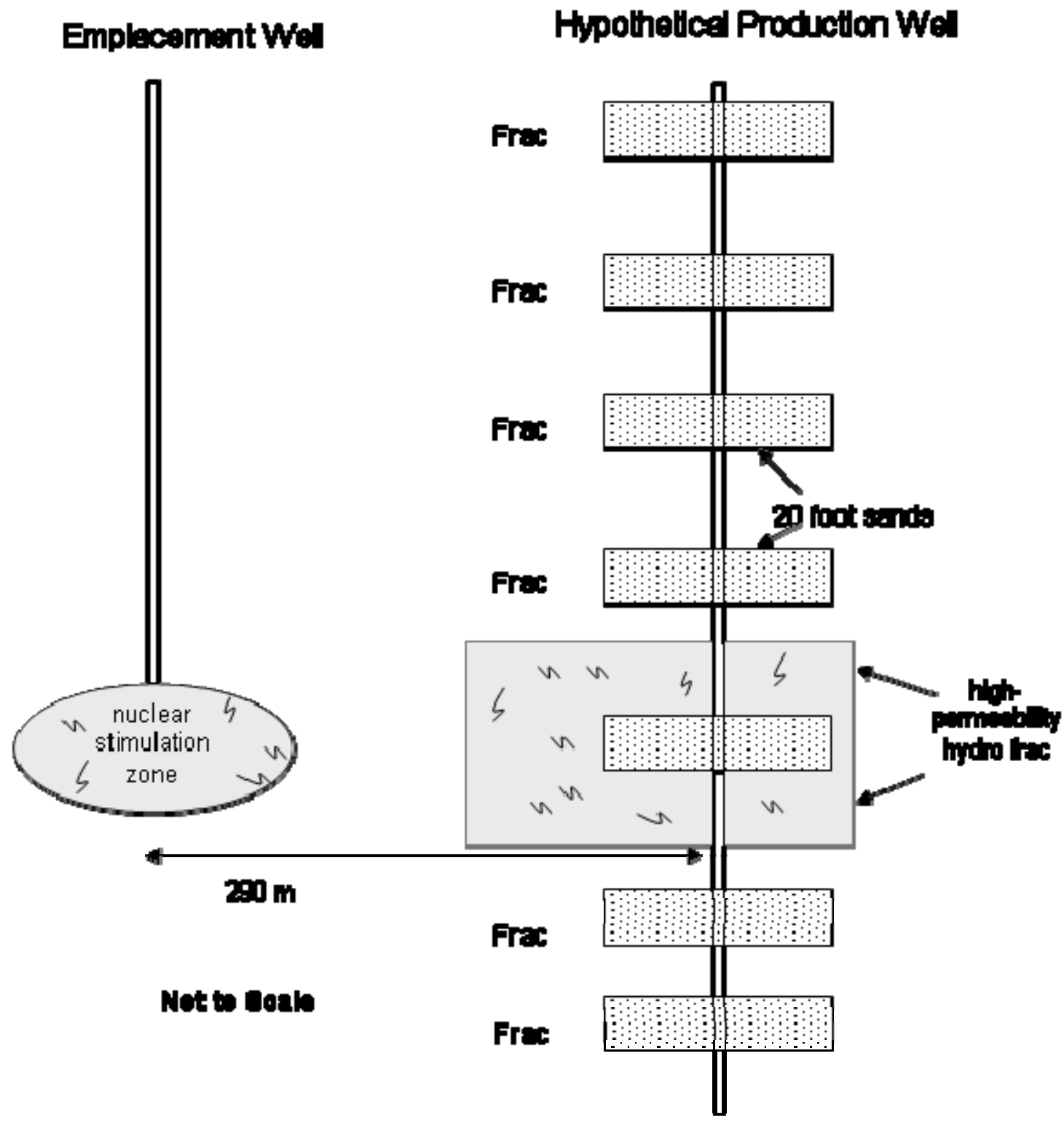

Figure 12. Cross section of relationship between hydrofrac for gas production and nuclear stimulation zone. The hydrofracs are associated with gas-producing sand lenses. The model assumes that a fractured sand is centered at the same elevation as one of the test points. 
Emplacement

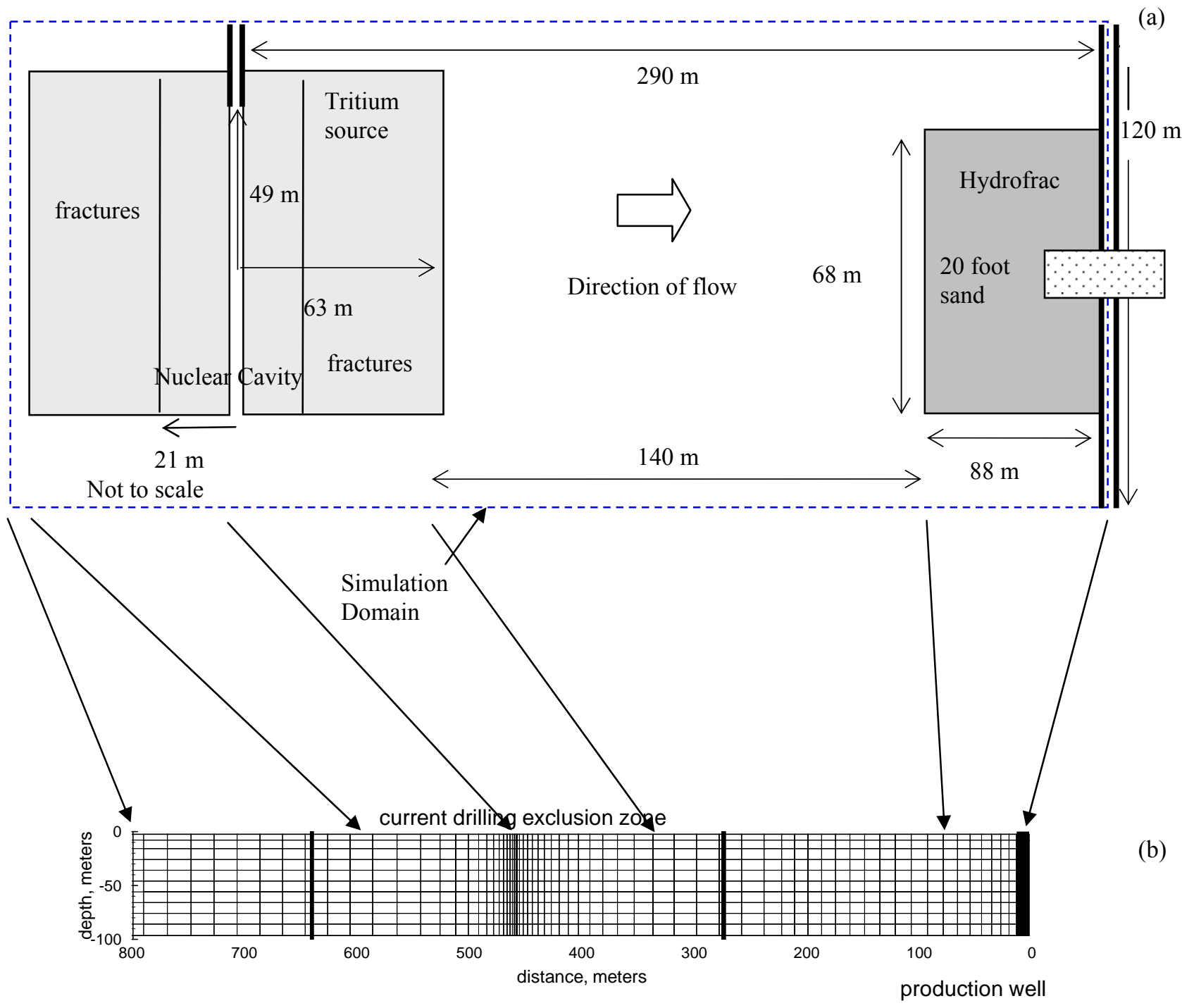

Figure 13. Model formulation for gas flow and tritium transport to a pumping well (a), and integral finite-difference grid for simulation (b). The boundary conditions for the two planes parallel to flow, in the plane of the page, are no flow and zero prescribed concentration. 
The three-dimensional simulations required six hydraulic and six transport boundary conditions, as shown in Figure 14. For these simulations, the upper horizontal boundary condition was set as no flow, which contrasted with the boundary condition in the simulations without the well. The reason is that these models simulated flow from the middle cavity only. It was assumed that flow from each cavity would be nearly horizontal to the production well. To maintain this (nearly) horizontal flow, the upper and lower boundaries were set as no flow. A prescribed pressure boundary allows for infinite flow, while maintaining the pressure. If, instead, pressure had been prescribed for either horizontal boundary, as in the two-dimensional simulations, an infinite supply of mass (gas and liquid) would have been supplied from the boundary, which would be unrealistic. This would have short-circuited flow from the cavity, limiting contaminant transport.

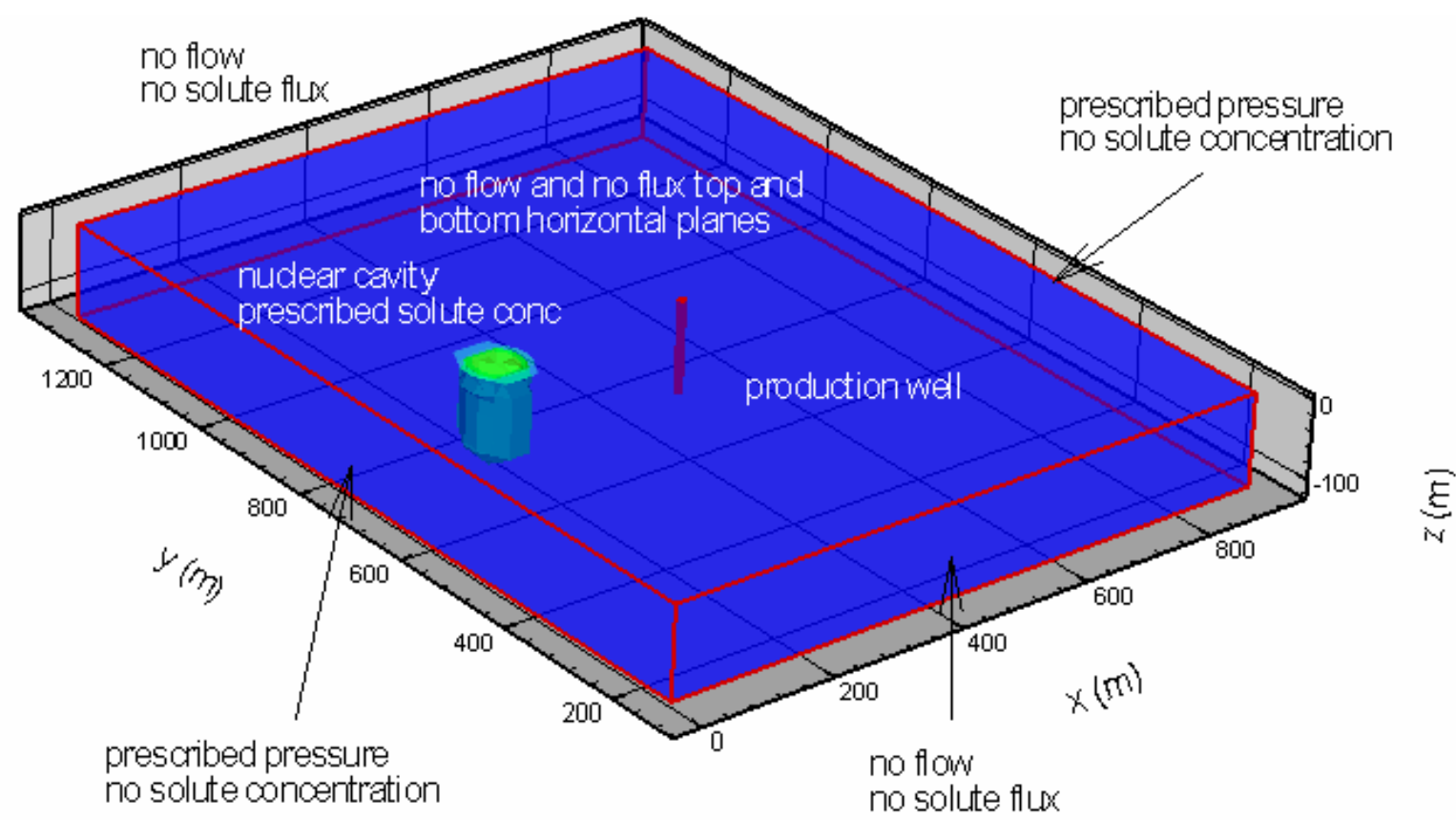

Figure 14. Hydraulic and transport boundary conditions for the three dimensional simulations. Flow is away from the nuclear cavity toward the production well.

The vertical boundary conditions up- and downgradient from the flow direction were set as no flow and prescribed pressure, respectively, as in the two-dimensional simulations without the producing well. The lateral boundaries were set as no flow such that flow could not enter or leave the domain in the $y$-direction (horizontal and lateral to the flow direction).

As in the two-dimensional simulations, the transport boundary conditions coincided with analogous flow boundary conditions. That is, no flux and no flow appear on the same boundary, and prescribed (zero) concentration and no flow appear together. 


\section{INPUT DATA FOR DETERMINISTIC SIMULATIONS}

The initial conditions used in the deterministic simulations are listed in Table 3.

These are also the mean values used in the Monte Carlo simulations, which are discussed in a following section.

Table 3. Initial conditions for simulations.

\begin{tabular}{|c|c|c|}
\hline Parameter & Value & Source \\
\hline Intrinsic permeability (formation), $\mathrm{m}^{2}$ & $3.4 \times 10^{-17}$ & Various sources (see text) \\
\hline Intrinsic permeability (cavity and fractures), $\mathrm{m}^{2}$ & $2.96 \times 10^{-14}$ & Assumed similar to hydrofrac perm \\
\hline Intrinsic permeability (hydrofracs) $\mathrm{m}^{2}$ & $2.96 \times 10^{-14}$ & Commun. with drilling engineers \\
\hline Relative permeability & $K_{l}=S^{4}$ & Corey, 1954 \\
\hline Capillary pressure curve & measured & \\
\hline Porosity & 0.105 to 0.124 & $\begin{array}{l}\text { CER Geonuclear (1970) Toman } \\
\text { and Tewes, } 1972\end{array}$ \\
\hline Rock grain density, $\mathrm{kg} \mathrm{m}^{-3}$ & 2,680 & Toman and Tewes, 1972 \\
\hline Formation pressure, $\mathrm{Pa}$ & $23 \mathrm{MPa}$ at base & Various sources (see text) \\
\hline Formation dip, $\mathrm{m} \mathrm{m}^{-1}$ & 0.1894 & $\begin{array}{l}\text { Structure contour map, Rocky Mtn } \\
\text { Map Co. }\end{array}$ \\
\hline Liquid saturation & 0.2 to 0.6 & $\begin{array}{l}\text { CER Geonuclear (1970); Toman } \\
\text { and Tewes, } 1972\end{array}$ \\
\hline Gas saturation & 0.4 to 0.8 & $\begin{array}{l}\text { CER Geonuclear (1970); Toman } \\
\text { and Tewes, } 1972\end{array}$ \\
\hline Mass fraction tritium, upper cavity & $4.86 \times 10^{-12}$ & various sources (see text) \\
\hline Mass fraction tritium, middle cavity & $7.34 \times 10^{-12}$ & various sources (see text) \\
\hline Mass fraction tritium, lower cavity & $6.71 \times 10^{-12}$ & various sources (see text) \\
\hline${ }^{3} \mathrm{H}$ radioactivity, liquid and gas, $\mathrm{Ci}$ & 1,200 & Colorado Dept. of Health, 1980 \\
\hline Diffusion coefficient, THO in methane, $\mathrm{m}^{2} \mathrm{~s}^{-1}$ & $7.26 \times 10^{-5}$ & Cussler, 1997 \\
\hline Diffusion coefficient, THO in liquid water, $\mathrm{m}^{2} \mathrm{~s}^{-1}$ & $3.47 \times 10^{-9}$ & Mills, 1973 \\
\hline Diffusion coefficient, He in methane, $\mathrm{m}^{2} \mathrm{~s}^{-1}$ & $6.75 \times 10^{-5}$ & Cussler, 1997 \\
\hline Diffusion coefficient, He in liquid water, $\mathrm{m}^{2} \mathrm{~s}^{-1}$ & $6.28 \times 10^{-9}$ & Cussler, 1997 \\
\hline Diffusion coefficient, $\mathrm{CH}_{4}$ in liquid water, $\mathrm{m}^{2} \mathrm{~s}^{-1}$ & $1.49 \times 10^{-9}$ & Reid et al., 1987 (calculated) \\
\hline Diffusion coefficient, ${ }^{85} \mathrm{Kr}$ in methane, $\mathrm{m}^{2} \mathrm{~s}^{-1}$ & $2.62 \times 10^{-5}$ & Reid et al., 1987 (calculated) \\
\hline Diffusion coefficient, ${ }^{85} \mathrm{Kr}$ in liquid water, $\mathrm{m}^{2} \mathrm{~s}^{-1}$ & $1.32 \times 10^{-9}$ & Mills, 1973 \\
\hline${ }^{3} \mathrm{H}$ half life, $\mathrm{yr}$ & 12.26 & Parrington et al., 1996 \\
\hline${ }^{85} \mathrm{Kr}$ half life, $\mathrm{vr}$ & 10.76 & Parrington et al. 1996 \\
\hline Rock grain specific heat, $\mathrm{J} \mathrm{kg}^{-1}$ & 1,000 & \\
\hline Thermal conductivity (unsaturated) of rocks, $\mathrm{W} \mathrm{m}^{-1}{ }^{\circ} \mathrm{C}$ & 2 & \\
\hline
\end{tabular}

\section{Liquid and Gas Properties}

As distributed by DOE, TOUGH2 does not have the capability to model methane as the principal component of the gas phase. Modifications were therefore made to replace air with methane as the primary component of the gas phase. The modifications were to change the molecular weight of air to that for methane $\left(16.05 \mathrm{~g} \mathrm{~mol}^{-1}\right)$, and to change some values in the correlations used to compute dynamic viscosity. TOUGH2 estimates viscosity based upon the Chung method (Reid et al., 1987), so values for the characteristic diameter of the molecule, characteristic energy, and the collision integral were replaced with values correct for methane. The values were taken from Appendix B of Reid et al. (1987). 


\section{Rock Properties}

$\underline{\text { Intrinsic Permeability }}$

The intrinsic permeability was derived from several sources. Gas well testing methods (Al-Hussainy and Ramey, 1966; Al-Hussainy et al., 1966; Mathews and Russell, 1967; Millheim and Cichowicz, 1968) used to analyze pressure drawdown and response on the Fawn Creek Government No. 1 well resulted in estimated effective permeabilities between 18 and $59 \mu$ darcy $\left(1.8 \times 10^{-17} \mathrm{~m}^{2}\right.$ to $5.8 \times 10^{-17} \mathrm{~m}^{2}$; CER Geonuclear, 1970). From cores acquired from the emplacement hole, Toman and Tewes (1972) reported permeabilities between 20 and $40 \mu$ darcy $\left(2.0 \times 10^{-17} \mathrm{~m}^{2}\right.$ to $\left.3.9 \times 10^{-17} \mathrm{~m}^{2}\right)$. However, the analysis was done on unfractured cores, and is therefore only a measure of matrix permeability.

Additional core permeability data were available from two sources: (1) samples from RB-E-01 and RB-MHF-3, a borehole used for testing massive hydraulic fracturing methods; and (2) a $\log$ (called a "Saraband ${ }^{\odot}$ " $\log$ ) that was run in well RB-AR-2 as a suite of geophysical logs run after the completion of drilling. The Saraband ${ }^{\odot} \log$ uses the results of resistivity, density, neutron, and sonic logs as input to an empirical equation to estimate intrinsic permeability of the matrix on unfractured sections of rock (Timur, 1968). Log analysis of heavily washed-out sections of the borehole (presumably where fractures were located) were not included, as these sections violate some of the assumptions upon which the permeability analysis was based.

A frequency distribution of the two data sets showed that there are clear differences between both the results of core analysis and Saraband ${ }^{\odot} \log$ estimates and between the Mesaverde Group and Fort Union Formation as shown in Table 4. Smaller permeability values were found in the core analysis for both the Fort Union Formation and Mesaverde Group than were seen in the Saraband ${ }^{\odot}$ estimates for the same formations. At the time of borehole logging, the Saraband ${ }^{\odot} \log$ could estimate a minimum permeability of $100 \mu$ darcy. In contrast, the minimum permeability reported by the core analysis was $1 \mu \mathrm{darcy}$. The Mesaverde permeabilities were lower than those of the Fort Union samples; this is seen in the Mean, Q25, Median, and Q75 columns in Table 4. Information on the minimum detection limits was not available for the core measurements due to the age of the records (late 1960s and early 1970s). The estimates from geophysical logs are empirical, using fits developed in the oil and gas industry at that time. Since at the time of the logging, tight sands gas deposits like those found at Rio Blanco were commonly considered not economic, the fitting should be considered more reliable for higher permeability environments. More wells had been drilled and logged in higher permeability settings, so more calibration of the empirical fit had taken place.

Table 4. Summary statistics for $\log _{10}$ permeability $\left(\mathrm{m}^{2}\right)$.

\begin{tabular}{llrlllllc}
\hline Formation/Group & Data Source & \multicolumn{1}{c}{ N } & Mean & Std.Dev. & Variance & Q25 & Median & Q75 \\
\hline Fort Union & Core & 268 & -14.8249 & .758179 & .574835 & -15.3067 & -14.8296 & -14.2982 \\
Fort Union & Log & 243 & -14.4803 & .416604 & .173559 & -15.0057 & -14.4036 & -14.2275 \\
Mesaverde & Core & 132 & -15.5966 & .488997 & .239118 & -16.0514 & -15.5286 & -15.2671 \\
Mesaverde & Log & 20 & -14.6245 & .286043 & .081821 & -15.0057 & -14.5286 & -14.4036 \\
Fort Union & Combined & 511 & -14.6610 & .642626 & .412969 & -15.0057 & -14.7047 & -14.2275 \\
Mesaverde & Combined & 152 & -15.4687 & .571332 & .326420 & -16.0514 & -15.4036 & -15.1316 \\
All Data & & 663 & -14.8462 & .712768 & .508038 & -15.3067 & -14.8296 & -14.3067 \\
\hline
\end{tabular}


The core analyses were useful for evaluating the nature of the lower permeability portion of the distribution. However, the two left-most plots in Figure 15 show lower tails, which depart significantly from log normality. The most probable explanation is that these very low permeabilities approached the detection limit of the equipment of the time (early 1970s).

Figures 16 through 19 show the cumulative density functions for both formations using the core analyses and using the Saraband ${ }^{\odot} \log$ data. A short discussion of uncertainty in the Saraband ${ }^{\odot} \operatorname{logs}$ is presented in Appendix B.

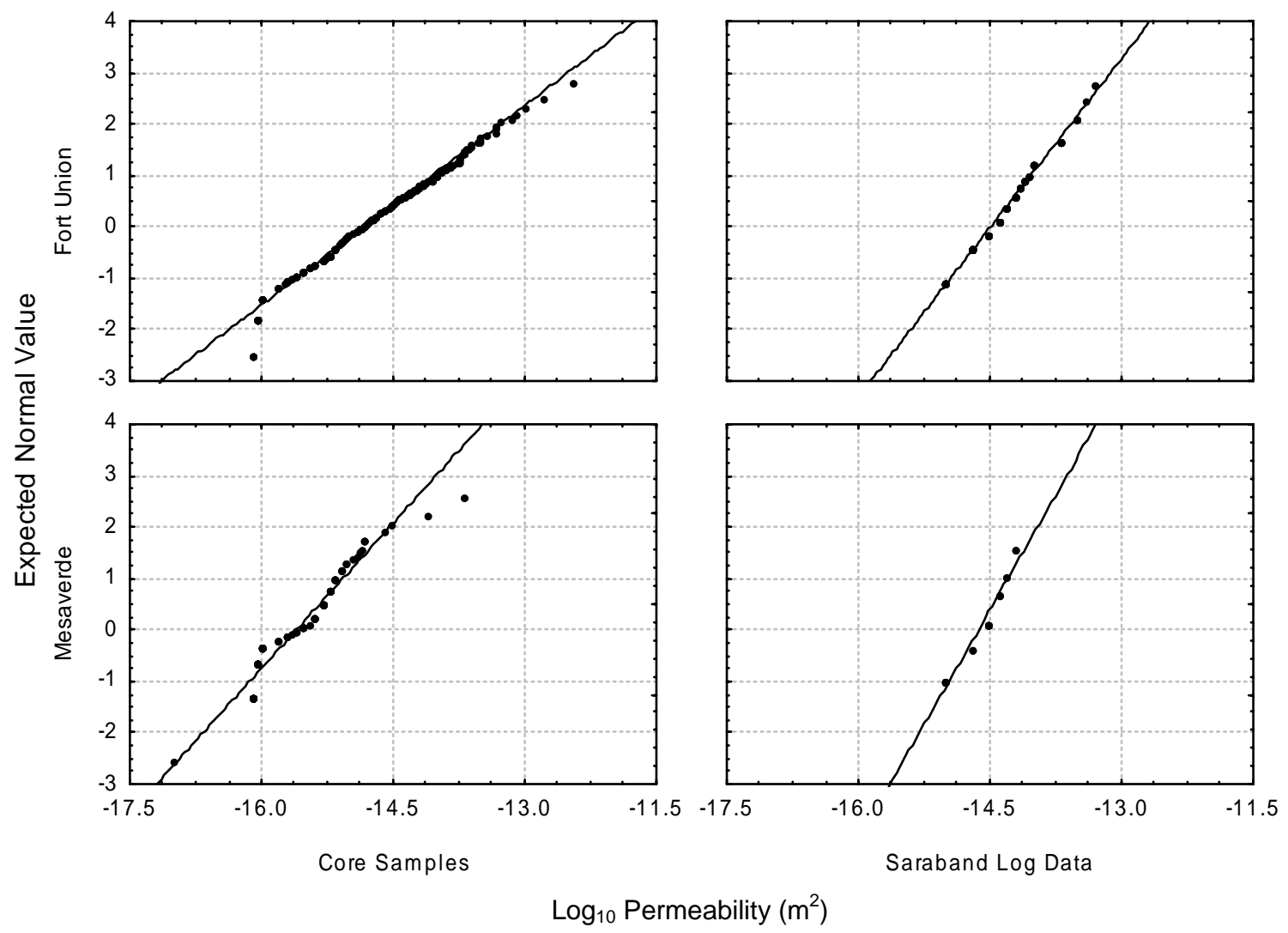

Figure 15. Lognormal probability-probability plot of intrinsic permeability for the Fort Union Formation and Mesaverde Group. The upper two plots are for the Fort Union Formation, while the lower two are for the Mesaverde Group. The two plots on the left are based upon data from cores, while the two on the right are from the Saraband logs. 


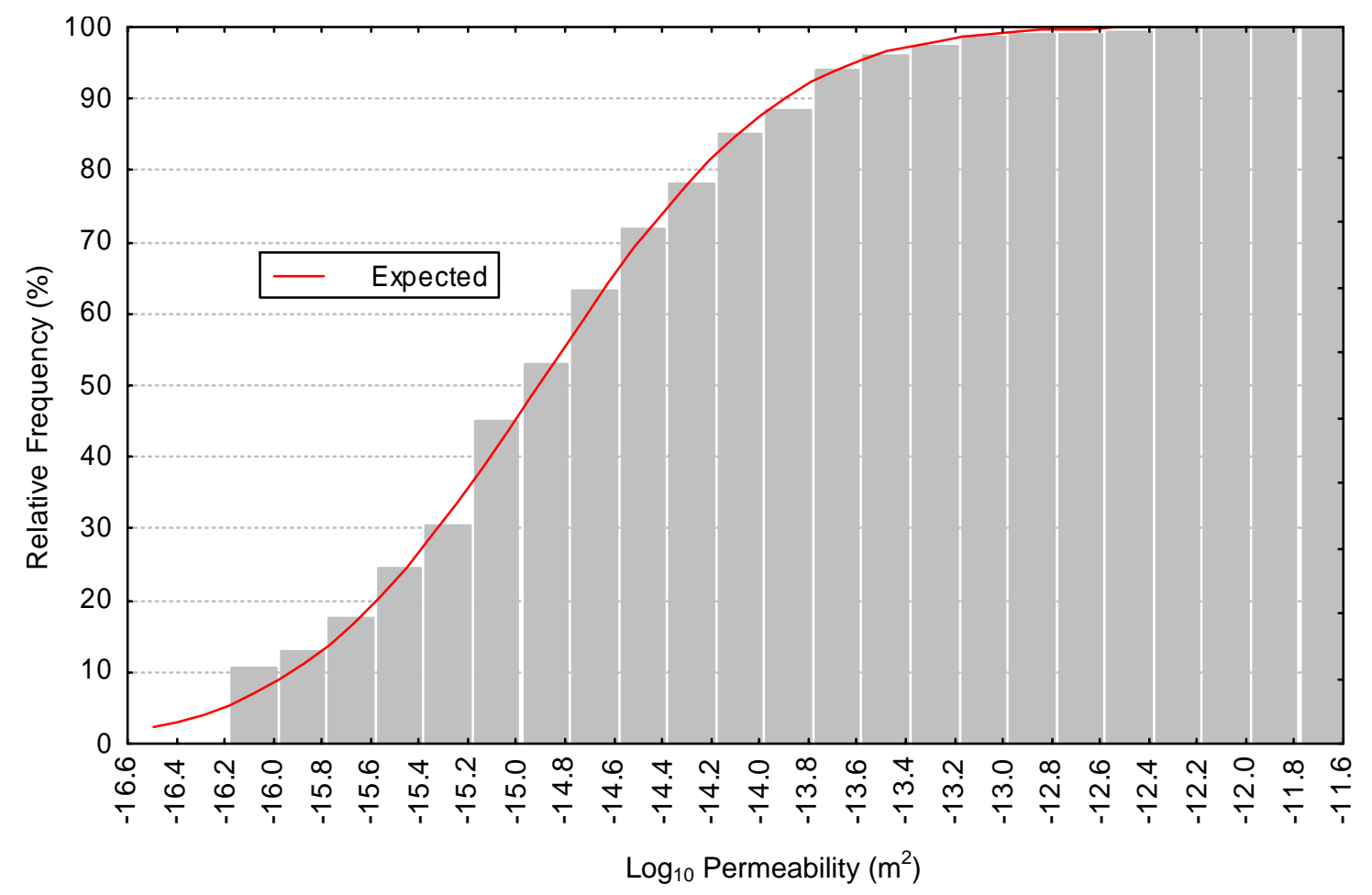

Figure 16. Fort Union $\log _{10}$ permeability CDF based on core analyses.

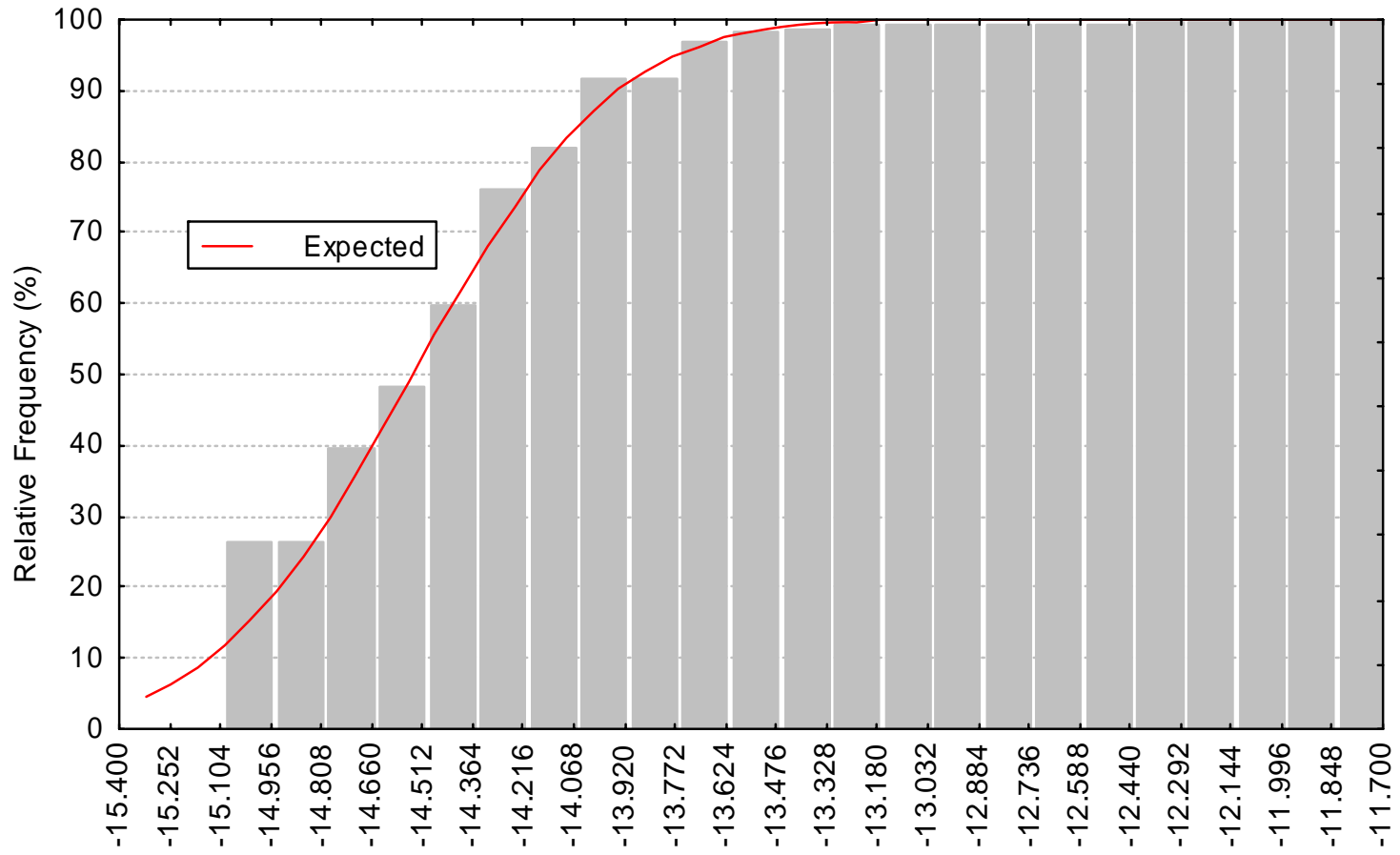

$\log _{10}$ Permeability $\left(\mathrm{m}^{2}\right)$

Figure 17. Fort Union $\log _{10}$ permeability CDF based on Saraband ${ }^{\odot} \log$ estimates. 


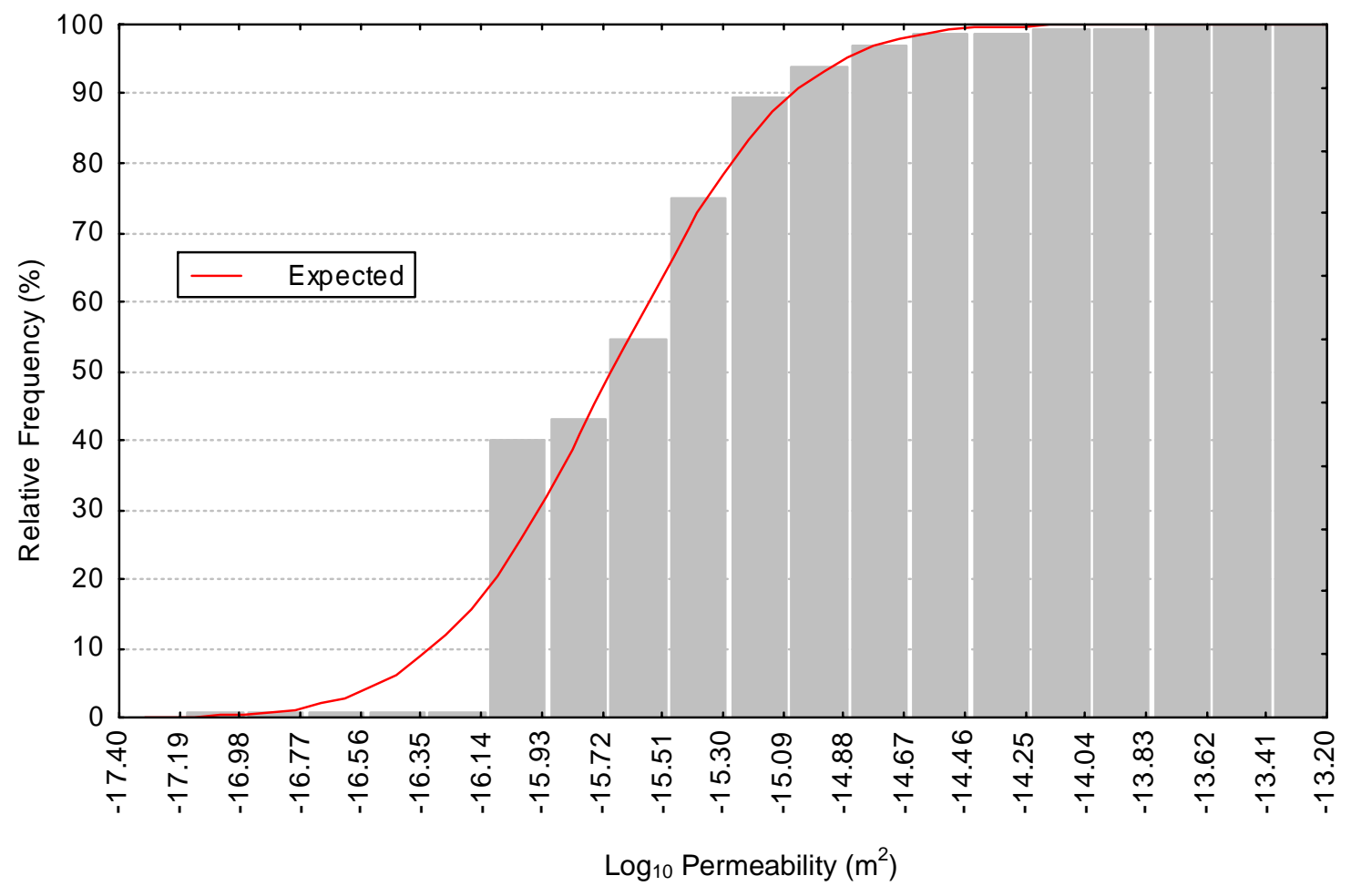

Figure 18. Mesaverde $\log _{10}$ permeability CDF based on core analyses.

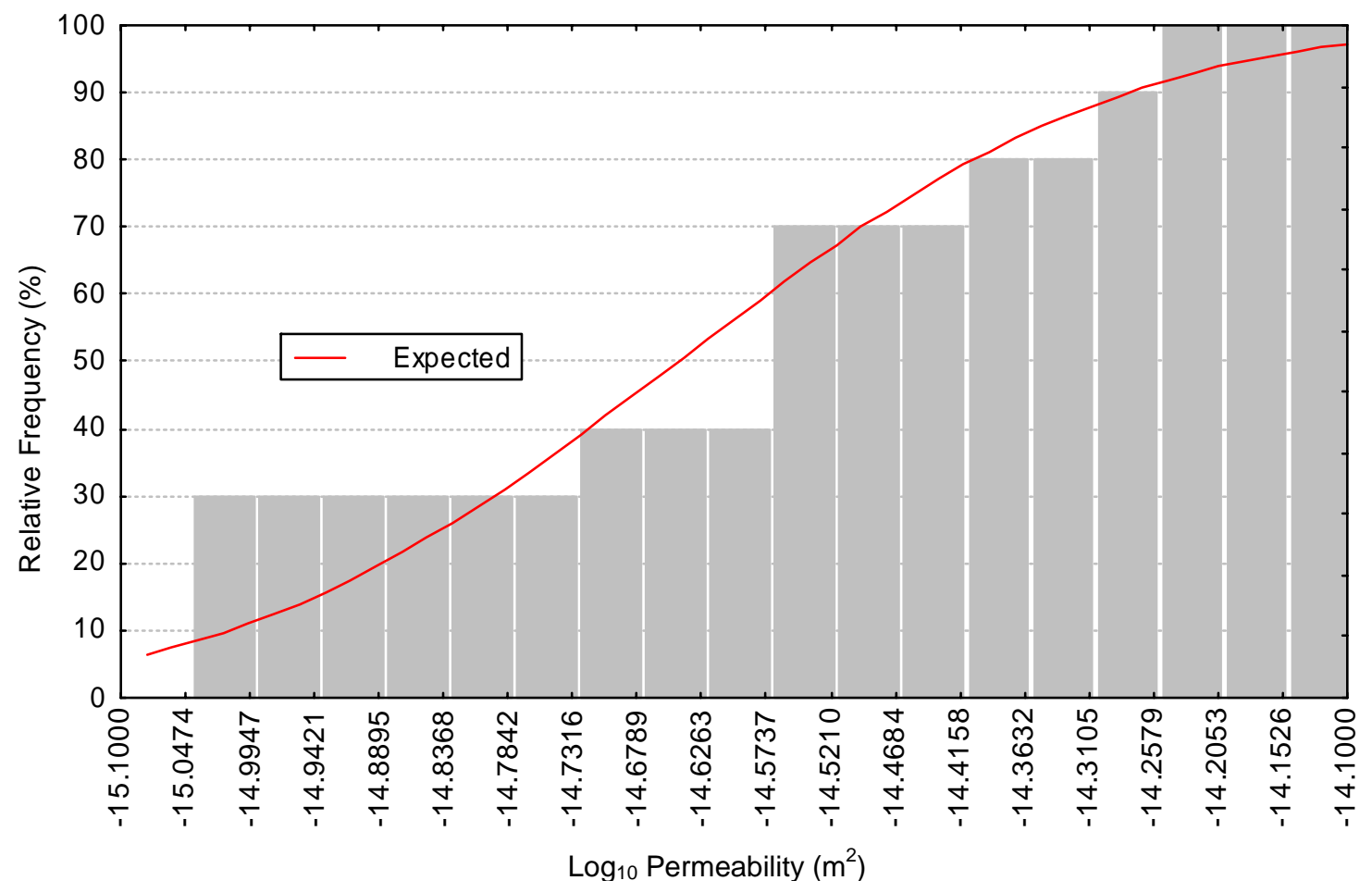

Figure 19. Mesaverde $\log _{10}$ permeability CDF based on Saraband ${ }^{\odot} \log$ estimates. 


\section{Porosity, Saturation, Matric Potential and Relative Permeability}

The effective porosity for the Mesaverde Group was estimated as 0.105 (CER Geonuclear, 1970) based upon analysis of cores retrieved from the Fawn Creek well. Measurements on cores from RB-E-01 suggested a mean porosity of 0.124 (Toman and Tewes, 1972). A porosity value of 0.105 was used in the simulations.

The gas saturation estimated by CER Geonuclear (1970) was 0.4. This was based on logs from the nearby Fawn Creek Government No. 1 well (the well upon which much of the reservoir characterization is based). This, however, contrasts with the gas saturation value derived from the core data of Toman and Tewes (1972). Using mean values of saturated bulk density $\left(\rho_{b}=2,470 \mathrm{~kg} \mathrm{~m}^{-3}\right)$, effective porosity $(n=0.124)$, and gravimetric liquid content $\left(\theta_{g, l}=0.05\right)$, and assuming a liquid density $\left(\rho_{l}\right)$ equal to sea water (approximately $1,040 \mathrm{~kg} \mathrm{~m}^{-3}$; a density is not reported), volumetric liquid content is $\theta_{v, l}=\left(\rho_{b} / \rho_{l}\right) \theta_{g, l}$ (approximately 0.119$)$. This results in a volumetric liquid saturation of approximately 0.96 . For a liquid density equivalent to freshwater $\left(1,000 \mathrm{~kg} \mathrm{~m}^{-3}\right)$, the volumetric liquid saturation is even higher, 0.996. For gas saturation on the order of 0.6, gas could be the controlling phase and more mobile of the two. For gas saturations less than 0.05 , it is most likely that the liquid phase is more mobile, and that perhaps the gas phase is even discontinuous.

Matric potential as a function of moisture content $(\psi-\theta)$ was measured on a sample of very fine-grained sandstone taken from a core of RB-E-01, located at the USGS Core Library in Denver, Colorado. The sample depth was $1,745 \mathrm{~m}$, which is $35 \mathrm{~m}$ above the location of the upper detonation. This sample was chosen because it was representative of the coarsest-grained material in the core, which would have more control on gas flow than the finer-grained material. It was also chosen because more values of matric potential could be gathered within the range of the analytical instrument. It is assumed that the $\psi-\theta$ relationship scaled the same for all reservoir rocks. No core is available from the elevations of any of the three test points. Several 2.54-cm (1-inch) diameter plugs were taken from the core using a hole saw. These plugs were later broken into approximately 10-g fragments for measurement of matric potential using a WP-4 Dew Point Potential meter (Decagon Instruments, Pullman, Washington). This instrument converts measurements of relative humidity in soils and rock fragments into matric potential, based upon the Kelvin equation (Gee et al., 1992). The WP-4 is capable of measuring matric potential between values of $-0.1 \mathrm{MPa}$ and $-86 \mathrm{MPa}$, with a precision of $\pm 0.1 \mathrm{MPa}$. Nonzero measurements of matric potential were recorded for values of volumetric liquid saturation less than 0.04 . For values of $S_{v, l}$ above this, the matric potential was measured as zero MPa. This implies that the capillary pressure is zero throughout much of the reservoir, as $0.6<S_{v, l}<0.9$. The data are plotted in Figure 20, and are fit to the TRUST retention curve in TOUGH2 (which is essentially the Brooks and Corey [1964] function with a slightly different definition of effective saturation)

$$
\begin{array}{cc}
P_{c a p}=-P_{e}-P_{o}\left[\frac{1-S_{l}}{S_{l}-S_{l r}}\right]^{1 / \eta} & \text { for } S_{l}<1 \\
P_{c a p}=0 & \text { for } S_{l}=1
\end{array}
$$


where $P_{o}$ is a reference pressure $(1,000 \mathrm{~Pa}), S_{l r}=0.01, \eta=3.6, P_{e}=10^{5} \mathrm{~Pa}$, and the saturations are all volumetrically based.

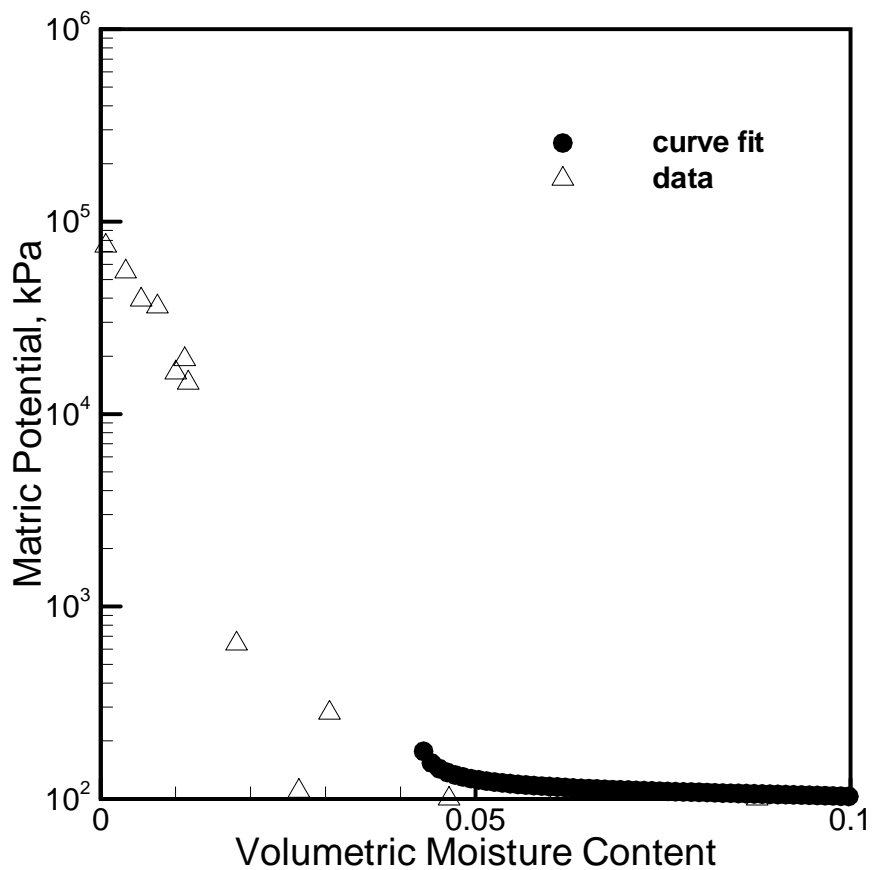

Figure 20. Moisture retention curve based upon three samples from a plug taken at 1,745.5 m from the RB-E-01 core. The curve fit is based upon the TRUST capillary function in TOUGH2 (which is based upon Brooks and Corey, 1964) with $S_{l r}=0.01, P_{e}=10^{5}$, $P_{o}=10^{3}$, and $\eta=3.6$. The uncertainty on the data is $\pm 100 \mathrm{kPa}$.

The relative permeability curves are presented in Figure 21 and are based on Corey's (1954) curves

$$
\begin{gathered}
k_{r l}=\hat{S}^{4} \\
k_{r g}=(1-\hat{S})^{2}\left(1-\hat{S}^{2}\right)
\end{gathered}
$$

where

$$
\hat{S}=\frac{\left(S_{l}-S_{l r}\right)}{1-S_{l r}-S_{g r}}
$$

No data exist to test or evaluate an appropriate relative permeability function. An important feature of these curves is that unlike most relative permeability relationships, the relative permeabilities for each phase $\left(k_{r, l}\right.$ and $\left.k_{r, g}\right)$ do not necessarily sum to unity for any given saturation. This is important, as extensive experimentation in the 1950s and 1960s indicated that $k_{r, g}+k_{r, l} \neq 1$ (Bear, 1988). 


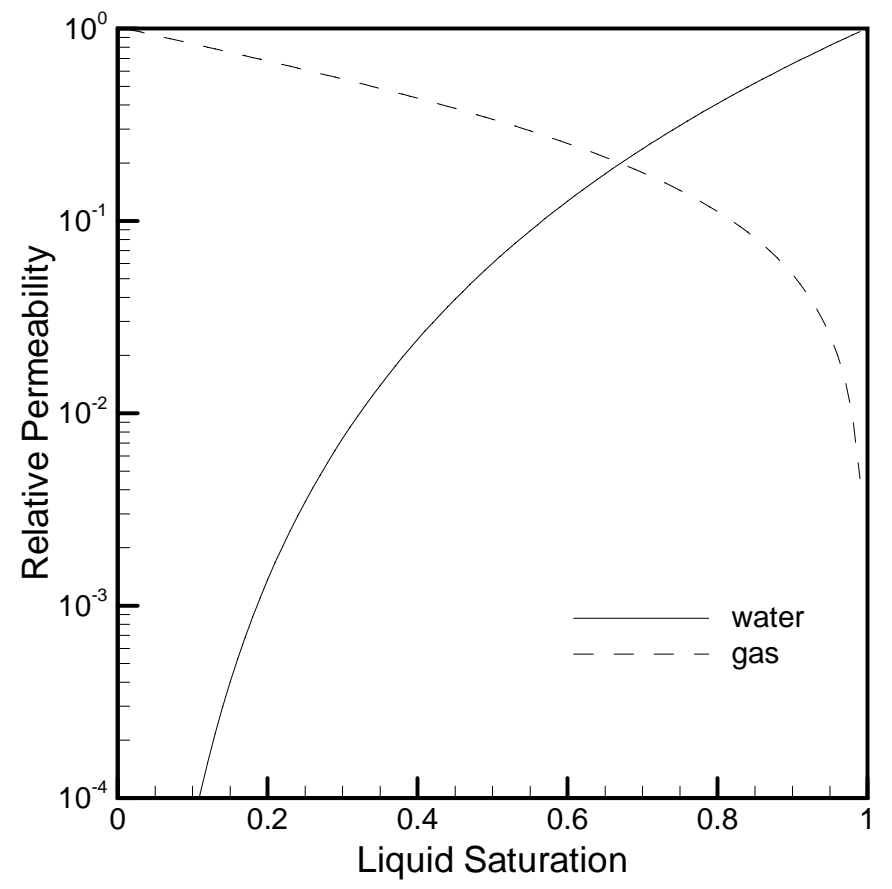

Figure 21. Relative permeability curves for gas and water.

The rock grain density, needed for calculation of specific heat, is $2,680 \mathrm{~kg} \mathrm{~m}^{-3}$ (Toman and Tewes, 1972; no units given in report, but these are the only plausible ones for the values reported).

\section{Chemical Transport Properties}

The following diffusion coefficients for gas mixtures are required: tritiated water $\left({ }^{3} \mathrm{HHO}\right.$ or $\left.\mathrm{THO}\right)$ and helium (the nonradioactive decay product of tritium) in methane. The free-air diffusion coefficient for helium has been measured and is reported in Cussler (1997). The free-air diffusion coefficient for tritiated water in methane was calculated using the method of Chapman and Cowling (see Reid et al., 1987). The effect of pressure on diffusivity (Reid et al., 1987, eq. 11-5.1) was investigated. For the reservoir conditions at Rio Blanco (approximately $20 \mathrm{MPa}$ ), the diffusion coefficients changed only by 2 percent, well within the uncertainty of the estimates at low pressure. In the liquid phase, molecular diffusion coefficients were required for THO and He in water. Again, measured values of He at infinite dilution are provided in Cussler (1997), while tritiated water in liquid water was determined using the method of Wilke and Chang, which accounts for reservoir pressure (see Reid et al., 1987). The product of the free-air (for gases) and molecular diffusion (for liquids) coefficients with a tortuosity value results in the effective diffusion coefficient through the reservoir rocks. As defined in TOUGH2, tortuosity can be defined as having a porous medium-dependent part, $\tau_{o}$, and a saturation-dependent part, $\tau_{\beta}$. The most commonly implemented model of tortuosity is the Millington-Quirk model (Millington, 1959; Millington and Quirk, 1961) that includes phase-dependent saturation as the tortuosity model. That is, 


$$
\tau_{o} \tau_{\beta}=\phi^{1 / 3} S_{\beta}^{10 / 3}
$$

where $\phi$ is porosity. A relative permeability based tortuosity model was also tested, where

$$
\tau_{o} \tau_{\beta}\left(S_{\beta}\right)=\tau_{o} k_{r \beta}\left(S_{\beta}\right)
$$

As stated in the section on the Conceptual Model, mechanical dispersion in the liquid phase was not included.

Values for Henry's constant of methane dissolution in water vary between $4.41 \times 10^{-10} \mathrm{~Pa}^{-1}\left(0^{\circ} \mathrm{C}\right)$ and $1.41 \times 10^{-10} \mathrm{~Pa}^{-1}\left(100^{\circ}\right)$ (Perry and Green, 1997). Since the values change by only a factor of three, and because the geothermal gradient relates to a temperature of approximately $100^{\circ} \mathrm{C}$ throughout much of the reservoir, the default value for air dissolution in water was used $\left(10^{-10} \mathrm{~Pa}^{-1}\right)$. This is not expected to have a significant effect on the results, as methane dissolution in water is small.

Finally, the half lives of ${ }^{3} \mathrm{H}$ and ${ }^{85} \mathrm{Kr}$ are 12.26 and $10.76 \mathrm{yr}$, respectively (Parrington et al., 1996).

\section{$\underline{\text { Knudsen Diffusion }}$}

The mean free path is the characteristic distance a molecule travels before colliding with another molecule. If this distance is on the order of the pore diameter, the no-slip boundary condition assumed for molecular diffusion is violated and the diffusion coefficient must be adjusted for additional viscous forces. The mean free path of a gas molecule is calculated from (Furbish, 1998)

$$
l=\frac{\kappa}{4 \sqrt{2} \pi r^{2}} \frac{T}{P}
$$

where $\kappa$ is Boltzmann's constant $\left(1.38 \times 10^{-23} \mathrm{~J} \mathrm{~K}^{-1}\right), T$ is temperature $(\mathrm{K})$, and $P$ is pressure. The mean free path for a typical molecule of radius $r \sim 0.065 \mu \mathrm{m}$ is approximately $4 \times 10^{-9} \mu \mathrm{m}$. A characteristic pore diameter of the Mesaverde Group and Fort Union Formation is between 100 and $200 \mu \mathrm{m}$ (Toman and Tewes, 1972). Near the surface, Knudsen diffusion would be an important consideration; at reservoir pressures on the order of 10 to $20 \mathrm{MPa}$ it is of negligible significance.

\section{Radioactive Source Values}

The three detonations produced approximately 3,000 $\mathrm{Ci}$ of ${ }^{3} \mathrm{H}$, with 40 percent of that being part of the glass and considered immobile under the time scales of interest (i.e., several hundred years; Toman and Tewes, 1972). Given that the amount in the melt is not known with certainty, and that it is conservative to assume less is in the melt, the tritium source for this modeling effort assumes only five percent is in the melt glass. Following the distribution of tritium reported by Smith (1975) in cavity gas samples, the initial tritium radioactivity for each nuclear cavity in the model was distributed as $50 \mathrm{Ci}$ in the solid phase (melt glass), $70 \mathrm{Ci}$ in gas (methane), and $880 \mathrm{Ci}$ in water. Production testing of the two re-entry wells RB-E-01 (following detonation) and RB-AR-2 resulted in tritium being both flared to the atmosphere and removed as part of the liquid water that was produced with the gas. The amount of tritiated water produced from both RB-E-01 and RB-AR-2 was $177.8 \mathrm{Ci}$, which 
was injected into the Fawn Creek Government No. 1 well (injection interval between 1,716 and $1,851 \mathrm{~m}$ below surface). (This number is incorrectly reported by the Colorado Department of Health (1980) as being $278 \mathrm{Ci}$.) The amount of tritium withdrawn from RB-AR-2 was $27.868 \mathrm{Ci}$ and $23.022 \mathrm{Ci}$, contained in the water and methane, respectively. Accepting that $177.8 \mathrm{Ci}$ tritium was injected into the Fawn Creek well, and that $75.31 \mathrm{Ci}$ tritium was flared (Colorado Department of Health, 1980), the tritium removed from production testing of RB-E-01 and RB-AR-2 is calculated in Table 5.

Table 5. Tritium withdrawn from wells RB-E-01 and RB-AR-2 in dry gas (methane) and liquid.

\begin{tabular}{cccc}
\hline Well Number & $\begin{array}{c}\text { Tritium in methane } \\
(\mathrm{Ci})\end{array}$ & $\begin{array}{c}\text { Tritium in water } \\
(\mathrm{Ci})\end{array}$ & $\begin{array}{c}\text { Tritium in gas and water } \\
(\mathrm{Ci})\end{array}$ \\
\hline RB-E-01 (top) & 52.288 & 149.932 & 202.22 \\
RB-AR-02 (bottom) & 23.022 & 27.868 & 50.89 \\
Total & 75.31 & 177.8 & 253.11 \\
\hline
\end{tabular}

The results of testing both re-entry wells suggested that the cavities were not connected (Tewes, 1979). The initial radioactivity of the middle cavity, therefore, remained unchanged, as no wells were drilled into it. The tritium radioactivities calculated in Table 5 can then be used to determine the tritium distribution within the three cavities. These radioactivities remaining in each of the three cavities are shown in Table 6.

Table 6. Tritium distribution remaining within the three cavities

\begin{tabular}{cccc}
\hline Cavity & Tritium in methane $(\mathrm{Ci})$ & Tritium in water $(\mathrm{Ci})$ & Tritium in melt $(\mathrm{Ci})$ \\
\hline Top & 17.712 & 730.068 & 50 \\
Middle & 70 & 880 & 50 \\
Bottom & 46.978 & 852.132 & 50 \\
Total & 134.69 & 2462.2 & 150 \\
\hline
\end{tabular}

As reported by Smith (1975), the distribution of tritium in the different phases is not at equilibrium for standard reservoir conditions. The TOUGH2 computer program, however, assumes equilibrium between phases according to Henry's law (between gas and liquid; the immobile solid phase is ignored). Additionally, tritium is released in the gas phase, and probably as tritium gas. In the model presented here, however, it is assumed that individual tritium atoms bind with nonradioactive hydrogen $\left({ }^{1} \mathrm{H}\right)$ and oxygen to form molecules of tritiated water $\left({ }^{3} \mathrm{HHO}\right.$ or THO). This is largely based upon reports that large amounts of tritiated water are found in gas and water samples collected from drillbacks at the Nevada Test Site. The TOUGH2 program requires that radioactive sources be entered as mass fraction in the liquid phase; the mass fractions are then partitioned between phases during the first time step. Tritium mass is calculated from radioactivity (curies) from the following expression (where dps is "disintegrations per second"):

$$
\begin{gathered}
1 C i^{3} H\left(\frac{3.7 \times 10^{10} d p s}{1 C i{ }^{3} H}\right)\left(\frac{\text { atom }{ }^{3} \mathrm{H}}{1.78 \times 10^{-9} d p s}\right) \\
\left(\frac{1 \mathrm{~mol}^{3} \mathrm{H}}{6.02 \times 10^{23} \text { atoms }{ }^{3} \mathrm{H}}\right)\left(\frac{0.003 \mathrm{~kg}^{3} \mathrm{H}}{1 \mathrm{~mol}{ }^{3} \mathrm{H}}\right)\left(\frac{0.020 \mathrm{kgTHO}}{0.003 \mathrm{~kg}{ }^{3} \mathrm{H}}\right) \\
=6.906 \times 10^{-7} \mathrm{~kg} \mathrm{THO}
\end{gathered}
$$


In Equation (7), $\mathrm{pCi}$ is the abbreviation for picocuries (one picocurie is $10^{-12}$ curies). A curie is defined as $3.7 \times 10^{10} \mathrm{dps}$, while the decay constant for tritium $\left(1.78 \times 10^{-9} \mathrm{dps}\right)$ is defined as $\ln 2 / t_{1 / 2}$, where $t_{1 / 2}$ is the half-life of tritium (in seconds). The mass is partitioned between phases in the following manner. If $C$ is denoted as the total mass of tritium, and $A$ and $B$ are tritium mass in the aqueous and gas phases, respectively, then $A+B=C$. $A$ is calculated using the mass fraction $X_{l}^{T H O}$ specified in initial condition and water mass in the element based on element volume $V_{\text {ele }}$, porosity $\phi_{\text {ele }}$, and liquid saturation $S_{l}$, i.e., $A=\rho_{l} V_{\text {ele }} \phi_{\text {ele }} S_{l} X_{l}^{T H O}$. (Mass fraction is the mass of a component within a phase divided by the total mass of that phase.) $B$ is calculated using Henry's law and ideal gas law. The pressure corresponding to mass fraction $X_{l}^{T H O}$ is first calculated using Henry's law $P=K_{h} X_{l}^{T H O}$, where $K_{h}$ is Henry's constant. One mole of tritium is then calculated using the ideal gas law $n=\frac{P V}{R T}=\frac{K_{h} X_{l}^{T H O} V_{e l e} \phi_{e l e} S_{g}}{R T}$, where $S_{g}=1-S_{l}$ is the gas saturation. Therefore, the mass of tritium in gas phase is $B=\frac{K_{h} X_{l}^{T H O} V_{e l e} \phi_{e l e} S_{g}}{R T} \times 20$, where 20 is molecular weight of tritiated water. Since $A+B=C$,

$$
\rho_{l} V_{\text {ele }} \phi_{\text {ele }} S_{l} X_{l}^{T H O}+\frac{K_{h} X_{l}^{T H O} V_{\text {ele }} \phi_{\text {ele }} S_{g}}{R T} \times 20=X_{l}^{T H O}\left(\rho_{l} V_{\text {ele }} \phi_{\text {ele }} S_{l}+\frac{K_{h} V_{\text {ele }} \phi_{\text {ele }} S_{g}}{R T} \times 20\right)=C
$$

and $X_{l}^{T H O}$ is estimated as

$$
X_{l}^{T H O}=C /\left(\rho_{l} V_{\text {ele }} \phi_{\text {ele }} S_{l}+\frac{K_{h} V_{\text {ele }} \phi_{\text {ele }} S_{g}}{R T} \times 20\right)
$$

Toman and Tewes (1972) estimated the amount of water in the three cavities as $2.6 \times 10^{7} \mathrm{~kg}$. All of this water is assumed nonradioactive for calculations of mass fraction, since 1,200 Ci tritium is only approximately 0.8 gr. This mass of water was assumed to be divided equally between the three chimneys, that is, such that $8.67 \times 10^{6} \mathrm{~kg}$ liquid water was present in each cavity.

\section{$\underline{\text { Regulatory Context of Radionuclide Mass Fraction Results }}$}

As described above, the modeling calculations were performed in terms of mass fraction. Particularly when considering gases, mass fraction simplifies issues such as ensuring consistency in the pressure-volume-temperature conditions under consideration (i.e., concentrations in a gas are dependent on the volume, which is itself dependent on pressure and temperature). Though using mass fraction maintained correctness in the calculations, it could be difficult to intuitively grasp the meaning of the values. The following information provided a context for the tritium mass fraction values, though a number of assumptions must be made. 
Two points of reference are useful for evaluating the mass fractions. First is the regulatory dose limit set by the State of Colorado Department of Public Health and Environment (http://www.cdphe.state.co.us/op/regs/radiationregs.asp) for individual members of the public. This limit states that the annual average concentrations of radioactive material released in gaseous and liquid effluents at the boundary of an unrestricted area cannot exceed the values specified in Table II of Part 4 Appendix B of 6 CCR 1007-1; and that for an individual continually present in an unrestricted area, the dose from external sources would not exceed 0.02 milliSievert ( $\mathrm{mSv}$ - equivalent to $0.002 \mathrm{rem}$ ) in an hour and $0.5 \mathrm{mSv}(0.05 \mathrm{rem})$ in a year. The value for tritium in water vapor in air in Table II is $1 \times 10^{-7} \mu \mathrm{Ci} \mathrm{ml}^{-1}$, which can also be expressed as $1 \times 10^{5} \mathrm{pCi} \mathrm{m}^{-3}$. Using the decay constant for tritium to determine the number of tritium atoms necessary to produce $1 \times 10^{5} \mathrm{pCi} \mathrm{m}^{-3}$ $\left(2.067 \times 10^{12}\right.$ atoms $\left.{ }^{3} \mathrm{H} \mathrm{m}^{-3}\right)$, and assuming 5 percent water vapor in a cubic meter of atmosphere at standard temperature and pressure (leading to $2.69 \times 10^{24}$ atoms of $\mathrm{H} \mathrm{m}^{-3}$ ), the mass fraction for the Colorado regulatory limit for tritium in atmospheric water vapor is approximately $7.7 \times 10^{-13}{ }^{3} \mathrm{H} / \mathrm{H}$.

The second point of reference is the background, or natural abundance, of tritium. Tritium is produced by gamma radiation in the upper atmosphere and thus occurs naturally, though nuclear testing and other man-made nuclear activities produced much larger amounts. The estimated ratio prior to weapons testing is one tritium atom for every $10^{18}$ hydrogen atoms (referred to as a "tritium unit"). Monitoring by the U.S. Environmental Protection Agency around the Nevada Test Site determined that concentrations of tritiated water vapor in air of $0.25 \mathrm{pCi} \mathrm{m}^{-3}$ were representative of environmental background in 1990 (U.S. EPA, 1992). Using the same assumptions for converting to mass fraction as described above for the Colorado regulatory limit leads to an equivalent mass fraction for $0.25 \mathrm{pCi} \mathrm{m}^{-3}$ of $1.92 \times 10^{-18}{ }^{3} \mathrm{H} / \mathrm{H}$, only slightly higher than the pre-weapons testing estimate. The preweapons testing estimated tritium abundance of $10^{-18}$ mass fraction of ${ }^{3} \mathrm{H} / \mathrm{H}$ is used on many of the subsequent plots to represent background conditions.

\section{PRODUCTION OF NATURAL GAS FROM A WELL}

Some of the simulations assumed the placement of a producing gas well at the boundary of the drilling exclusion zone $183 \mathrm{~m}(600 \mathrm{ft})$ from the center of the three cavities. Production characteristics in the Rulison field, southeast of Rio Blanco but in the Piceance Basin, are used as a basis for these simulations because they represents current development practice. A production decline curve provided by Presco, Inc. (Houston) was used in the simulations (Table 7). The curve was based upon producing histories in gas fields in the vicinity of the Rulison nuclear test, where gas was produced from the Mesaverde Group. Each production well within a field was different, although gas was typically produced from between 10 and $156.1-\mathrm{m}(20-\mathrm{ft})$ long intervals. In this model, it was assumed that production occurred from a 6.1-m zone, which produced 10 percent of the rate provided by Presco, Inc. The reasons for this were discussed previously, where the geometric configuration of the well was discussed. It was assumed that production would begin in 2008, i.e., 35 years after the nuclear detonations. That is, radionuclides were transported under "natural" processes -- such as advection, dispersion, and diffusion -- from 1973 until 2008, at which time production began. Gas production is assumed to take place for 30 years, after which production ceases and radionuclide transport occurs in the presence of the recovering pressure field. 
Table 7. Gas decline curve for simulations with gas production. Values are in million cubic feet of gas (MCFG) for the entire month.

\begin{tabular}{rrrlllllllllll}
\hline \multicolumn{1}{c}{ Jan } & Feb & \multicolumn{1}{l}{ Mar } & \multicolumn{1}{l}{ Apr } & \multicolumn{1}{l}{ May } & \multicolumn{1}{l}{ Jun } & \multicolumn{1}{l}{ Jul } & Aug & Sep & Oct & Nov & Dec \\
\hline 1992 & 39,000 & 35,400 & 31,350 & 24,000 & 21,000 & 18,600 & 16,500 & 15,900 & 15,000 & 14,400 & 14,100 & 13,950 \\
1993 & 11,550 & 11,550 & 11,550 & 10,800 & 10,800 & 10,800 & 10,260 & 10,260 & 10,260 & 9,750 & 9,750 & 9,750 \\
1994 & 9,000 & 9,000 & 9,000 & 8,250 & 8,250 & 8,250 & 7,860 & 7,860 & 7,860 & 7,500 & 7,500 & 7,500 \\
1995 & 7,050 & 7,050 & 7,050 & 6,600 & 6,600 & 6,600 & 6,450 & 6,450 & 6,450 & 6,300 & 6,300 & 6,300 \\
1996 & 6,150 & 6,150 & 6,150 & 6,000 & 6,000 & 6,000 & 5,850 & 5,850 & 5,850 & 5,700 & 5,700 & 5,700 \\
1997 & 5,550 & 5,550 & 5,550 & 5,400 & 5,400 & 5,400 & 5,250 & 5,250 & 5,250 & 5,100 & 5,100 & 5,100 \\
1998 & 4,950 & 4,950 & 4,950 & 4,800 & 4,800 & 4,800 & 4,710 & 4,710 & 4,710 & 4,650 & 4,650 & 4,650 \\
1999 & 4,560 & 4,560 & 4,560 & 4,500 & 4,500 & 4,500 & 4,380 & 4,380 & 4,380 & 4,260 & 4,260 & 4,260 \\
2000 & 4,140 & 4,140 & 4,140 & 4,050 & 4,050 & 4,050 & 3,900 & 3,900 & 3,900 & 3,810 & 3,810 & 3,810 \\
2001 & 3,690 & 3,690 & 3,690 & 3,600 & 3,600 & 3,600 & 3,450 & 3,450 & 3,450 & 3,300 & 3,300 & 3,300 \\
\hline
\end{tabular}

\section{OUTLINE OF DETERMINISTIC SIMULATIONS}

Both deterministic and Monte Carlo simulations were run. The deterministic simulations modeled (1) two-dimensional transport away from the three nuclear cavities, in an unstressed reservoir; and (2) three-dimensional transport away from a single (middle) cavity toward a hypothetical gas-producing well. The Monte Carlo simulations were based upon the deterministic three-dimensional simulations, and consisted of 500 realizations.

The results section below begins with a discussion of several simulations in which fractures were included in the solution domain. Prior to conducting the three-dimensional simulations, several two-dimensional simulations were performed in which idealized flowcontrolling fractures were included in the domain at various spacings. (The fractures were assumed to be "natural" and not a result of the hydraulic stimulation of the production well.) The results of these simulations provide confidence that flow and transport in the vicinity of the Rio Blanco tests could be simulated. Several steps are required to complete a fully threedimensional, transient radionuclide transport simulation. The first step involved setting up the upgradient and downgradient pressure boundaries by solving the steady-state flow in a single vertical column with prescribed pressures above and below. Steady state was defined by large time steps on the order of $10^{4}$ years or greater. This resulted in hydrostatic gravitycapillarity equilibrium conditions. A two-dimensional mesh was then formulated, with the vertical pressure distributions up- and downgradient, and the flow was again run to steady state. To complete the development of the steady-state pressure field, the two-dimensional mesh was expanded laterally (in the $y$-direction) and the three-dimensional flow problem was run. Radionuclide mass fractions were then added at the appropriate grid blocks, as well as gas production (if required). In simulations that included gas production, the simulator was stopped at $35 \mathrm{yr}$ of simulation time, the hydraulic fractures were added, and then the code was restarted. Production occurred for $30 \mathrm{yr}$, beginning $35 \mathrm{yr}$ after detonation (i.e., the year 2008). It was then stopped in the year 2038. All transport simulations were carried out for 1,000 years. 


\section{RESULTS OF DETERMINISTIC SIMULATIONS}

\section{Effect of Fractures}

Several simulations were conducted to understand the effect that fractures might have on controlling flow in the near field $(<100 \mathrm{~m})$ of the nuclear cavity. The fractures were included in a highly idealized manner (i.e., smooth-walled fractures, permeability expressed as cubic law), using the MINC (multiple interacting continua) subroutine in TOUGH2. This idealized representation, however, gives an indication of the minimum distance between connecting fractures required for their discrete inclusion in the model.

The simulations were run in two dimensions, and with matrix $k=3 \times 10^{-17} \mathrm{~m}^{2}$, fracture permeability $3 \times 10^{-16} \mathrm{~m}^{2}$, matrix porosity 0.105 , and fracture porosity 0.01 . The fractures were included in the model with uniform spacing in both directions, i.e., a "sugar cube" model (Figure 22). Within each matrix, two subcontinua were implemented, each with its own set of rock properties. Four simulations were conducted, with two different matrix permeabilities and two different fracture spacings. Figure 23 shows the mass fraction of tritium in both the gas (Figure 23a) and liquid (Figure 23b) phases for the two different fracture spacings $(5$ and $20 \mathrm{~m})$. The average value of mass fraction in both the matrix and fractures is plotted as a function of distance from the tritium source. For a 5-m spacing between connecting fractures, the matrix and fractures have nearly identical concentrations, suggesting that for these initial and boundary conditions, the permeability field could be considered homogeneous. The reason that the mass fractions are nearly identical is due to diffusion of tritium into the fractures. For closely connected fractures, diffusion spreads tritium throughout a greater percentage of rock matrix. For a $20-\mathrm{m}$ fracture spacing, however, a difference in mass fraction is seen between the matrix and fractures. For all simulations, the difference in mass fraction between the fracture and matrix increases with distance from the source. Identical results are seen in the liquid phase. Figure $24 a, b$ shows the results of two similar simulations, except that the permeability field is increased by an order of magnitude in the fractures $\left(k=3 \times 10^{-15} \mathrm{~m}^{2}\right)$. In this case, tritium mass fraction in both phases is more

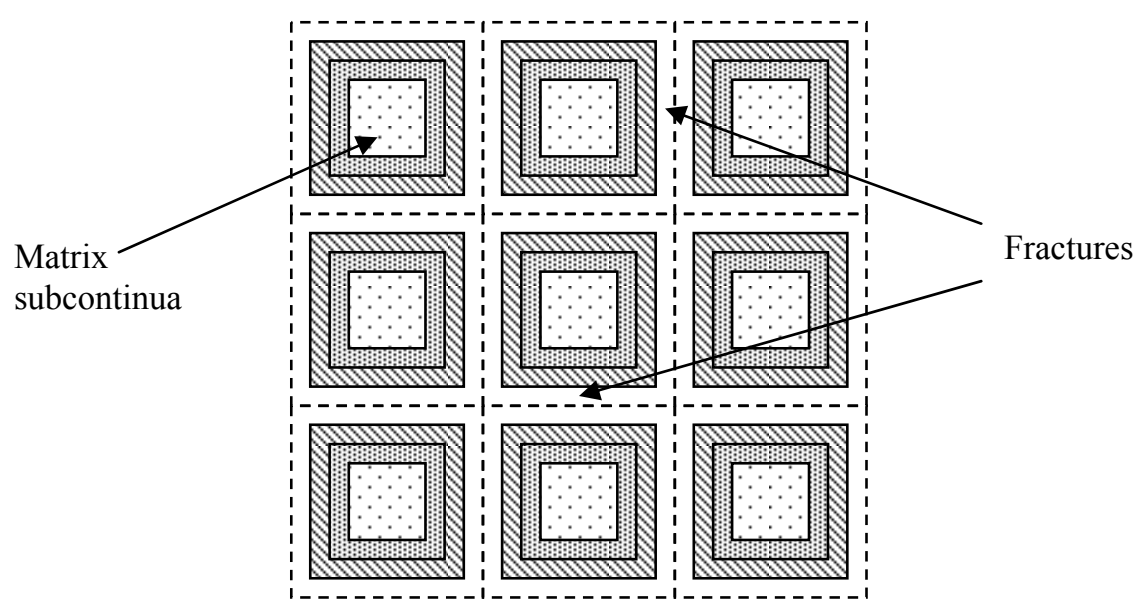

Figure 22. Schematic of how fractures are incorporated using the MINC subroutine in TOUGH2. This method essentially uses the ideas of dual porosity/permeability, where the matrix (the concentric squares) has one (or multiple) set of properties while fractures have another. 

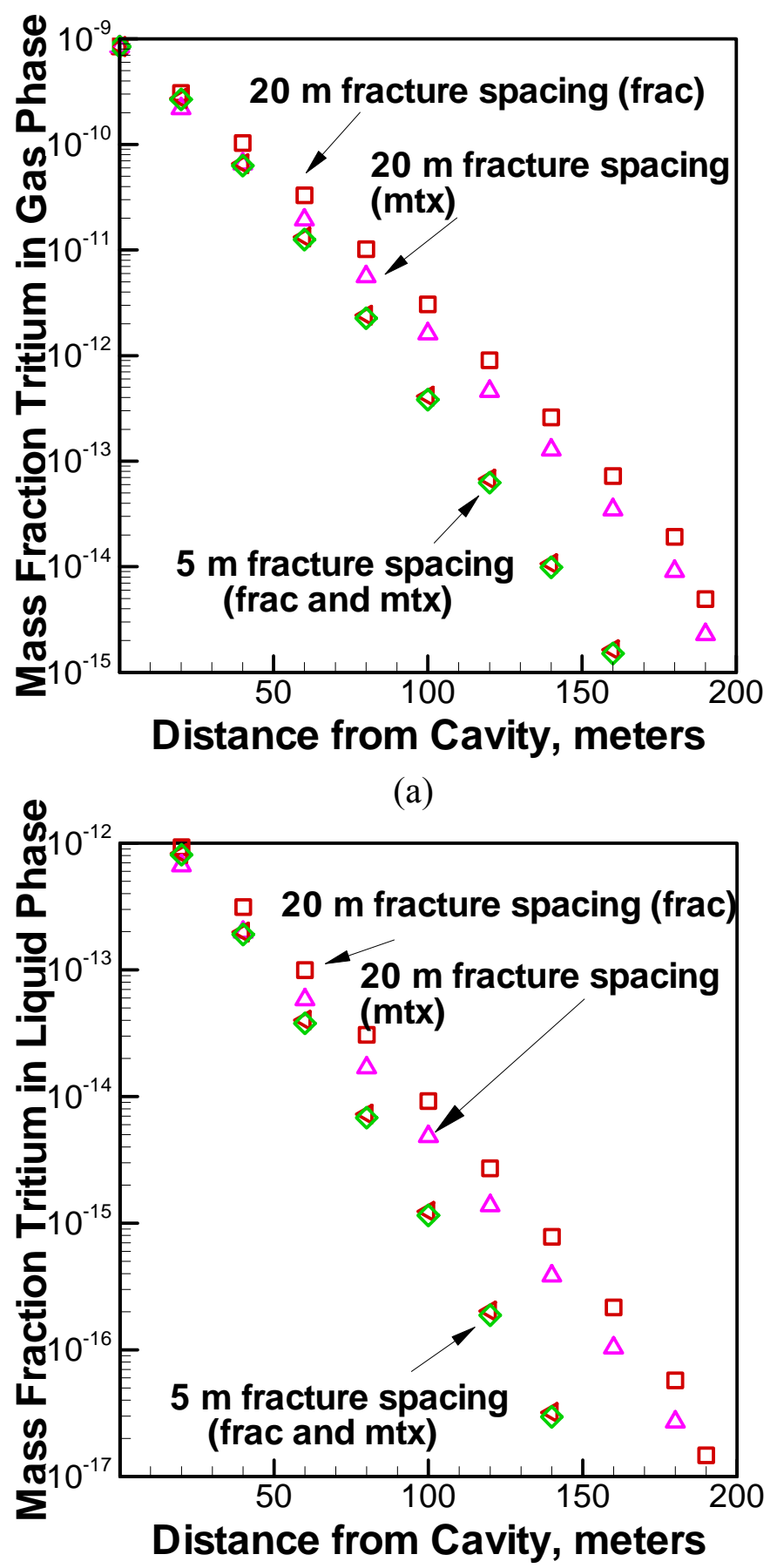

(b)

Figure 23. Gas and liquid phase mass fractions of tritium -20 yrs. The abbreviations "frac" and "mtx" are for the values in either the fracture or matrix for the location. 

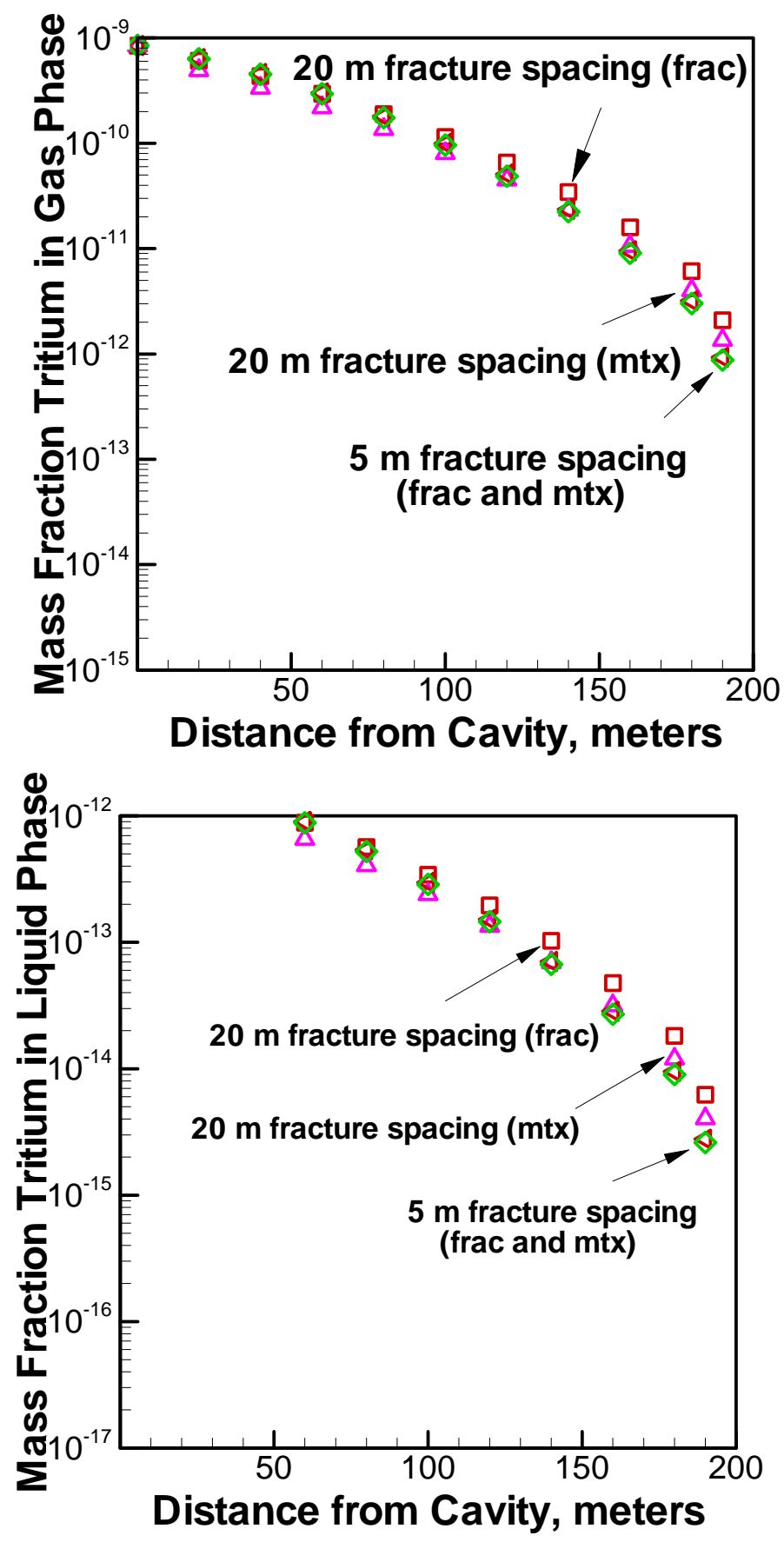

Figure 24. One order-of-magnitude increase in fracture permeability $-20 \mathrm{yrs}$. 
similar, for both fracture spacings. These simulations suggest that for a fracture density of

$5 \mathrm{~m}$, flow may be considered homogeneous. For a smaller fracture density (i.e., $20 \mathrm{~m}$ fracture spacing), a discrete concentration difference (plotted as mass fraction) exists between the matrix and fractures. If flow-controlling fractures are spaced widely apart, a dual permeability or porosity may more accurately depict the concentration field. For closely spaced fractures, the domain may be able to be modeled as an equivalent porous medium, which is the approach taken in this report.

\section{Two-dimensional Transport of Tritiated Water in an Unstressed Gas Reservoir}

Two-dimensional simulations that investigated transport away from the three cavities in an unstressed (non-gas-producing) reservoir are discussed in this section. Figure 25a through 251 shows the THO mass fraction in the gas phase $\left(X_{g}{ }^{T H O}\right)$ ranging in time between one month and 500 years following the detonations, for the mean conditions given in Table 3 $\left(k=3.4 \times 10^{-17} \mathrm{~m}^{2}, S_{g}=0.4\right.$, no horizontal pressure gradient). The figures are vertical cross sections of the Mesaverde Group and Fort Union Formation; the division is a horizontal line (not shown) separating the upper and middle cavities. The current drilling exclusion boundary is shown with the vertical yellow line, and is located $183 \mathrm{~m}(600 \mathrm{ft})$ from the edge of the cavity (at $x=404 \mathrm{~m}$, which is $200 \mathrm{~m}$ [the center of the cavity in the computation domain] $+21 \mathrm{~m}$ [cavity radius] $+183 \mathrm{~m}$ ). (The drilling exclusion boundary is defined as a distance from the edge of the cavity, not from ground zero.) In the absence of a regional (horizontal) pressure gradient, the mass fraction field is symmetric about the cavities, in response to equivalent concentration gradients in those directions.

To prevent communication between the three cavities, as was observed in the posttest drilling, a several-meter-thick, low-permeability layer $\left(k=10^{-21} \mathrm{~m}^{2}\right)$ separates the upper and lower cavities from the middle, and also lies above and below the upper and lower cavities, respectively. Tritium is completely mixed within each cavity at the start of each simulation (Figure 25a, which shows the $X_{g}^{T H O}$ field one month after the detonation). The low-permeability units separating the three cavities are the reason that tritium is never mixed uniformly among the cavities.

Within the first 10 years following the detonation, the maximum extent of tritium in the gas phase is approximately $75 \mathrm{~m}$ from the center of each cavity (Figures $25 \mathrm{~b}$ and $25 \mathrm{c}$ ). Most of this distance $(63 \mathrm{~m})$ is through high-permeability fractured rock associated with the nuclear detonations. By $45 \mathrm{yr}$ (Figure 25f), tritium migration has reached its maximum extent, or approximately $100 \mathrm{~m}$ away from the center of the cavities. After this time, transport is balanced by radioactive decay such that the "plume" seems to not move, but merely dissipates in time (Figures $25 \mathrm{~g}$ through 251). Sometime between 100 and $150 \mathrm{yr}$, the volume of the tritium "plume" begins to get smaller through gas diffusion, phase separation, and radioactive decay. A "core" of tritium in the gas phase remains at $500 \mathrm{yr}$ (approximately 40 half lives of tritium), although the $X_{g}^{T H O}$ is only about two orders of magnitude greater than background. By 1,000 yr (not shown), the $X_{g}^{T H O}$ field is zero everywhere within the domain.

Figures 26a through 261 shows the results of a simulation in which the intrinsic permeability of the Mesaverde Group and Fort Union Formation was raised by one order of magnitude. The results are very similar; as in the absence of a pressure gradient, permeability has little direct control on transport solutes in either phase. Transport is affected, however, 
through tortuosity, $\tau$, which is dependent upon saturation of the relevant phase (i.e., the Millington-Quirk model, where $\tau \sim S_{\beta}{ }^{10 / 3}$ [or $\tau \sim \theta_{\beta}{ }^{4 / 3}$ ] where $\beta$ is the phase). The difference is apparent beyond $100 \mathrm{yr}$ (Figure 26i). By $100 \mathrm{yr}$, all tritium has been reduced to the background level. This is different from what happened in the reference simulation, when the mass fraction of tritium in the gas phase was still two to three orders of magnitude above background.

(a)
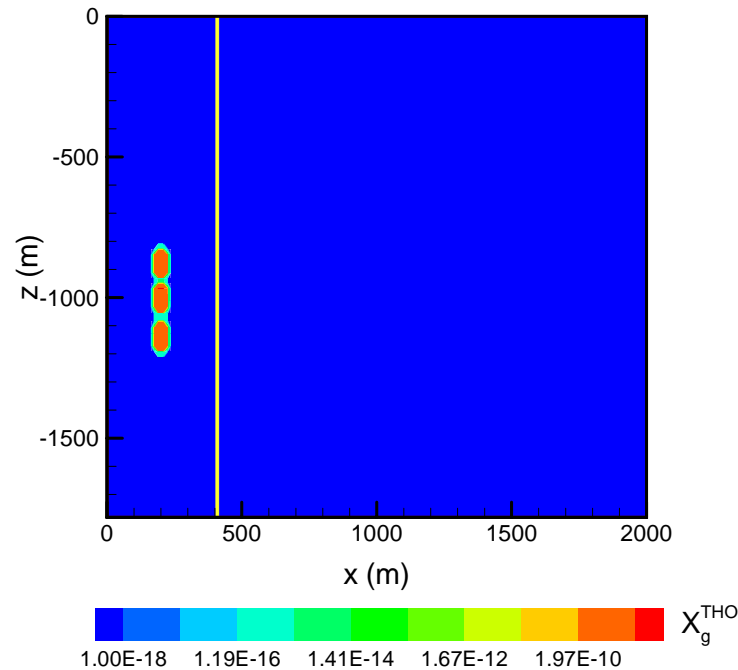

(c)

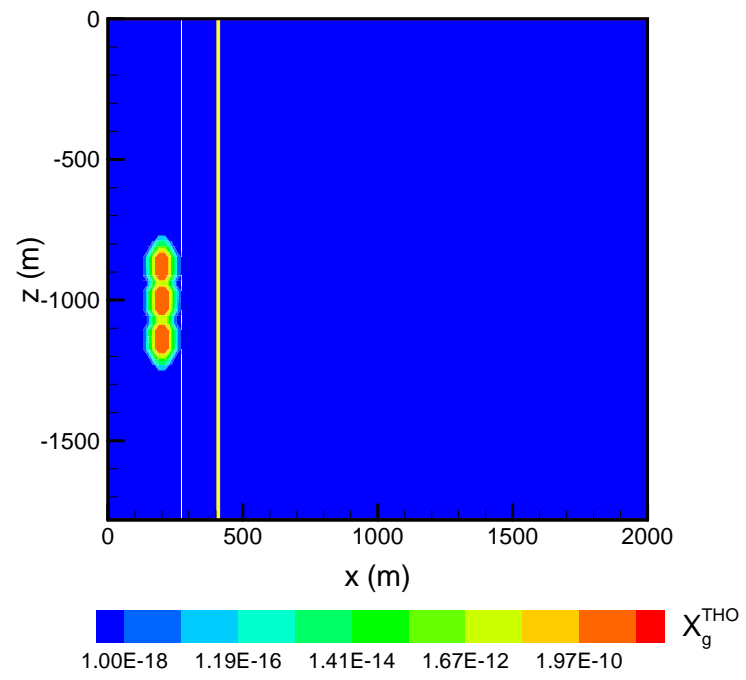

(b)

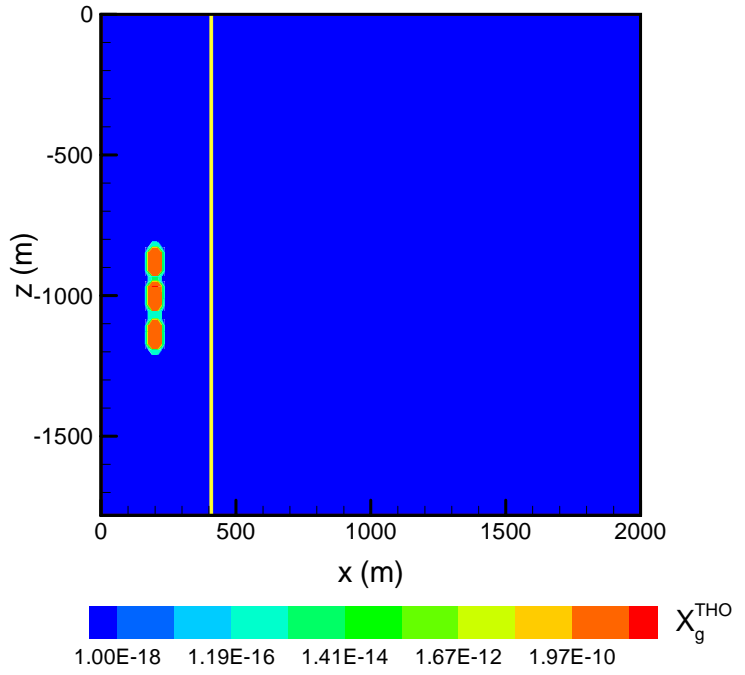

(d)

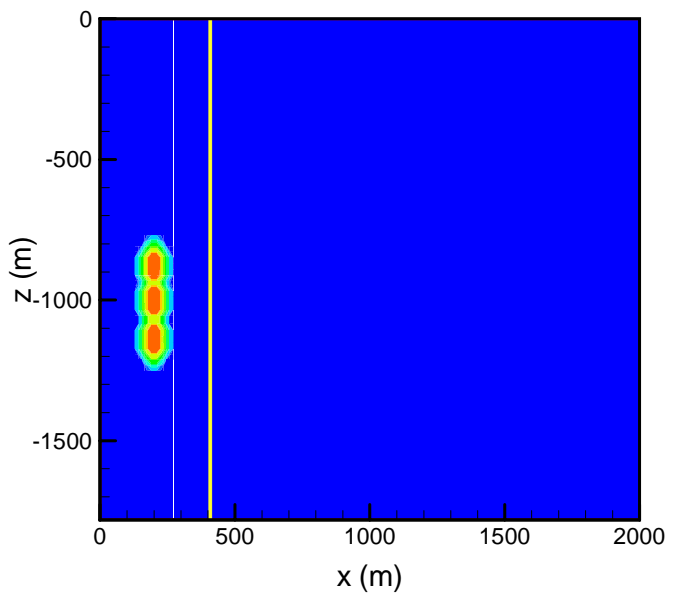

$1.00 \mathrm{E}-18 \quad 1.19 \mathrm{E}-16 \quad 1.41 \mathrm{E}-14 \quad 1.67 \mathrm{E}-12 \quad 1.97 \mathrm{E}-10$

Figure 25. Results of a two-dimensional simulation showing $X_{g}{ }^{T H O}$ with the mean properties from Table 3. This is the reference simulation in which the remaining two-dimensional simulations will be compared. Results for 12 times (after the three detonations) are shown: (a) 1 month, (b) 1 yr, (c) $10 \mathrm{yr}$, (d) $20 \mathrm{yr}$, (e) $34 \mathrm{yr}$, (f) $45 \mathrm{yr}$, (g) $55 \mathrm{yr}$, (h) $66 \mathrm{yr}$, (i) $100 \mathrm{yr}$, (j) $150 \mathrm{yr},(\mathrm{k}) 250 \mathrm{yr}$, and (1) $500 \mathrm{yr}$. The vertical line located at $x=404 \mathrm{~m}$ shows the location of the drilling exclusion boundary with respect to the location of the detonations. 
(e)

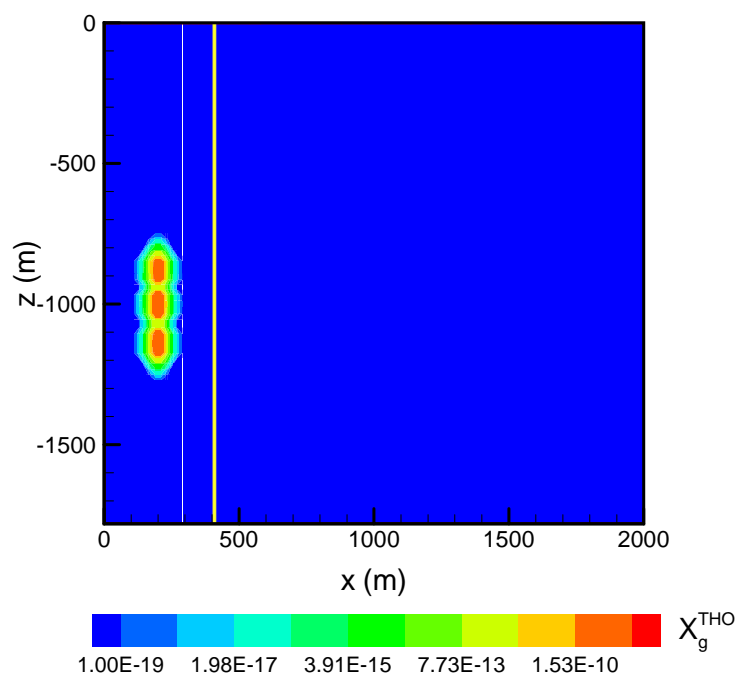

(g)

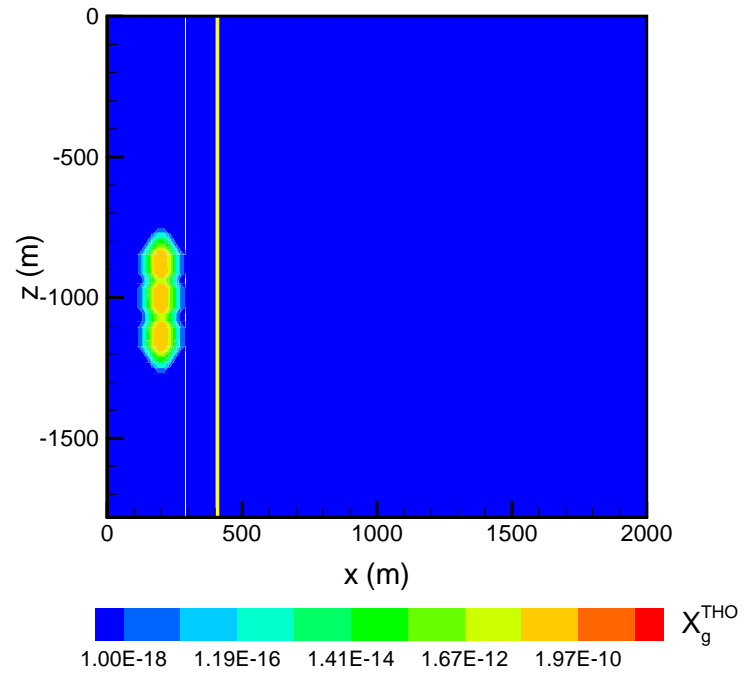

(f)

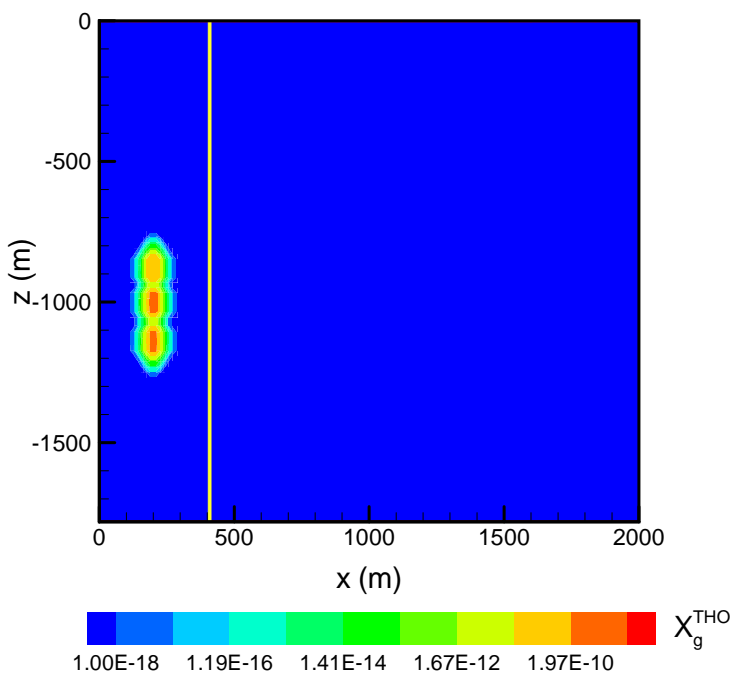

(h)

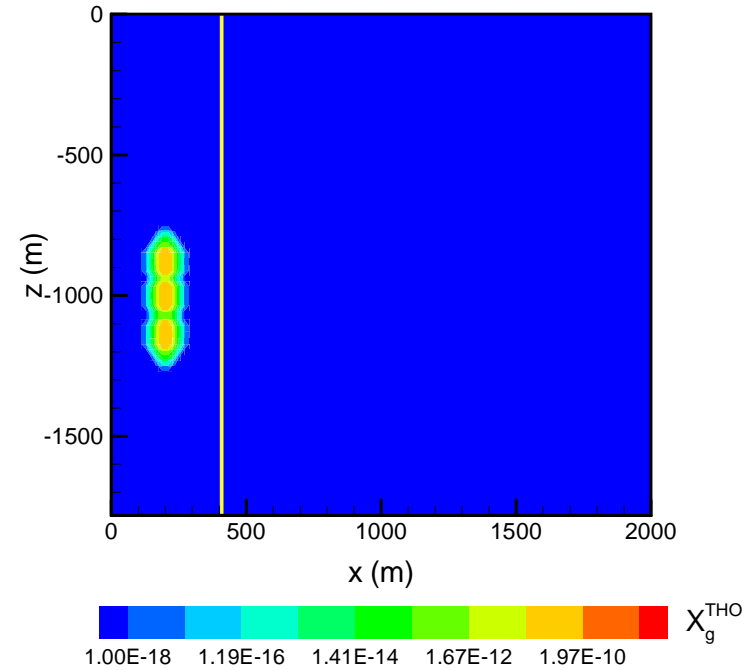

Figure 25. Results of a two-dimensional simulation showing $X_{g}^{T H O}$ with the mean properties from Table 3. This is the reference simulation in which the remaining two-dimensional simulations will be compared. Results for 12 times (after the three detonations) are shown: (a) 1 month, (b) $1 \mathrm{yr}$, (c) $10 \mathrm{yr}$, (d) $20 \mathrm{yr}$, (e) $34 \mathrm{yr}$, (f) $45 \mathrm{yr}$, (g) $55 \mathrm{yr}$, (h) $66 \mathrm{yr}$, (i) $100 \mathrm{yr}$, (j) $150 \mathrm{yr}$, (k) $250 \mathrm{yr}$, and (l) $500 \mathrm{yr}$. The vertical line located at $x=404 \mathrm{~m}$ shows the location of the drilling exclusion boundary with respect to the location of the detonations (continued). 
(i)

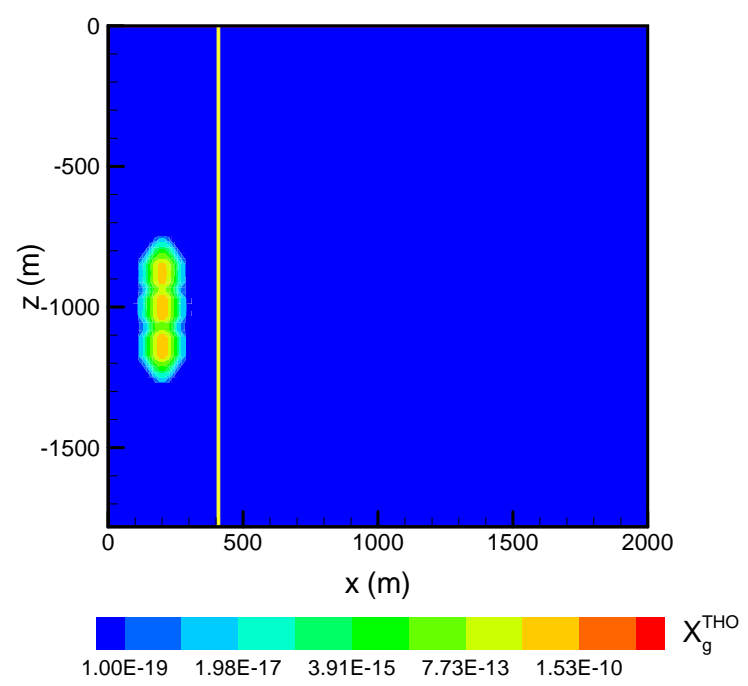

$(\mathrm{k})$

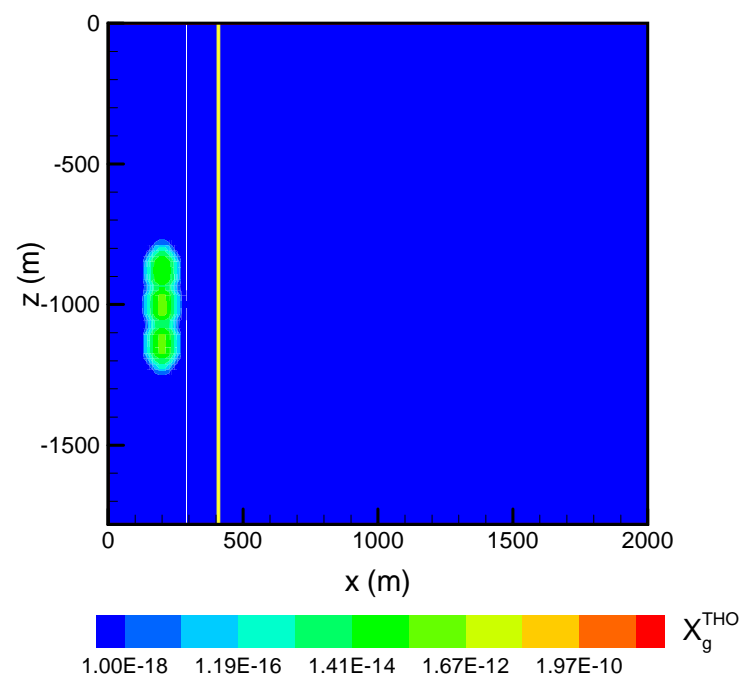

(j)

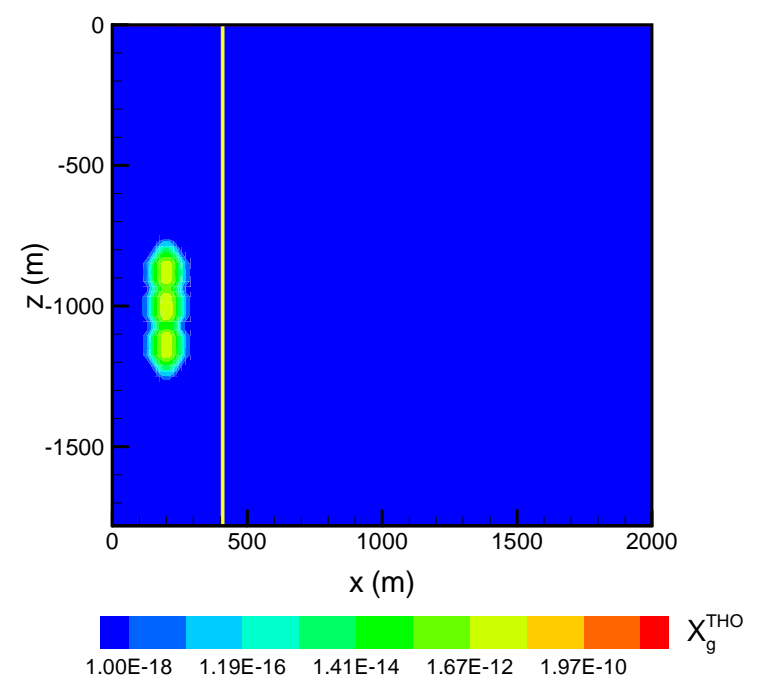

(l)

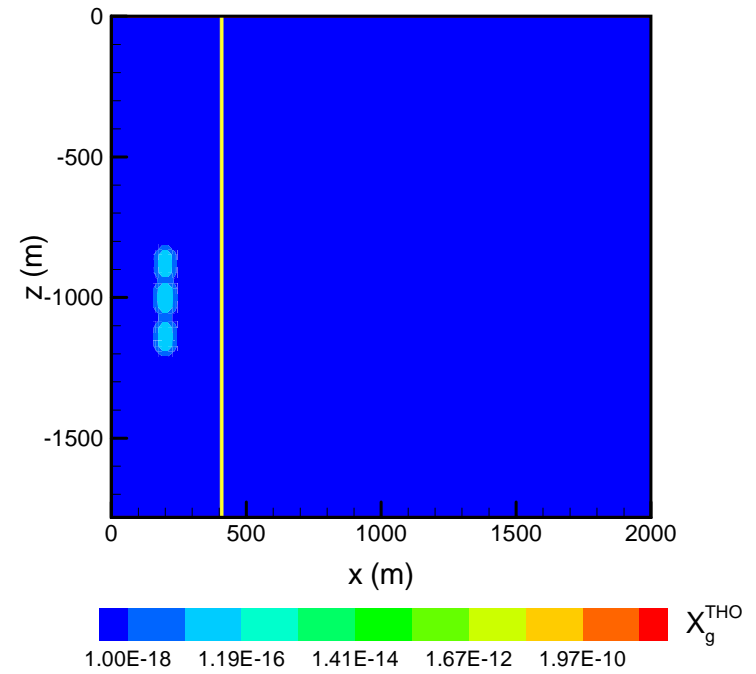

Figure 25. Results of a two-dimensional simulation showing $X_{g}{ }^{T H O}$ with the mean properties from Table 3. This is the reference simulation in which the remaining two-dimensional simulations will be compared. Results for 12 times (after the three detonations) are shown: (a) 1 month, (b) $1 \mathrm{yr}$, (c) $10 \mathrm{yr}$, (d) $20 \mathrm{yr}$, (e) $34 \mathrm{yr}$, (f) $45 \mathrm{yr}$, (g) $55 \mathrm{yr}$, (h) $66 \mathrm{yr}$, (i) $100 \mathrm{yr}$, (j) $150 \mathrm{yr}$, (k) $250 \mathrm{yr}$, and (l) $500 \mathrm{yr}$. The vertical line located at $x=404 \mathrm{~m}$ shows the location of the drilling exclusion boundary with respect to the location of the detonations (continued). 
(a)

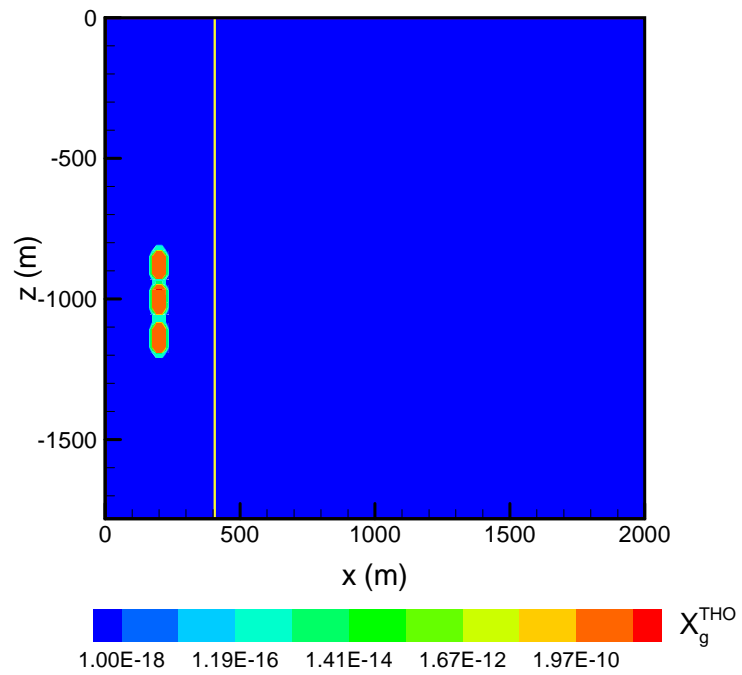

(c)

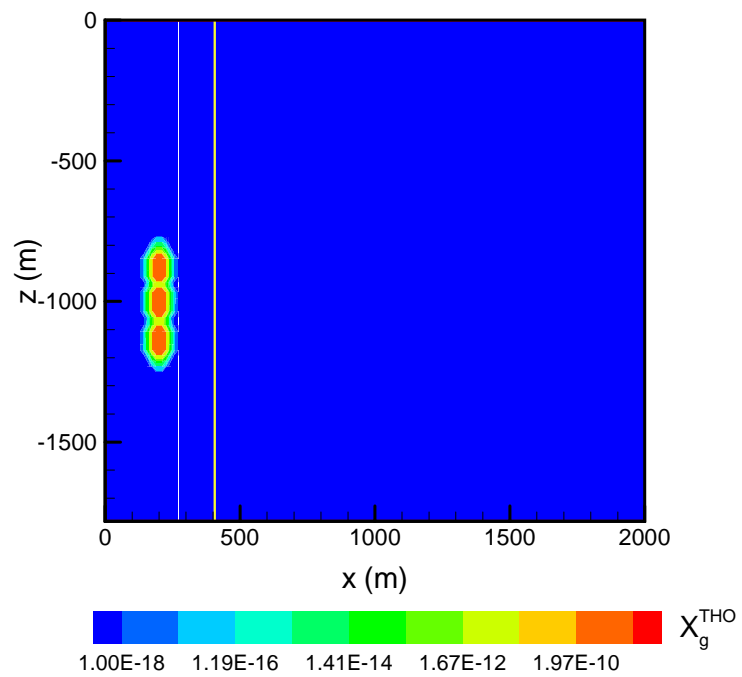

(b)

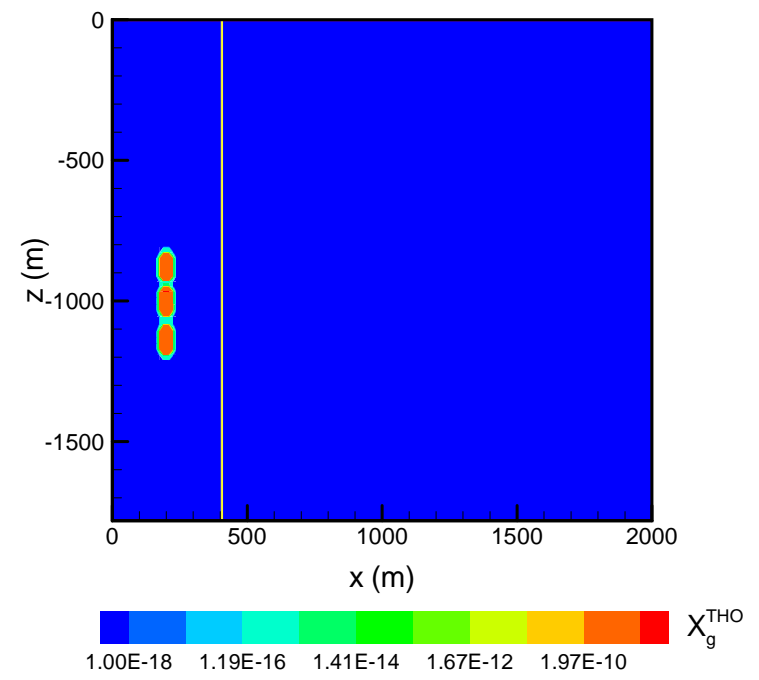

(d)

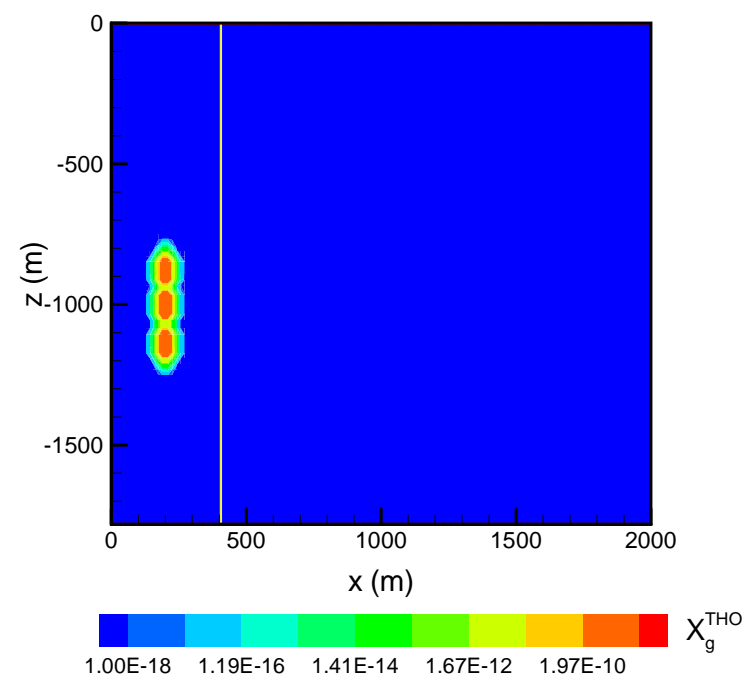

Figure 26. Results of a two-dimensional simulation showing $X_{g}^{T H O}$ with the k one order of magnitude greater than in the previous "reference" simulation. Results for 12 times (after the three detonations) are shown: (a) 1 month, (b) $1 \mathrm{yr}$, (c) $10 \mathrm{yr}$, (d) $20 \mathrm{yr}$, (e) $34 \mathrm{yr}$, (f) $45 \mathrm{yr}$, (g) $55 \mathrm{yr}$, (h) $66 \mathrm{yr}$, (i) $100 \mathrm{yr}$, (j) $150 \mathrm{yr}$, (k) $250 \mathrm{yr}$, and (l) $500 \mathrm{yr}$. The vertical line located at $x=404 \mathrm{~m}$ shows the location of the drilling exclusion boundary with respect to the location of the detonations. 
(e)

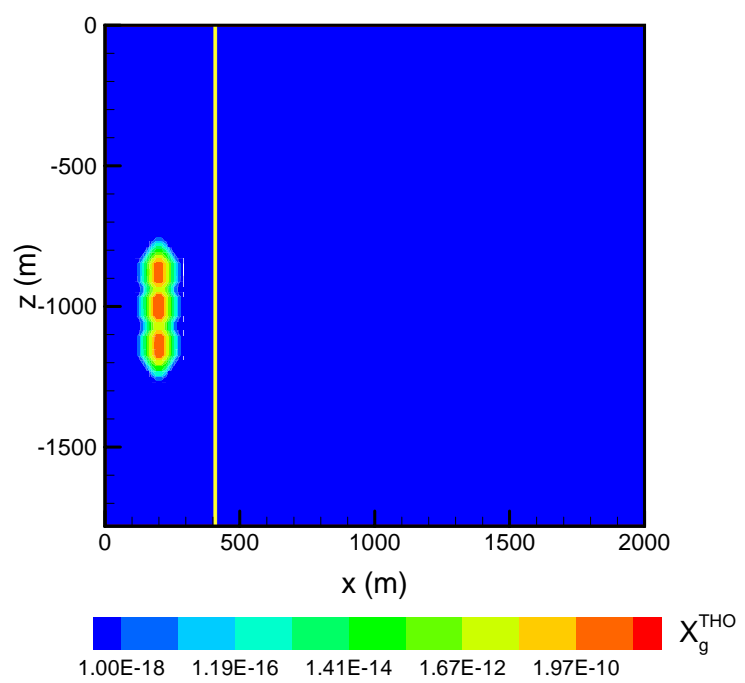

(g)

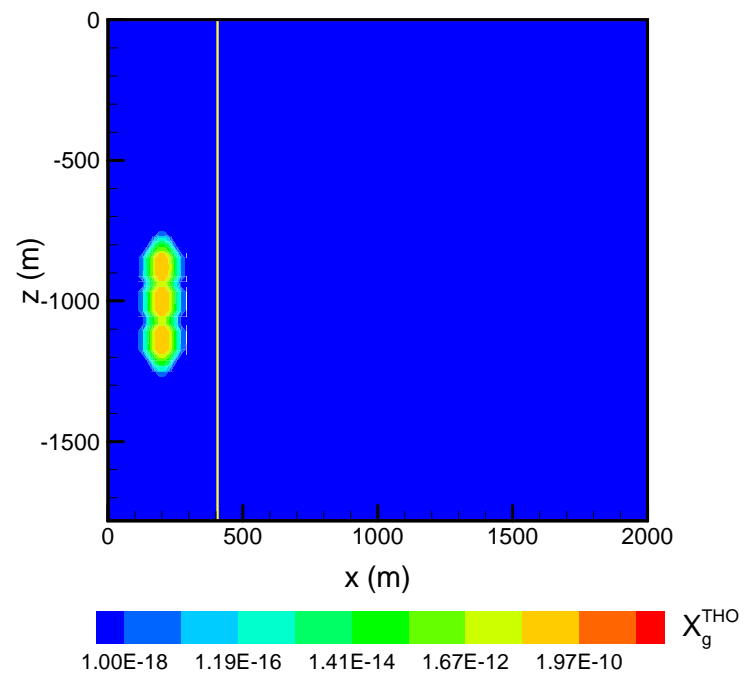

(f)

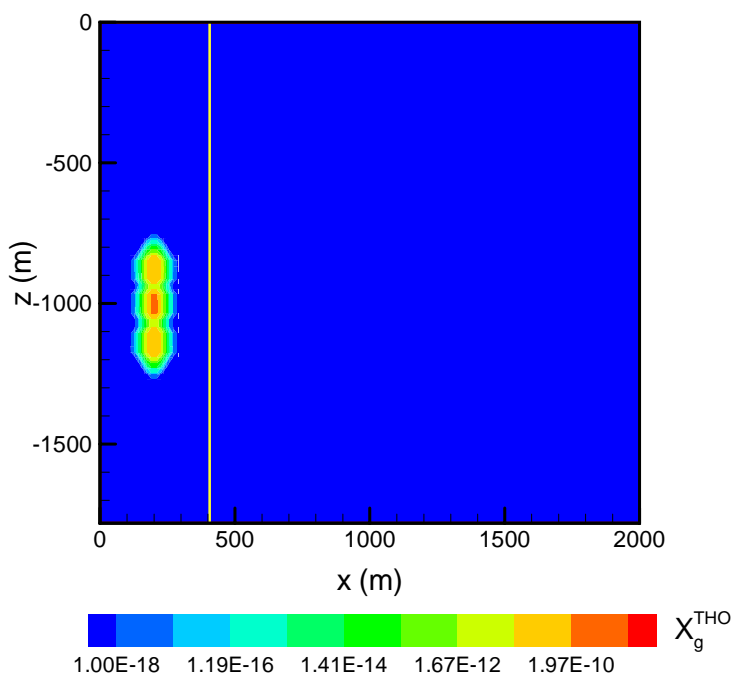

(h)

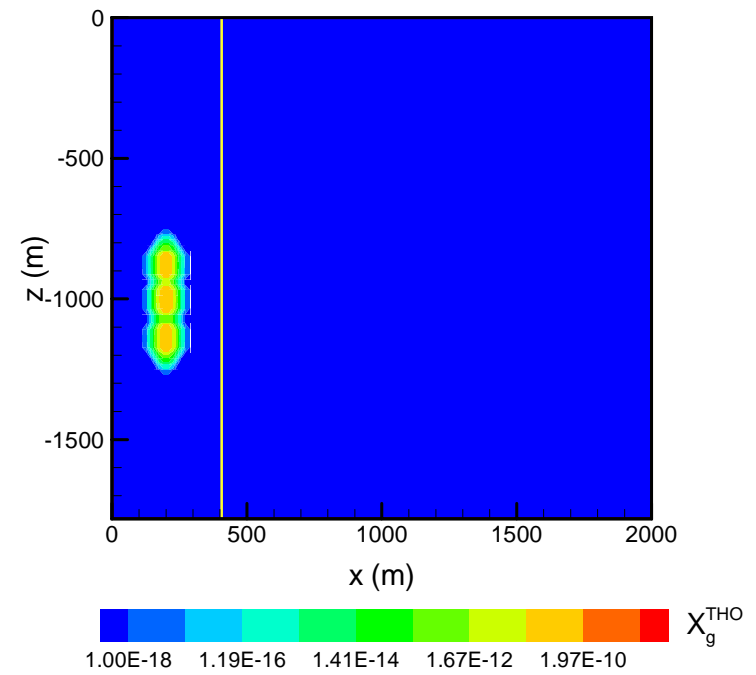

Figure 26. Results of a two-dimensional simulation showing $X_{g}^{T H O}$ with the k one order of magnitude greater than in the previous "reference" simulation. Results for 12 times (after the three detonations) are shown: (a) 1 month, (b) $1 \mathrm{yr}$, (c) $10 \mathrm{yr}$, (d) $20 \mathrm{yr}$, (e) $34 \mathrm{yr}$, (f) $45 \mathrm{yr}$, (g) $55 \mathrm{yr}$, (h) $66 \mathrm{yr}$, (i) $100 \mathrm{yr}$, (j) $150 \mathrm{yr}$, (k) $250 \mathrm{yr}$, and (l) $500 \mathrm{yr}$. The vertical line located at $x=404 \mathrm{~m}$ shows the location of the drilling exclusion boundary with respect to the location of the detonations (continued). 
(i)

(e)

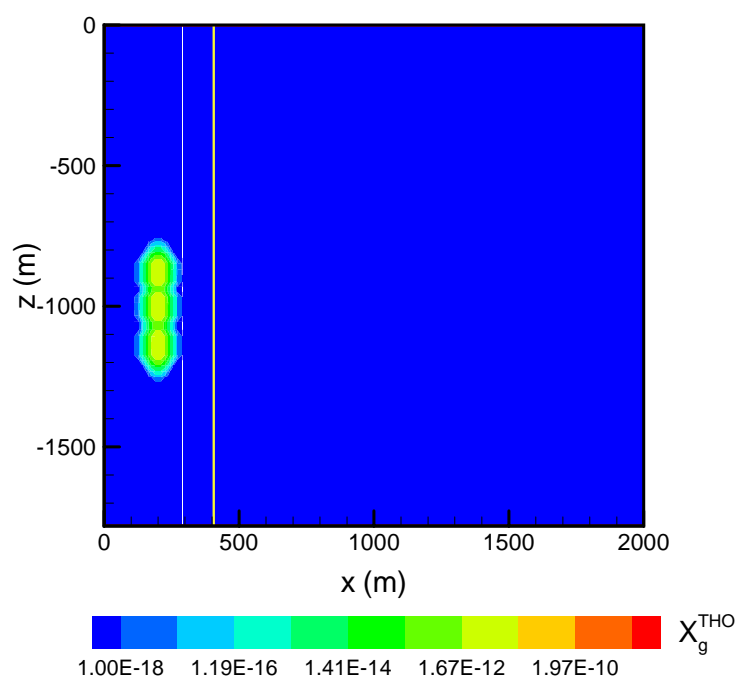

(k)

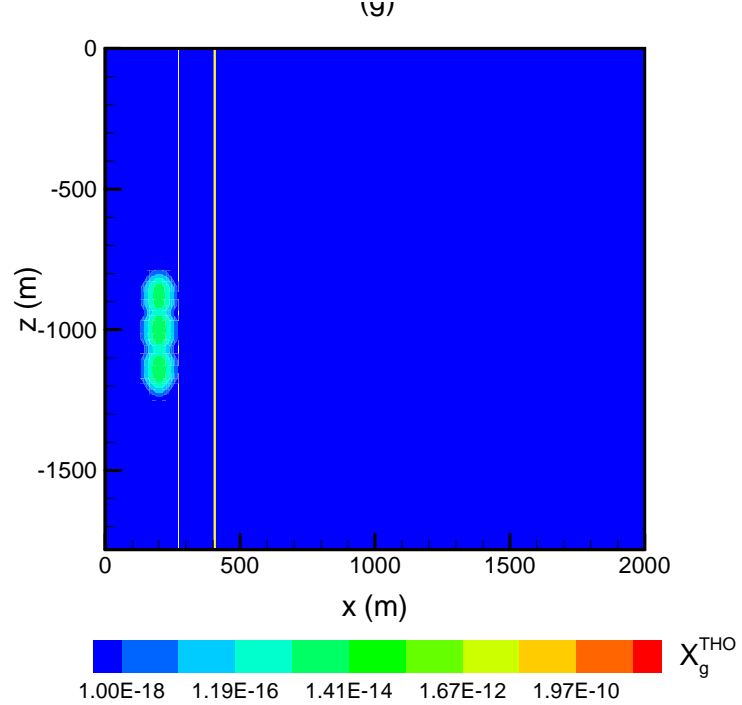

(j)

(f)

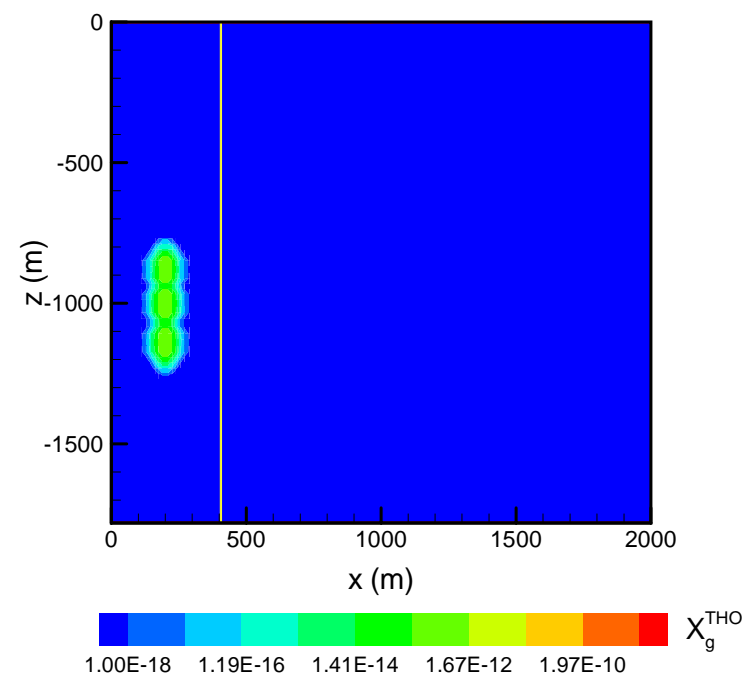

(1)

$\left(r_{1}\right.$,

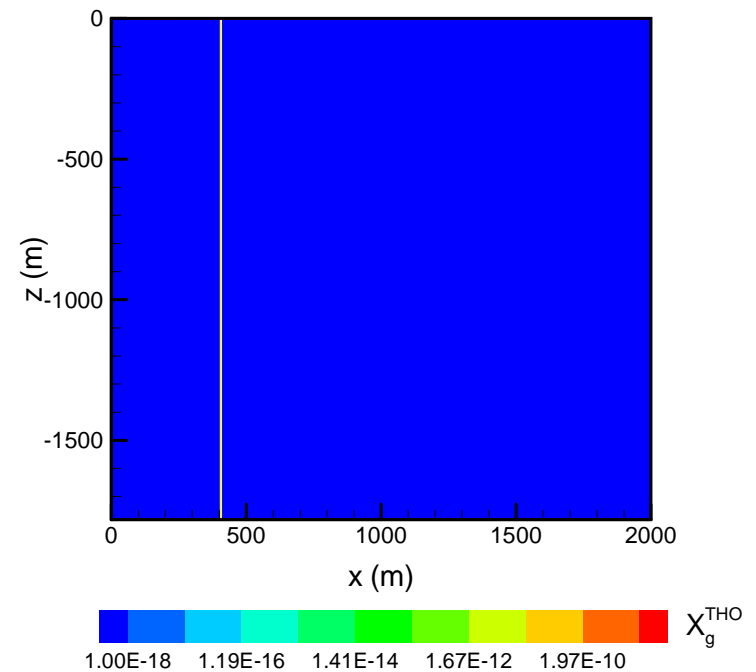

Figure 26. Results of a two-dimensional simulation showing $X_{g}^{T H O}$ with the k one order of magnitude greater than in the previous "reference" simulation. Results for 12 times (after the three detonations) are shown: (a) 1 month, (b) $1 \mathrm{yr}$, (c) $10 \mathrm{yr}$, (d) $20 \mathrm{yr}$, (e) $34 \mathrm{yr}$, (f) $45 \mathrm{yr}$, (g) $55 \mathrm{yr}$, (h) $66 \mathrm{yr}$, (i) $100 \mathrm{yr}$, (j) $150 \mathrm{yr}$, (k) $250 \mathrm{yr}$, and (l) $500 \mathrm{yr}$. The vertical line located at $x=404 \mathrm{~m}$ shows the location of the drilling exclusion boundary with respect to the location of the detonations (continued). 
Figure 27 shows the results of a simulation in which a $9.81 \mathrm{~Pa} \mathrm{~m}^{-1}$ pressure gradient was applied. The pressure gradient is small enough that it resulted in very little transport compared to the purely diffusive (i.e., no horizontal pressure gradient) case. There is a slight bit more diffusion when compared to equivalent times for the reference simulation, but the extent of tritium transport is only extended by $20 \mathrm{~m}$ or so. The applied horizontal pressure gradient, $9.81 \mathrm{~Pa} \mathrm{~m}^{-1}$, is approximately the same as a $0.001 \mathrm{~m} \mathrm{~m}^{-1}$ gradient in an equivalent fresh water head.

(a)

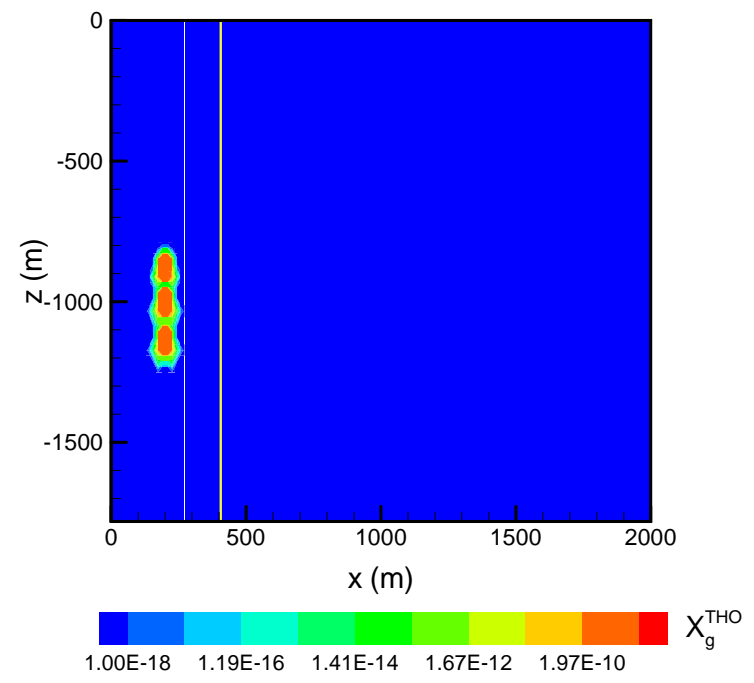

(c)

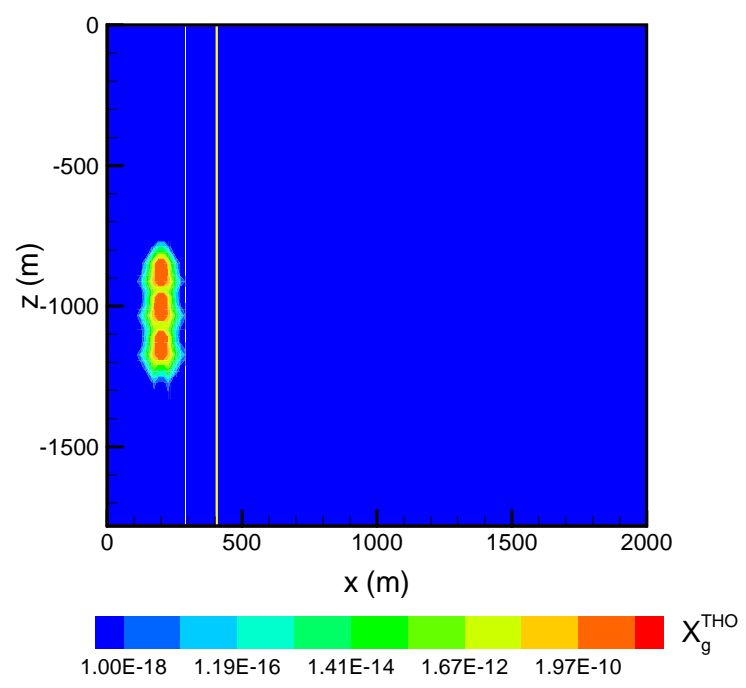

(b)

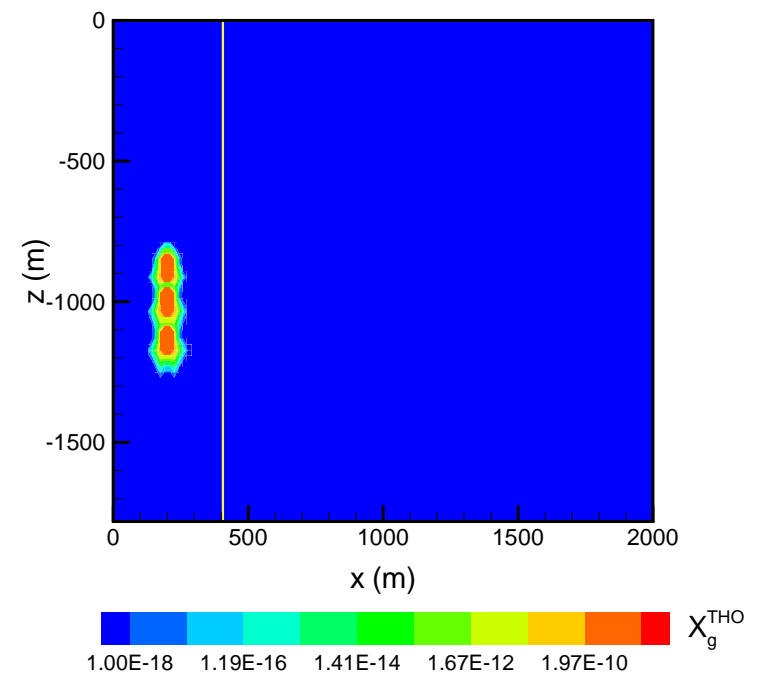

(d)

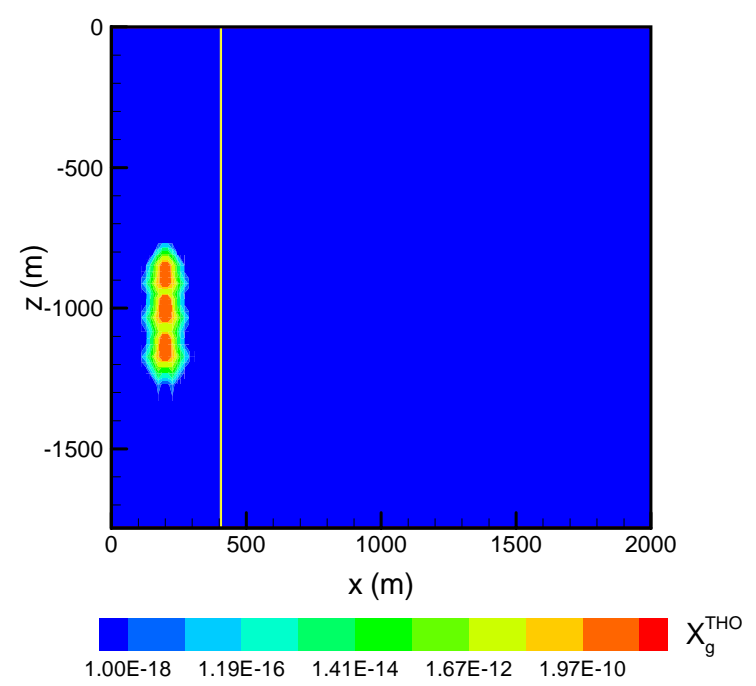

Figure 27. Results of a two-dimensional simulation showing $X_{g}^{T H O}$ with the mean properties from Table 3 and a slight horizontal pressure gradient of $9.81 \mathrm{~Pa} \mathrm{~m}^{-1}$ (equivalent to $0.001 \mathrm{~m} \mathrm{~m}^{-1}$ of freshwater head) imposed across the domain. Results for 12 times (after the three detonations) are shown: (a) 1 month, (b) $1 \mathrm{yr}$, (c) $10 \mathrm{yr}$, (d) $20 \mathrm{yr}$, (e) $34 \mathrm{yr}$, (f) $45 \mathrm{yr}$, (g) $55 \mathrm{yr}$, (h) $66 \mathrm{yr}$, (i) $100 \mathrm{yr}$, (j) $150 \mathrm{yr}$, (k) $250 \mathrm{yr}$, and (l) $500 \mathrm{yr}$. 
(e)

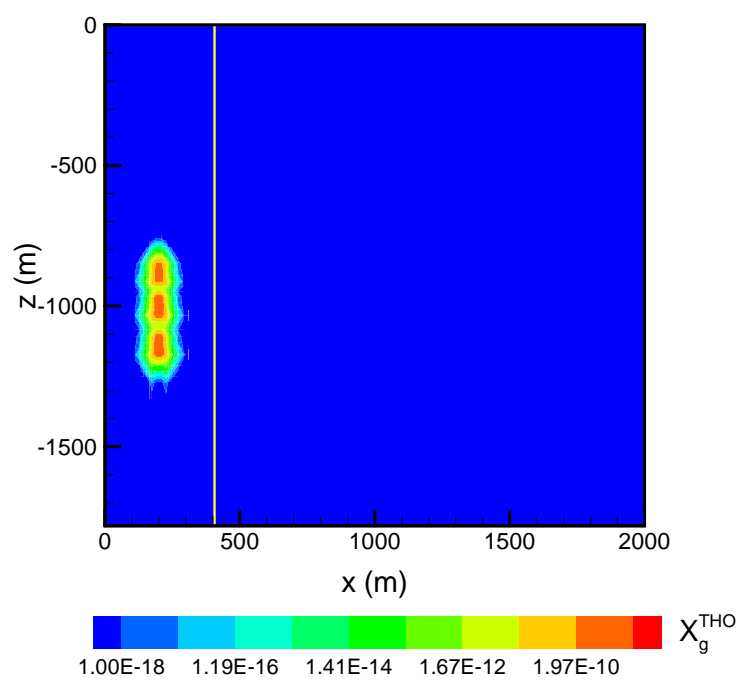

(g)

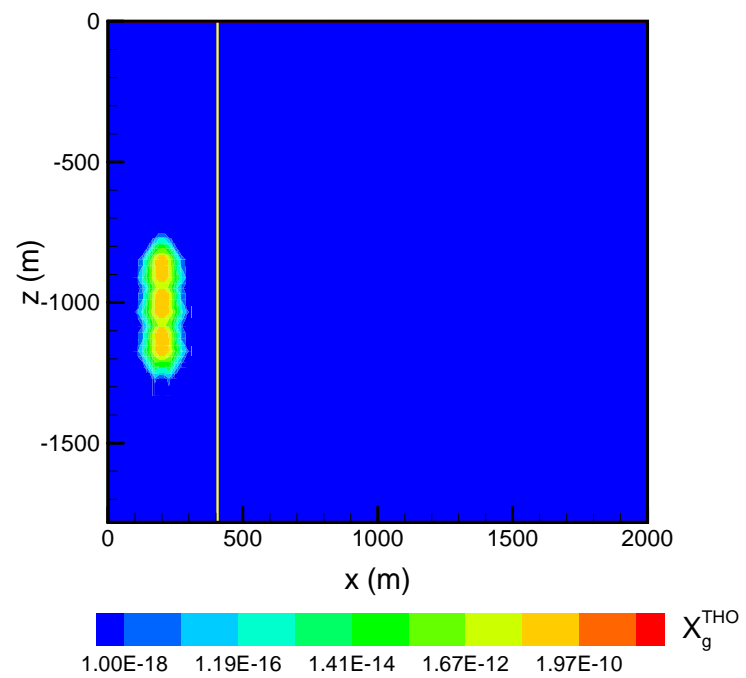

(f)

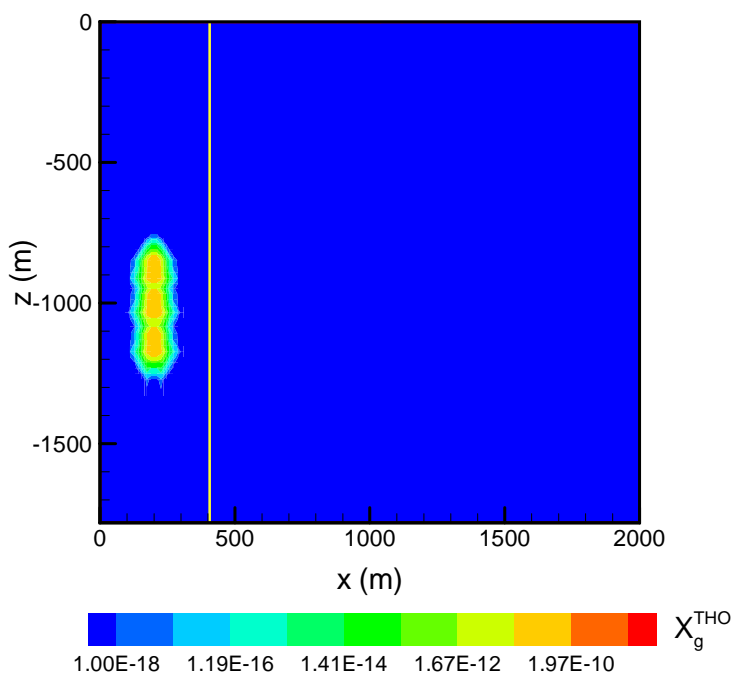

(h)

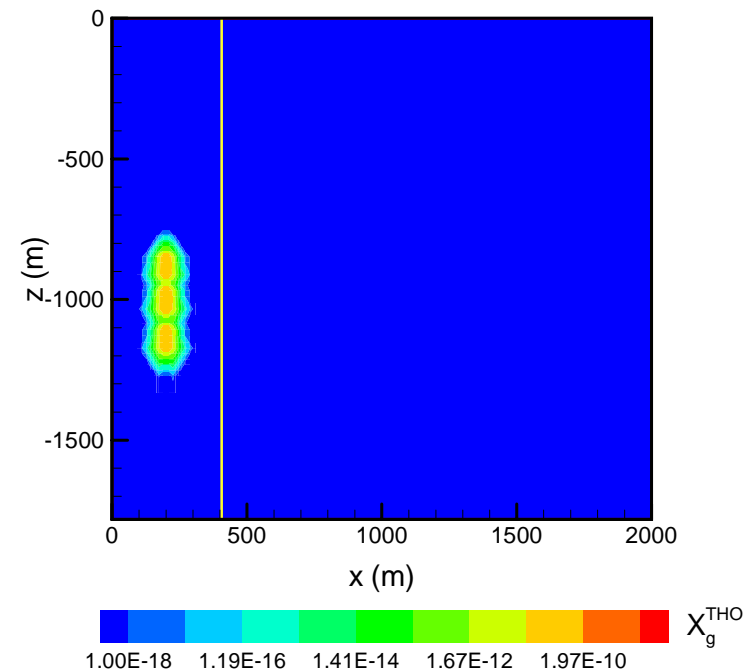

Figure 27. Results of a two-dimensional simulation showing $X_{g}^{T H O}$ with the mean properties from Table 3 and a slight horizontal pressure gradient of $9.81 \mathrm{~Pa} \mathrm{~m}^{-1}$ (equivalent to $0.001 \mathrm{~m} \mathrm{~m}^{-1}$ of freshwater head) imposed across the domain. Results for 12 times (after the three detonations) are shown: (a) 1 month, (b) $1 \mathrm{yr}$, (c) $10 \mathrm{yr}$, (d) $20 \mathrm{yr}$, (e) $34 \mathrm{yr}$, (f) $45 \mathrm{yr}$, (g) $55 \mathrm{yr}$, (h) $66 \mathrm{yr}$, (i) $100 \mathrm{yr}$, (j) $150 \mathrm{yr}$, (k) $250 \mathrm{yr}$, and (l) $500 \mathrm{yr}$ (continued). 
(i)

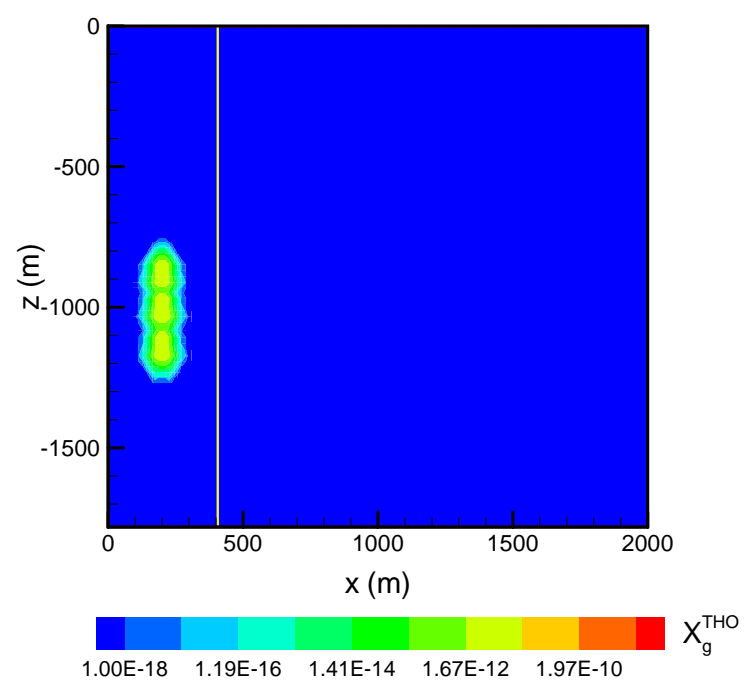

(k)

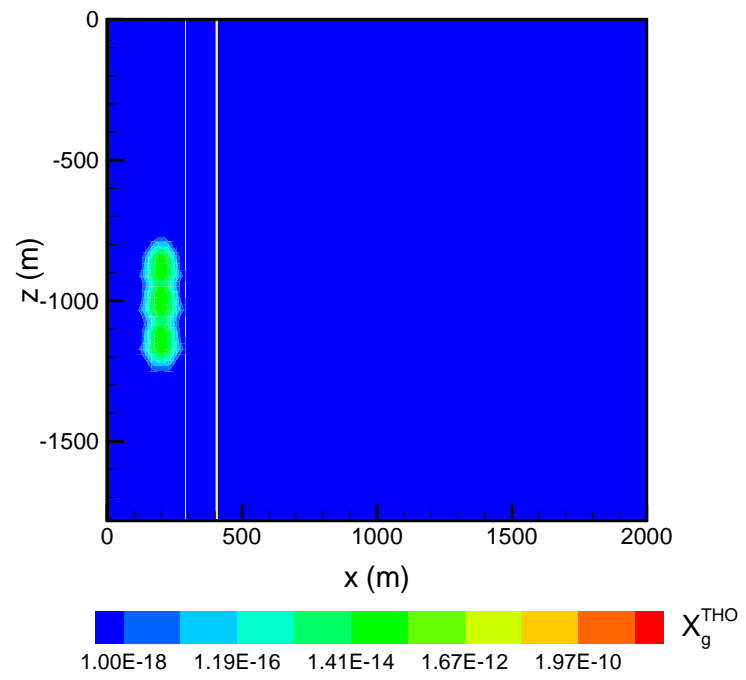

(j)

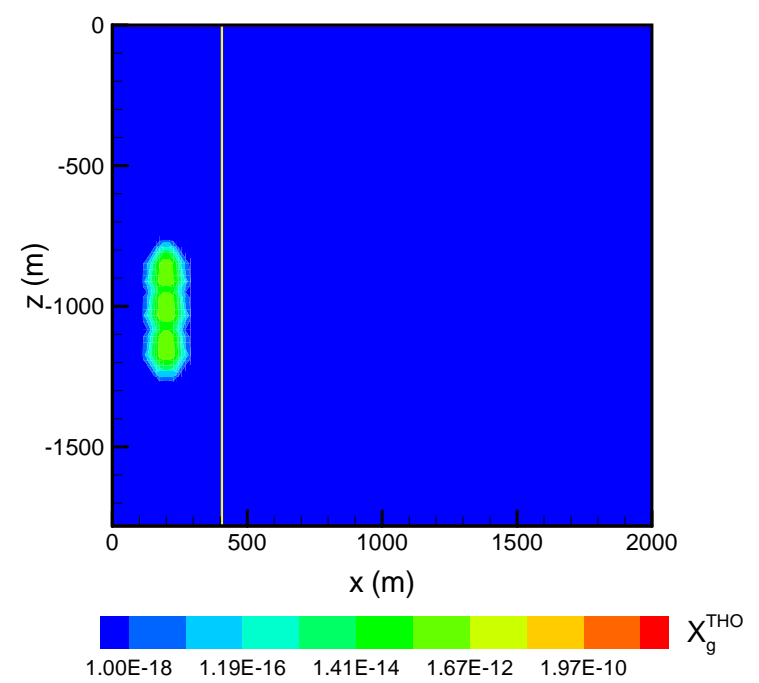

(l)

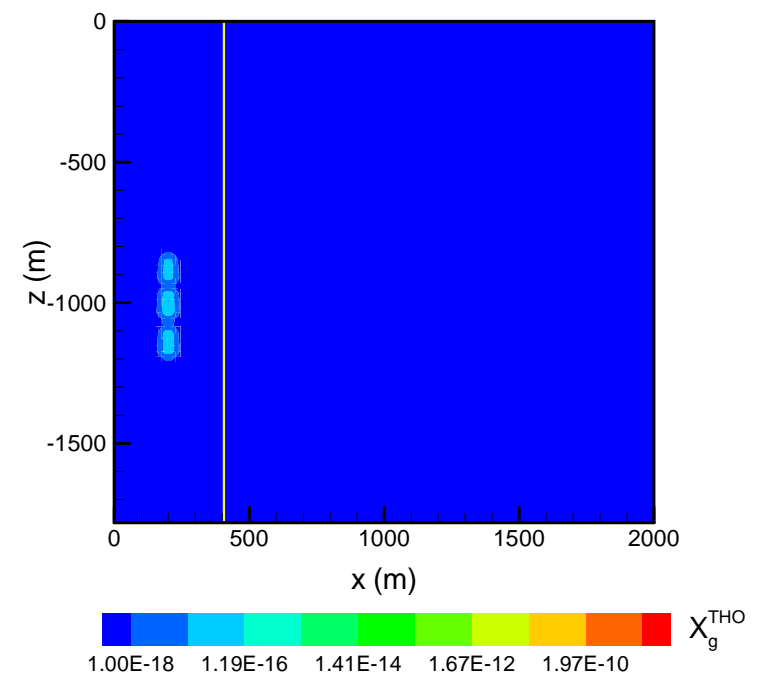

Figure 27. Results of a two-dimensional simulation showing $X_{g}{ }^{T H O}$ with the mean properties from Table 3 and a slight horizontal pressure gradient of $9.81 \mathrm{~Pa} \mathrm{~m}^{-1}$ (equivalent to $0.001 \mathrm{~m} \mathrm{~m}^{-1}$ of freshwater head) imposed across the domain. Results for 12 times (after the three detonations) are shown: (a) 1 month, (b) $1 \mathrm{yr}$, (c) $10 \mathrm{yr}$, (d) $20 \mathrm{yr}$, (e) $34 \mathrm{yr}$, (f) $45 \mathrm{yr}$, (g) $55 \mathrm{yr}$, (h) $66 \mathrm{yr}$, (i) $100 \mathrm{yr}$, (j) $150 \mathrm{yr}$, (k) $250 \mathrm{yr}$, and (l) $500 \mathrm{yr}$ (continued).

The results of a simulation in which krypton replaced tritiated water as the radionuclide are shown in Figures 28a through 281. The larger krypton molecule results in a smaller gas diffusion coefficient (Table 1), although the result is hardly perceptible in the figures (the half lives are nearly the same: $10.76 \mathrm{yr}$ for ${ }^{85} \mathrm{Kr}$ versus $12.26 \mathrm{yr}$ for ${ }^{3} \mathrm{H}$ ). Even 
though the transport seems to be dominated by diffusion, the one-third difference in diffusion coefficients is not great enough to result in differences in the shape of the mass fraction contours.

(a)

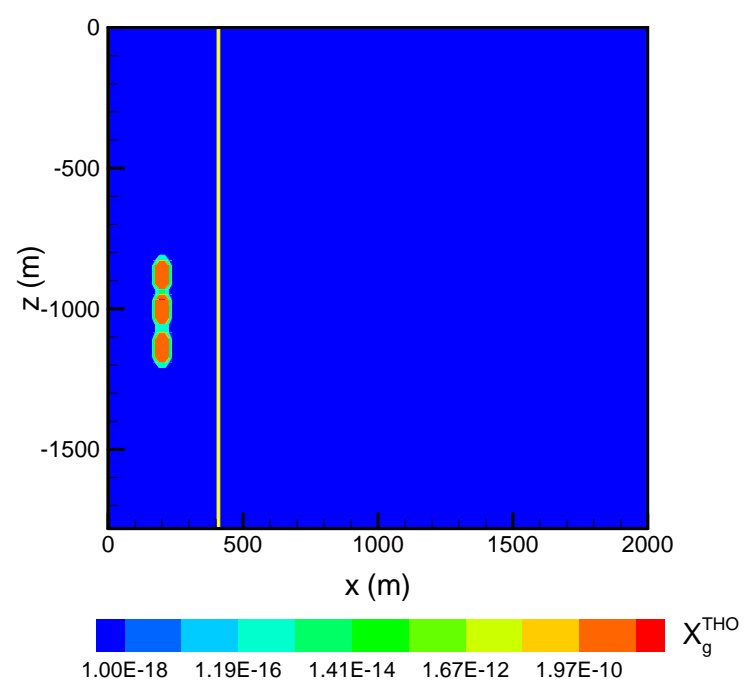

(c)

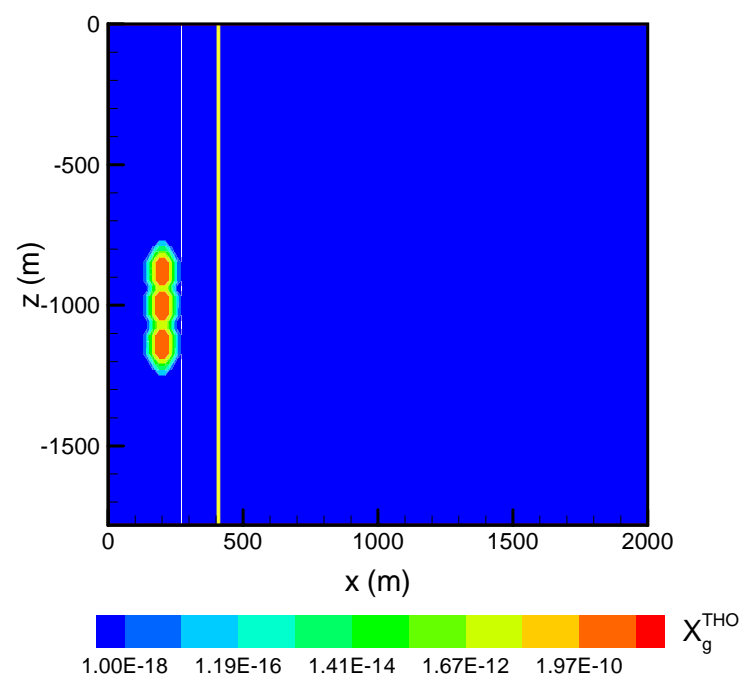

(b)

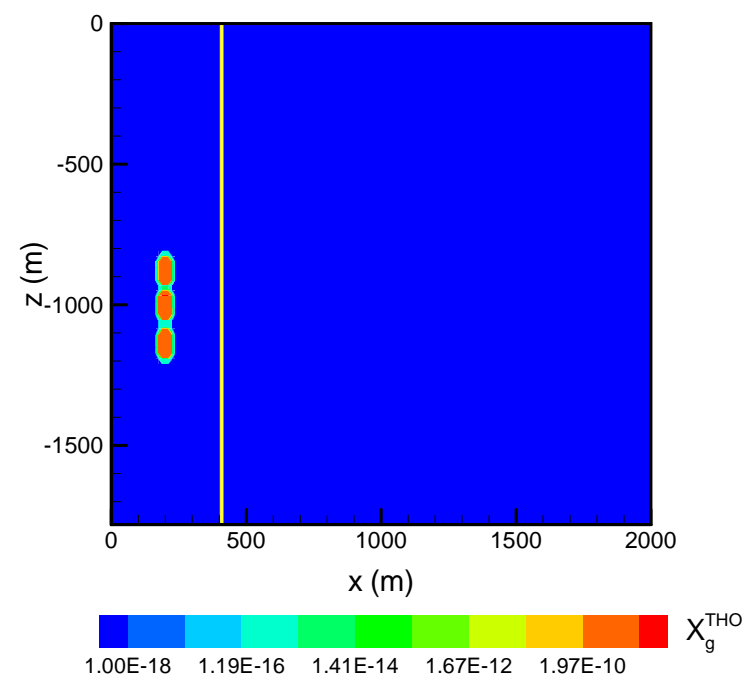

(d)

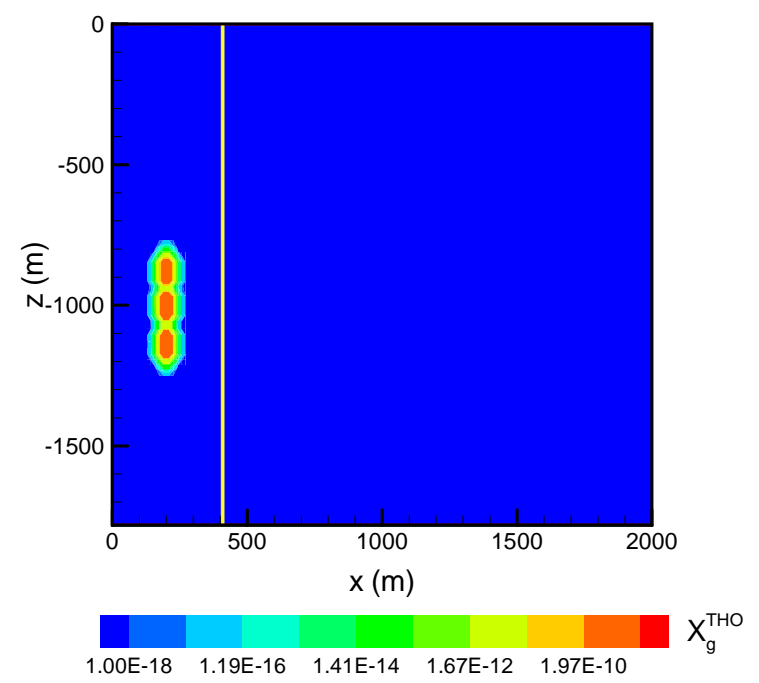

Figure 28. Results of a two-dimensional simulation showing $X_{g}^{K r}$ (krypton mixed in the gas phase). The diffusion coefficients are nearly the same, as are the half lives. The differences between this simulation and the reference simulation for tritium are nearly imperceptible. Results for 12 times (after the three detonations) are shown: (a) 1 month, (b) $1 \mathrm{yr}$, (c) $10 \mathrm{yr}$, (d) $20 \mathrm{yr}$, (e) $34 \mathrm{yr}$, (f) $45 \mathrm{yr}$, (g) $55 \mathrm{yr}$, (h) $66 \mathrm{yr}$, (i) $100 \mathrm{yr},(\mathrm{j}) 150 \mathrm{yr},(\mathrm{k}) 250 \mathrm{yr}$, and (l) $500 \mathrm{yr}$. 
(e)

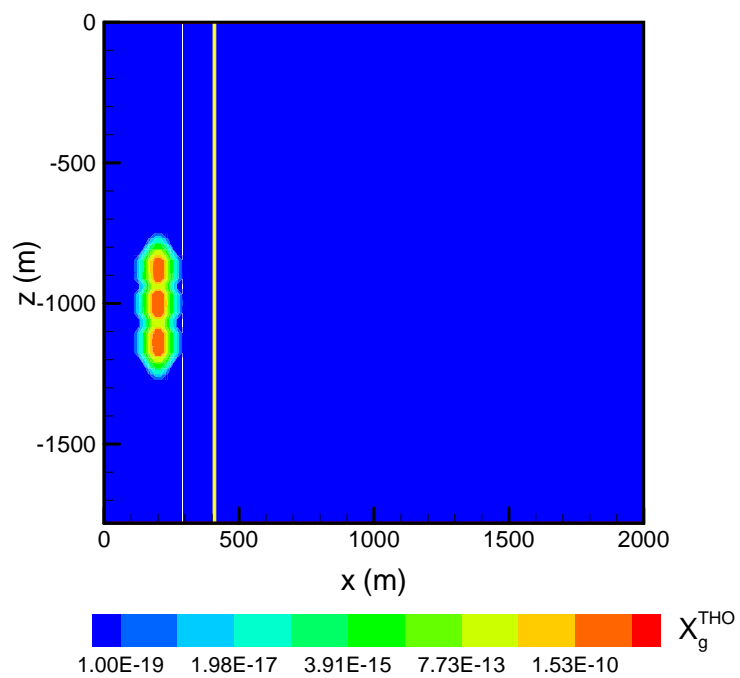

(g)

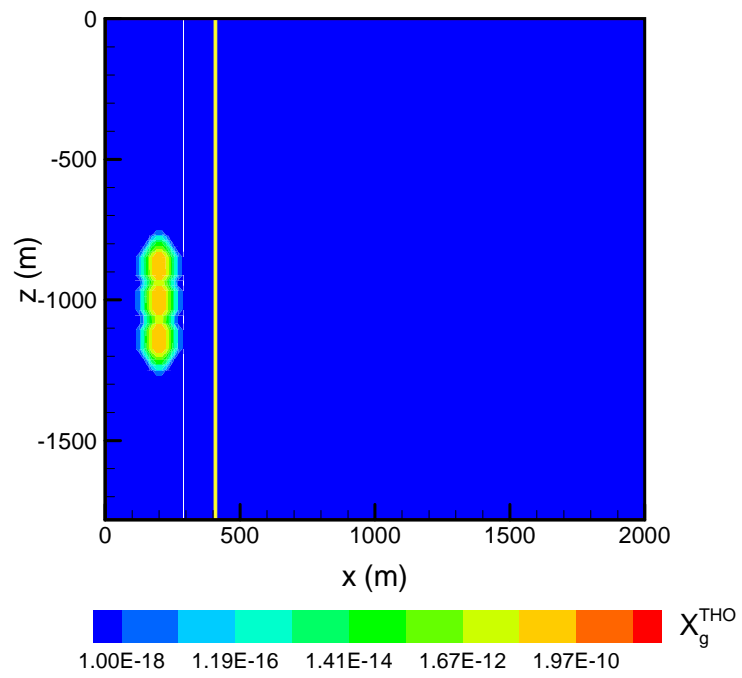

(f)

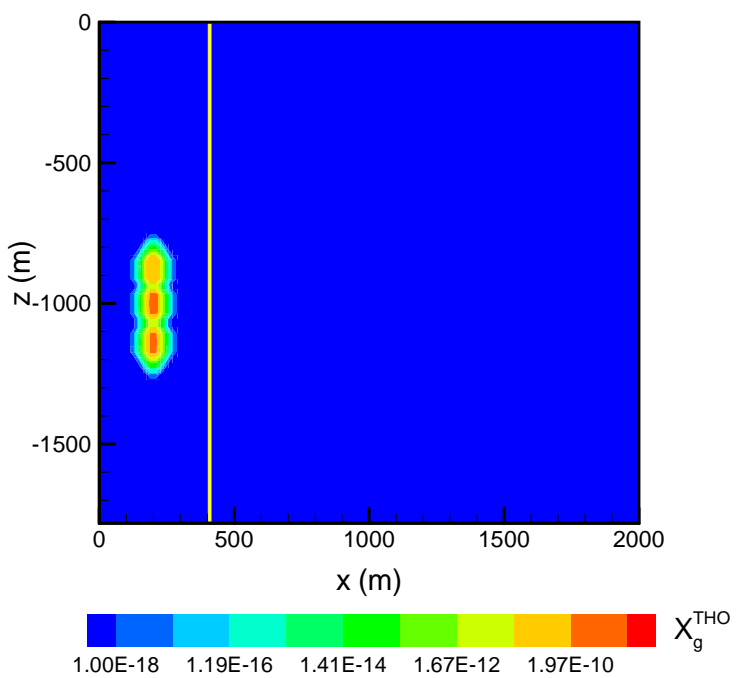

(h)

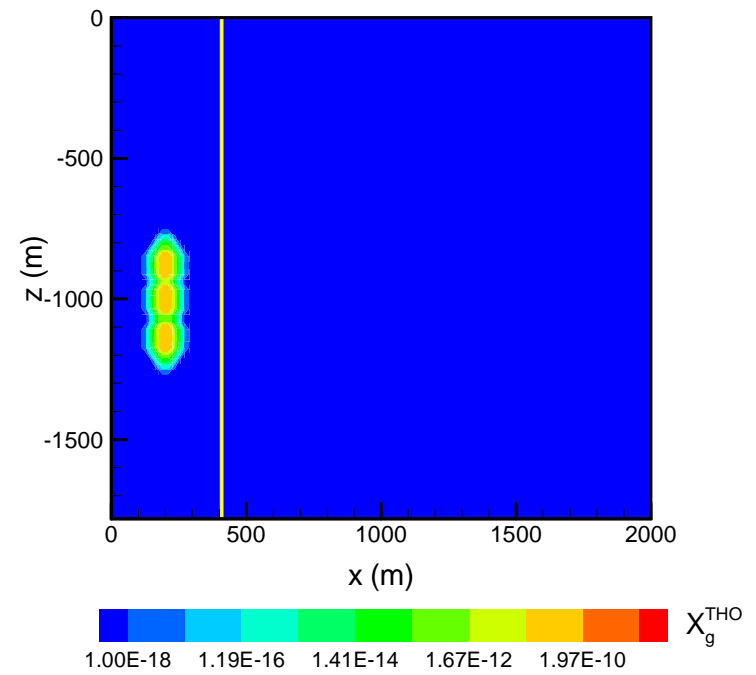

Figure 28. Results of a two-dimensional simulation showing $X_{g}^{K r}$ (krypton mixed in the gas phase). The diffusion coefficients are nearly the same, as are the half lives. The differences between this simulation and the reference simulation for tritium are nearly imperceptible. Results for 12 times (after the three detonations) are shown: (a) 1 month, (b) $1 \mathrm{yr}$, (c) $10 \mathrm{yr}$, (d) $20 \mathrm{yr}$, (e) $34 \mathrm{yr}$, (f) $45 \mathrm{yr}$, (g) $55 \mathrm{yr}$, (h) $66 \mathrm{yr}$, (i) $100 \mathrm{yr}$, (j) $150 \mathrm{yr},(\mathrm{k}) 250 \mathrm{yr}$, and (1) $500 \mathrm{yr}$ (continued). 
(i)

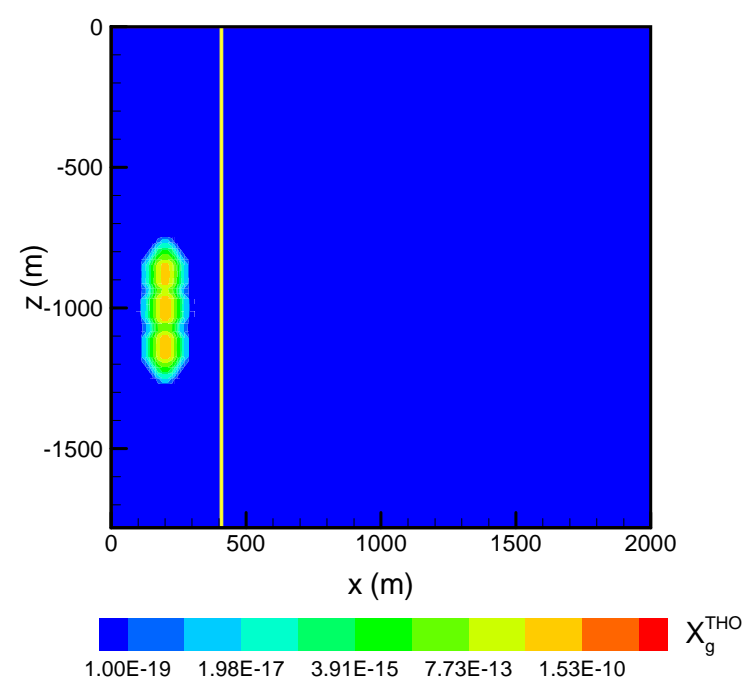

$(\mathrm{k})$

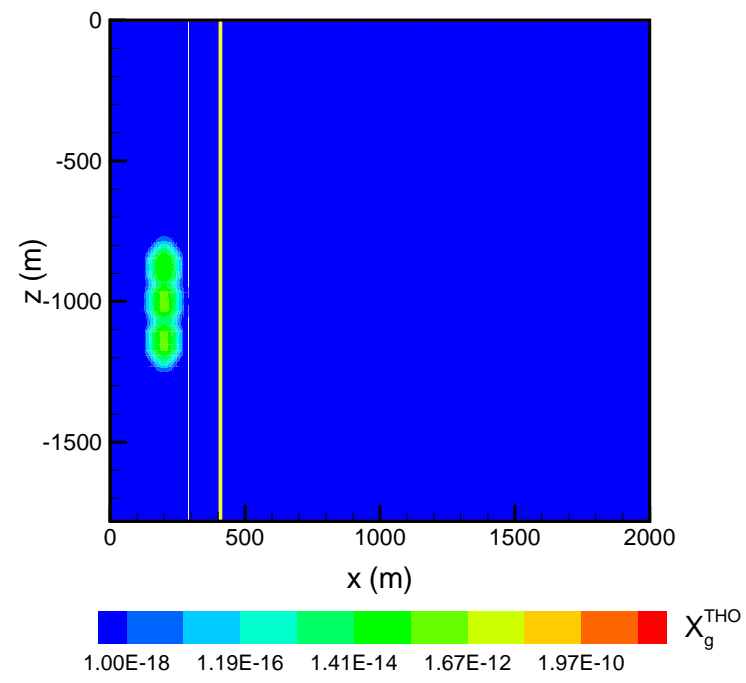

(j)

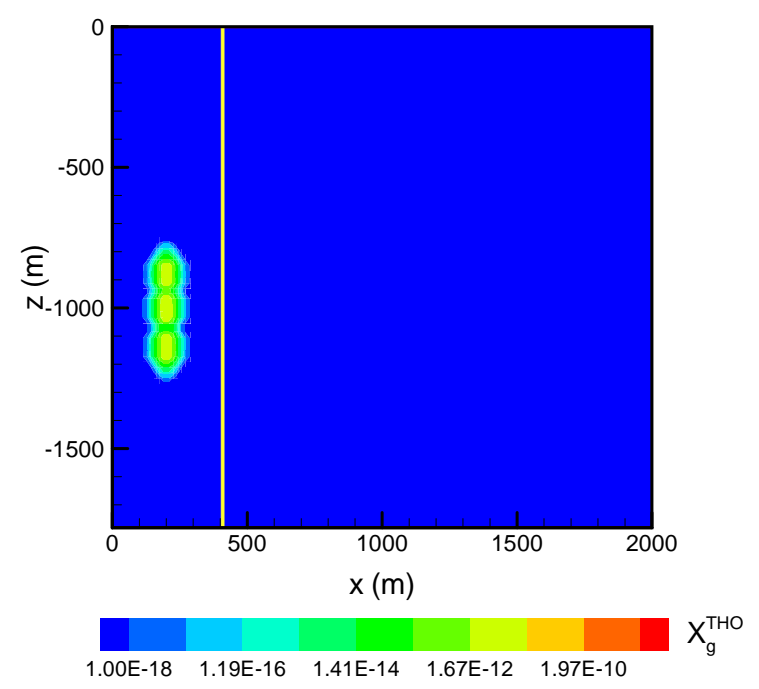

(l)

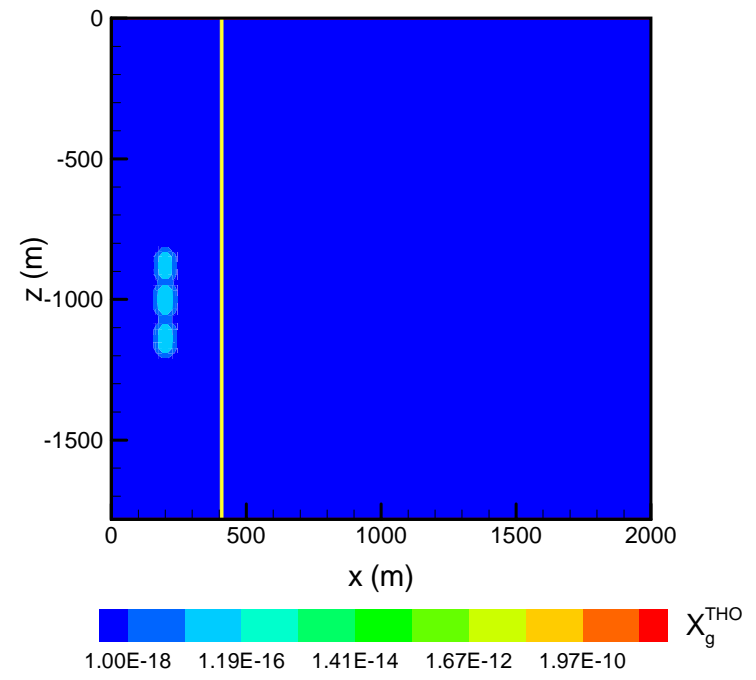

Figure 28. Results of a two-dimensional simulation showing $X_{g}^{K r}$ (krypton mixed in the gas phase). The diffusion coefficients are nearly the same, as are the half lives. The differences between this simulation and the reference simulation for tritium are nearly imperceptible. Results for 12 times (after the three detonations) are shown: (a) 1 month, (b) $1 \mathrm{yr}$, (c) $10 \mathrm{yr}$, (d) $20 \mathrm{yr}$, (e) $34 \mathrm{yr}$, (f) $45 \mathrm{yr}$, (g) $55 \mathrm{yr}$, (h) $66 \mathrm{yr}$, (i) $100 \mathrm{yr},(\mathrm{j}) 150 \mathrm{yr},(\mathrm{k}) 250 \mathrm{yr}$, and (1) $500 \mathrm{yr}$ (continued). 
The two-dimensional simulations in a "natural" setting, without nearby producing wells, show that within the first month after the nuclear detonations, tritium is mixed within each cavity/chimney. Within several years, transport of tritium is approximately $75 \mathrm{~m}$ from the center of the cavity/chimney, which is the distance in which fractures extend away from the cavity/chimney. Beyond that time, transport is slow because it is controlled by diffusion of gas and very little by liquid diffusion, as the liquid velocities are nearly zero. These simulations were useful for setting up simulations in which the reservoir had an external stress induced by a producing gas well. This external force creates a pressure gradient towards the well, which enhances transport.

\section{Transport of Tritium in a Producing Gas Reservoir}

A series of simulations was conducted in which radionuclide transport was away from a single cavity/chimney, toward a producing gas well located outside the current drilling exclusion boundary. Figures 29a through 291 show a time series of tritium mass fraction in the gas phase $\left(X_{g}{ }^{T H O}\right)$ at 12 times: 1 month, $1 \mathrm{yr}, 10 \mathrm{yr}, 20 \mathrm{yr}, 34 \mathrm{yr}, 45 \mathrm{yr}, 55 \mathrm{yr}, 66 \mathrm{yr}, 100$ $\mathrm{yr}, 150 \mathrm{yr}, 250 \mathrm{yr}$, and $500 \mathrm{yr}$ for the "reference" case where $\left(k=3.4 \times 10^{-16} \mathrm{~m}^{2}\right.$ and $S_{l}=0.6$. This case models transport away from a single nuclear cavity, with the properties of the Fort Union Formation. Some, or all, of these same times are shown for all of the results discussed in this section. Transport is away from the cavity in the lower left of each figure toward the producing well (the red vertical line) near the center of each figure. In each figure is shown a vertical slice that bisects the flow field in the direction of flow (the $x$-direction). A second, parallel slice located $120 \mathrm{~m}$ away is also shown.

Tritiated gas fills the cavity within the first month of the nuclear detonation (Figure 29a) and begins to diffuse radially outward from the cavity (Figures 29b through $29 \mathrm{e})$. Just prior to the start of gas production (35 years after the detonation, or the year 2008) the extent of the tritium is approximately $100 \mathrm{~m}$ from the center of the cavity (Figure 29f). This is also apparent from the cross-sectional slice located at $y=860 \mathrm{~m}$, where the $X_{g}{ }^{T H O}$ is approximately $10^{-18}$ in Figure $29 \mathrm{~g}$, which is the background level. Production of gas occurs for 35 years (Figures $29 \mathrm{f}$ through $29 \mathrm{~h}$ ), after which time pumping ceases. Gas production has limited effect on tritium transport, as it is draws radioactive gas only an additional 40 to $50 \mathrm{~m}$

during the duration of production. Figure 291 shows the $X_{g}{ }^{T H O}$ field 100 years after the nuclear detonations; at this time, tritium migration is balanced by its radioactive decay such that the plume dimensions have stabilized. The mass fraction of tritium (i.e., concentration) has, however, decreased due entirely to radioactive decay. Beyond this time, the mass fraction field diminishes due to radioactive decay (Figures 29i through 291). Gas-phase tritium never reaches the production well under this scenario.

Figures 30a through 301 show transport in the liquid (aqueous) phase $\left(X_{l}^{T H O}\right)$ away from the cavity. The times for these figures are exactly as those in the previous figures. The characteristics of the plume - geometry and distribution of mass in the liquid phase - are nearly identical to those of the gas phase (however, note the change of scale due to partitioning between phases). Liquid phase velocities are several orders less than those in the gas phase due to smaller liquid-phase diffusion coefficients, yet tritium in the liquid phase has traveled the same distances as in the gas phase. The reason is due to phase change; that is, tritium moves away from the cavity in the gas phase and partitions into the liquid phase. This partitioning acts to diminish $X_{g}{ }^{T H O}$ at the expense of gaining mass in the liquid phase. In combination with radioactive decay, this acts to constrain the dimensions of the plume, as 
both processes (phase partitioning and radioactive decay) work together to diminish mass fraction of tritium in both phases.

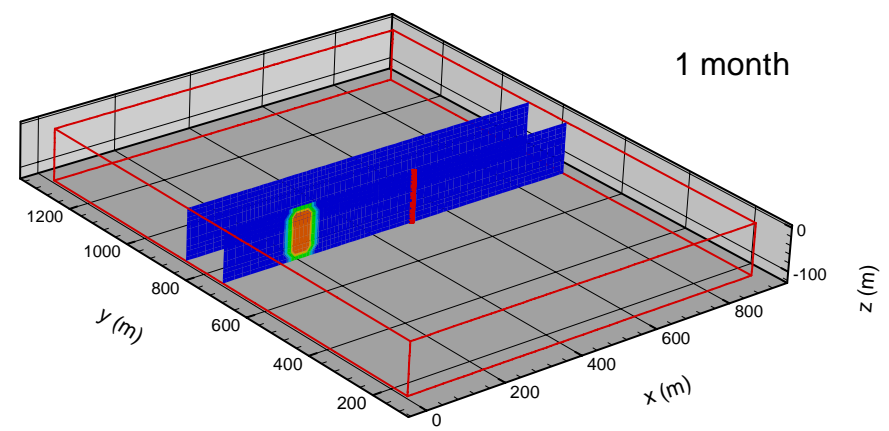

(a)
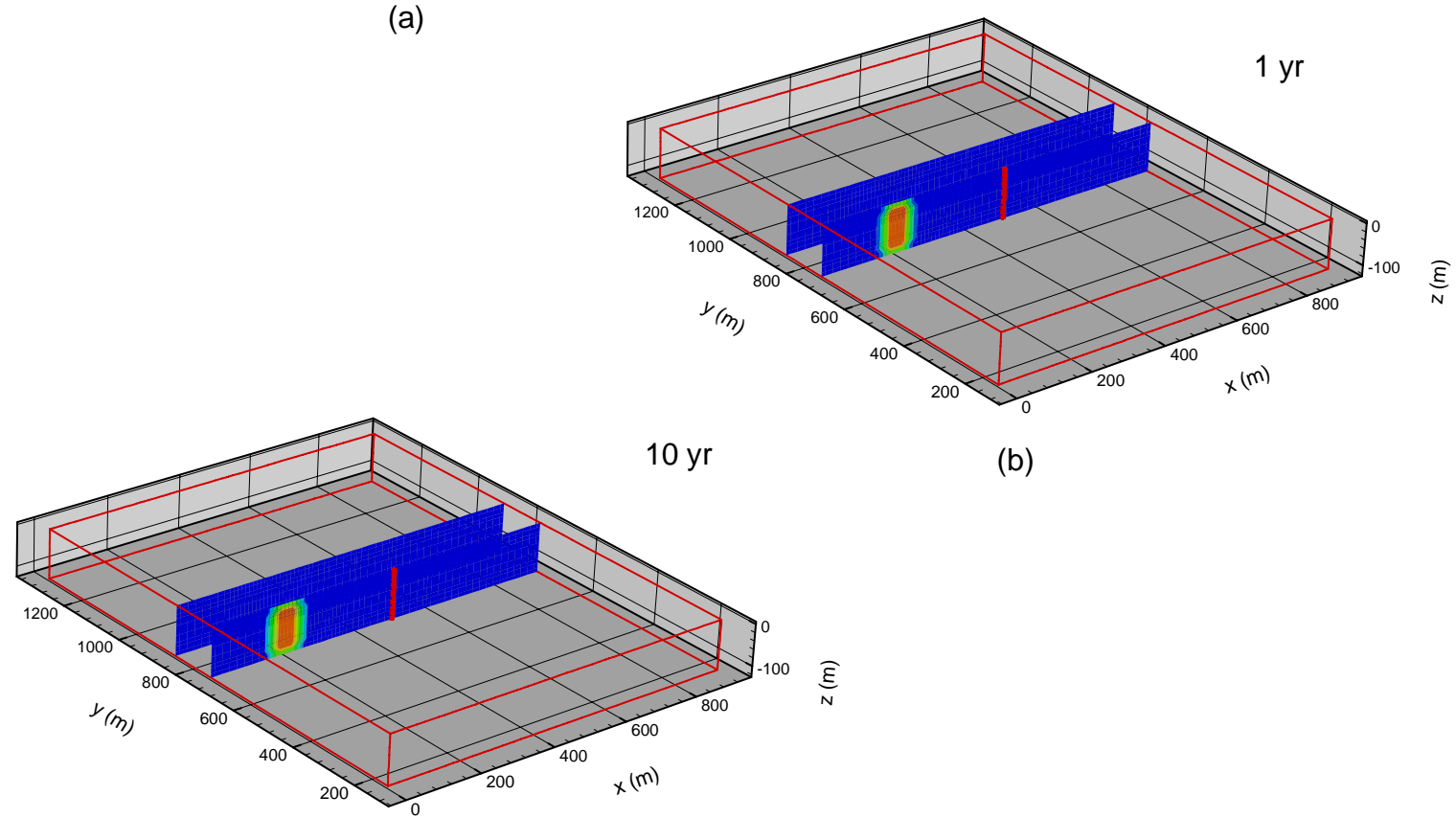

(b)

(c)
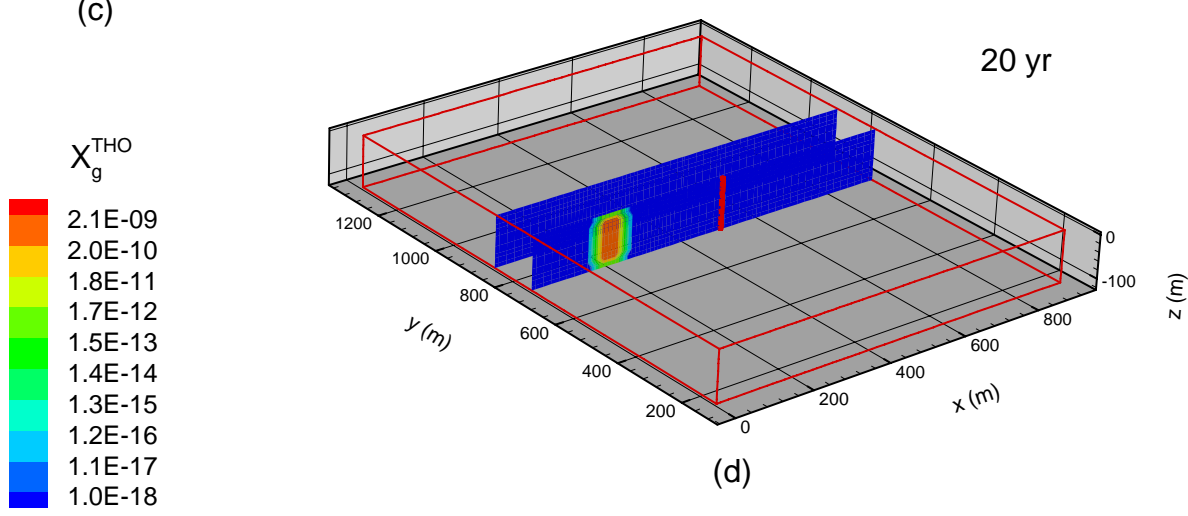

(d)

Figure 29. Mass fraction of tritium in the gas phase $\left(X_{g}{ }^{T H O}\right.$ ) after (a) 1 month, (b) $1 \mathrm{yr}$, (c) $10 \mathrm{yr}$, (d) $20 \mathrm{yr}$, (e) $34 \mathrm{yr}$, (f) $45 \mathrm{yr}$, (g) $55 \mathrm{yr}$, (h) $66 \mathrm{yr}$, (i) $100 \mathrm{yr}$, (j) $150 \mathrm{yr}$, (k) $250 \mathrm{yr}$, and (l) $500 \mathrm{yr}$ for the "reference" simulation with mean properties. 


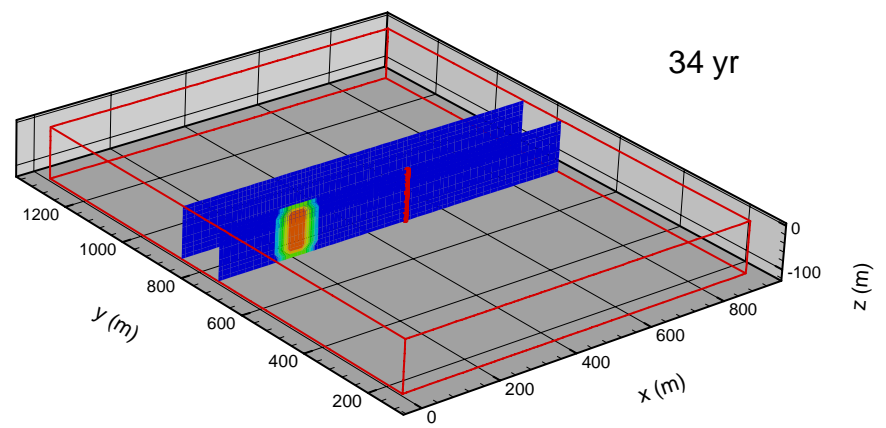

(e)
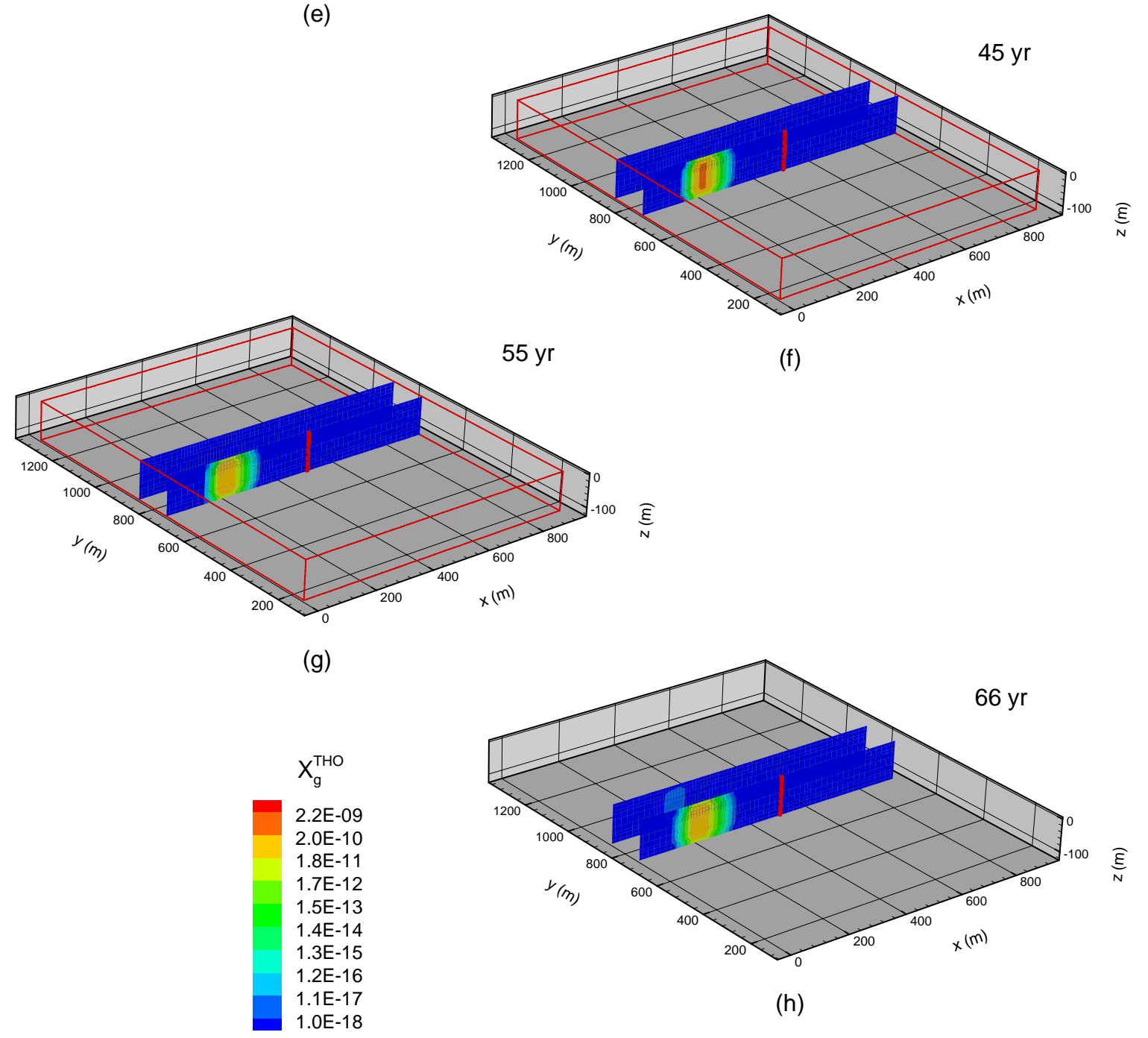

Figure 29. Mass fraction of tritium in the gas phase $\left(X_{g}{ }^{T H O}\right.$ ) after (a) 1 month, (b) $1 \mathrm{yr}$, (c) $10 \mathrm{yr}$, (d) $20 \mathrm{yr}$, (e) $34 \mathrm{yr}$, (f) $45 \mathrm{yr}$, (g) $55 \mathrm{yr}$, (h) $66 \mathrm{yr}$, (i) $100 \mathrm{yr}$, (j) $150 \mathrm{yr}$, (k) $250 \mathrm{yr}$, and (l) $500 \mathrm{yr}$ for the "reference" simulation with mean properties (continued). 


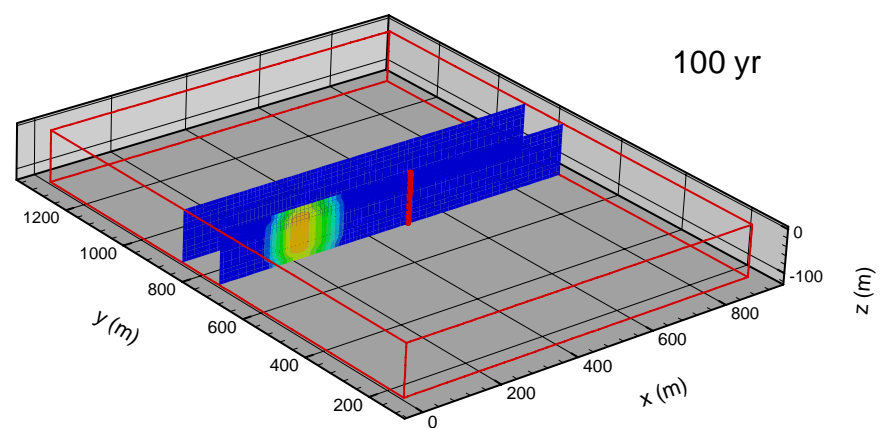

(i)

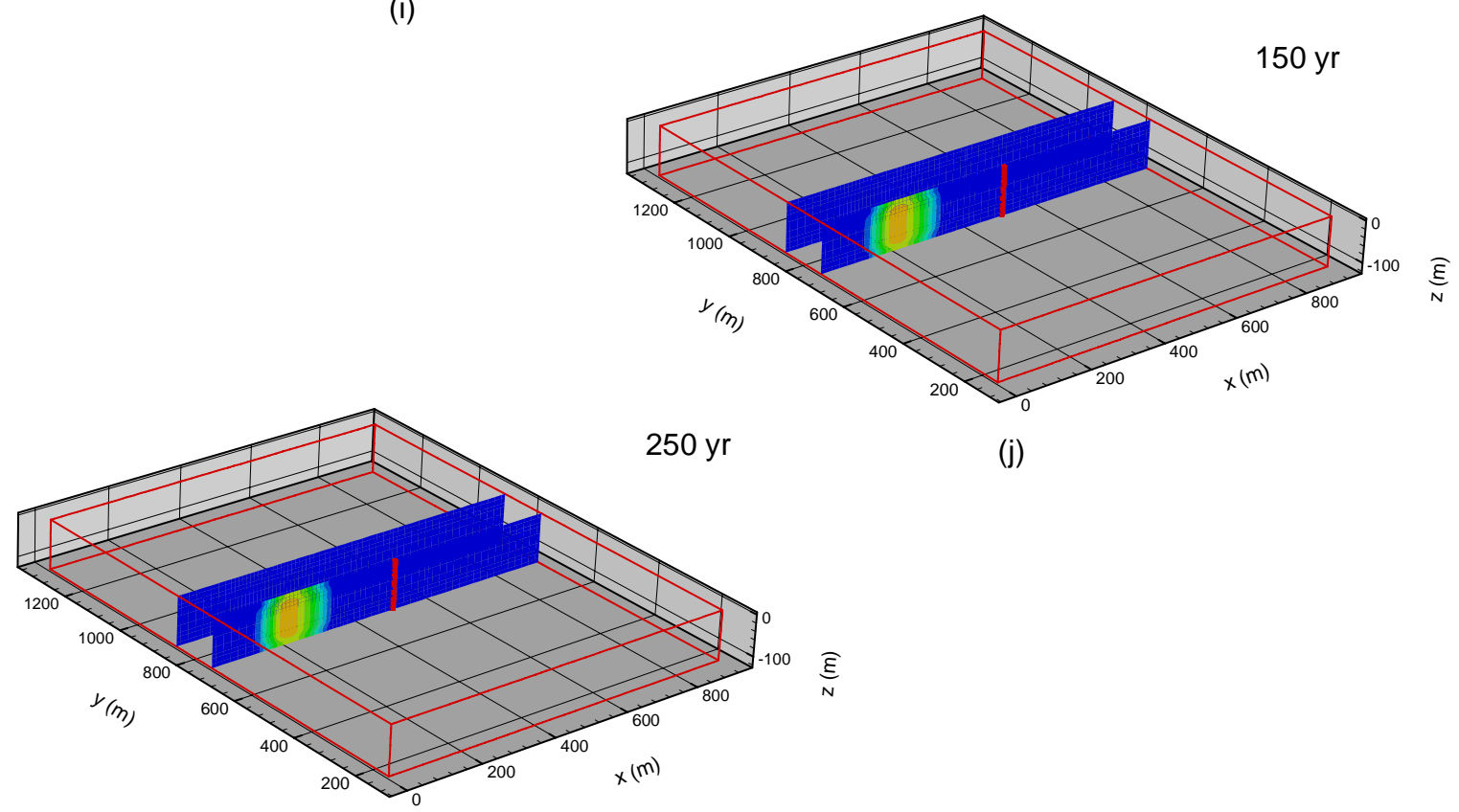

(k)
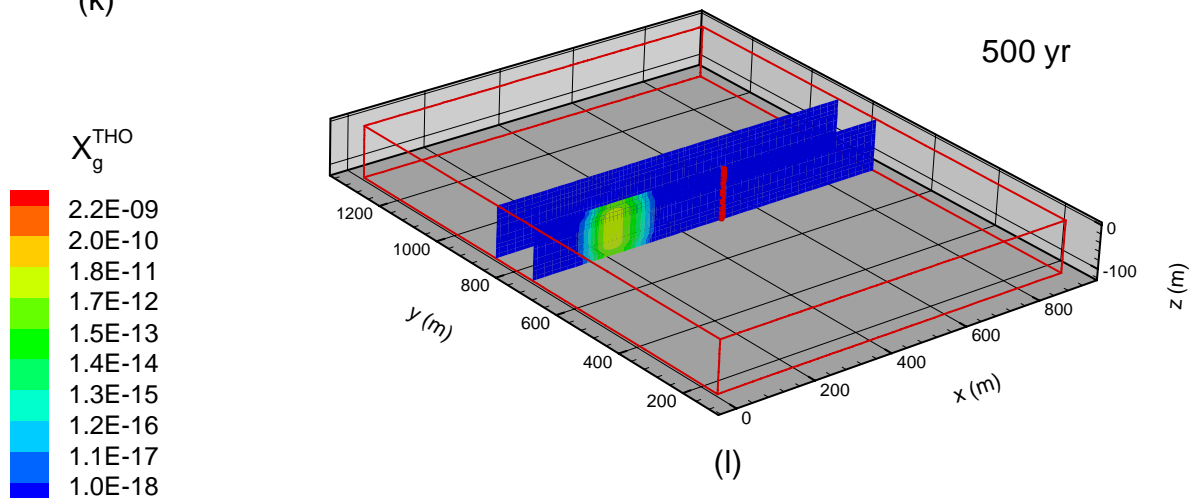

(l)

Figure 29. Mass fraction of tritium in the gas phase $\left(X_{g}{ }^{T H O}\right.$ ) after (a) 1 month, (b) $1 \mathrm{yr}$, (c) $10 \mathrm{yr}$, (d) $20 \mathrm{yr}$, (e) $34 \mathrm{yr}$, (f) $45 \mathrm{yr}$, (g) $55 \mathrm{yr}$, (h) $66 \mathrm{yr}$, (i) $100 \mathrm{yr}$, (j) $150 \mathrm{yr}$, (k) $250 \mathrm{yr}$, and (l) $500 \mathrm{yr}$ for the "reference" simulation with mean properties (continued). 


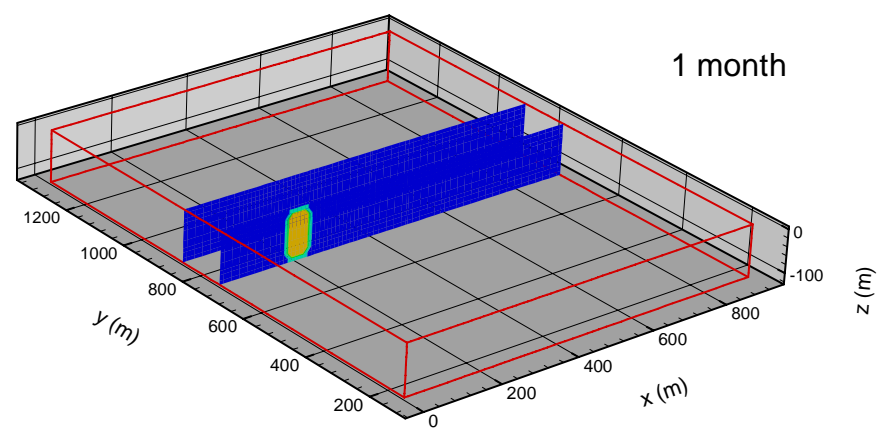

(a)
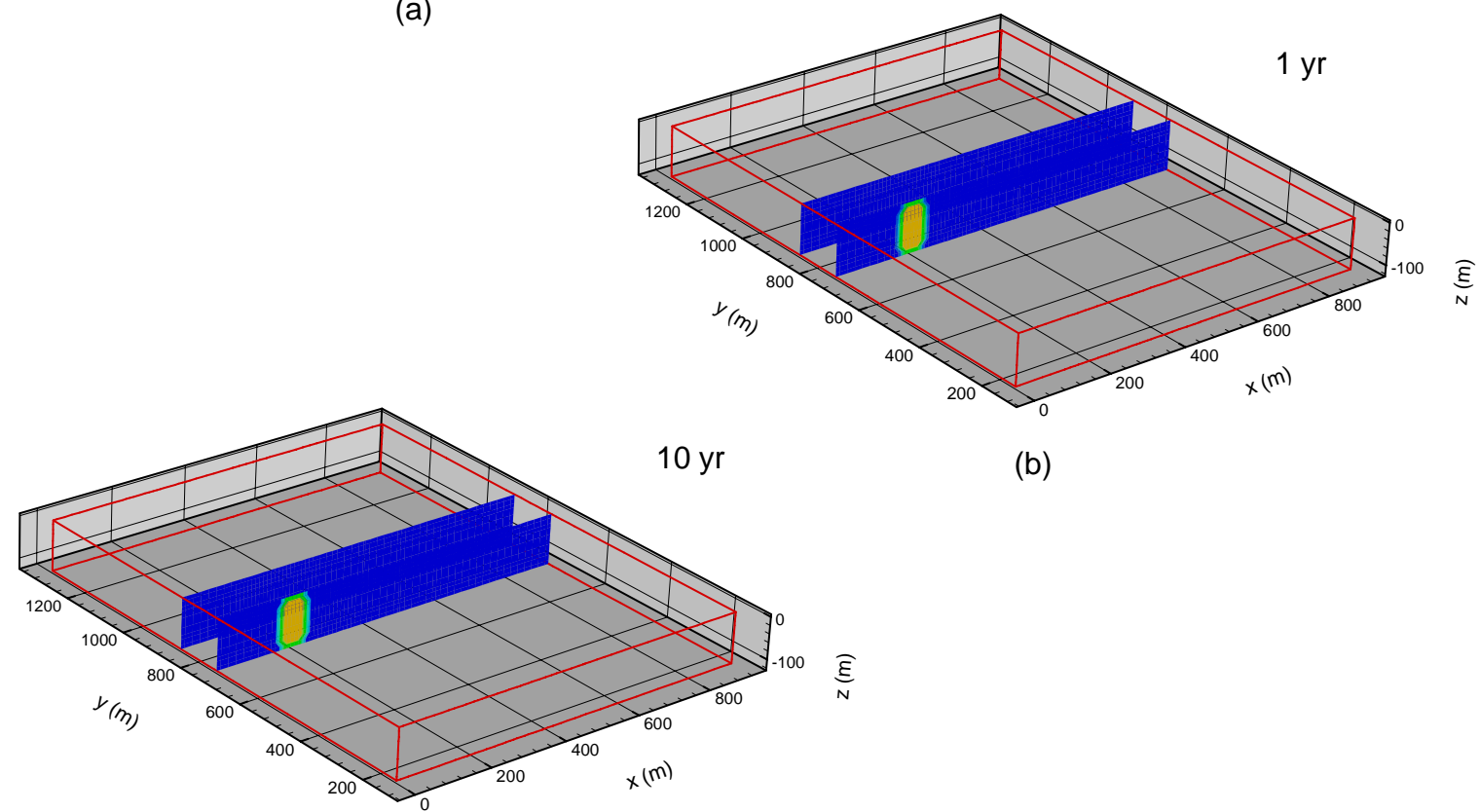

(b)
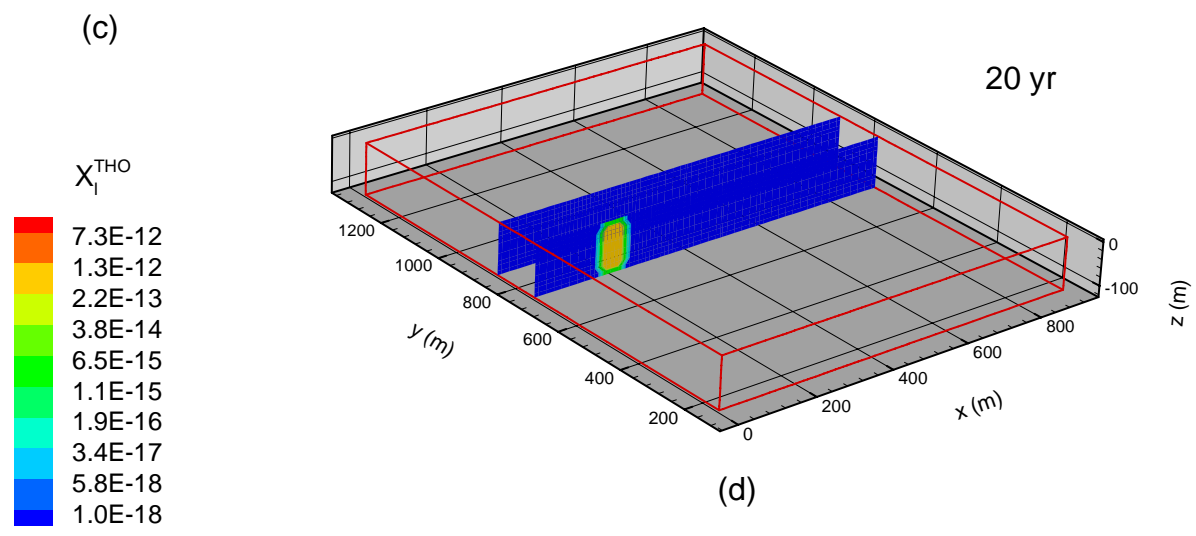

(d)

Figure 30. Mass fraction of tritium in the liquid phase $\left(X_{l}^{T H O}\right)$ after (a) 1 month, (b) $1 \mathrm{yr}$, (c) 10 yr, (d) $20 \mathrm{yr}$, (e) $34 \mathrm{yr}$, (f) $45 \mathrm{yr}$, (g) $55 \mathrm{yr}$, (h) $66 \mathrm{yr}$, (i) $100 \mathrm{yr}$, (j) $150 \mathrm{yr}$, (k) $250 \mathrm{yr}$, and (l) $500 \mathrm{yr}$ for the "reference" simulation with mean properties. 


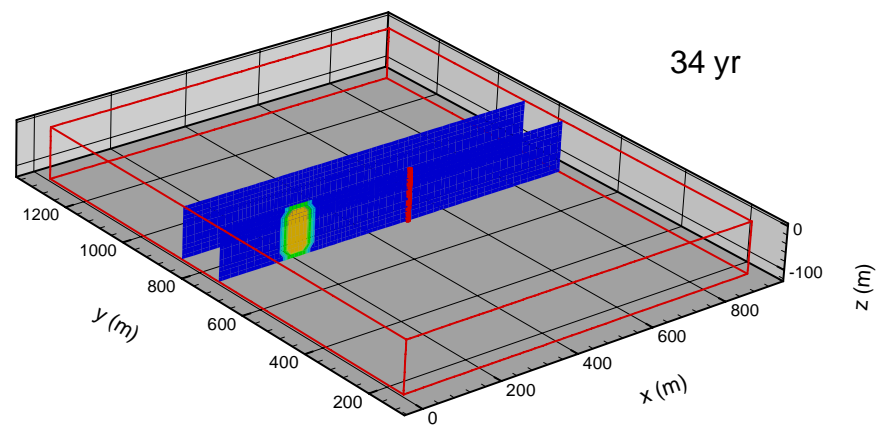

(e)
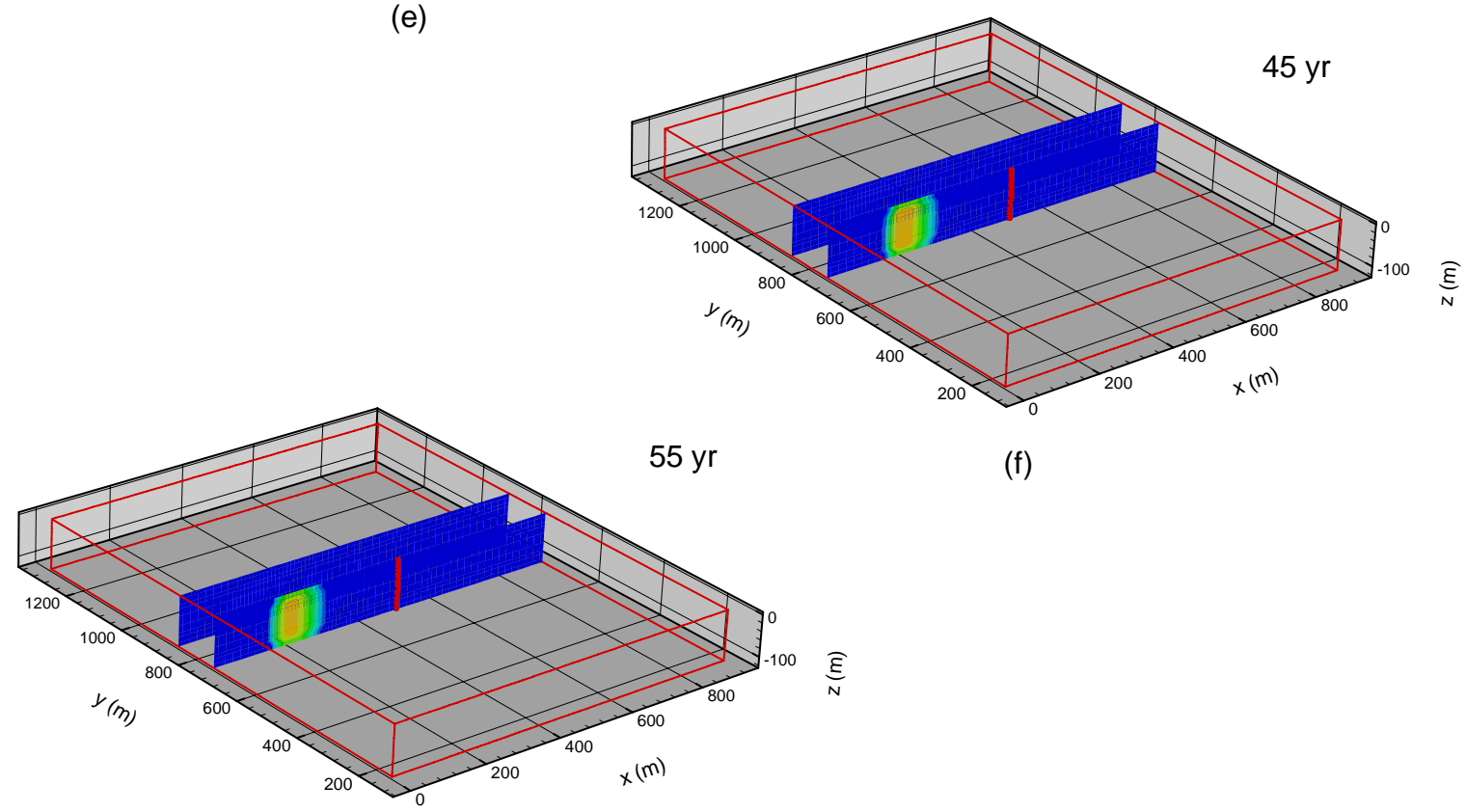

(g)
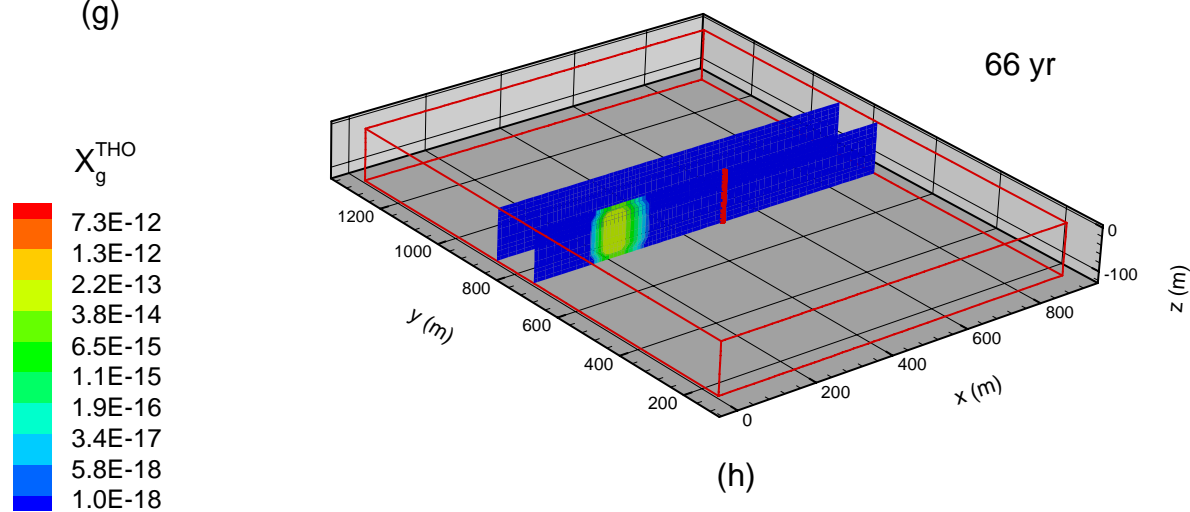

(h)

Figure 30. Mass fraction of tritium in the liquid phase ( $X_{l}^{T H O}$ ) after (a) 1 month, (b) $1 \mathrm{yr}$, (c) 10 yr, (d) $20 \mathrm{yr}$, (e) $34 \mathrm{yr}$, (f) $45 \mathrm{yr}$, (g) $55 \mathrm{yr}$, (h) $66 \mathrm{yr}$, (i) $100 \mathrm{yr}$, (j) $150 \mathrm{yr}$, (k) $250 \mathrm{yr}$, and (l) $500 \mathrm{yr}$ for the "reference" simulation with mean properties (continued). 


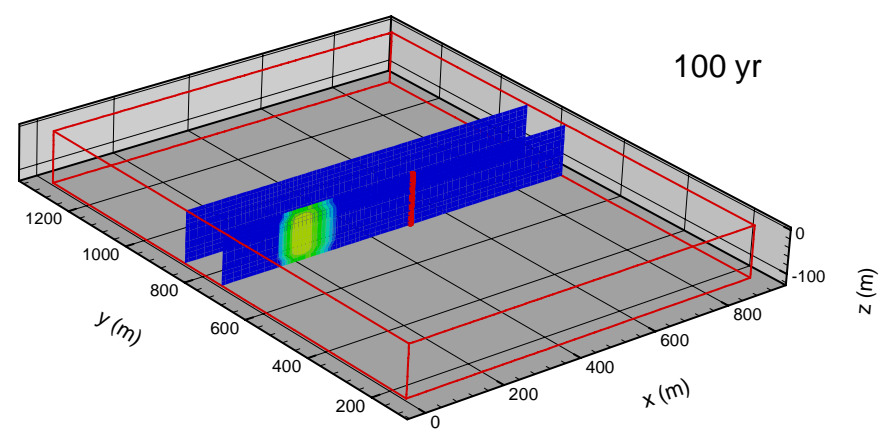

(i)
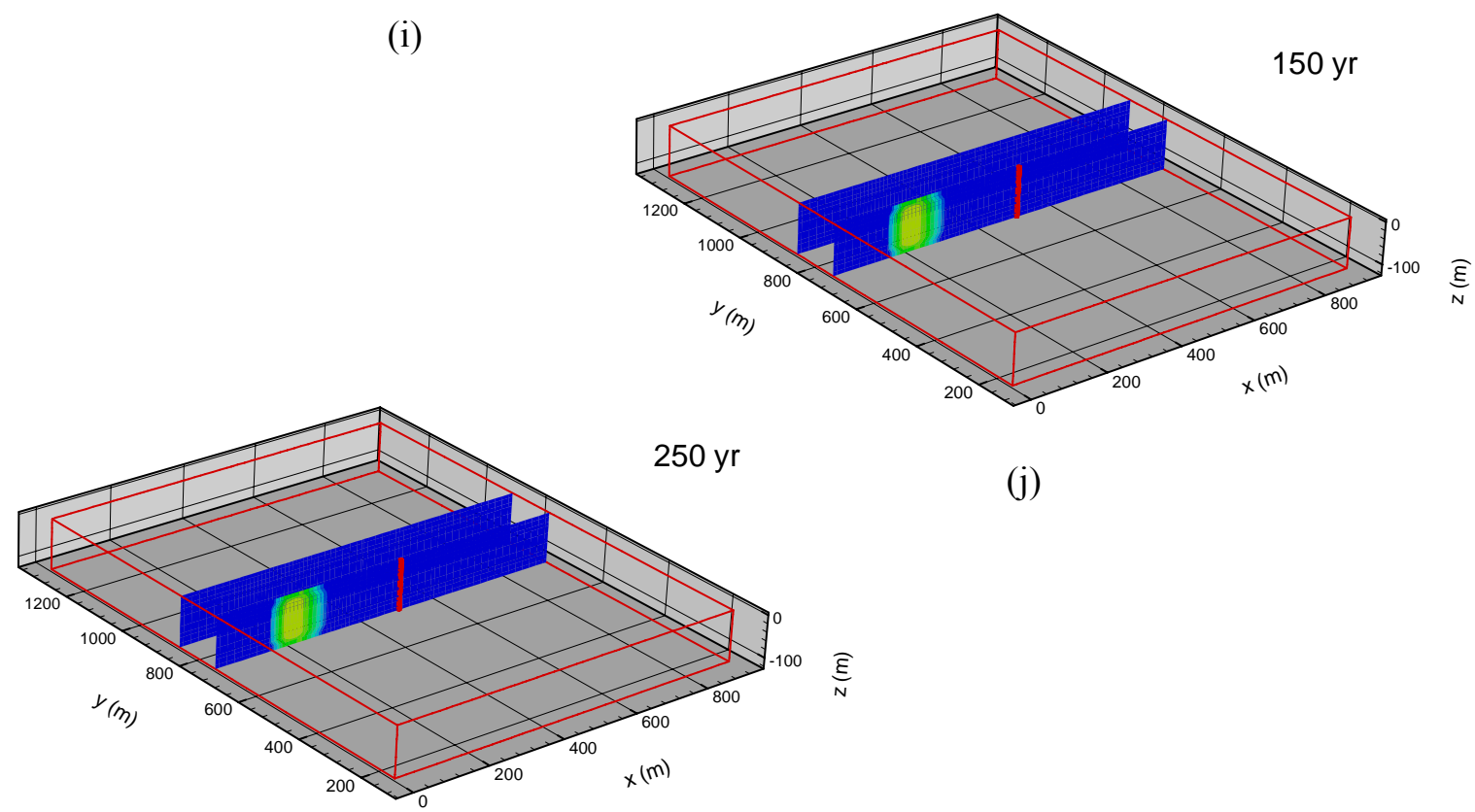

(k)
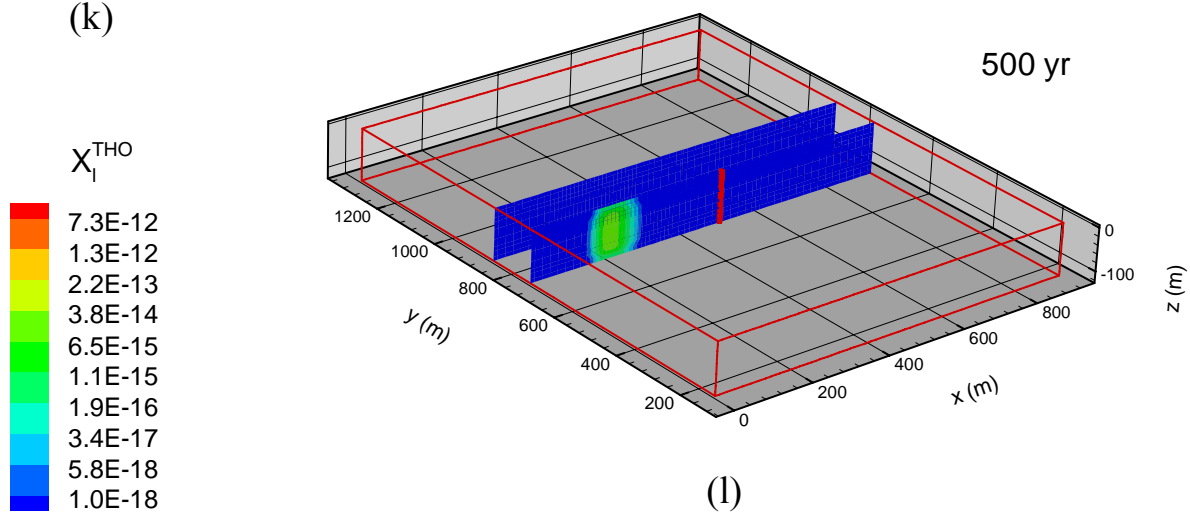

(1)

Figure 30. Mass fraction of tritium in the liquid phase $\left(X_{l}^{T H O}\right)$ after (a) 1 month, (b) $1 \mathrm{yr}$, (c) 10 yr, (d) $20 \mathrm{yr}$, (e) $34 \mathrm{yr}$, (f) $45 \mathrm{yr}$, (g) $55 \mathrm{yr}$, (h) $66 \mathrm{yr}$, (i) $100 \mathrm{yr}$, (j) $150 \mathrm{yr}$, (k) $250 \mathrm{yr}$, and (1) $500 \mathrm{yr}$ for the "reference" simulation with mean properties (continued). 
A simulation similar to the reference case, but with a one order of magnitude increase in permeability, is shown in Figure 31 . The first $35 \mathrm{yr}$ look similar to the previous simulation, as the difference is due solely to tortuosity associated with changes in saturation as a result of the different intrinsic permeabilities (Figures 31a through 31e). Gas production, however (Figures $31 \mathrm{f}$ through $31 \mathrm{~h}$ ), has a slight effect of allowing tritium to migrate closer to the well, although only about $20 \mathrm{~m}$ closer when production ceases at $65 \mathrm{yr}$ (Figure $31 \mathrm{~h}$ ) than in the reference simulation. Although not shown, the $X_{l}^{T H O}$ field has a similar appearance to the $X_{g}{ }^{T H O}$, although scaled differently as explained above. The reason for the similar appearance of tritium mass fraction in the two phases is the same as that for the reference case. That is, tritium in the gas phase travels faster, and therefore further, than in the liquid phase.

Thermodynamic phase partitioning, however, allows for the extent of tritium migration to be equivalent in the two phases.

The next simulation (Figures 32a through 32h) shows the $X_{g}{ }^{T H O}$ field with all of the same properties as the simulation for the reference case but with a 25 percent increase in the rate of gas production at the well. The first 35 years are identical because there was no production. Beyond that time, however, the mass fraction fields are nearly identical except for details along the edges of the contours where the tritium mass fraction blends into the background mass fraction. The additional pumping rate allows for an additional 10 to $20 \mathrm{~m}$ of transport. Other than that, the extent of transport and the distribution of tritium within the "plume" are nearly identical.

A simulation was conducted in which the gas saturation was increased from 0.4 to 0.6. For this simulation, a new three-dimensional flow problem (with residual liquid saturation, $S_{l r}$, decreased from 0.6 [from the reference simulation] to 0.4 ) was first run to steady state and the results were used as initial conditions for the transport simulation. The results are shown in Figures 33a through 33h. The first figure, Figure 33a is the $X_{g}{ }^{T H O}$ field has not undergone any pumping. However, Figure $33 \mathrm{~b}$ shows that 10 years of pumping in conjunction with the high gas saturation has allowed tritium to migrate nearly $200 \mathrm{~m}$ from the center of the nuclear cavity. This is greater migration, by approximately $50 \mathrm{~m}$, than any of the previous simulations. The reason for the further tritium transport is because the relative permeability has increased from approximately 0.45 to 0.70 (see Figure 21). The higher gas saturation, when compared to the reference simulation, shows that there is more mixing, hence dilution, in the gas phase. This is especially prevalent in Figures 33e through $33 \mathrm{~h}$ (compare to Figures 29d through 29g, which are for the same times).

A simulation was run in which the initial gas saturation was decreased from 0.4 to 0.2 as compared to the reference simulation (this required raising $S_{l r}$ from 0.6 to 0.8 to prevent downward drainage of liquid water). The results of this simulation are present in Figures $34 \mathrm{a}$ through $34 \mathrm{~h}$. There is less mixing than in the corresponding simulations for the reference simulation $\left(S_{g}=0.4\right)$ or the above simulation in which $S_{g}$ was initially set at 0.6 . Production acts to promote mixing and diffusion of tritium in the gas phase for high $S_{g r}$; however, after production ceases, tritium is more concentrated in the simulation with the low $S_{g}$, and therefore the "plume" tends to persist longer than for the other simulations. This is easily seen by comparing Figure $34 \mathrm{~h}$ (initial $S_{g}=0.2$ ) with Figures 291 and Figure $32 \mathrm{~h}$ (initial $\left.S_{g}=0.6\right)$. 


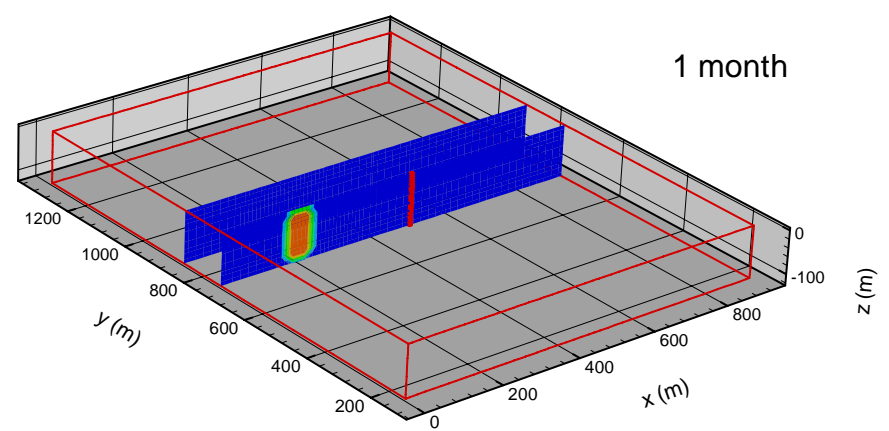

(a)
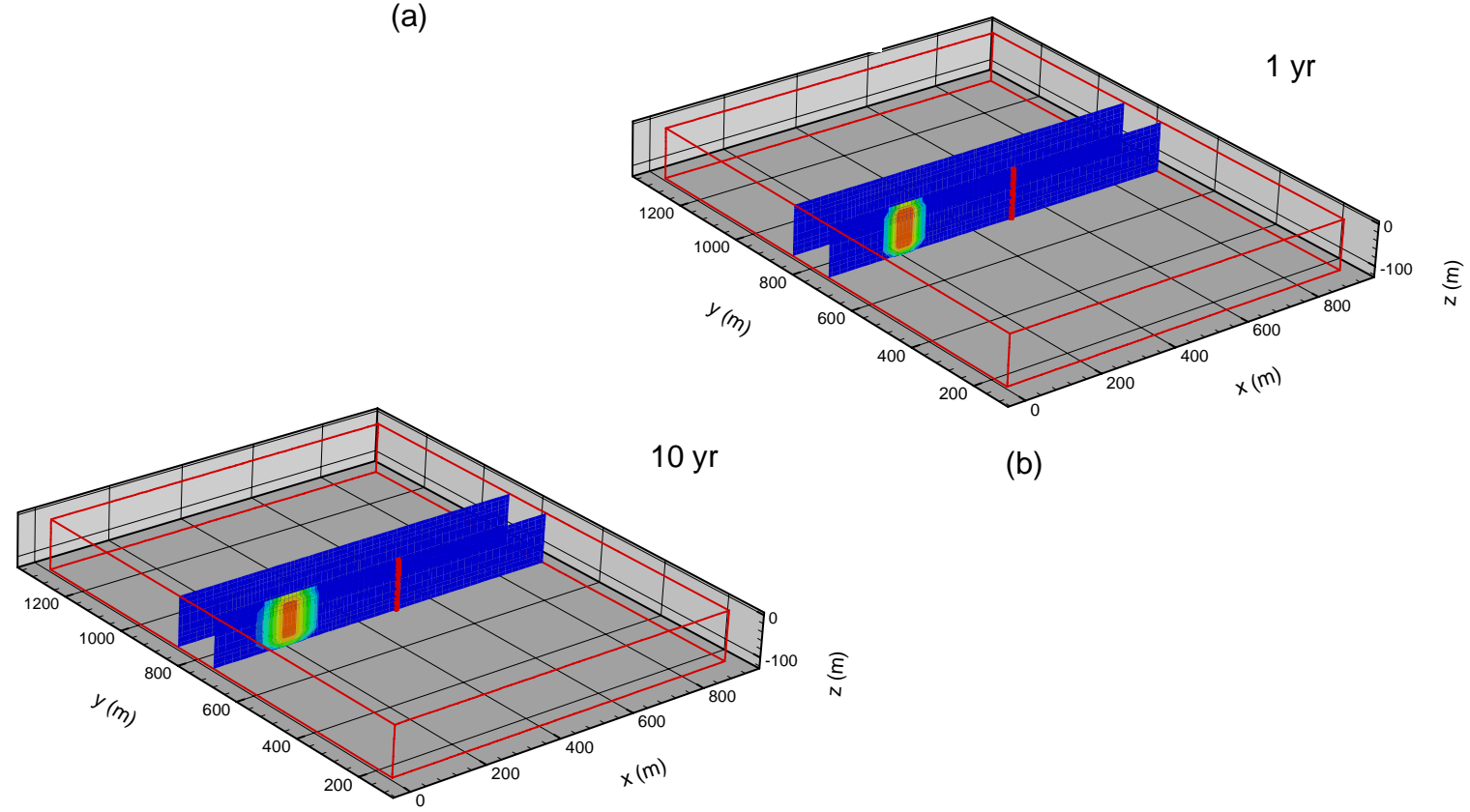

(c)
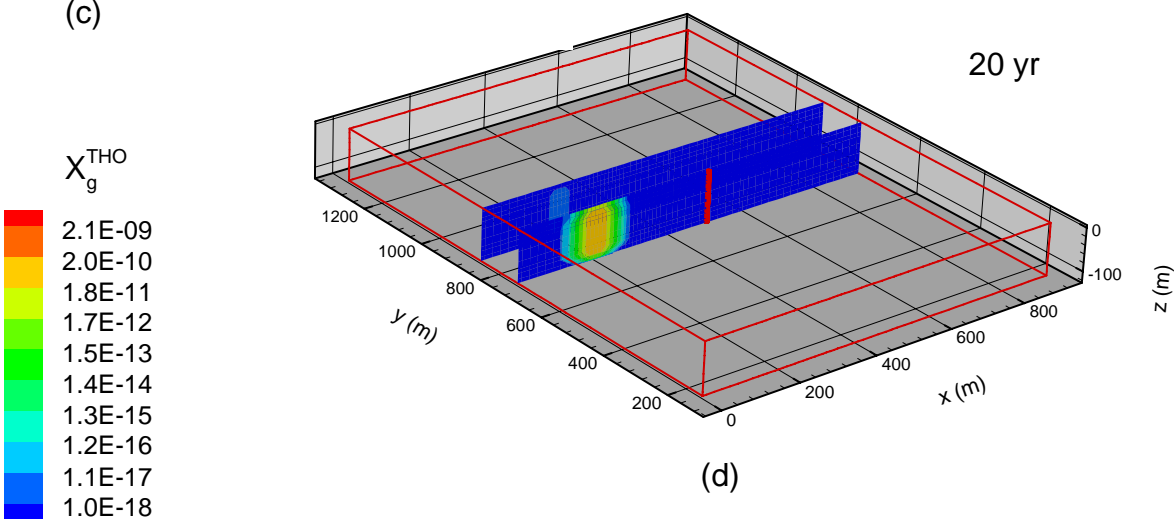

(d)

Figure 31. Mass fraction of tritium in the gas phase $\left(X_{g}{ }^{T H O}\right.$ ) after (a) 1 month, (b) $1 \mathrm{yr}$, (c) $10 \mathrm{yr}$, (d) $20 \mathrm{yr}$, (e) $34 \mathrm{yr}$, (f) $45 \mathrm{yr}$, (g) $55 \mathrm{yr}$, (h) $66 \mathrm{yr}$, (i) $100 \mathrm{yr}$, (j) $150 \mathrm{yr}$, (k) $250 \mathrm{yr}$, and (l) $500 \mathrm{yr}$ for the condition of permeability, $k=3.4 \times 10^{-15} \mathrm{~m}^{2}$, or one order of magnitude higher than the "reference" case. 


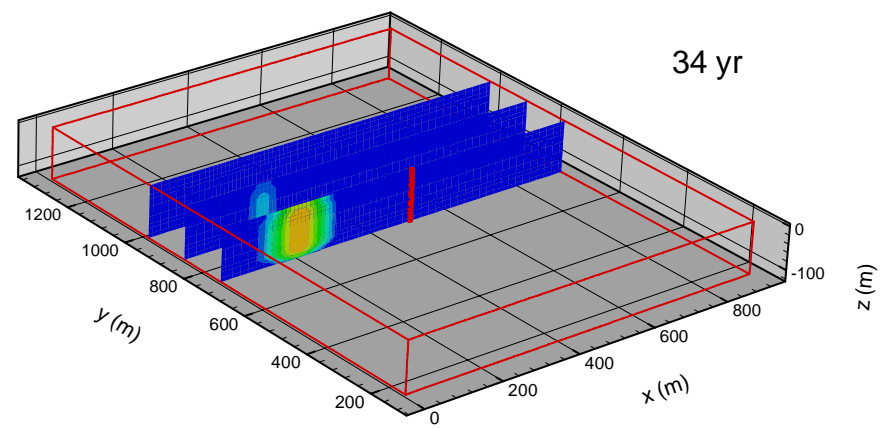

(d)
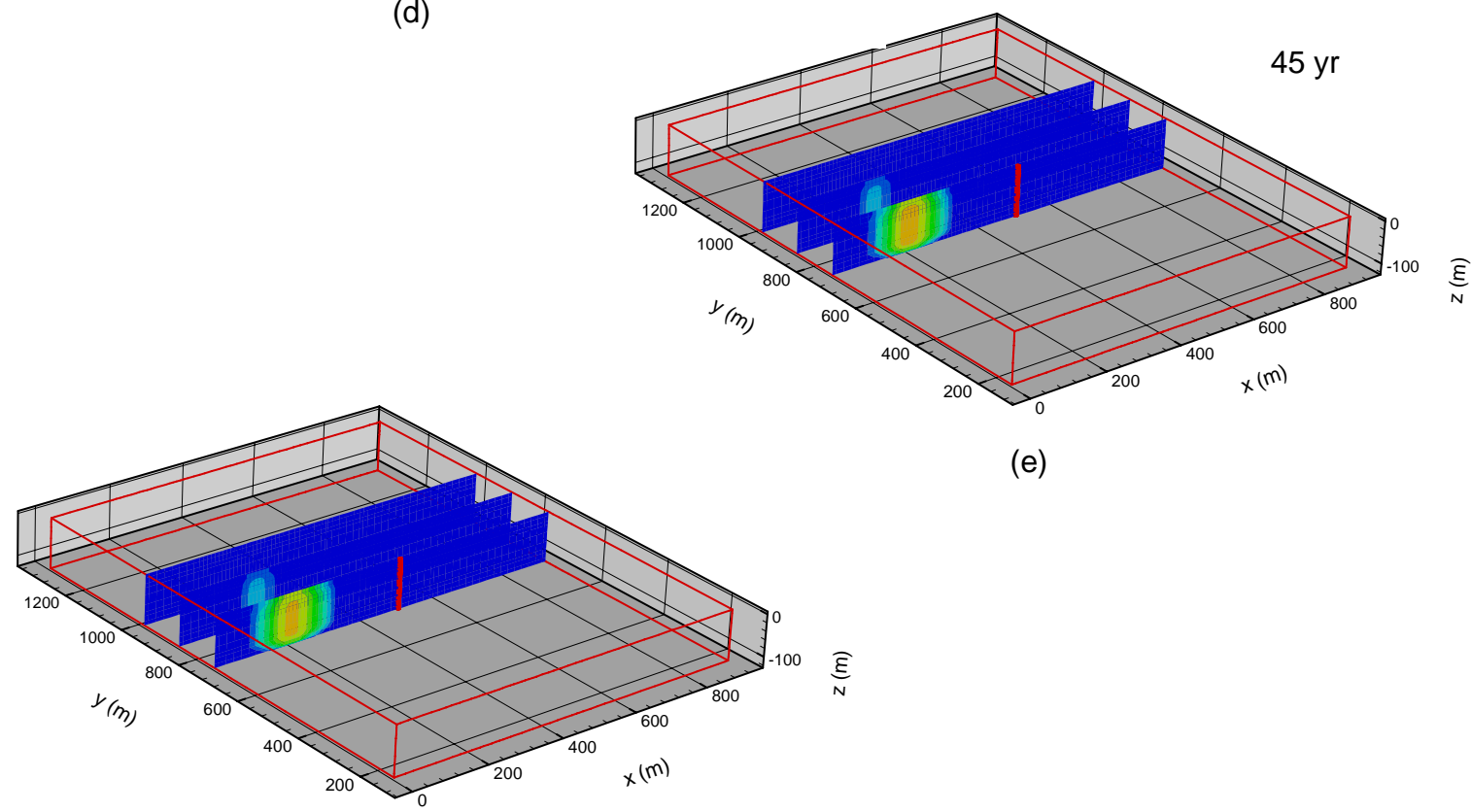

(e)
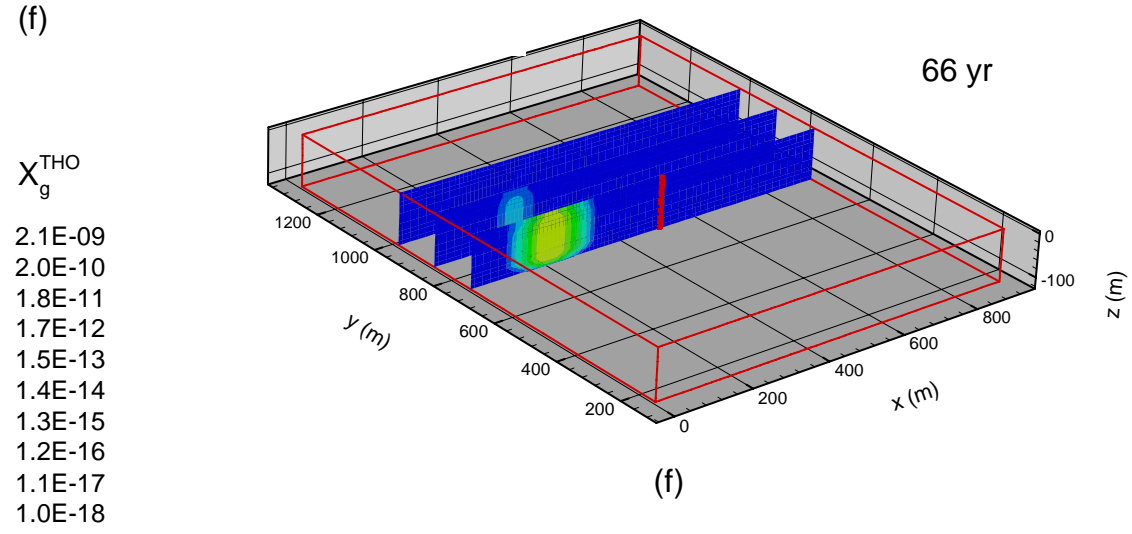

(f)

Figure 31. Mass fraction of tritium in the gas phase $\left(X_{g}{ }^{T H O}\right.$ ) after (a) 1 month, (b) $1 \mathrm{yr}$, (c) $10 \mathrm{yr}$, (d) $20 \mathrm{yr}$, (e) $34 \mathrm{yr}$, (f) $45 \mathrm{yr}$, (g) $55 \mathrm{yr}$, (h) $66 \mathrm{yr}$, (i) $100 \mathrm{yr}$, (j) $150 \mathrm{yr}$, (k) $250 \mathrm{yr}$, and (l) $500 \mathrm{yr}$ for the condition of permeability, $k=3.4 \times 10^{-15} \mathrm{~m}^{2}$, or one order of magnitude higher than the "reference" case (continued). 


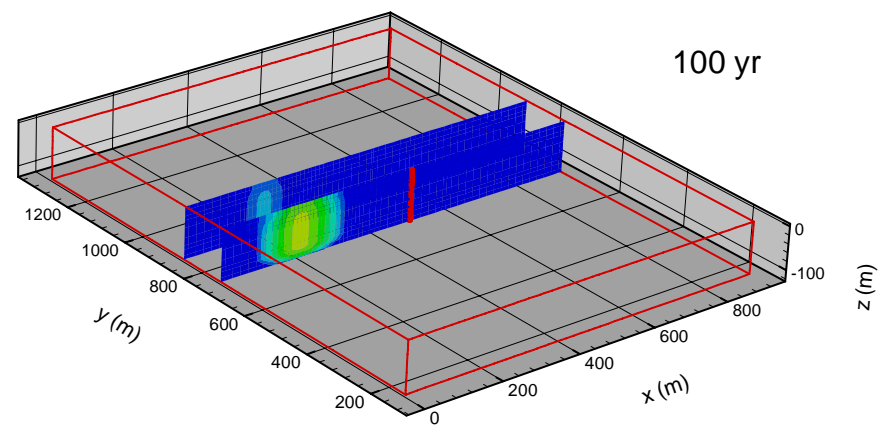

(i)
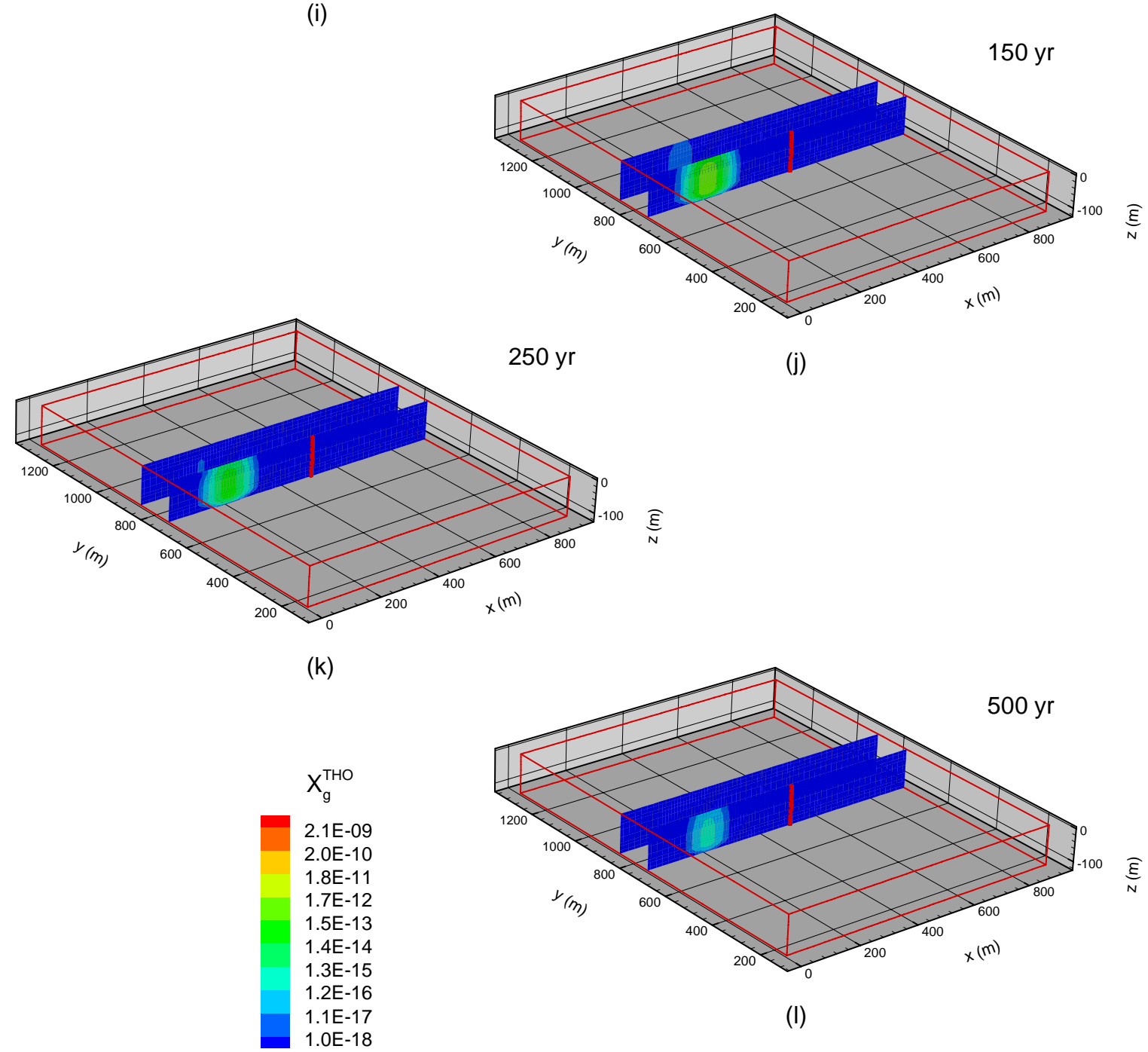

(l)

Figure 31. Mass fraction of tritium in the gas phase $\left(X_{g}{ }^{T H O}\right.$ ) after (a) 1 month, (b) $1 \mathrm{yr}$, (c) $10 \mathrm{yr}$, (d) $20 \mathrm{yr}$, (e) $34 \mathrm{yr}$, (f) $45 \mathrm{yr}$, (g) $55 \mathrm{yr}$, (h) $66 \mathrm{yr}$, (i) $100 \mathrm{yr}$, (j) $150 \mathrm{yr}$, (k) $250 \mathrm{yr}$, and (l) $500 \mathrm{yr}$ for the condition of permeability, $k=3.4 \times 10^{-15} \mathrm{~m}^{2}$, or one order of magnitude higher than the "reference" case (continued). 


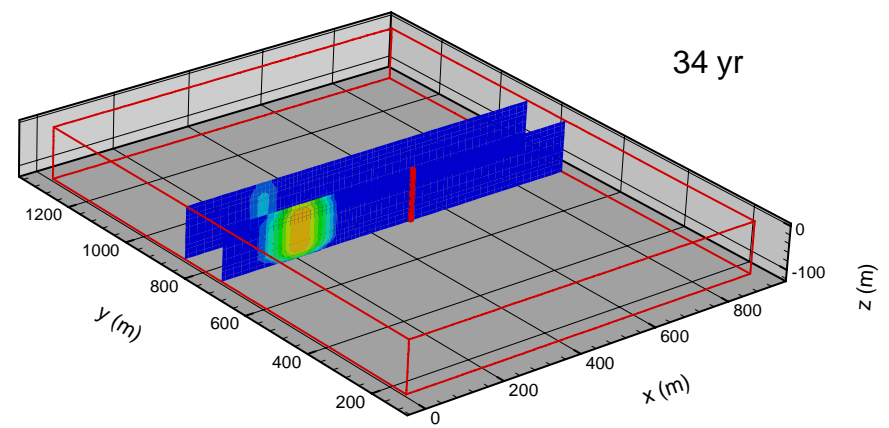

(a)
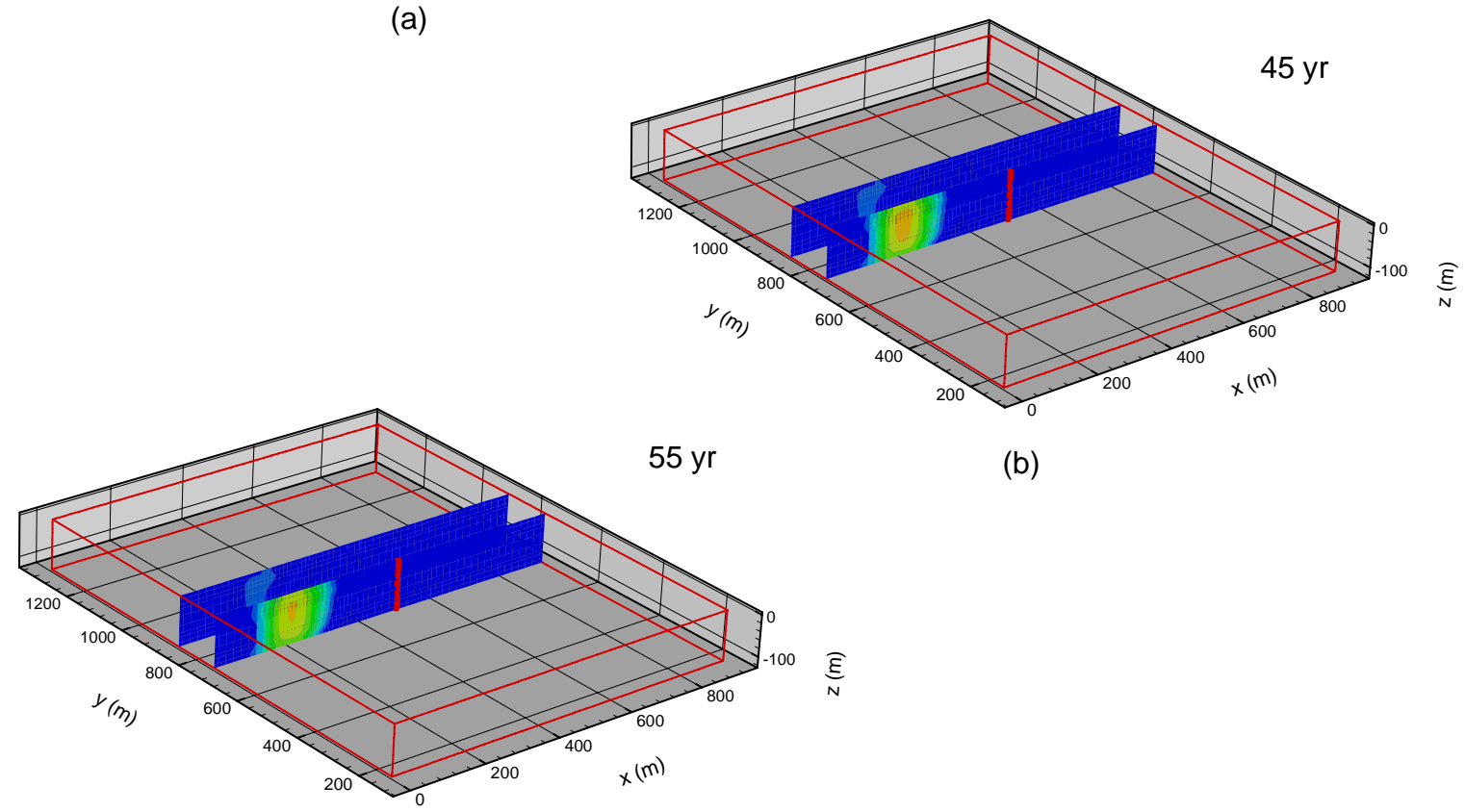

(c)
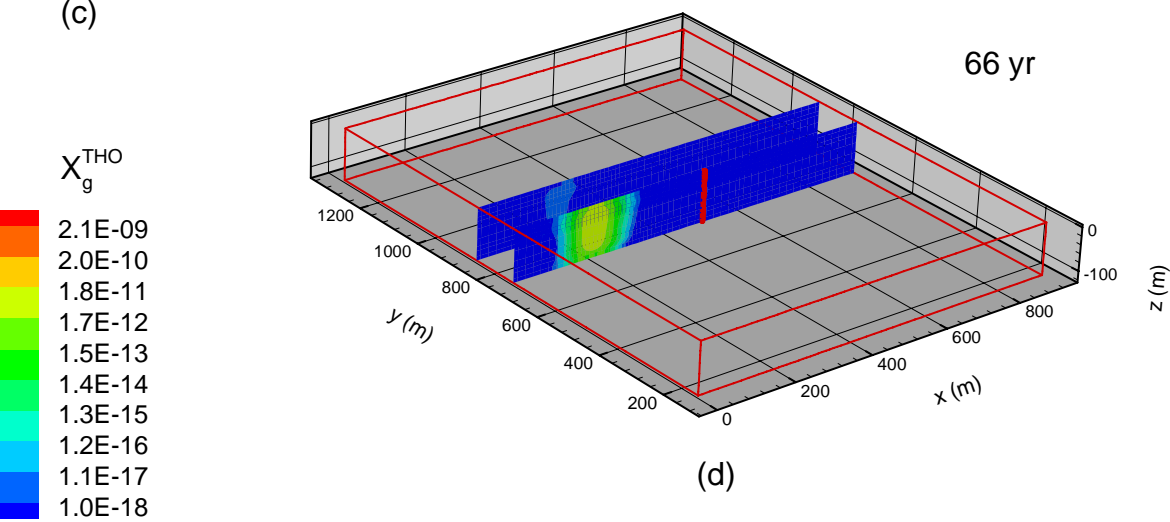

(d)

Figure 32. Mass fraction of tritium in the gas phase ( $X_{g}{ }^{T H O}$ ) after (a) $34 \mathrm{yr}$, (b) $45 \mathrm{yr}$, (c) $55 \mathrm{yr}$, (d) $66 \mathrm{yr}$, (e) $100 \mathrm{yr}$, (f) $150 \mathrm{yr}$, (g) $250 \mathrm{yr}$, and (h) $500 \mathrm{yr}$ for the conditions similar to the "reference" simulation but with a 25 percent higher rate of gas production. 


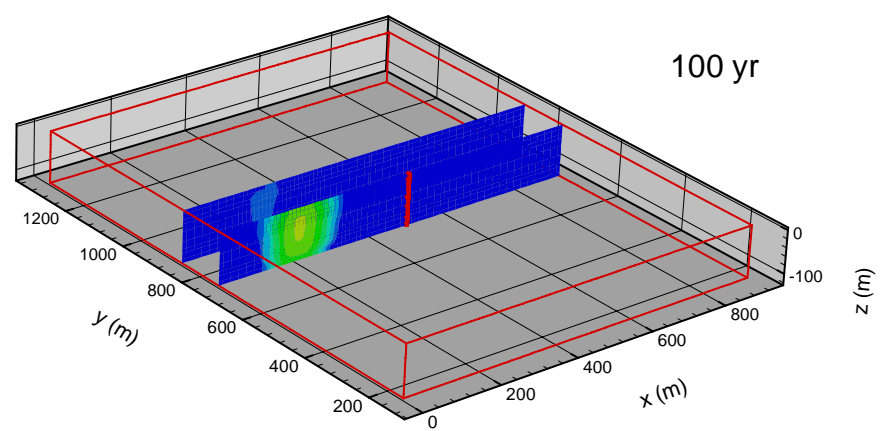

(e)
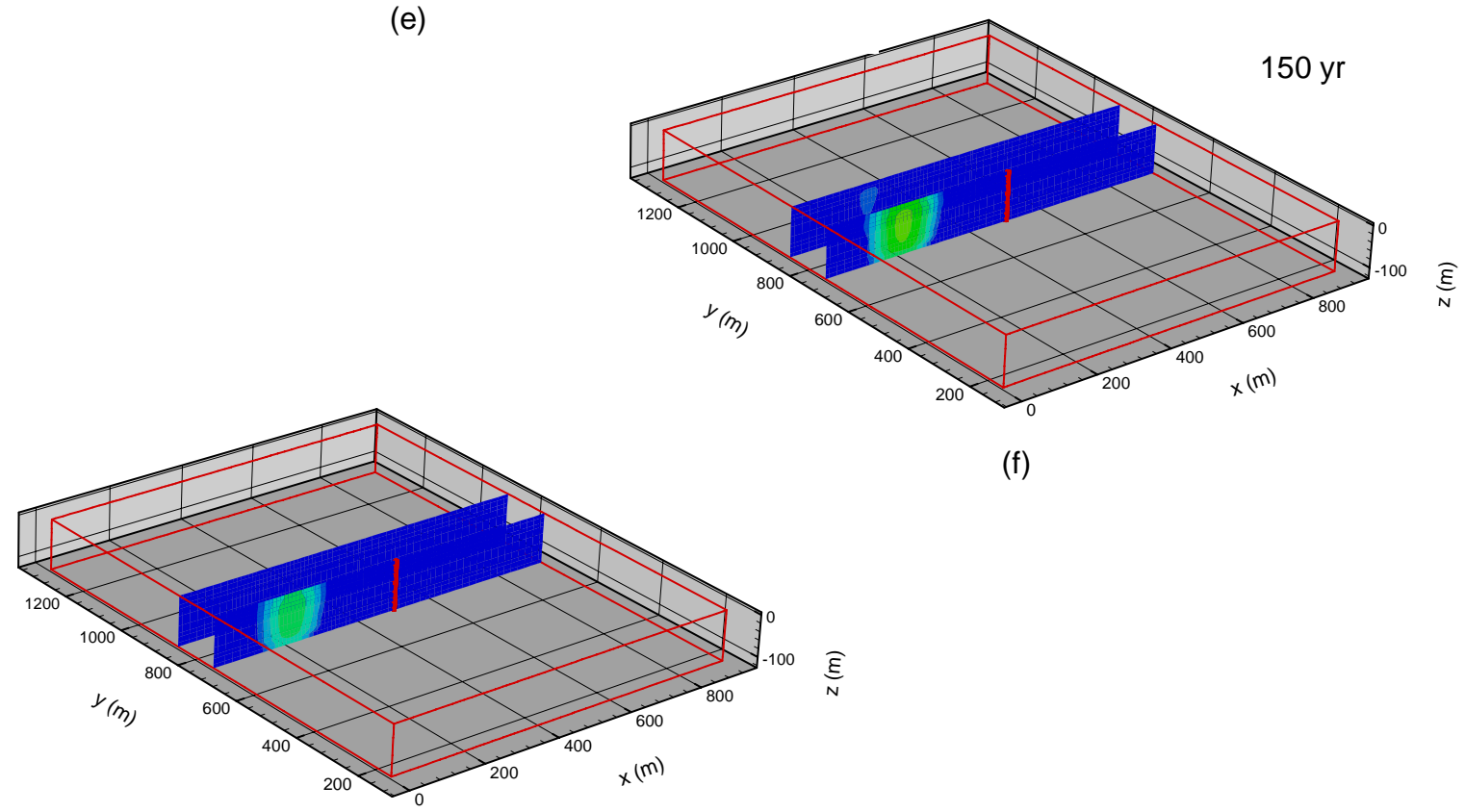

(g)
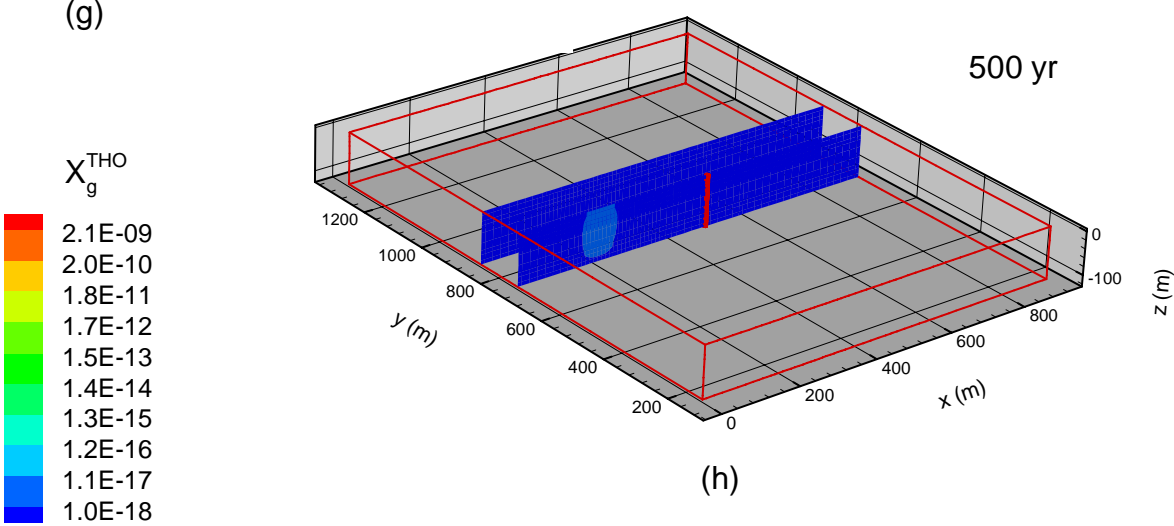

(h)

Figure 32. Mass fraction of tritium in the gas phase ( $X_{g}{ }^{T H O}$ ) after (a) $34 \mathrm{yr}$, (b) $45 \mathrm{yr}$, (c) $55 \mathrm{yr}$, (d) $66 \mathrm{yr}$, (e) $100 \mathrm{yr}$, (f) $150 \mathrm{yr}$, (g) $250 \mathrm{yr}$, and (h) $500 \mathrm{yr}$ for the conditions similar to the "reference" simulation but with a 25 percent higher rate of gas production (continued). 


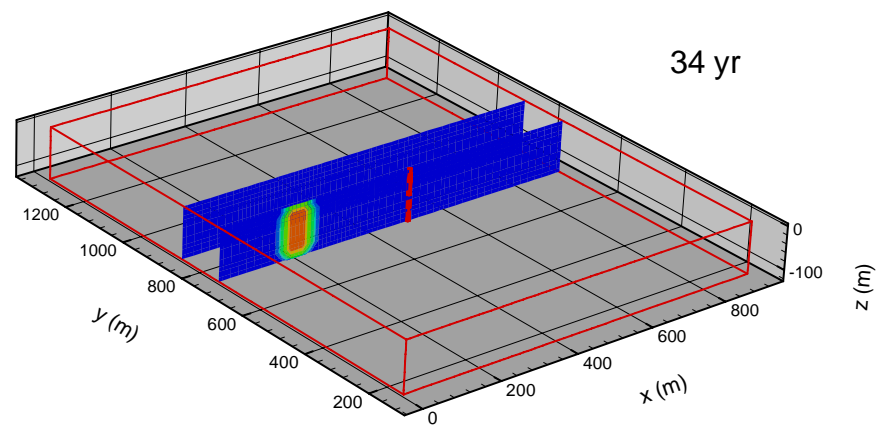

(a)
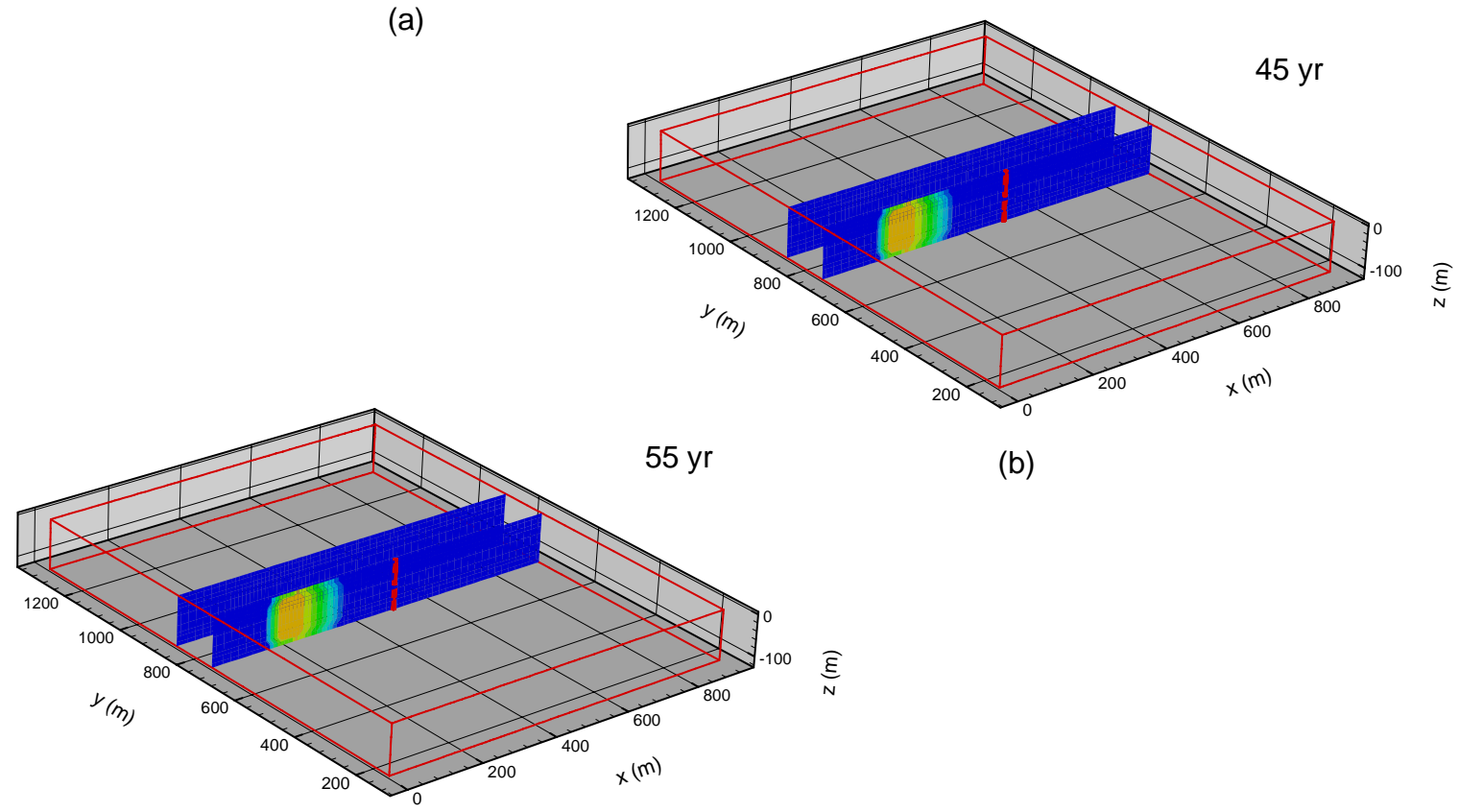

(c)
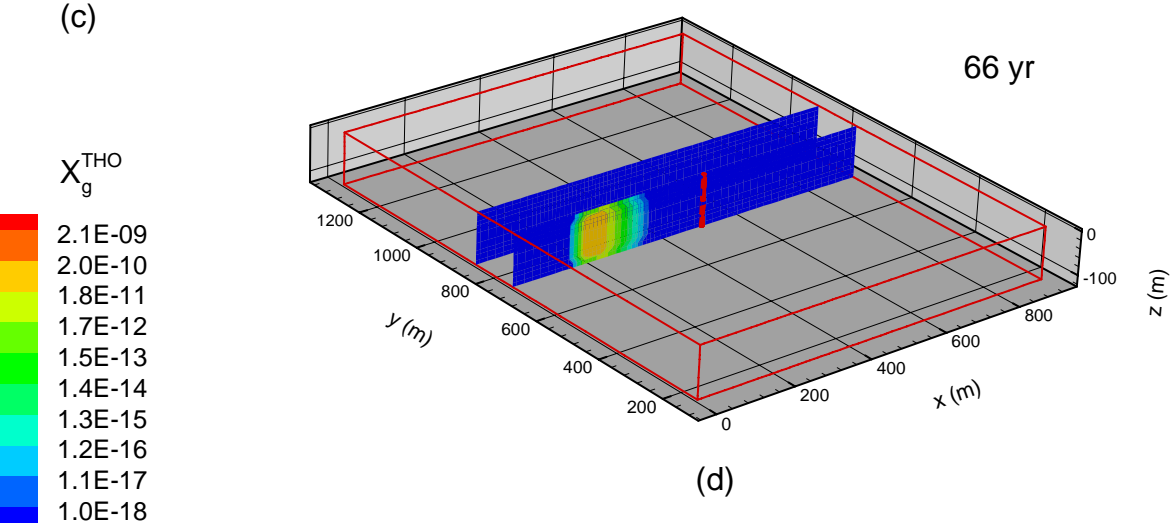

(d)

Figure 33. Mass fraction of tritium in the gas phase ( $X_{g}{ }^{T H O}$ ) after (a) $34 \mathrm{yr}$, (b) $45 \mathrm{yr}$, (c) $55 \mathrm{yr}$, (d) $66 \mathrm{yr}$, (e) $100 \mathrm{yr}$, (f) $150 \mathrm{yr}$, (g) $250 \mathrm{yr}$, and (h) $500 \mathrm{yr}$ for simulations with the initial gas saturation as 0.6 . 


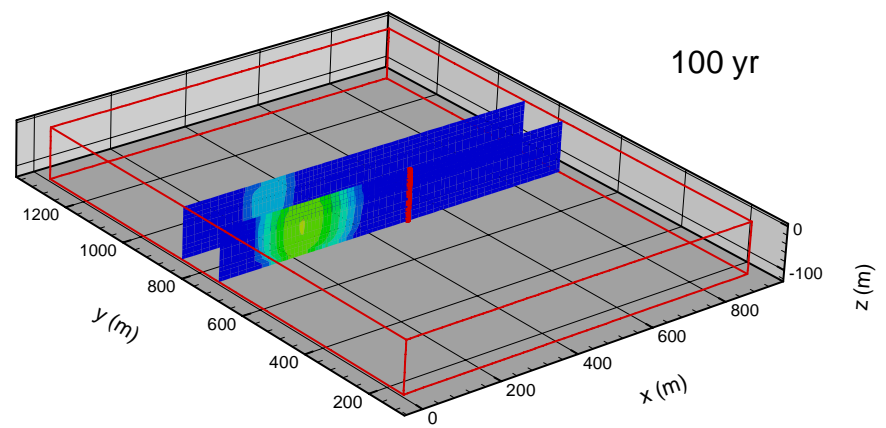

(e)
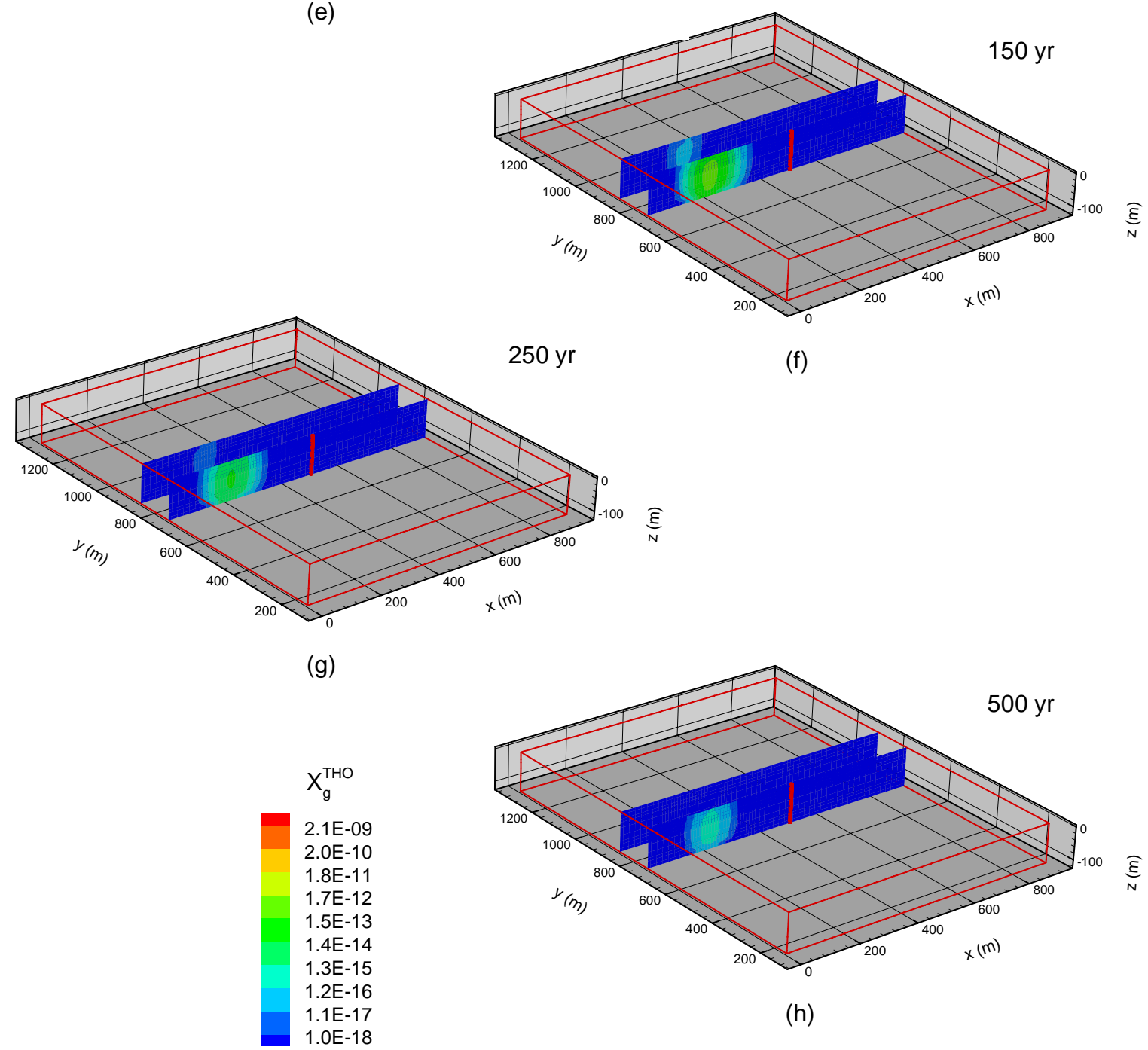

(h)

Figure 33. Mass fraction of tritium in the gas phase ( $X_{g}{ }^{T H O}$ ) after (a) $34 \mathrm{yr}$, (b) $45 \mathrm{yr}$, (c) $55 \mathrm{yr}$, (d) $66 \mathrm{yr}$, (e) $100 \mathrm{yr}$, (f) $150 \mathrm{yr},(\mathrm{g}) 250 \mathrm{yr}$, and (h) $500 \mathrm{yr}$ for simulations with the initial gas saturation as 0.6. (continued). 


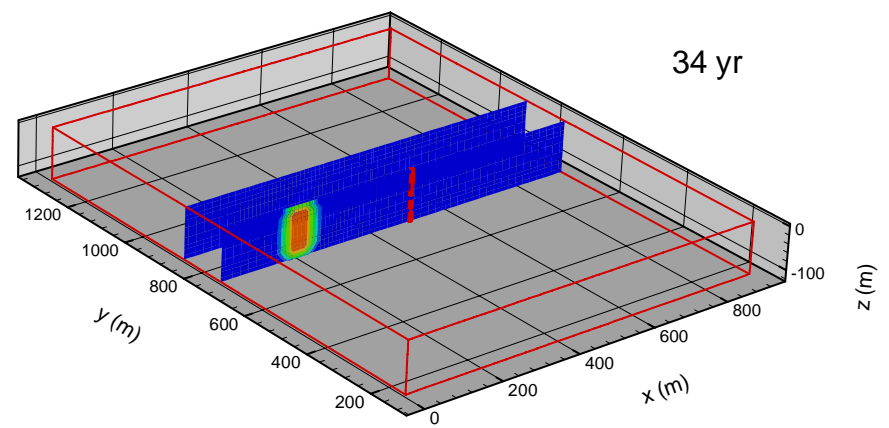

(a)
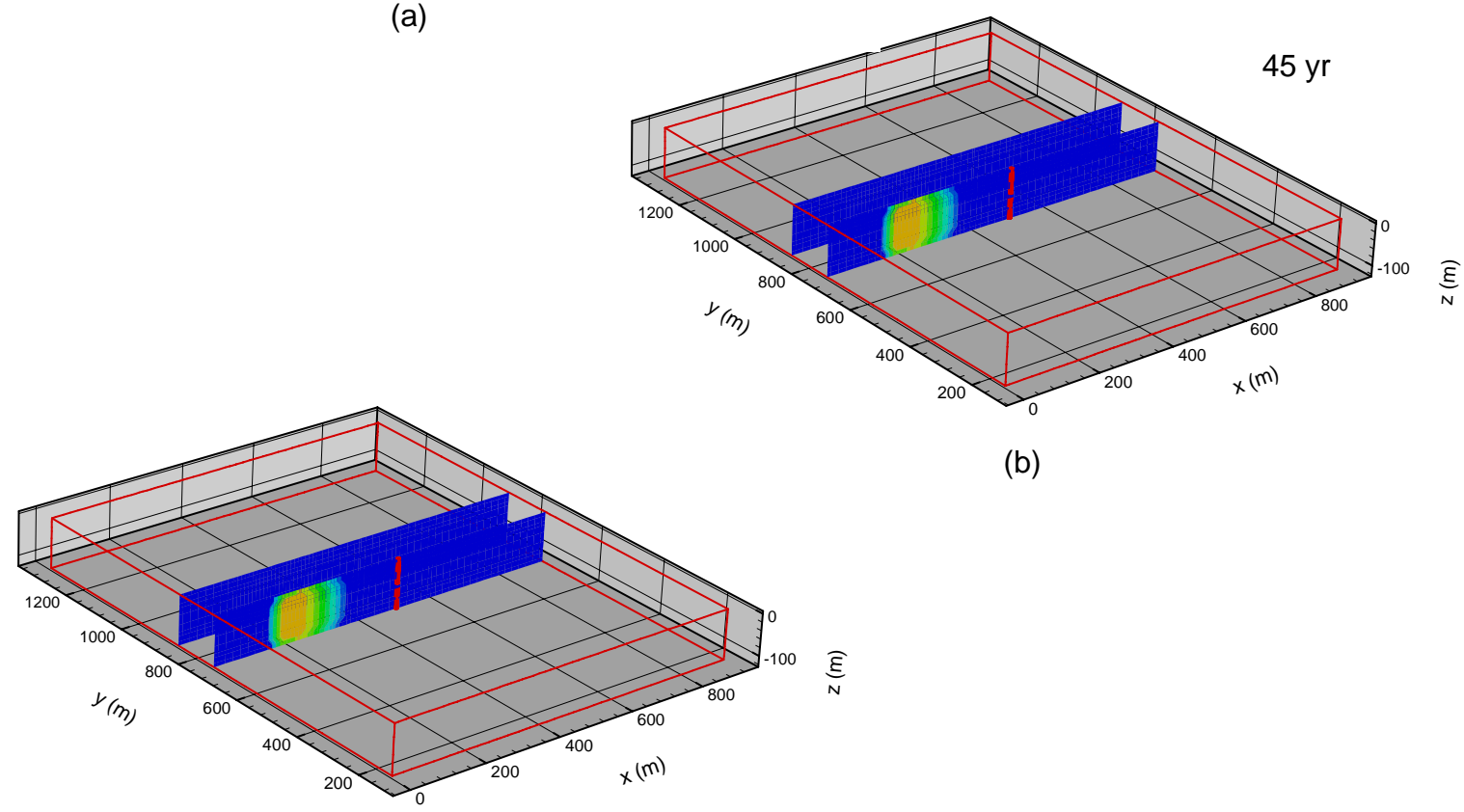

(b)

(c)
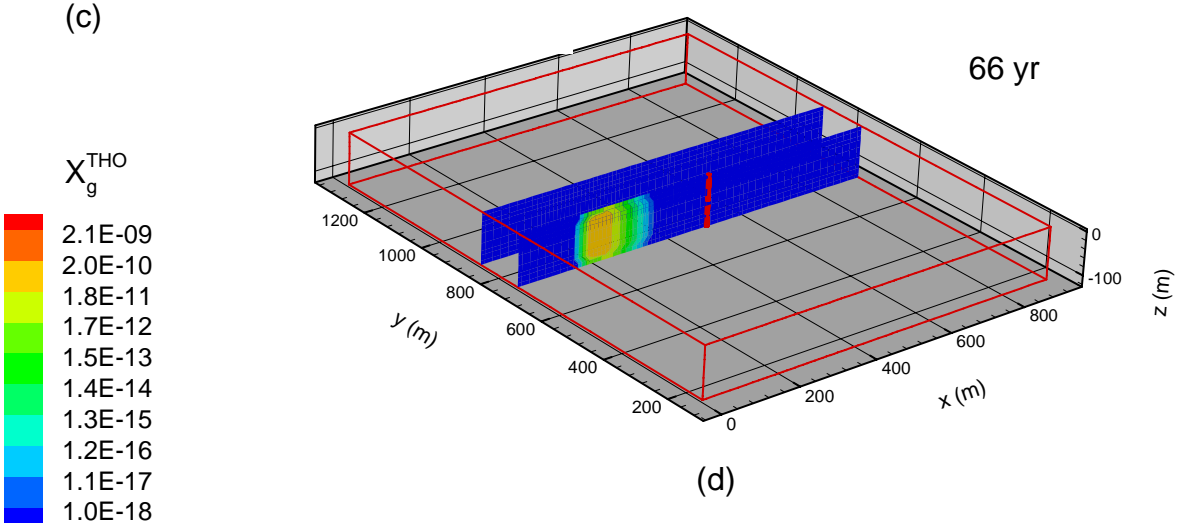

(d)

Figure 34. Mass fraction of tritium in the gas phase ( $X_{g}{ }^{T H O}$ ) after (a) $34 \mathrm{yr}$, (b) $45 \mathrm{yr}$, (c) $55 \mathrm{yr}$, (d) $66 \mathrm{yr}$, (e) $100 \mathrm{yr}$, (f) $150 \mathrm{yr}$, (g) $250 \mathrm{yr}$, and (h) $500 \mathrm{yr}$ for simulations with the initial gas saturation as 0.2 . 


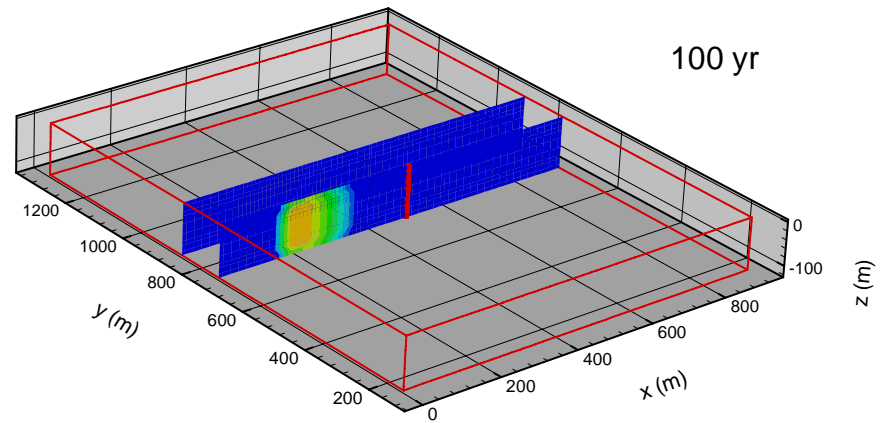

(e)
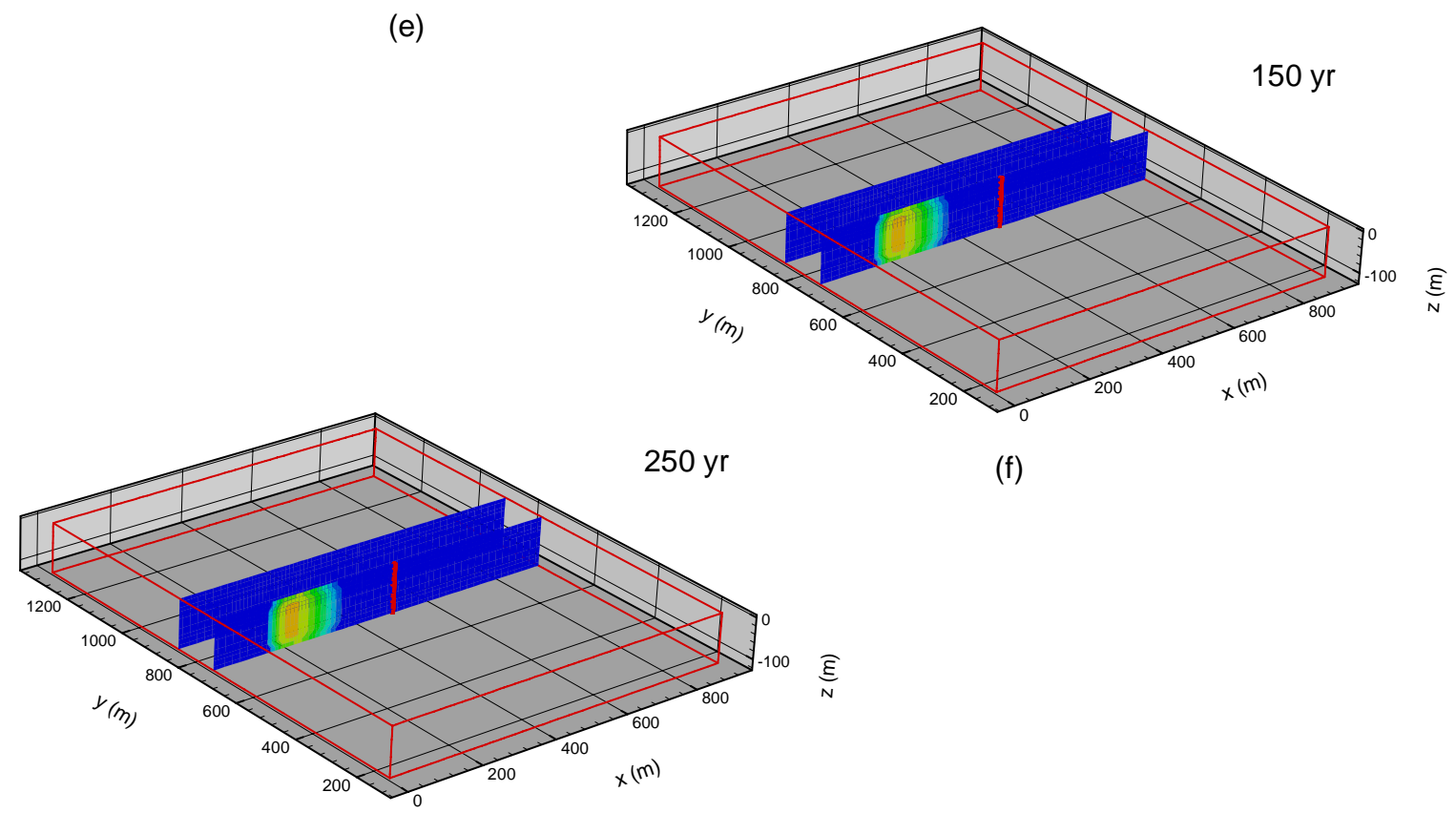

(g)
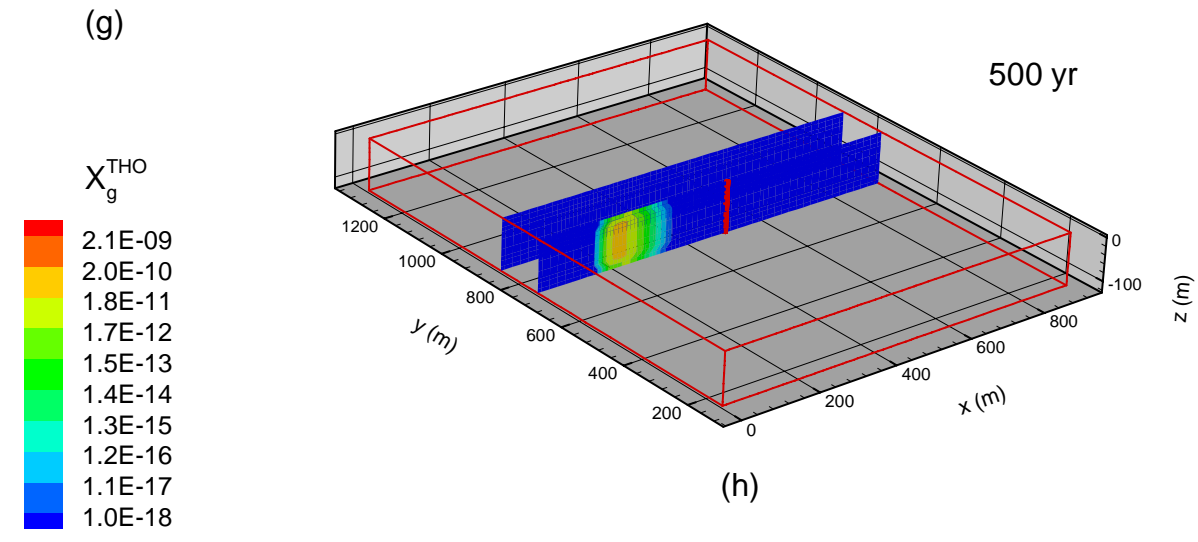

(h)

Figure 34. Mass fraction of tritium in the gas phase $\left(X_{g}{ }^{T H O}\right.$ ) after (a) $34 \mathrm{yr}$, (b) $45 \mathrm{yr}$, (c) $55 \mathrm{yr}$, (d) $66 \mathrm{yr}$, (e) $100 \mathrm{yr}$, (f) $150 \mathrm{yr}$, (g) $250 \mathrm{yr}$, and (h) $500 \mathrm{yr}$ for simulations with the initial gas saturation as 0.2 . (continued). 
Finally, Figures $35 \mathrm{a}$ through $35 \mathrm{x}$ show the results when a relative permeability based tortuosity model is implemented (Equation [5]). The figures are arranged such that the left-

hand column shows $X_{g}{ }^{T H O}$ while the right-hand side shows $X_{l}^{T H O}$ for the same times. The figures show the same times as in the previous figures, that is, (a through h): 1 month, $1 \mathrm{yr}$, $10 \mathrm{yr}, 20 \mathrm{yr}$; (i through p): $34 \mathrm{yr}, 45 \mathrm{yr}, 55 \mathrm{yr}, 66 \mathrm{yr}$; (q through x): $100 \mathrm{yr}, 150 \mathrm{yr}, 250 \mathrm{yr}$, and $500 \mathrm{yr}$ after detonation. There is little change in the mass fraction fields for tritium in either phase prior to the initiation of gas production from the well (Figures 35a through 35h); however, the relative permeability model enhances transport in both phases once gas production has been initiated. This is seen at $45 \mathrm{yr}$ ( $10 \mathrm{yr}$ after the start of production) where tritium in both phases has diffused laterally (in the $y$-direction) beyond the $120-\mathrm{m}$ parallel slice located at $y=860 \mathrm{~m}$. Between 66 and $100 \mathrm{yr}$, the edge of the tritium field has come to within $50 \mathrm{~m}$ of the production well. Beyond that time (Figures $35 \mathrm{j}$ through 351 ) the $X_{g}{ }^{T H O}$ has broken up. This may be due to either the tortuosity model breaking down at high relative permeabilities (tortuosity changes logarithmically in the relative $k$ model as opposed to arithmetically in the Millington-Quirk model), or due to numerical dispersion at such low mass fractions. In the liquid phase, the $X_{l}^{T H O}$ field is more uniform and never extends to within $100 \mathrm{~m}$ of the production well.

\section{OUTLINE OF MONTE CARLO SIMULATIONS}

Monte Carlo simulations are conducted in the following three steps to assess uncertainty of tritium transport in the Rio Blanco gas reservoir:

(1) Distributions of random variables are identified based on site parameter measurements (assuming that they are representative) and numerous equally likely realizations of the random variables are generated. Johnson transformations (Johnson, 1987; Carsel and Parrish, 1988) and Lilliefors tests are used to identify the distributions of random permeability and porosity; Latin Hypercube Sampling (LHS) (McKay et al., 1979) method is used to generate 500 realizations of the two random variables. Other model parameters are treated deterministically, since their measurements are too sparse and their uncertainty cannot be addressed properly.

(2) Numerical simulations of tritium transport are conducted for each random realization. Except for the values of random permeability and porosity, other model parameters are adopted from the reference Type 2 simulations.

(3) Statistics of variables of interest (i.e., mass fraction of tritium in liquid and gas phases) are evaluated and uncertainty quantified using these statistics.

\section{Identification of the Distributions of Permeability and Porosity}

Carsel and Parrish (1988) applied three Johnson transformations (Johnson, 1987) to soil hydraulic parameters of 12 different soil textural classes and employed the KolmogorovSmirnov test to select the best transform that renders the transformed data Gaussian or nearly Gaussian. Although they referred to the statistical test as the Kolmogorov-Smirnov test, it is actually the Lilliefors test, since mean and variance are determined from the data, not specified a priori (i.e., the tested distributions are not completely specified [Bowen and Bennett, 1988]). In this project, the three Carsel and Parrish transforms are applied to the site 
measurements of permeability and porosity; the Lilliefors test is then applied to the transformed and original data sets to select the best transform.

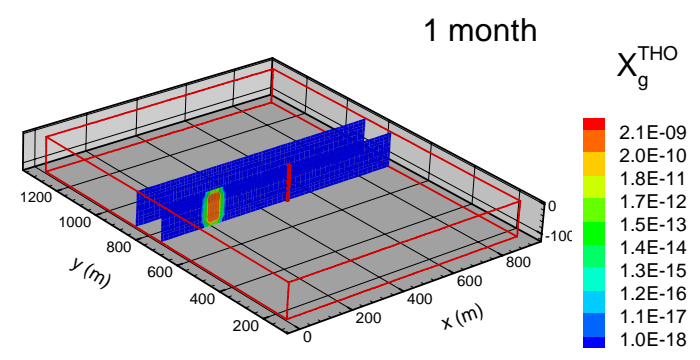

(a)

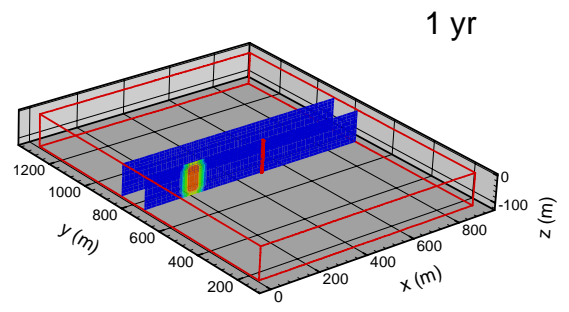

(b)

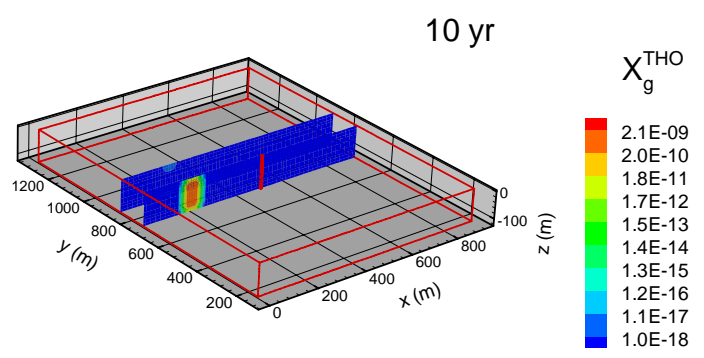

(c)

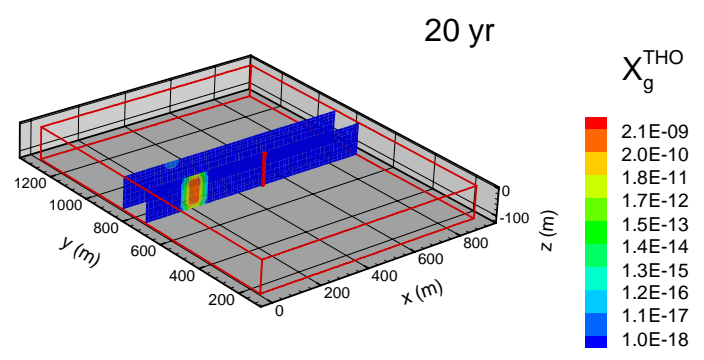

(d)

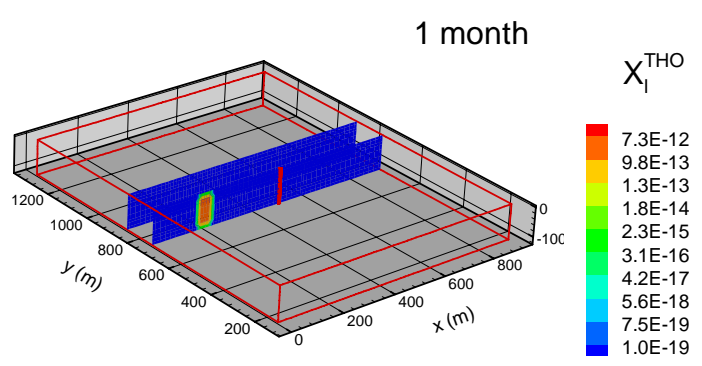

(e)

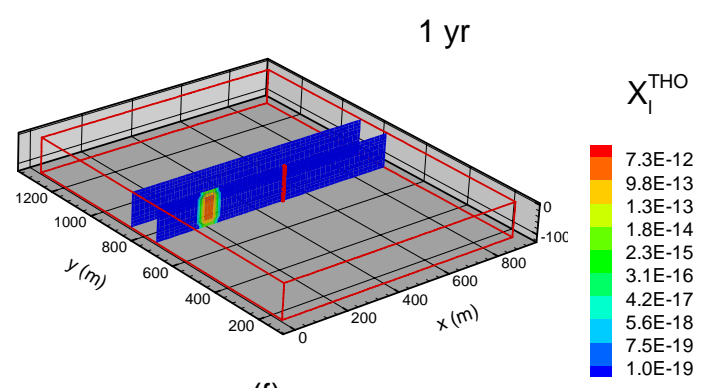

(f)

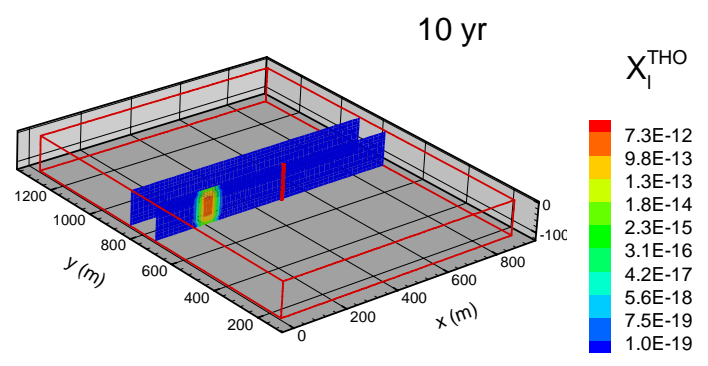

(g)

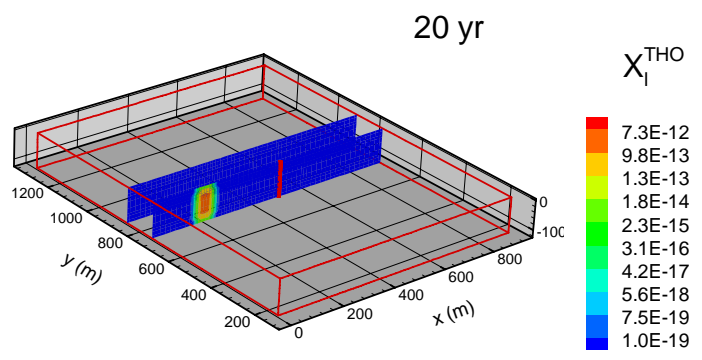

(h)

Figure 35. Mass fraction tritium in the gas phase $\left(X_{g}^{T H O}\right.$, left-hand column, a-d) and mass fraction tritium in the liquid phase $\left(X_{l}^{T H O}\right.$, right-hand column, e-h) for simulation with conditions similar to the "reference" model except that tortuosity has been changed from a Millington-Quirk saturation-based model to a relative permeability based model. 
$34 \mathrm{yr}$

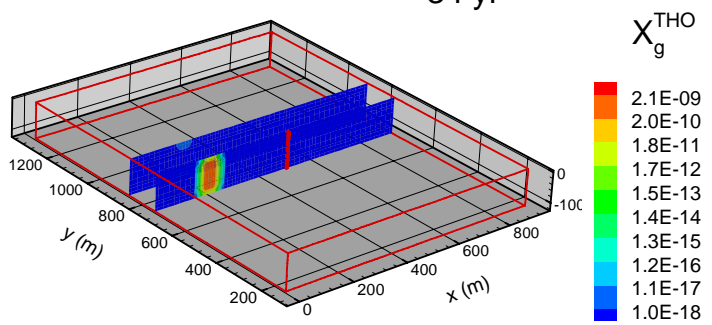

(i)

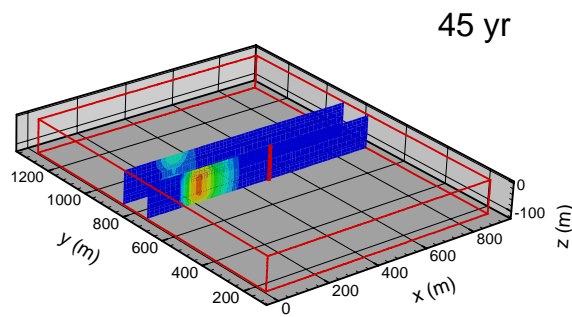

(j)

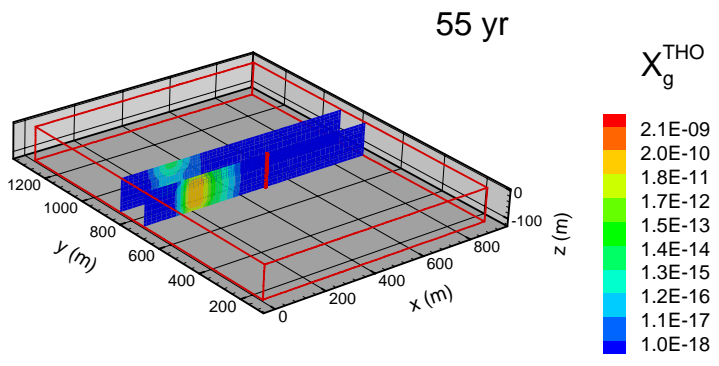

$(\mathrm{k})$

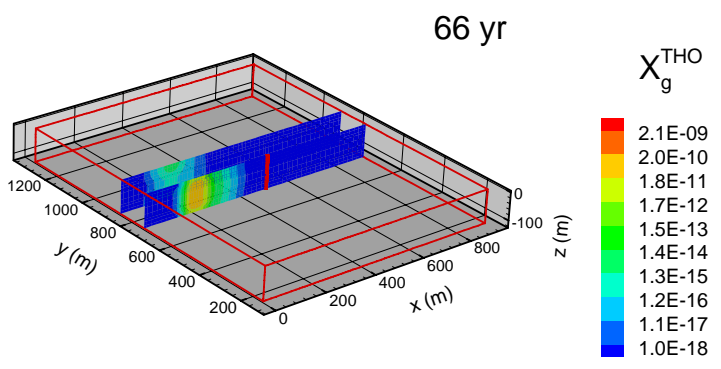

(l)

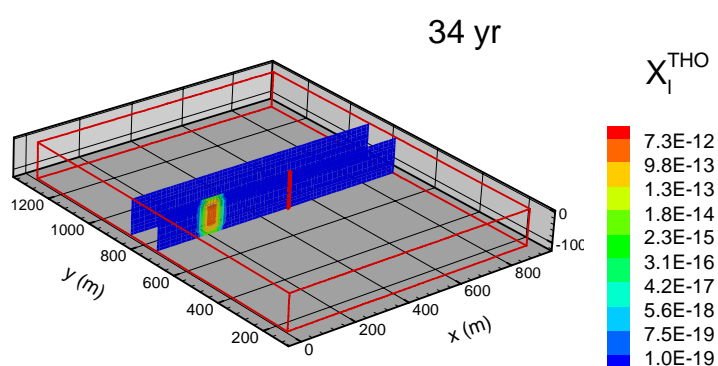

(m)

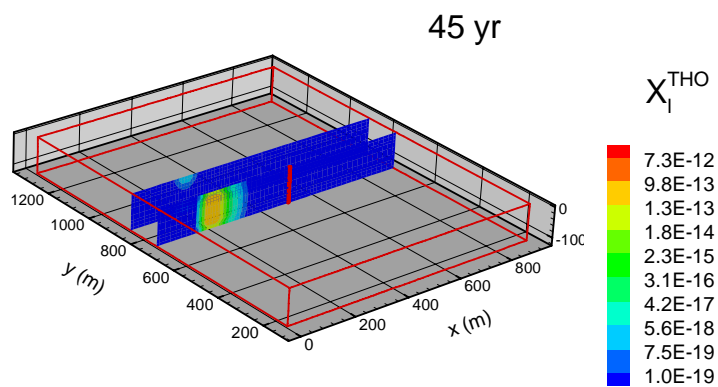

(n)

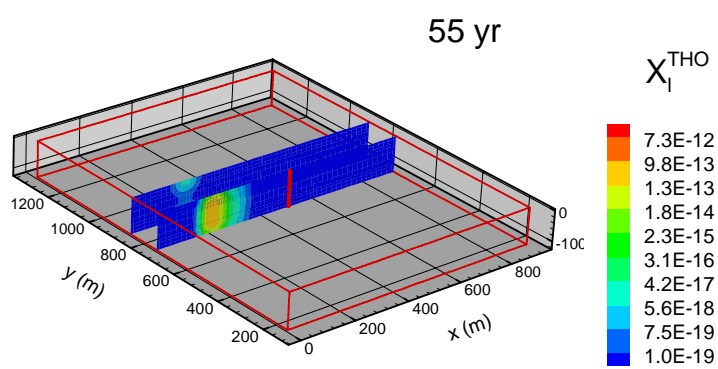

(o)

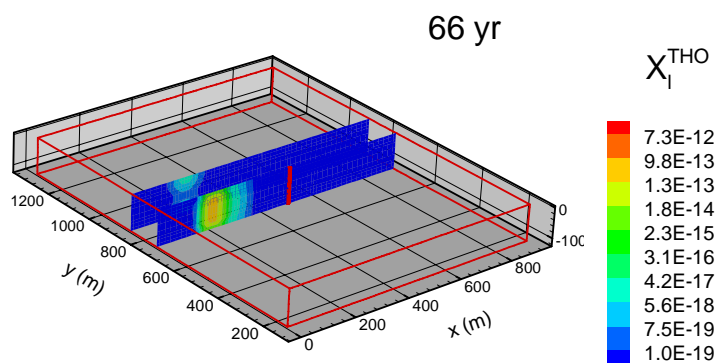

(p)

Figure 35. Mass fraction tritium in the gas phase ( $X_{g}^{T H O}$, left-hand column, i-1) and mass fraction tritium in the liquid phase ( $X_{l}^{T H O}$, right-hand column, m-p) for simulation with conditions similar to the "reference" model except that tortuosity has been changed from aMillington-Quirk saturation-based model to a relative permeability based model (continued). 


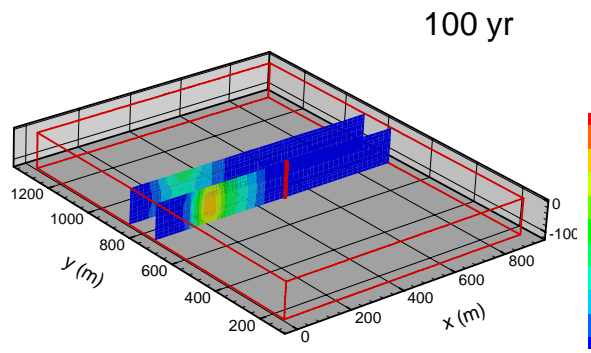

(q)

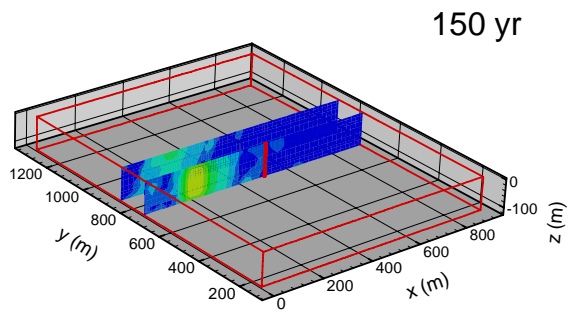

$(r)$

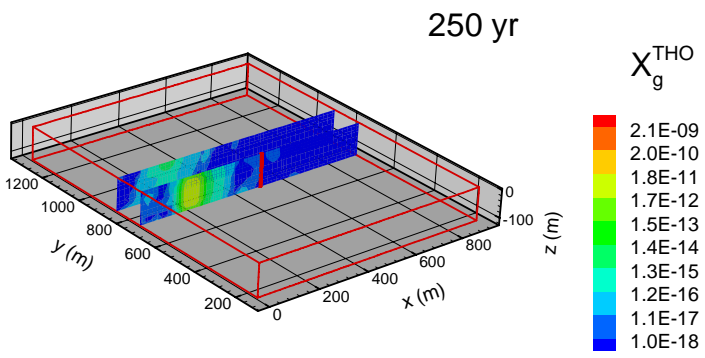

(s)

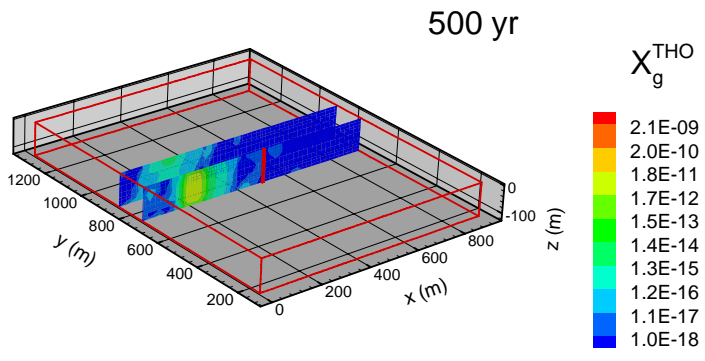

$(\mathrm{t})$

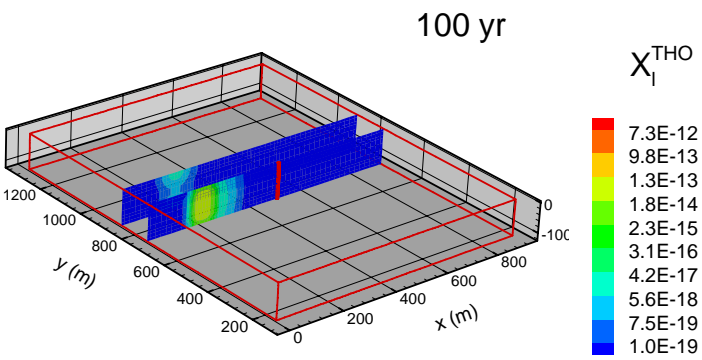

(u)

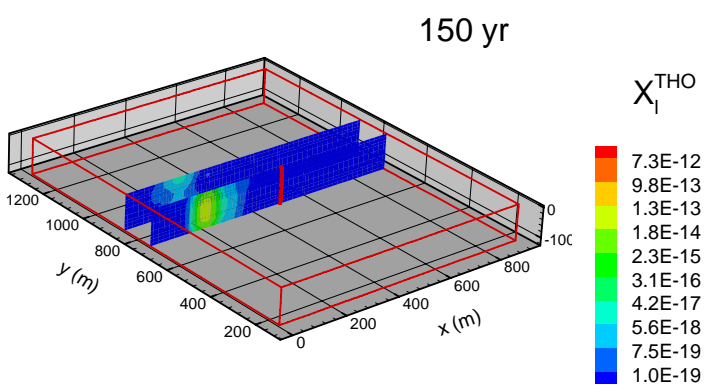

(v)

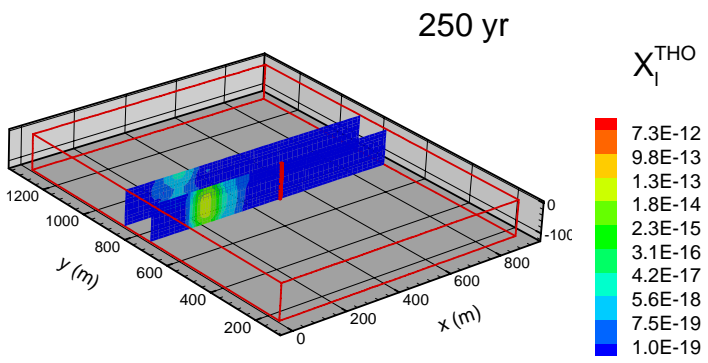

(w)

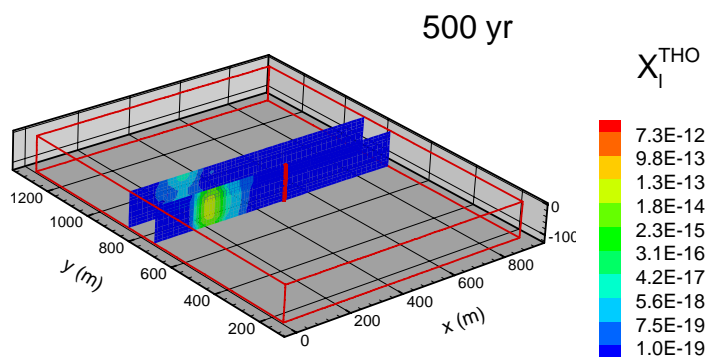

$(\mathrm{x})$

Figure 35. Mass fraction tritium in the gas phase $\left(X_{g}^{T H O}\right.$, left-hand column, $\left.\mathrm{q}-\mathrm{t}\right)$ and mass fraction tritium in the liquid phase $\left(X_{l}^{T H O}\right.$, right-hand column, $\left.\mathrm{u}-\mathrm{x}\right)$ for simulation with conditions similar to the "reference" model except that tortuosity has been changed from a Millington-Quirk saturation-based model to a relative permeability based model (continued). 
The three distribution types of transforms were lognormal (LN), log ratio (SB), and hyperbolic arcsine (SU) (Johnson, 1987)

$$
\begin{gathered}
\text { LN: } Y=\ln (X) \\
\text { SB: } Y=\ln [(X-A) /(B-X)] \\
\text { SU: } Y=\sinh ^{-1}(U)=\ln \left(U+\sqrt{1+U^{2}}\right)
\end{gathered}
$$

where $X$ is the untransformed variable with limits of variation from $A$ to $B(A<X<\mathrm{B})$ and $U=(X-A) /(B-X)$. Denoting the original data as NO, yields four data sets: NO, LN, SB, and SU.

The Lilliefors test for normality, a variant of the Kolmogorov-Smirnov test, is used to test goodness-of-fit of a set of observations to a normal distribution with mean and variance estimated from the data set (not specified a priori as the Kolmogorov-Smirnov test does). The steps of the Lilliefors test are as follows:

(1) Normalize a data set with mean and standard deviation estimated from the data

$$
z_{i}=\frac{x_{i}-\bar{x}}{s}(i=1,2, \ldots, N)
$$

where $z_{i}$ and $x_{i}$ are normalized and original data, respectively; $\bar{x}$ and $s$ are sample mean and standard deviation of $X$, respectively; and $N$ is the number of the data, which was at least 4 for the Lilliefors test.

(2) Calculate the empirical cumulative distribution function (CDF), $G(z)$, of $z$ and the standard normal $\mathrm{CDF}, F^{*}(z)$;

(3) Evaluate the maximum absolute difference $\left(T^{*}\right)$ of $F^{*}(z)$ and $G(z)$

$$
T^{*}=\max \left|F^{*}\left(z_{i}\right)-G\left(z_{i}\right)\right|, \quad i=1,2, \ldots n
$$

(4) Select a level of significance $\alpha$ to obtain the Lilliefors test statistic $T$ from Bowen and Bennett (1988). If $T^{*}$ exceeds $T$, the hypothesis of normality is rejected at the significance level of $\alpha$.

Measurements of permeability and porosity of the Fort Union Formation were obtained from three sources: core analysis of the RB-MHF-3 borehole, core analysis of the RB-E-O1 borehole, and Saraband log of the RB-AR-2 borehole. Hereinafter, the measurements of cores from the two boreholes are referred to as Core data, while those from Saraband $\log$ are referred to as Log data. In general, the Core and Log data reflect small- and large-scale parameter variability, respectively. Statistical analysis of permeability measurements is discussed in the section on Rock Properties. Two hundred ninety-one Core and 417 Log data are available for porosity and their descriptive statistics are listed in Table 8. Figure 36 plots the histograms of the Core and Log data of $\log _{10}$ permeability of the Fort Union Formation, and a normal distribution is fitted to the histogram using the statistical software MINITAB (the $\log _{10}$ permeability is superior to permeability for the sake of presentation). Figure 37 plots the histograms of the Core and Log data of porosity (\%). Figure 36 indicates the scaling effect in the permeability of Core and Log measurements: large-scale Log data have a larger mean and smaller variance than the small-scale Core data. 
Since the Core data span wider than Log data and the Log data are considered less accurate than the Core data due to the limits of the method used to obtain the measurements in the early 1970s, Core data were thus used to identify the distributions of permeability and porosity.

Table 8. Descriptive statistics of porosity measurements of the Fort Union Formation obtained from core analysis (Core) and Saraband $\log (\mathrm{Log})$.

\begin{tabular}{ccccccccc}
\hline $\begin{array}{c}\text { Data } \\
\text { Source }\end{array}$ & $\mathrm{N}$ & Mean & $\begin{array}{c}\text { Standard } \\
\text { Deviation }\end{array}$ & Min & Q25 & Median & Q75 & Max \\
\hline Core & 291 & 7.608 & 2.626 & 0.2 & 6.2 & 8.0 & 9.1 & 13.5 \\
Log & 417 & 5.858 & 2.674 & 0.1 & 3.6 & 6.0 & 8.1 & 13.0 \\
\hline
\end{tabular}

After applying LN, SB, and SU transforms to the Core data, a Lilliefors test was conducted for the three transformed data sets and the original data. Their empirical CDFs are compared to CDFs of normal distribution in Figure 38 for permeability and Figure 39 for porosity. The corresponding maximum differences, $T^{*}$, of the four data sets are listed in Table 9 , which also lists $T$ value of $0.05,0.10$, and 0.15 significance levels obtained from Bowen and Bennett (1988). Comparing $T^{*}$ and $T$ showed that LN- and SB-transformed permeability data passed Lilliefors test at the significance level $\alpha=0.05$ and $\alpha=0.10$, respectively. Accordingly, permeability of SB transform was used to generate random fields of permeability. For porosity, results of the Lilliefors test in Table 9 suggest that the original data without any transform (NO) are the closest to a normal distribution. Although it was likely that the data followed other distributions, Figure 39a shows that the deviation of the empirical and theoretical CDF is not significant and the normal distribution can be used to generate random fields of porosity.

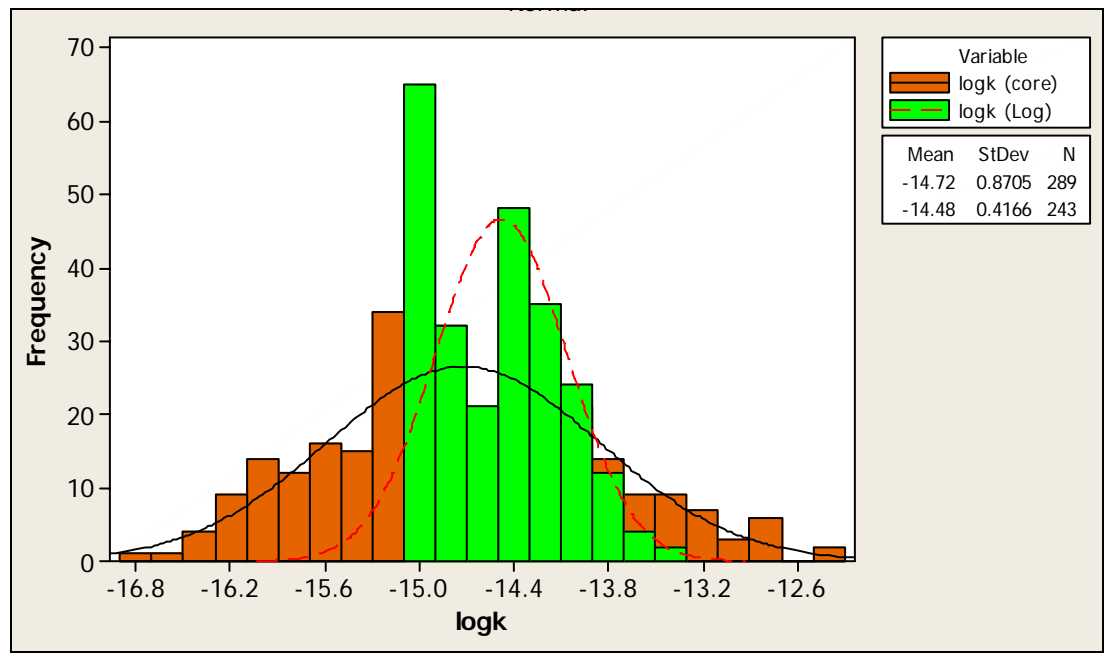

Figure 36. Histograms of Core and $\log$ data of $\log _{10}$ permeability of the Fort Union Formation. Normal distribution is fitted to the histogram. 


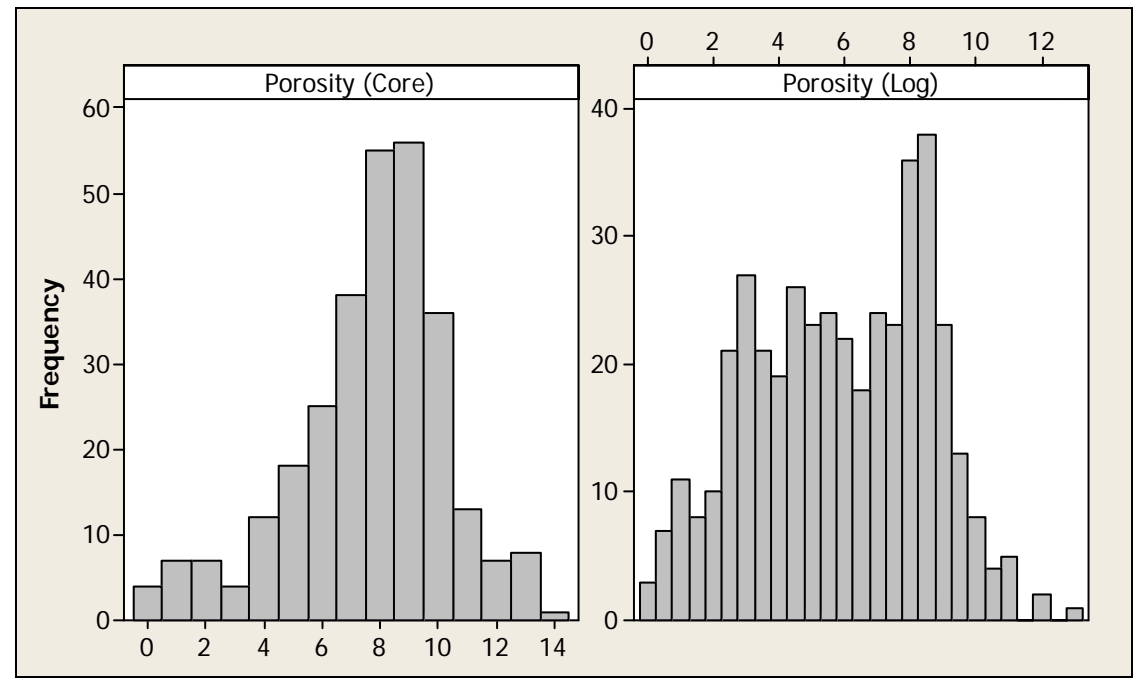

Figure 37. Histograms of Core and Log data of porosity (\%) of the Fort Union Formation.
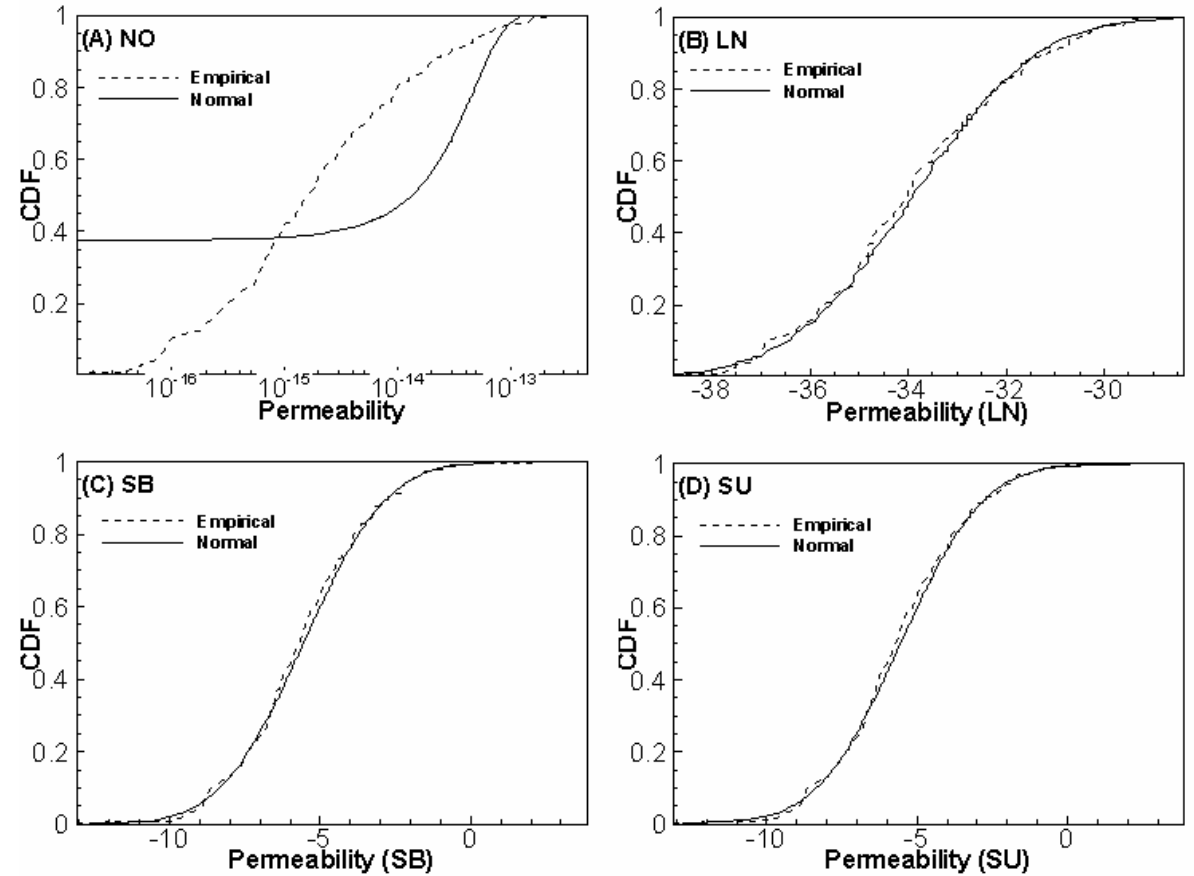

Figure 38. Empirical cumulative distribution function (CDF) of (a) permeability of Fort Union Formation obtained from core analysis and its (b) LN, (c) SB, and (d) SU transforms. 
Table 9. Lilliefors statistics of the original and transformed permeability and porosity of the Fort Union Formation. NO, LN, SB, and SU denote the original data and the three Johnson transformations ( $\dagger$ denotes selected transformations for permeability and porosity).

\begin{tabular}{ccc}
\hline Transform & $\mathrm{T}^{*}$ (permeability) & $\mathrm{T}^{*}$ (porosity) \\
\hline NO & 0.375 & $0.106^{\dagger}$ \\
LN & 0.0500 & 0.218 \\
SB & $0.0464^{\dagger}$ & 0.165 \\
SU & 0.370 & 0.122 \\
$\mathrm{~T}(\alpha=0.05)$ & 0.0521 & 0.0519 \\
$\mathrm{~T}(\alpha=0.10)$ & 0.0474 & 0.0472 \\
$\mathrm{~T}(\alpha=0.15)$ & 0.0452 & 0.0450 \\
\hline
\end{tabular}
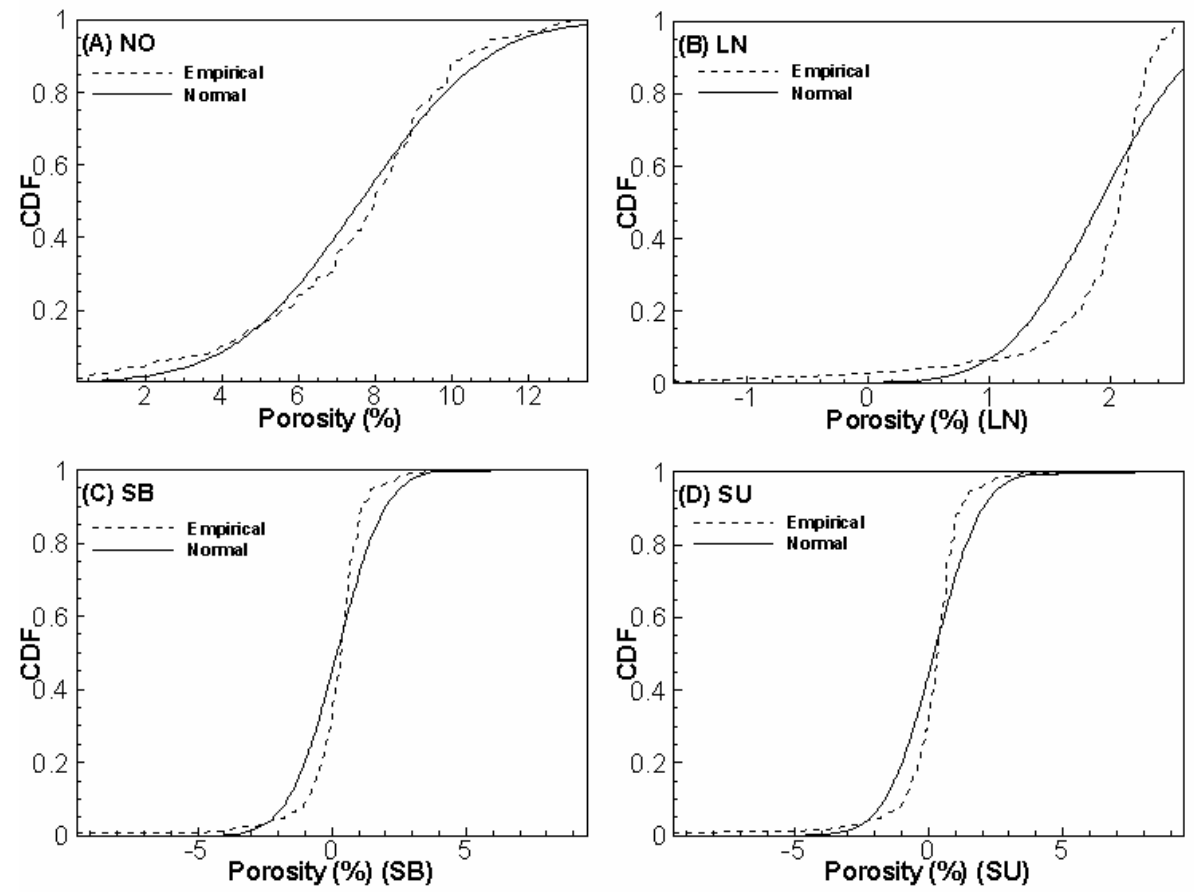

Figure 39. Empirical cumulative distribution function (CDF) of (a) porosity of the Fort Union Formation obtained from core analysis and its (b) LN, (c) SB, and (d) SU transforms.

\section{Random Field Generation}

Figure 40 exhibits the positive correlation between the SB-transformed permeability and porosity. Correlated random fields of permeability and porosity are generated in this project using the Latin Hypercube Sampling (LHS) method (Mckay et al., 1979) and the correlation is measured by the Spearman rank correlation. 


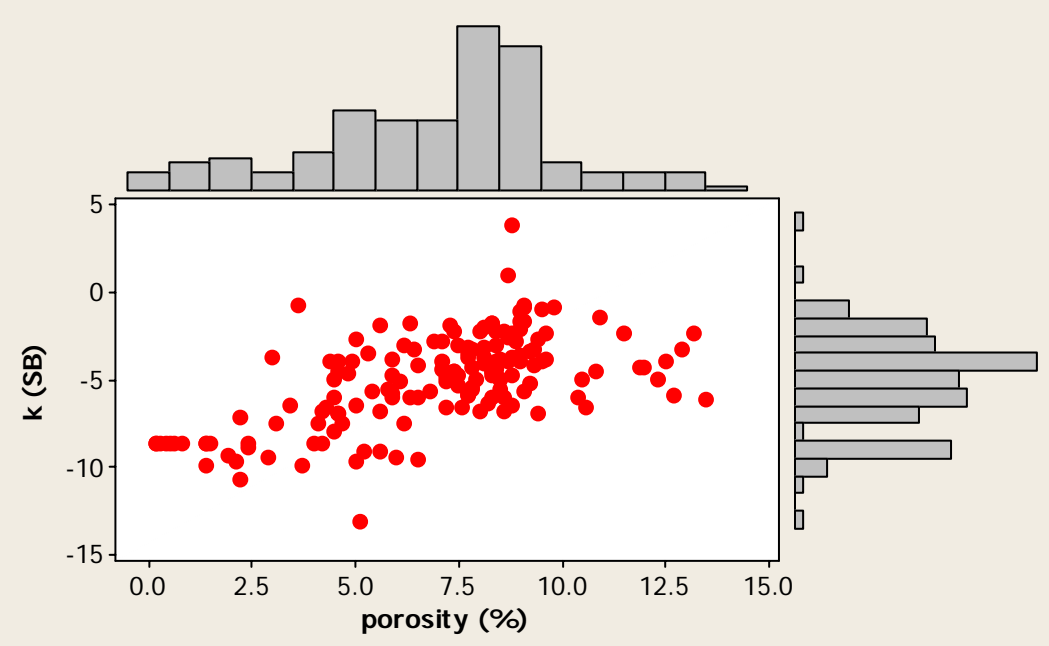

Figure 40. Correlation between SB transformed permeability and porosity of the Fort Union Formation.

Latin Hypercube Sampling is an efficient sampling method and its sampling processes of uncorrelated random variables are as follows (Helton and Davis, 2000):

(1) Divide the range of each variable into $n$ intervals with equal probability;

(2) Select one value from each interval randomly;

(3) Pair the obtained $n$ values for the first variable with the $n$ values of the second variable randomly; and

(4) Combine these $n$ pairs randomly with the $n$ values of the third variable to form $n$ triplets and continue pairing until the last variable is combined with others.

The correlations between random variables were incorporated into the sampling process using the method of Iman and Conover (1982), who introduced a restricted pairing method based on a desired rank correlation matrix to generate samples with correlations among the variables. In other words, the generated original values were retained and only the pairing was affected by the desired rank correlation. The Spearman rank correlation, $r$, was used as the desired rank correlation in this study, and is estimated by

$$
r=1-6 \sum_{i=1}^{N} \frac{d_{i}^{2}}{N\left(N^{2}-1\right)}
$$

where $d_{i}$ is the difference in statistical rank of the corresponding variables and $N$ is the sample size. The Spearman rank correlation of the SB-transformed permeability and porosity (Figure 40) is 0.57 . The LHS code of Iuzzolino (2003) is used in the project.

When generating the random fields of permeability, normally distributed random numbers were first generated using the mean and variance obtained from the SB-transformed permeability. These numbers were then inverted back to the original scale by (Carsel and Parrish, 1988) 


$$
X=[B \exp (Y)+A] /[1+\exp (Y)]
$$

where $X$ and $Y$ were the original and SB transformed data. The LHS code of Iuzzolino (2003) used 1 and 99 percentiles of the random variable, instead of mean and variance to generate a normal distribution. These two percentiles can be calculated according to the mean $(\mu)$ and the standard deviation $(\sigma)$ of the normal distribution by (Swiler and Wyss, 2004)

$$
V_{0.01}=\mu-2.326 \sigma ; V_{0.95}=\mu+2.326 \sigma
$$

Figure 41 plots the CDFs of the measured and generated permeability and porosity values (log permeability is plotted for better presentation). It shows that the distributions of generated parameters agree well with those of measurements.
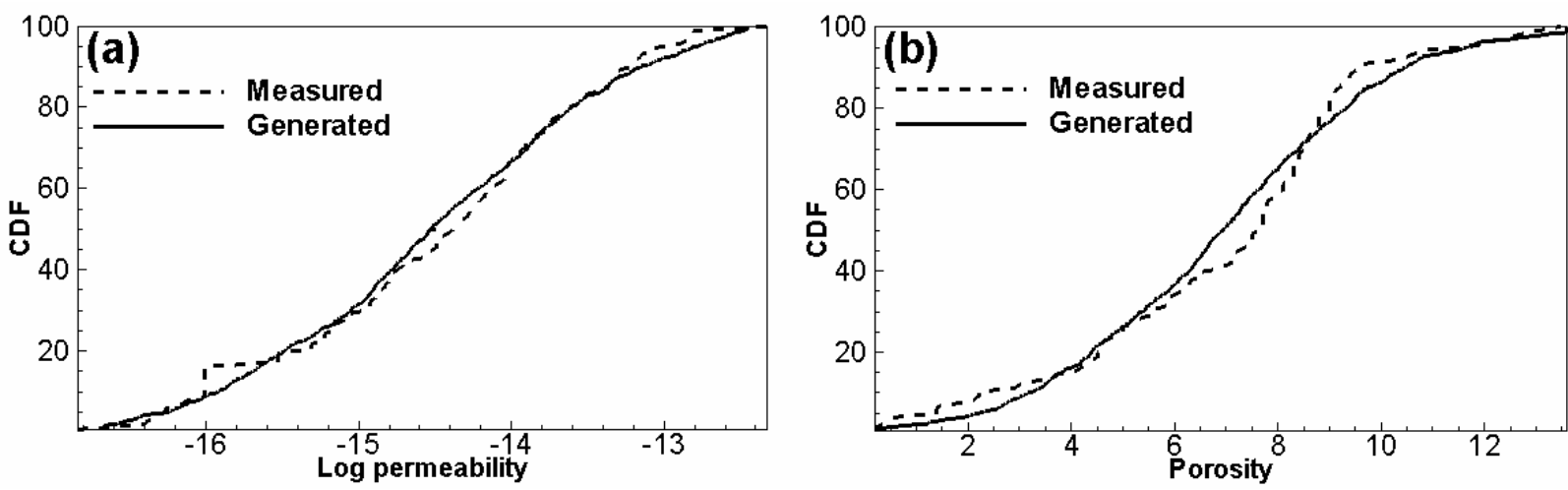

Figure 41. Cumulative distribution functions (CDFs) of measured (dashed) and generated (solid) (a) $\log$ permeability and (b) porosity.

\section{Monte Carlo Simulations}

The correlated realizations of permeability and porosity generated above were used to construct TOUGH2 input files. Except for the values of the two random variables, the values of other model parameters were adopted from the Type 2 simulations with reference parameters. As there is no well-developed method to investigate convergence of Monte Carlo simulations (i.e., the sample statistics obtained from the multiple realizations were representative of the ensemble statistics with probability 1 ), an empirical method was used to examine the stabilization of the statistics (e.g., mean and variance) of the variables of interest with the number of realizations at representative elements. Figure 42 plots the mean and variance of tritium mass fraction in the liquid (Figure 42a) and gas (Figure 42b) phases at the production well at simulation time 55 years after the detonation. The investigation concluded that 200 realizations were enough to obtain converged mean, while convergence of variance required 500 realizations.

\section{Results of Monte Carlo Simulations}

Various statistics can be obtained from the 500 Monte Carlo realizations and the most commonly used ones in uncertainty analysis are mean, variance, 5 th, $50^{\text {th }}$, and 95 th percentiles. Mean $(\mu)$ and standard deviation $(\sigma)$ can be used to form the 95 percent confidence interval $(\mu \pm 2 \sigma)$ of the quantities of interest, which, in this project, are mass 
fraction of tritium in gas and liquid phases. If the quantities follow normal distributions, the probability that the quantities reside in the 95 percent confidence interval is 95 percent. This is not the case, however, if the quantities do not follow normal distributions. If so, the confidence interval may under- or over-estimate uncertainty, depending on the magnitude of the variance. The term 50th percentile means that half of the predicted mass fractions are smaller than the percentile and the other half larger. Similarly, for the 5th and 95th percentiles, 5 percent of predicted mass fractions are smaller than the 5 th percentile, while 5 percent larger than the 95th percentile. In other words, the 5th and 95th percentiles bracket 90 percent of the predictions and exclude the 10 percent in the upper and lower extremes (50 realizations in this project). Whereas the 5th and 95th percentiles - also called uncertainty bounds - are often used in uncertainty analysis, they exclude extreme events that may be of concern to the decision-makers and stakeholders. In risk analysis, the first and 99th percentiles are also used to include the extreme events if necessary.

The statistics above of tritium mass fractions in liquid and gas phases were estimated and compared to select the most appropriate ones for uncertainty assessment in this report. Figures $43 \mathrm{a}$ and $\mathrm{b}$ plot the mean $(\mu)$ and upper bound $(\mu+2 \sigma)$ of the 95 percent confidence interval; Figures $43 \mathrm{c}$ through $\mathrm{f}$ plot the 50th, 75th, 95th, and 99th percentiles of tritium mass fraction in the gas phase at simulation time $66 \mathrm{yr}$ (one year after production has stopped), when tritium has mixed throughout the largest volume of the reservoir. Comparing the mean and 50th percentile shows that the mean tritium plume has spread wider than the 50th percentile. This is not surprising, because the mean takes into account all of the 500 realizations (including the extremes), while the 50th percentile does not. Since the mean significantly differs from the 50th percentile, it indicates that the mass fractions do not follow normal distributions. While the 95 th percentile of the tritium plume spreads slightly wider than the 75th percentile, the spreading of the 99th percentile of the tritium plume is significantly larger than that of the 95th percentile, indicating that some extreme predictions exist. While the 99th percentile of the tritium plume (Figure 43f) appears similar to the upper bound of the 95 percent confidence interval of the tritium plume (Figure 43b), the uncertainty measured by the latter is not rigorous, since the tritium mass fractions do not follow normal distributions. As a summary, rather than using the mean and associated 95 percent confidence interval for uncertainty analysis, 50th and 95th percentiles are used.

Figure 44 shows plots of the 50th (a1 through 11) and 95th (a2 through 12) percentiles of tritium mass fraction in the gas phase. Note that the percentiles are estimated at each cell of the computational grid and there is no guarantee, or need, to ensure that the tritium mass was the same for each percentile. Figures 44a through 44e correspond to the period after the detonation and before the pumping (0 to $34 \mathrm{yr}$ ). Uncertainty of tritium transport during this period was small such that the 50th and 95th percentiles were similar. However, the uncertainty dramatically increased when gas production starts (Figures $44 \mathrm{f}$ through $44 \mathrm{hl} 35$ to $66 \mathrm{yr}$ ), as indicated by the larger size of the plumes within the 95th percentiles, as compared to the 50th percentile. The plumes of the 50th percentile resemble those of the deterministic simulation. After gas production ceased (Figures 44i through 441), the uncertainty decreased with time, as the effect on transport from gas production diminished. The patterns of tritium mass fraction in the liquid phase are similar to those in the gas phase (not shown), whereas mass fraction in the liquid phase was significantly smaller, as explained in the discussion of the deterministic results. 

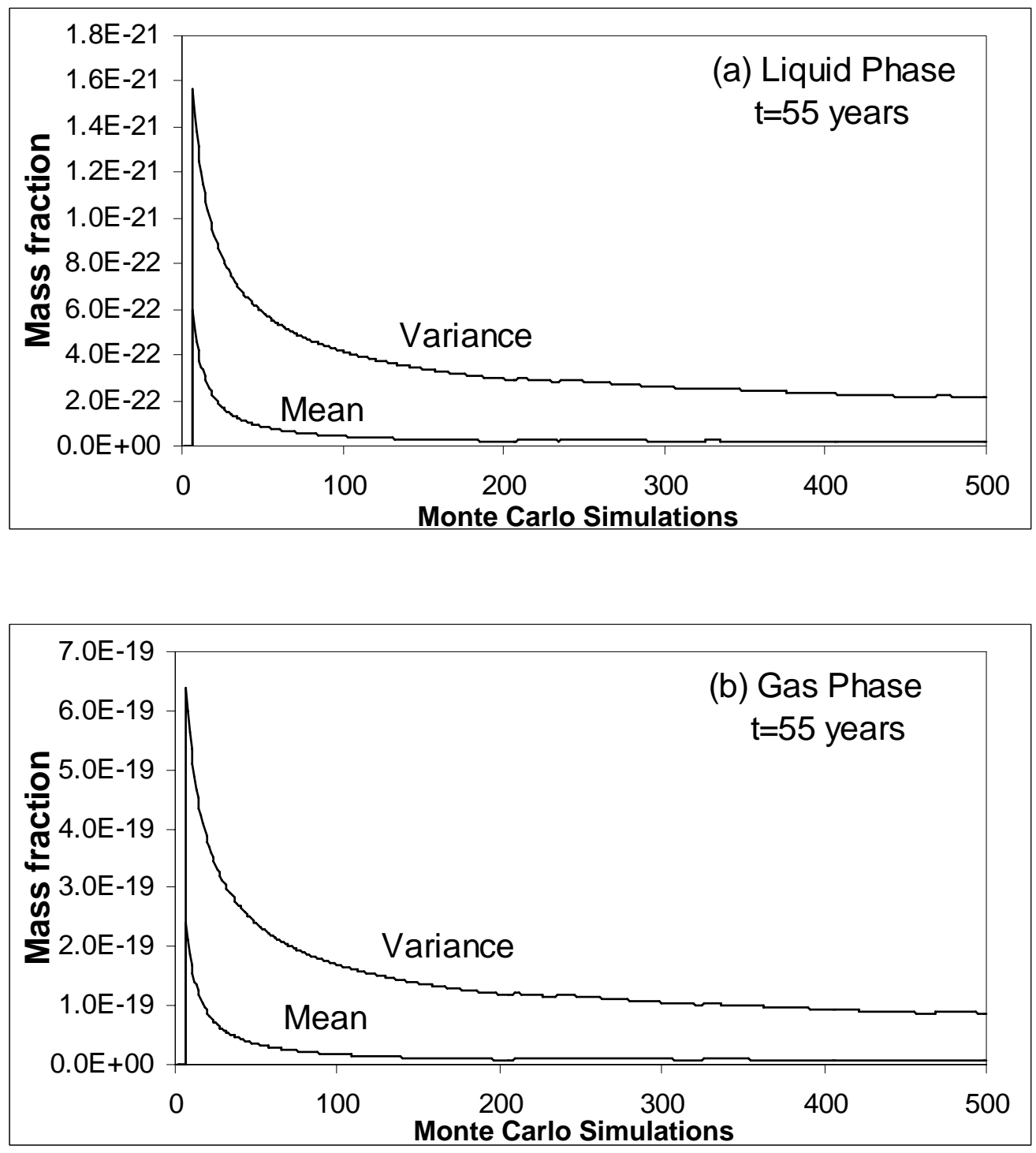

Figure 42. Examination of convergence of Monte Carlo simulations of mass fractions of tritium at (a) liquid and (b) gas phases at the production well. 

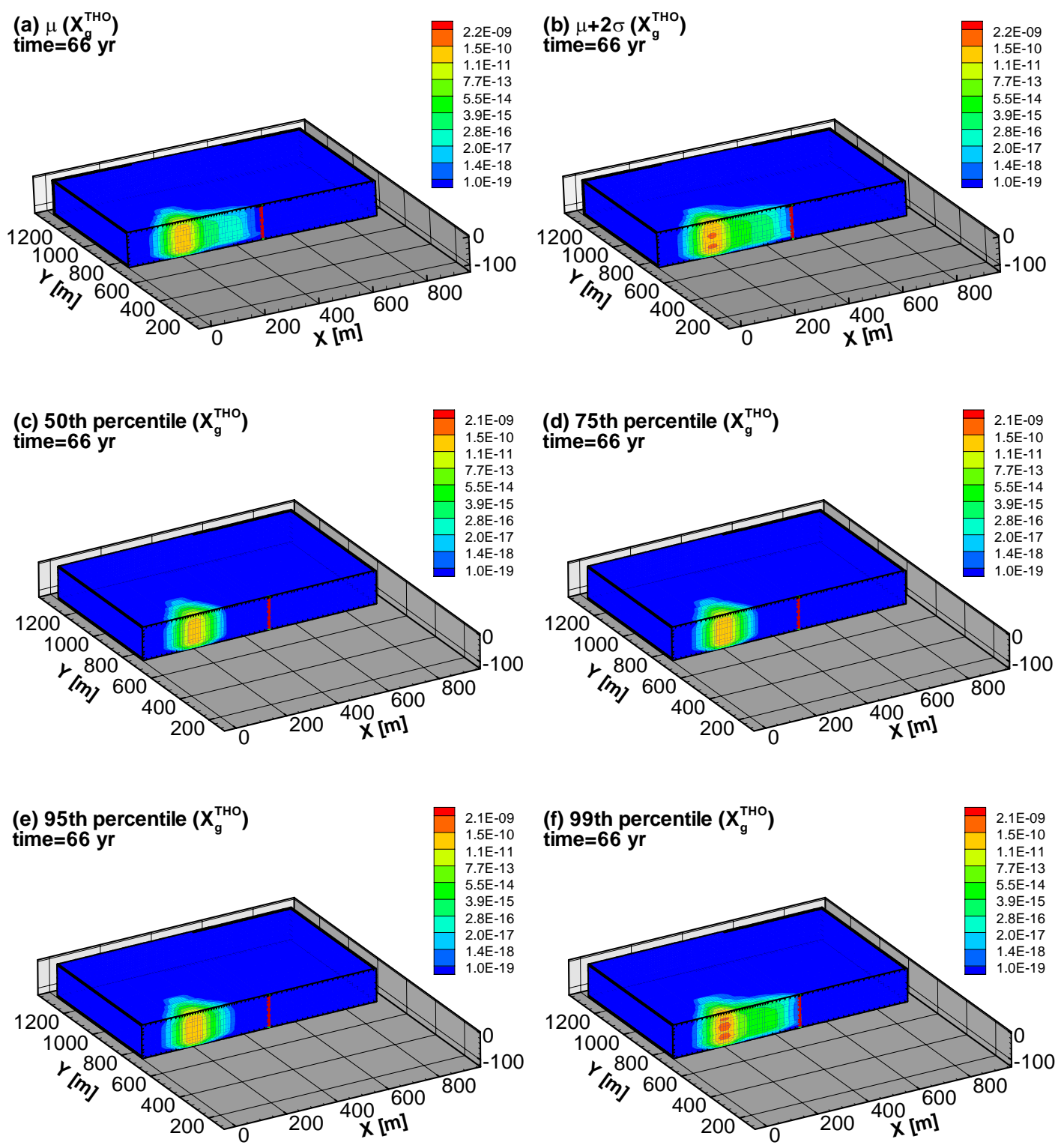

Figure 43. (a) Mean $(\mu)$, (b) upper bound of the 95 percent confidence interval $(\mu+2 \sigma)$, (c) 50 th percentile, (d) 75th percentile, (e) 95th percentile, and (f) 99th percentile of mass fraction of tritium in gas phase at 66 years after the detonation (one year after the end of gas production). 

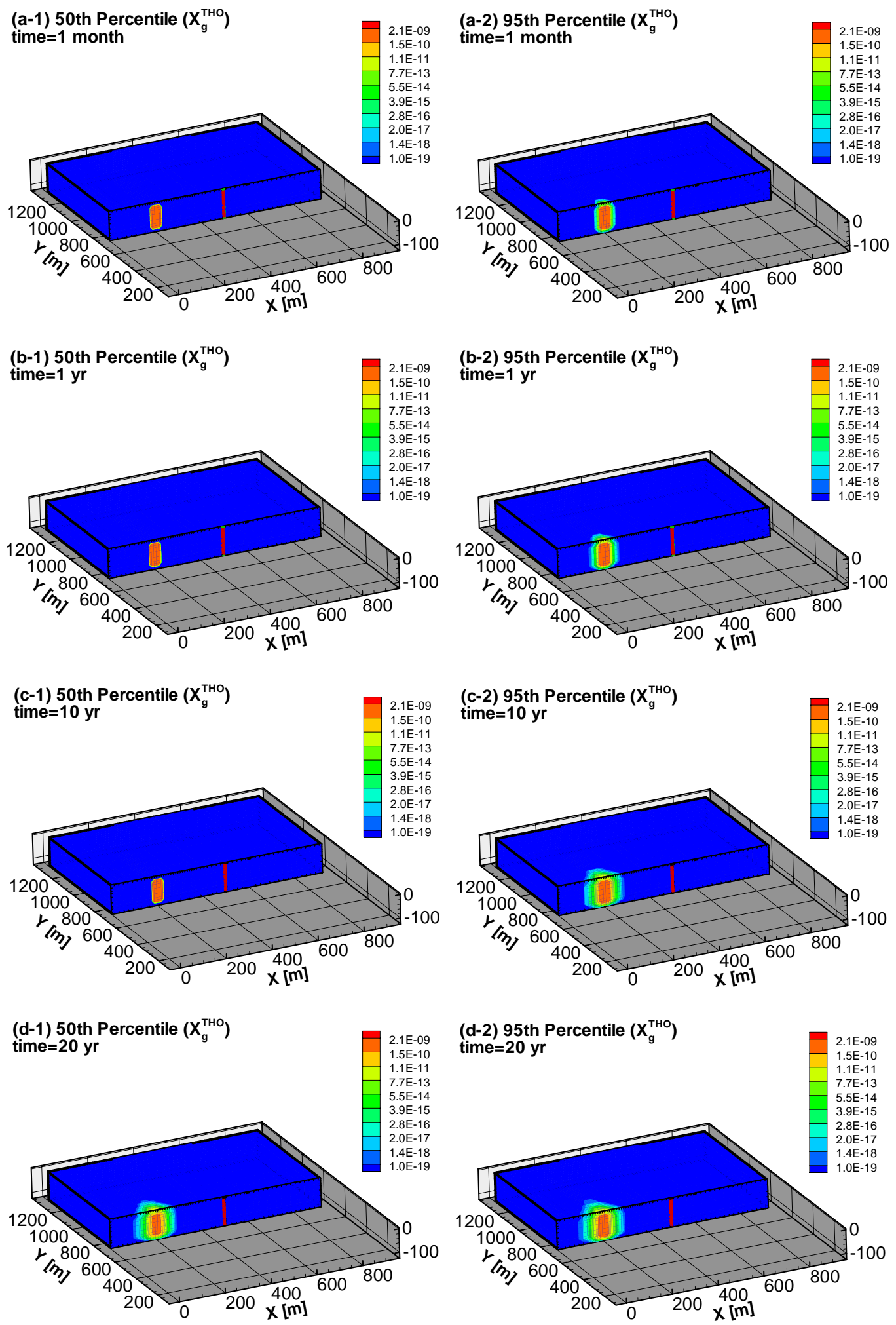

Figure 44. (a-1) through (1-1) 50th and (a-2) through (1-2) 95th percentiles of mass fraction of tritium in the gas phase after (a) 1 month, (b) $1 \mathrm{yr}$, (c) $10 \mathrm{yr}$, (d) $20 \mathrm{yr}$, (e) $34 \mathrm{yr}$, (f) $45 \mathrm{yr}$, (g) $55 \mathrm{yr}$, (h) $66 \mathrm{yr}$, (i) $100 \mathrm{yr}$, (j) $150 \mathrm{yr}$, (k) $250 \mathrm{yr}$, and (l) $500 \mathrm{yr}$ of detonation. 

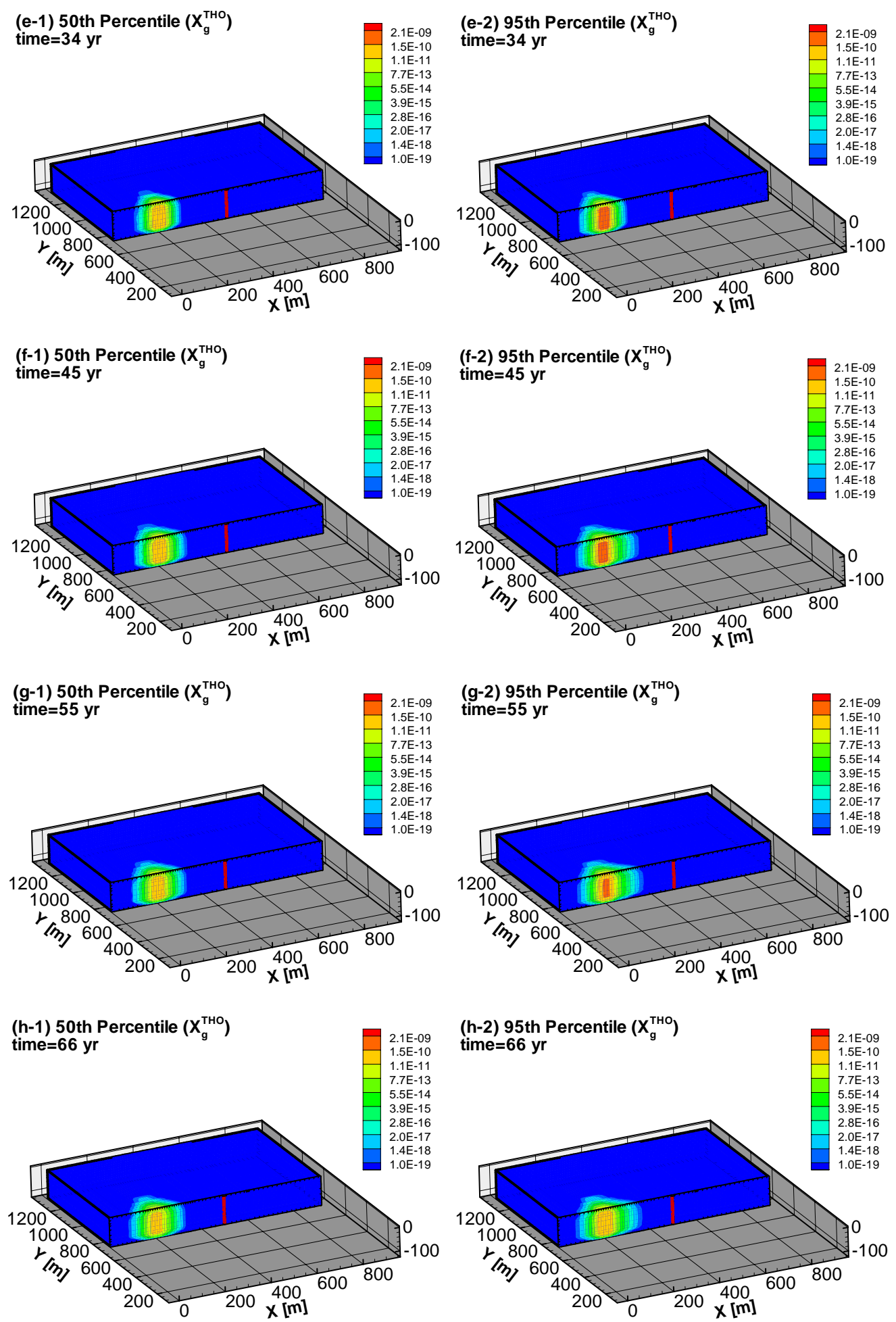

Figure 44. (a-1) through (1-1) 50th and (a-2) through (1-2) 95th percentiles of mass fraction of tritium in the gas phase after (a) 1 month, (b) $1 \mathrm{yr}$, (c) $10 \mathrm{yr}$, (d) $20 \mathrm{yr}$, (e) $34 \mathrm{yr}$, (f) $45 \mathrm{yr}$, (g) $55 \mathrm{yr}$, (h) $66 \mathrm{yr}$, (i) $100 \mathrm{yr}$, (j) $150 \mathrm{yr}$, (k) $250 \mathrm{yr}$, and (l) $500 \mathrm{yr}$ of detonation (continued). 

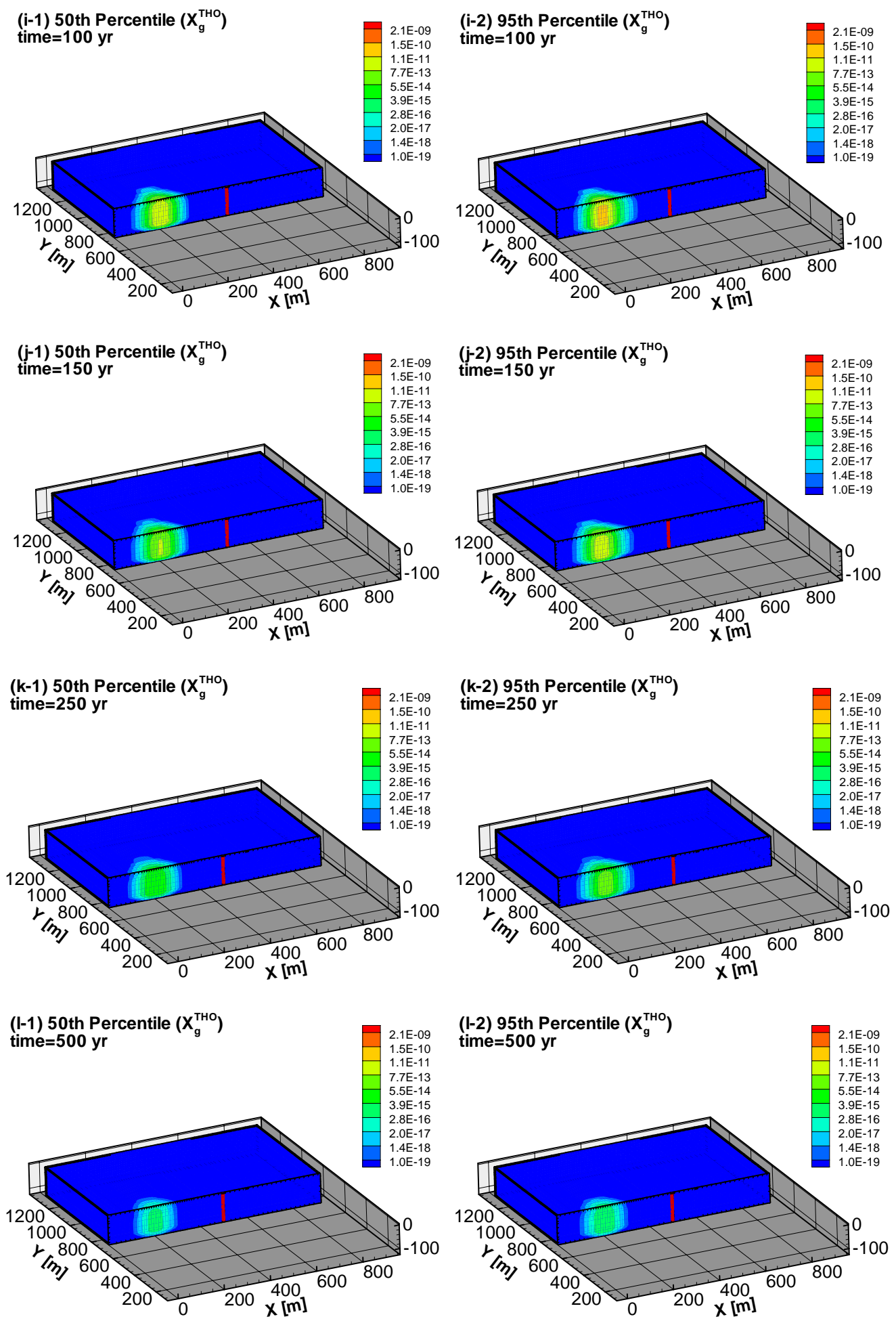

Figure 44. (a-1) through (1-1) 50th and (a-2) through (1-2) 95th percentiles of mass fraction of tritium in the gas phase after (a) 1 month, (b) $1 \mathrm{yr}$, (c) $10 \mathrm{yr}$, (d) $20 \mathrm{yr}$, (e) $34 \mathrm{yr}$, (f) $45 \mathrm{yr}$, (g) $55 \mathrm{yr}$, (h) $66 \mathrm{yr}$, (i) $100 \mathrm{yr}$, (j) $150 \mathrm{yr}$, (k) $250 \mathrm{yr}$, and (l) $500 \mathrm{yr}$ of detonation (continued). 


\section{SUMMARY AND DISCUSSION}

This research investigated transport of gaseous radionuclides (primarily tritiated water, but also krypton) through a natural gas reservoir in which three 33-kiloton nuclear devices were simultaneously detonated on May 17, 1973. The detonations resulted in the formation of three 21-m radius cavity/chimneys (estimated) containing a suite of radionuclides. Except for several gaseous radionuclides, most of the radionuclides are thought to be assimilated into the melt glass, and therefore immobile.

The purpose of this research is to evaluate the distance that radionuclides could travel away from the cavity/chimney at the Rio Blanco site and resulting concentrations. A set of numerical models (i.e., computer simulations) is presented in which transport of radionuclides within the underground gas reservoir is investigated for various parameters. The flow and transport models were developed around a conceptual and geologic model, and incorporate data from published, peer-reviewed sources (permeability, porosity); unpublished reports developed by petroleum companies working in the area at the time of the detonations (permeability, pressure gradients); calculations for parameters that have not been measured (diffusion coefficients, viscosity relations); and measurements (one moisture retention curve).

Two types of models were formulated: Type 1 models were those in which methane gas and liquid water with a single radionuclide (mixed in both phases) migrated within the gas reservoir in response to gas and liquid diffusion, and slight regional pressure gradients; Type 2 models were those in which flow was confined to a zone centered about a single cavity, toward a hypothetical producing gas well located outside of the drilling exclusion zone. The Type 2 simulations also included an extensive uncertainty analysis in which the porosity and intrinsic permeability were considered as random variables due to their heterogeneity at the site. Probability distribution and ranges of the random variables were determined based on site core measurements from two boreholes, and assumed that the measurements are representative of the properties within the natural gas field. The producing well was located such that the estimated extent of the network of hydraulic fractures just reached the exclusion zone. Hydraulic fractures are fractures that are created around the well bore as part of well development, that is, as a step in preparing a well for production. The formation permeability associated with the fractures was great enough that once tritium reached the fracture zone, the travel time to the well was rapid, i.e., on the scale of months to only several years.

\section{Tritium Transport in an Unstressed Reservoir}

For models in which flow and transport from the three nuclear devices were modeled (Type 1), the results show that tritium (as part of a water molecule) is transported a maximum distance of approximately $100 \mathrm{~m}$ from the edge of the cavity, which is approximately another $100 \mathrm{~m}$ from the drilling exclusion boundary. The results show that transport distances are similar for purely diffusive transport (i.e., no applied horizontal pressure gradient) and in the presence of a slight $9.81 \mathrm{~Pa} \mathrm{~m}^{-1}$ pressure gradient (equivalent to a $0.001 \mathrm{~m} \mathrm{~m}^{-1}$ of freshwater head). This is a source of uncertainty, as pressure gradients, and the degree to which pressures even connect within the domain, are largely uncertain in the vicinity of the emplacement hole. For a pressure gradient equivalent to a freshwater head of $0.001 \mathrm{~m} \mathrm{~m}^{-1}$, the maximum extent of radionuclide travel is within approximately $50 \mathrm{~m}$ of the 
drilling exclusion boundary. A one order-of-magnitude increase in permeability results in a nearly imperceptible change in the mass fraction (i.e., concentration) field within either the gas or liquid phase because the permeability usually only affects transport in the presence of a significant pressure gradient. An exception to this is, however, discussed further below, where the choice of the tortuosity model affects the degree to which tritium is transported.

\section{Radionuclide Transport in a Producing Gas Field}

The Type 2 simulations involved transport of a radionuclide (usually tritium, but one simulation was conducted with krypton) from a single cavity (the center one) toward a producing gas well located $292 \mathrm{~m}$ from the center of the cavity. The distance was chosen such that the furthest extent of hydraulic fractures $(88 \mathrm{~m}$ from the production well in the direction of the cavity/chimney) was terminated at the drilling exclusion boundary, $183 \mathrm{~m}$ $(600 \mathrm{ft})$ from the edge of the cavity/chimney (the radius of the cavity/chimney was $21 \mathrm{~m}$ ). These simulations were run in three dimensions, for a total of 1,000 yr past the time of detonation. The simulations were first run for $35 \mathrm{yr}$ under "natural" conditions. At this time, the simulations were stopped, hydraulic fractures were added in the vicinity of the well (as an effective intrinsic permeability - not as discrete fractures), and gas production occurred for $30 \mathrm{yr}$. After $30 \mathrm{yr}$, (65 yr after the nuclear detonation), production was stopped, pressures were able to relax to the initial conditions, and transport was in response to diffusion in both phases, and to the relic pressure gradient left from the gas production.

The simulations showed that for the "reference" simulation (with the best estimate of parameters), tritium travels approximately $100 \mathrm{~m}$ from the center of the cavity, and reaches a sort of quasi-steady state, which exists because radioactive decay happens on approximately the same time scale as diffusive transport. Therefore, although it appears that the tritium mass fraction field remains static, it actually migrates as tritium simultaneously decays into its daughter product at a nearly similar rate at which it is transported. The mass fraction field of tritium in the liquid phase has a similar shape and appearance as that in the gas phase due to equilibrium phase partitioning, and not due to transport as a separate liquid phase (the liquid phase velocities are nearly zero throughout the domain, even in the vicinity of the pumping well). Velocities in the gas phase, on the other hand, are as great as $10^{-8} \mathrm{~m} \mathrm{~s}^{-1}$ (approximately $30 \mathrm{~cm} \mathrm{yr}^{-1}$ ) in the vicinity of the well and could be nearly zero at $100 \mathrm{~m}$ away.

The degree of saturation of either phase (i.e., liquid or gas saturation; the sum of the saturations always equals unity) was investigated in three simulations. In these simulations, the residual liquid saturation was set at the same value as the initial liquid saturation to maintain the uniform saturation profiles observed from cores. The best estimate of initial $\left(S_{e}\right)$ and residual $\left(S_{e r}\right)$ liquid saturation is 0.6 ; the $S_{l}$ and $S_{l r}$ values of 0.4 and 0.8 were also modeled. For the lowest value of liquid saturation (highest value of gas saturation), gas production tends to promote mixing and diffusion of tritium in the gas phase. Upon termination of gas production, the tritium field decays more rapidly under conditions of high saturation than low saturation (because tritium is more dispersed under conditions of higher gas saturation). The reason for the more rapid mixing with lower liquid saturation is that the relative permeability to gas for $S_{l} \sim 0.4$ is about twice that of $S_{l} \sim 0.8$. Under the condition of high liquid saturation, mixing does not occur as effectively as under low liquid saturation and the tritium plume is more concentrated (i.e., less dispersed) and takes longer to decay to background conditions. As a result, tritium is more persistent under conditions of high liquid saturation than conditions of low liquid saturation. Tritium in the low liquid saturation 
simulation (initial $S_{l}=0.4$ ) migrated approximately $150 \mathrm{~m}$ from the cavity/chimney, although was still $150 \mathrm{~m}$ short of the production well. The transport distance was similar for the situation when initial $S_{l}$ was 0.8 . After production ceased (i.e., beyond $66 \mathrm{yr}$ ), however, the mass fraction fields look quite different for the reasons given here.

With respect to rate of production, a 25-percent increase in gas production resulted in the front edge of the tritium "plume" extending only 10 to $20 \mathrm{~m}$ closer to the producing well than for the "reference" simulation with the "normal" production rate. The details of the mass fraction field in the gas phase looked very similar; the only observable difference is that the plume extended slightly further in response to the increased rate of production.

Two tortuosity models were evaluated, resulting in significantly different results. Our results show that transport can be significantly greater when a relative permeability based model is used, as opposed to the more commonly implemented saturation-based model. Most models of tortuosity are based upon a research conducted in the late 1950s and early 1960s; as such, little work has been done on tortuosity in two-phase systems since then.

\section{Uncertainty Analysis}

An uncertainty analysis of tritium transport to the producing well was conducted using the Monte Carlo method. In this analysis, intrinsic permeability and porosity were treated as random parameters, and 500 Monte Carlo simulations were run to evaluate the 95th percentile of the simulated tritium mass fraction field. The uncertainty analysis showed no breakthrough to the well at the 95th percentile level. When 100 percent of the realizations are considered, the largest mass fraction of tritium in the gas phase at the production well was $1.69 \times 10^{-18}$, which was barely above the background level of $10^{-18}$.

The deterministic and Monte Carlo simulations were run with the same input files, except for values of porosity and intrinsic permeability. The three-dimensional "reference" deterministic simulation (the first simulation described in which flow and transport are toward the production well) is not the same as that for the 50th percentile Monte Carlo simulation, although the two simulation results appear similar. The reason is that the intrinsic permeability used in the reference simulation was based upon reservoir tests in a single well near to the cavity, while the intrinsic permeability data for the Monte Carlo analysis were obtained from multiple wells in the area. The reservoir properties estimated from reservoir tests were chosen for the deterministic simulations, as these tests capture more reservoir volume (for example, in-situ fractures) than cores. However, the uncertainty analysis required many data points (268 permeability and 291 porosity values were used here), which could not be provided by the limited number of reservoir tests. The intrinsic permeability value used in the deterministic simulations for the Fort Union Formation, obtained from the reservoir tests, was $2.18 \times 10^{-16} \mathrm{~m}^{2}$. This is within the range of permeability values provided by the cores, which was $1.44 \times 10^{-17} \mathrm{~m}^{2}$ to $4.74 \times 10^{-13} \mathrm{~m}^{2}$. Nevertheless, it is smaller than the geometric mean of the core permeability, which was $1.49 \times 10^{-15} \mathrm{~m}^{2}$. This difference may be attributed to the fact that the permeability analyses of the cores might not have been done under confining pressures observed at the site (this information is not available in test reports). 
It must be emphasized that the uncertainty analysis took into account only the parametric uncertainty of intrinsic permeability and porosity. Additional uncertainties are present that were not quantified by the Monte Carlo analysis, either due to lack of data (e.g., the pressure gradient, which is assumed here to be dominated by the production well), or because the uncertainty is due to a conceptual component (e.g., the location of the production well, or presence of multiple wells). One of the largest additional sources of uncertainty is in the permeability-tortuosity model. Overall uncertainty of tritium transport is thus somewhat larger than indicated by the Monte Carlo analysis, when these other sources of uncertainty are considered.

\section{Limitations of the Models}

There are some processes that were not considered due to an absence of data. Following the detonations, the chimney gases reached temperatures of several thousand Kelvin, essentially allowing them to change phase to a critical state. Current understanding of the behavior of rocks, and the fluids contained within them, under these conditions is very limited. These initial effects, although they may last for several months, were ignored in the simulations. In addition, the rate of cooling of the cavities is unknown, which would be valuable in investigating the effect of large horizontal and vertical thermal gradients on fluid transport. It is perceived that an upward temperature gradient could induce buoyancy in both phases, such that stability considerations might need to be considered. Temperature gradients would also be important in enhancing gaseous radionuclide transport in the horizontal direction, as gas pressures could be significantly elevated in nonisothermal systems (as opposed to isothermal systems) through ideal gas-law considerations.

Other processes not considered in these models include the exclusion of tritium fractionation between water vapor and liquid water. Although easily included in two-phase simulations in unsaturated zones, where the gas phase is near atmospheric, it is not trivial to include fractionation in two-phase simulations with high (and spatially variable) gas pressures. However, fractionation may be of only second-order importance, as the fractionation factor for tritium in methane water systems is of order one.

As in any model, the results presented here are highly dependent upon the input data. These data, in turn, are dependent upon the degree and accuracy of characterization of the formations, and their fluid content and distribution. Some data are used with a higher degree of certainty (i.e., mean permeability values, fluid properties) than others (horizontal pressure gradients, permeability distribution, presence or absence of fractures, values of tortuosity, amount of water in the cavities). For example, although an extensive survey of fracture data was conducted, which resulted in the exclusion of fractures in the domain, the results could be entirely different if even a single flow-controlling fracture existed connecting the cavity downstream toward, and even beyond, the hypothetical producing well. None of the simulations is expected to be the "correct" one; however, they are presented in a logical order such that an individual could gain a rule-of-thumb understanding of what might be occurring within the subsurface for scenarios not presented here.

It is important to realize that when brought to the surface, gas volumes expand approximately 135 times (the formation volume factor, $B g \sim 135$ ) while the liquid phase is nearly incompressible at the pressure and temperature considered here. As the concentrations presented here (as mass fraction) are normalized to the mass of either phase, gas expansion 
should not be a factor. Expansion of the gas phase when brought to the land surface could, however, be important in models of dose assessments where exposure to members of the public are concerned.

\section{REFERENCES}

Al-Hussainy, R. and H.J. Ramey, 1966. Application of real gas flow theory to well testing and deliverability forecasting. J. Petroleum Tech., pp. 637-642.

Al-Hussainy, R., H.J. Ramey and P.B. Crawford, 1966. The flow of real gases through porous media. J. Petroleum Tech., pp. 624-636.

Bear, J., 1988. Dynamics of fluids in Porous Media. Dover reprint of 1972 Elsevier edition, $764 \mathrm{pp}$.

Beaver, D.W., 1972. Gas flow to multiple chimneys, Appendix I. In Toman and Tewes, Project Rio Blanco: Phase I Technical Studies. UCID-15968, Lawrence Livermore National Laboratory, pp. 75-106.

Borg, I.Y., 1975. Radioactivity trapped in melt produced by a nuclear explosion. Nuclear Technology, 26, 88-100.

Borg, I.Y., R. Stone, H.B. Levy and L.D. Ramspott, 1976. Information Pertinent to the Migration of Radionuclides In Groundwater at the Nevada Test Site, Part 1: review and analysis of existing information. Lawrence Livermore National Laboratory, UCRL-52078 Pt. 1, 216p.

Bowen, W.M. and C.A. Bennett, 1988. Statistical Methods for Nuclear Material Management. Battelle Pacific Northwest Laboratory, NUREG/CR-4604.

Brooks, R.H. and A.T. Corey, 1964. Hydraulic properties of porous media. Hydrology paper No. 3, Colorado State University, Ft. Collins, CO.

Carroll, C.J., 2003. Fractures in the Mesaverde Group at Somerset Coal Field, Delta and Gunnison Counties, Colorado. In Piceance Basin 2003 Guidebook, K.M. Peteson, T.M. Olson, and D.S. Anderson, editors, Rocky Mountain Assoc. Geologists, Denver, Colorado, pp. 194-206.

Carsel, R.F. and R.S. Parrish, 1988. Developing joint probability distribution of soil water retention characteristics. Water Resour. Res., 24 (5), 755-769.

CER Geonuclear Corporation, 1970. Project Rio Blanco Reservoir Report. PNE-RB-3, 266 pp.

Colorado Department of Health, 1980. Monitoring report "Project Rio Blanco Environmental Surveillance Summary Report Part 2 July 1973-December 1976" PNE-RB-77 (Pt. 2) 29p. plus appendices. Division of Occupational and Radiological Health.

Cooper, C.A. and J. Chapman, 2001. Modeling Approach for Evaluating Radionuclide Transport in Nuclear-stimulated Gas Reservoirs. Desert Research Institute, Division of Hydrologic Sciences Publication No. 45186, Las Vegas and Reno, NV, 36 pp.

Cooper, C. and C. Shirley, 2004. Rio Blanco Sampling of Proximate Producing Natural Gas Wells. Letter Report DOE/NV-994, Desert Research Institute, Las Vegas, NV, 7 pp. 
Corey, A.T., 1954. The interrelation between gas and oil relative permeabilities. Producer's Monthly, Vol. XIX, No. 1, November, pp. 38-44.

Corey, A.T., 1994. Mechanics of Immiscible Fluids in Porous Media. Water Resources Publications, Highland Ranch, Colorado, $252 \mathrm{pp}$.

Cussler, E.L., 1997. Diffusion Mass Transfer in Fluid Systems. $2^{\text {nd }}$ edition, Cambridge University Press, $580 \mathrm{pp}$.

Dahlberg, E.C., 1995. Applied Hydrodynamics in Petroleum Exploration. Springer-Verlag, $295 \mathrm{pp}$.

Evans, D.D., Nicholson, T.J. and T.C. Rasmussen (eds.), 2001. Flow and Transport through Unsaturated Fractured Rock, Geophysical Monograph 42, American Geophysical Union, $196 \mathrm{pp}$.

Fenix and Scisson, 1976. Project Rio Blanco Alternate Reentry Well RB-AR-2 Hole History. NVO-38-33, 13 pp. plus four appendices.

Frink, R.O. and J.A. Wethington, Jr., 1971. Tritium exchange between hydrocarbons and stead. Transactions of the American Nuclear Society 1971 Winter Meeting Miami Beach, pp. 467-468.

Furbish, D.J., 1997. Fluid Physics in Geology. Oxford Univ. Press. 476 pp.

Gee, G.W., Campbell, M.D., Campbell, G.S. and J.H. Campbell, 1992. Rapid measurement of low soil water potentials using a water activity meter. Soil Sci. Soc. A. J., 56:10681070 .

Gerritsen, M.G., and L.J. Durlofsky, 2005. Modeling fluid flow in oil reservoirs. Annu. Rev. Fluid Mech., v. 37, pp. 211-238.

Hansley, P.L. and R.C. Johnson, 1980. Mineralogy and diagenesis of low-permeability sandstones of Late Cretaceous age, Piceance Creek Basin, Northwestern Colorado. The Mountain Geologist, 17(4):88-129.

Helton, J.C. and F.J. Davis, 2000. Sampling-based methods, Sensitivity Analysis. A. Saltelli, K. Chan, and E.M. Scott (eds.), 101-152.

Hirschfelder, J.O., C.F. Curtiss and R.B. Bird, 1954. Molecular Theory of Gases and Liquids. John Wiley and Sons, New York.

Holzer, A., 1970. Gasbuggy in Perspective. In American Nuclear Society, Proceedings of Symposium on Engineering with Nuclear Explosives, January 14-16, 1970 Las Vegas, Nevada, CONF-700101, Vol. 1, pp.662-697.

Hubbert, M.K., 1953. Entrapment of petroleum under hydrodynamic conditions. American Assoc. Petroleum Geol., 37(8):1954-2026.

Iman, R.L. and W.J. Conover, 1982. A distribution-free approach to inducing rank correlation among input variables. Commun. Statist.-Simula. Computa., 11(3), 311-334.

International Atomic Energy Agency (IAEA), 1998. The Radiological Situation at the Atolls of Mururoa and Fangataufa. Technical Report in six volumes, published in Austria. 
Iuzzolino, H., 2003. Users Manual (Rev 00) for LHS, Version 2.51.uzz Civilian Radioactive Waste Management System Management and Operating Contractor, MOL.20040210.0391, Albuquerque, New Mexico

Jacobs, D.G., E.G. Struxness and C.R. Bowman, 1970. A Preliminary Assessment of the Radiological Implications of Commercial Utilization of Natural Gas from a Nuclear Stimulated Well. In American Nuclear Society, Proceedings of Symposium on Engineering with Nuclear Explosives, January 14-16, 1970 Las Vegas, Nevada, CONF700101, Vol. 1, pp.831-849.

Johnson, M.E., 1987. Multivariate Statistical Simulation, John Wiley and Sons, Inc., New York, 230p.

Johnson, R.C., 1989. Geologic History and Hydrocarbon Potential of Late Cretaceous-Age, Low-Permeability Reservoirs, Piceance Basin, Western Colorado. Chapter E of Evolution of Sedimentary Basins - Uinta and Piceance Basins, U.S. Geological Survey Bulletin, 1787, E1-E51.

Law, B.E. and W.W. Dickinson, 1985. Conceptual model for origin of abnormally pressured gas accumulations in low-permeability reservoirs. Am. Assoc. Petrol. Geologists Bull., 69(8):1295-1304.

Lerche, I. and R.O. Thomsen, 1994. Hydrodynamics of Oil and Gas. Plenum, 308 pp.

Masters, J.A. 1979. Deep basin gas trap, Western Canada. Am. Assoc. Petrol. Geol. Bull., 63(2): 152-181.

Matthews, C.S. and D.G. Russell, 1967. Pressure Buildup and Flow Tests in Wells. American Institute of Mining, Metallurgical, and Petroleum Engineers, Inc., 167 pp.

McKay, M.D., R.J. Beckman, and W.J. Conover, 1979. A comparison of three methods for selecting values of input variables in the analysis of output from a computer code. Technometrics, 21(2), 239-245.

McKee, C.R. and M.E. Hanson, 1975. Explosively created permeability from single charges. Soc. Petrol. Eng. J., 15:495-501.

Millheim, K.K. and L. Cichowicz, 1968. Testing and analyzing low-permeability fractured gas wells. Trans. AIME, 243:193-198.

Millington, R.J., 1959. Gas diffusion in porous media. Science, 130:100-102.

Millington, R.J. and J.P. Quirk, 1961. Permeability of porous solids. Trans. Faraday Soc., 57:1200-1207.

Mills, R., 1973. Self-diffusion in normal and heavy water in the range 1-45'. J. Physical Chem., 77(5):685-688.

Nelson, P.H. and J.E. Kibler, 2003. A Catalog of Porosity and Permeability from Core Plugs in Silicicalstic Rocks. U.S. Geological Survey Open-file Report 03-420.

Parrington, J.R., H.D. Knox, S.L. Breneman, E.M. Baum and F. Feiner, 1996. Nuclides and Isotopes. Fifteenth Edition. General Electric Co., San Jose, CA, 64p.

Perry, R.H. and D.W. Green, 1997. Perry's Chemical Engineers' Handbook. McGraw-Hill, $7^{\text {th }}$ edition. 
Pruess, K., 1991. TOUGH2 - A General Purpose Numerical Simulator for Multiphase Fluid and Heat Flow. Lawrence Berkeley Laboratory Report LBL-29400, Berkeley, Calif.

Pruess, K., 1995. Proceedings of the TOUGH Workshop '95. Lawrence Berkeley Laboratory Report LBL-37200, Berkeley, Calif.

Pruess, K., 1998. Proceedings of the TOUGH Workshop '98. Lawrence Berkeley Laboratory Report LBNL-41995, CONF-980559, Berkeley, Calif.

Pruess and Narasimhan, 1985. A practical method for modeling heat and fluid flow in fractured porous media. Soc. Pet. Engine. J., 25,(1):14-26.

Pruess, K., C. Oldenburg and G. Moridis, 1999. TOUGH2 User's Guide, Version 2.0. Lawrence Berkeley Laboratory Report LBNL-43134, Berkeley, California.

Reid, R.C., J.M. Prausnitz and B.E. Poling, 1987. The Properties of Gases and Liquids. McGraw Hill, 741 pp.

Rocky Mountain Map Company, 1999. Structure Contour Map of N 1/2 Piceance Basin, Douglas Creek Arch, Colorado,Casper, Wyoming.

Rubin, B., L. Schwartz and D. Montan, 1972. An Analysis of Gas Stimulation Using Nuclear Explosives. Lawrence Livermore Laboratory Report UCRL-51226, 68p.

Shirley, C., 2004. Rio Blanco Sampling of Proximate Producing Natural Gas Wells. Desert Research Institute, Division of Hydrologic Sciences Letter Report No. DOE/NV--994, Las Vegas, NV.

Smith, C.F., 1975. Rio Blanco Gas Composition LLL Data Summary Calibration and Production Testing of RB-AR-02. Lawrence Livermore National Laboratory Report UCID-16762.

Smith, D.K., B.K. Esser and J.L. Thompson, 1995. Uncertainties Associated with the Definition of a Hydrologic Source Term for the Nevada Test Site. Lawrence Livermore National Laboratory Report, UCRL-ID-120322, 21 .

Swiler, L.P., and G.D. Wyss, 2004. A user's guide to Sandia's Latin Hypercube Sampling software: LHS UNIX library/standalone version, Technical Report SAND2004-2439, Sandia National Laboratories, Albuquerque, NM.

Taylor, R.W., 1972. Divining Gas Pressure at Rio Blanco, Appendix H. In Toman and Tewes, project Rio Blanco: Phase I Technical Studies. Lawrence Livermore National Laboratory Report UCID-15968, pp. 62-74.

Tewes, H.A., 1979. Survey of Gas Quality Results from Three-gas-well-stimulation Experiments by Nuclear Explosions. Lawrence Livermore Laboratory Report UCRL52656, $34 \mathrm{pp}$.

Thompson, J.L., 1996. Radionuclide distribution in a nuclear test cavity: the Baseball event. Radiochimica Acta, 72:157-162.

Timur, A., 1968. An investigation of permeability, porosity, and residual water saturation relationship for sandstone reservoirs. The Log Analyst, 9(4).

Toman, J., 1975. Production test data and preliminary analysis of top chimney/cavity. Nuclear Technology, 27:692-704. 
Toman, J., undated. Project Rio Blanco - Part II, Production Test Data and Preliminary Analysis of Top Chimney/cavity. IAEA-TC-1/4/5 pp. 117-140.

Toman, J. and H.A. Tewes, 1972. Project Rio Blanco: Phase I technical studies. Lawrence Livermore Laboratory Report UCID-15968, 138 pp.

U.S. Atomic Energy Commission, 1971. Environmental Statement Project Rio Blanco, Nevada Operations Office, 68p.

U.S. Department of Energy, 1986. Final Report Fawn Creek Government No. 1. Prepared by the Engineering and Energy Management Division, NVO-303, 14 pp. plus 5 appendices.

U.S. Department of Energy, 2000. Site Characterization Work Plan for the Rio Blanco Site, Colorado. Nevada Operations Office, Environmental Restoration Division, DOE/NV$607,59 \mathrm{p}$.

U.S. Energy Research and Development Administration, 1975. Project Rio Blanco Data Report, Production Testing Alternate Reentry Hole RB-AR-2, NVO-154.

U.S. Environmental Protection Agency (U.S. EPA), 1992. Offsite Environmental Monitoring Report: Radiation Monitoring Around United States Nuclear Test Areas Calendar Year 1990. EPA 600/4-91/030, 171p.

Wang, J.S.Y. and T.N. Narashimhan, 1985. Hydrologic mechanisms governing fluid flow in a partially saturated, fractured, porous medium, Water Resources Research, 21:18611874.

Woodruff, W.R. and R.S. Guido, 1974. Rio Blanco: Nuclear Operations and Chimney Reentry. Lawrence Livermore Laboratory report UCRL-51560, 95p. 


\section{APPENDIX A. Wells and Lithology}

Table A1. RB-E-01 stratigraphy/lithology.

\begin{tabular}{|c|c|c|c|}
\hline Top (Meters) & Base (Meters) & Formation/Litholgy & Data Source \\
\hline $2,019.91$ & 1989.43 & Alluvium & Fig 5.2 Site Characterization Report \\
\hline $1,989.43$ & 1776.07 & "A" Aquifer & Fig 5.2 Site Characterization Report \\
\hline $1,989.43$ & 1151.23 & Green River & Fig 5.2 Site Characterization Report \\
\hline $1,776.07$ & 1740.11 & Mahogany Zone & Fig 5.2 Site Characterization Report \\
\hline $1,740.11$ & 1593.19 & "B" Aquifer & Fig 5.2 Site Characterization Report \\
\hline $1,361.54$ & 1303.63 & Orange Marker & Fig 5.2 Site Characterization Report \\
\hline $1,151.23$ & 395.33 & Wasatch Group & Fig 5.2 Site Characterization Report \\
\hline 395.33 & 142.34 & Fort Union & Fig 5.2 Site Characterization Report \\
\hline 247.19 & 227.08 & Sand Zone & Appendix A,UCRL-51560 \\
\hline 240.34 & 240.34 & Explosive 3 Reference Point & Appendix A,UCRL-51560 \\
\hline 142.34 & -378.56 & Mesaverde & Appendix A,UCRL-51560 \\
\hline 122.23 & 119.79 & Sand Zone & Appendix A,UCRL-51560 \\
\hline 121.10 & 121.10 & Explosive 2 Reference Point & Appendix A,UCRL-51560 \\
\hline-17.98 & -29.57 & Sand Zone & Appendix A,UCRL-51560 \\
\hline-19.04 & -19.04 & Explosive 1 Reference Point & \\
\hline
\end{tabular}

Table A2. Government Fawn Creek \#1.

\begin{tabular}{|c|c|c|c|}
\hline Top (Meters) & Base (Meters) & Formation/Litholgy & Data Source \\
\hline $2,017.17$ & $1,986.69$ & Alluvium & Co. Oil \& Gas Comm. Database Scanned Document \\
\hline $1,986.69$ & $1,163.73$ & Green River & Co. Oil \& Gas Comm. Database Scanned Document \\
\hline $1,163.73$ & 401.73 & Wasatch Group & Co. Oil \& Gas Comm. Database Scanned Document \\
\hline 401.73 & 166.42 & Fort Union & Co. Oil \& Gas Comm. Database Scanned Document \\
\hline 166.42 & -388.62 & Mesaverde & Co. Oil \& Gas Comm. Database Scanned Document \\
\hline
\end{tabular}

Table A3. Paul Burton 'A.'

\begin{tabular}{|l|l|l|l|}
\hline Top (Meters) & Base (Meters) & Formation/Litholgy & Data Source \\
\hline $1,497.79$ & $1,333.20$ & Piceance Creek & Co. Oil \& Gas Comm. Database \\
\hline $1,333.20$ & 408.43 & Fort Union & Co. Oil \& Gas Comm. Database \\
\hline 408.43 & -185.01 & Mesaverde & Co. Oil \& Gas Comm. Database \\
\hline
\end{tabular}

Table A4. South Sulphur Creek Government 1-4.

\begin{tabular}{|l|l|l|l|}
\hline Top (Meters) & Base (Meters) & Formation/Litholgy & Data Source \\
\hline $2,021.13$ & $1,243.89$ & Green River & Co. Oil \& Gas Comm. Database (Completion Report) \\
\hline $1,243.89$ & 725.73 & Wasatch Group & Co. Oil \& Gas Comm. Database (Completion Report) \\
\hline 725.73 & 679.40 & Fort Union & Co. Oil \& Gas Comm. Database (Completion Report) \\
\hline
\end{tabular}

Table A5. Rio Blanco AR-2.

\begin{tabular}{|l|l|l|l|}
\hline Top (Meters) & Base (Meters) & Formation/Litholgy & Data Source \\
\hline 141.13 & 121.13 & Mesaverde & Figure 1, Preprint UCRL-78744 \\
\hline
\end{tabular}

Table A6. Government 397-19-1.

\begin{tabular}{|l|l|l|l|}
\hline Top (Meters) & Base (Meters) & Formation/Litholgy & Data Source \\
\hline-295.35 & -437.08 & Mesaverde & Co. Oil \& Gas Comm. Database \\
\hline
\end{tabular}


Table A7. Government (Federal) 398-10-1.

\begin{tabular}{|l|l|l|l|}
\hline Top (Meters) & Base (Meters) & Formation/Litholgy & Data Source \\
\hline $2,120.80$ & 743.10 & Green River & Co. Oil \& Gas Comm. Database \\
\hline 743.10 & 322.48 & Wasatch Group & Co. Oil \& Gas Comm. Database \\
\hline 322.48 & -746.76 & Mesaverde & Co. Oil \& Gas Comm. Database \\
\hline-746.76 & -818.08 & Trout Creek & Co. Oil \& Gas Comm. Database \\
\hline
\end{tabular}

Table A8. Government 398-17-1.

\begin{tabular}{|l|l|l|l|}
\hline Top (Meters) & Base (Meters) & Formation/Litholgy & Data Source \\
\hline 357.23 & -520.60 & Mesaverde & Co. Oil \& Gas Comm. Database \\
\hline-520.60 & -900.99 & Trout Creek & Co. Oil \& Gas Comm. Database \\
\hline-900.99 & $-1,343.56$ & Sego & Co. Oil \& Gas Comm. Database \\
\hline$-1,343.56$ & $-1,381.97$ & Castlegate & Co. Oil \& Gas Comm. Database \\
\hline$-1,381.97$ & $-1,500.84$ & Mancos B & Co. Oil \& Gas Comm. Database \\
\hline
\end{tabular}

Table A9. Rio Blanco RB-U-4.

\begin{tabular}{|l|l|l|l|}
\hline Top (Meters) & Base (Meters) & Formation/Litholgy & Data Source \\
\hline $2,011.68$ & $1,973.58$ & Alluvium & Co. Oil \& Gas Comm. Database Well Completion Doc \\
\hline $1,973.58$ & $1,127.76$ & Green River & Co. Oil \& Gas Comm. Database Well Completion Doc \\
\hline $1,752.60$ & $1,722.12$ & Mahogany Marker & Co. Oil \& Gas Comm. Database Well Completion Doc \\
\hline $1,341.12$ & $1,295.40$ & Orange Marker & Co. Oil \& Gas Comm. Database Well Completion Doc \\
\hline $1,127.76$ & 387.10 & Wasatch Group & Co. Oil \& Gas Comm. Database Well Completion Doc \\
\hline 387.10 & 134.11 & Fort Union & Co. Oil \& Gas Comm. Database Well Completion Doc \\
\hline 134.11 & -129.54 & Mesaverde & Co. Oil \& Gas Comm. Database Well Completion Doc \\
\hline
\end{tabular}

Table A10. Government (Federal) MHF-3.

\begin{tabular}{|l|l|l|l|}
\hline Top (Meters) & Base (Meters) & Formation/Litholgy & Data Source \\
\hline $1,983.34$ & $1,962.00$ & $\begin{array}{l}\text { Undifferentiated Surface } \\
\text { Material }\end{array}$ & As Built Report for RB-MHF-3 from Colorado O\&G Com \\
\hline $1,962.00$ & $1,847.70$ & Alluvium & As Built Report for RB-MHF-3 from Colorado O\&G Com \\
\hline $1,847.70$ & $1,075.03$ & Green River & As Built Report for RB-MHF-3 from Colorado O\&G Com \\
\hline $1,715.11$ & $1,715.11$ & Mahogany Marker & As Built Report for RB-MHF-3 from Colorado O\&G Com \\
\hline $1,677.93$ & $1,677.93$ & Black Marker & As Built Report for RB-MHF-3 from Colorado O\&G Com \\
\hline $1,288.39$ & $1,288.39$ & Orange Marker & As Built Report for RB-MHF-3 from Colorado O\&G Com \\
\hline $1,075.03$ & 279.50 & Wasatch Group & As Built Report for RB-MHF-3 from Colorado O\&G Com \\
\hline 279.50 & 16.76 & Fort Union & As Built Report for RB-MHF-3 from Colorado O\&G Com \\
\hline 16.76 & -504.44 & Mesaverde & As Built Report for RB-MHF-3 from Colorado O\&G Com \\
\hline
\end{tabular}




\section{APPENDIX B. \\ Fracture Data and Analysis}

The Rio Blanco gas stimulation test was conducted in geologic media described as,

“... fluvial channel fill and point bar sandstones" (CER Geonuclear, 1970). The Fort Union Formation and Mesaverde Group are described in detail in the outcrop study comprising Appendix 1 of the CER Geonuclear reservoir report.

\section{Local Directional Data}

Two sources of data were located and evaluated regarding local anisotropy, the outcrop geometric data from the previously cited CER Geonuclear reservoir report and maps from an informal Lawrence Livermore National Laboratory containment prospectus notebook. The maps show faults and joints in proximity to the Rio Blanco emplacement borehole, see Figures B1 and B2.

The bearings and lengths (in map units, not actual length) of these linear features were obtained by digitizing the maps. The data are presented in Tables B2 and B3. The geometric data (in actual length units) from the outcrop study is presented in Table B4. Circular statistical estimates for these data are presented in Table B1. In addition to frequency based statistics, length and elongation weighted estimates were made.

The mean direction of the fault (Map 1) data is $128.38^{\circ}$, roughly northwest to southeast. The mean direction of joint data is $113.76^{\circ}$, which approaches east to west. Hypothesis testing to determine if these two data sets have equal mean directions, i.e., can the data be reasonably characterized by a single distribution, is stated as

$$
H_{0}: \mu_{1}=\mu_{2} \text { against } H_{2}: \mu_{1} \neq \mu_{2}
$$

A small $\kappa$ value $(2<\kappa<10)$ F-test

$$
F_{1, n-2}=\left(1+\frac{3}{8 \kappa}\right) \frac{(n-2)\left(R_{1}+R_{2}-R_{p}\right)}{\left(n-R_{1}-R_{2}\right)}
$$

where $n$ is the pooled number of samples,

$\kappa$ is the concentration parameter of the pooled data,

$R_{1}$ is the resultant of the first data set, and

$R_{2}$ is the resultant of the second data set

was calculated for the fault and joint data (Figure B3 raw frequency and Figure B4 raw frequency in Table B1, respectively), yielding a result of 1.152, which is well below the critical value for rejecting the null hypothesis $H_{0}$ at the 95 percent confidence level. Thus, the fault joint and joint traces can be considered as being drawn from the pooled population shown in Figure B5 with the parameters listed as combined trace 1 and 2 in Table B1.

When evaluating features such as faults and joints, direction alone is inadequate. The size of features needs to be considered. A simple example can illustrate the effect of feature length. Consider a data set comprised of 11 observations of direction and feature length. Ten of the features bear $60^{\circ}$ and are 1 meter in length, the remaining feature bears $300^{\circ}$ and is 20 meters in length. Comparing Figures B6 to Figure B7 shows the effect of weighting. 


\section{Core Analysis}

\section{Method}

Core and cuttings from the Rio Blanco boreholes RB-U2 and RB-E01 as well as core from the nearby massive hydraulic fracturing test borehole, RB-MHF, are stored and were examined at the U.S. Geological Survey Core Research Center in Denver, Colorado. The cores were visually examined for evidence of fracturing using a binocular microscope and hand lens. Observations made on specific intervals during the examination of the core are summarized in Table B5. The core has been cut to roughly $2.5-\mathrm{cm}$ (1-in) thickness to save space in the library, and the original orientation of the core has not been recorded. The angle between the trace of a planar feature across the face of the core slab and the edge of the core was measured, as was the projection normal to the face (see Figure B14). From the measured angles $\alpha-90^{\circ}$ and $\beta-90^{\circ}$, a dip can be estimated (with the assumption that the core is from a vertical borehole), but because the bearing of the slab is unknown, strike cannot be estimated. The thinness of the slabs means that the apparent dip observed on the edge of the slab will be more uncertain than the apparent dip on the face of the slab.

\section{Results}

A small number of isolated, near vertical fractures were found in the core that was available for examination. In strata with visible laminae, core is prone to part along the thicker laminae. However, a number of intervals were found where drilling-induced parting cuts through visible lamina, so this should be considered as evidence only moderately supporting anisotropy. The laminae are generally oriented within a few degrees of horizontal.

\section{Conclusions}

The available recovered core did not show any evidence of pre-drilling fracturing. The finer-grained material, i.e., those trending toward shale, was recovered in smaller pieces than the coarser-grained sandstones, raising the possibility of textural or lithologic preference in fracturing. However, the crystal faces examined on all samples were fresh and unweathered. Virtually no evidence of fluid transport in the form of staining, void filling, or veining was found. Small oxidation halos could be seen on some mafic to ultramafic grains, but these were all submillimeter in thickness. While it is not possible to completely prove the absence of systematic fracturing from the available core, it is highly unlikely that all recovered samples would be devoid of evidence of extensive fracturing.

Additional sources of data to supplement the core observations were sought. The Nevada Test Site Archives and Records Center at Mercury was visited and a search conducted for geophysical logs with the assistance of Paul J. St. Marie. A total of 264 items (microfilmed records) were found with reference to "Rio Blanco." These items were examined and a number of geophysical logs were found for boreholes associated with the Rio Blanco test. Of the types of logs run, the variable density acoustic velocity log would have been the most useful. However, the only log of this type was run in a cased borehole to evaluate cement bonding, which was a problem during the construction of the borehole (Mann et al., 1972).

Lawrence Livermore National Laboratory was visited to examine a number of documents pertaining to the Rio Blanco tests. An acoustic televiewer log was run in RB-E-01; unfortunately, the logged interval extended only $815 \mathrm{~m}$ below the surface and the 
only copy of the log that could be located was physically damaged and largely unreadable (C. Shirley, personal observation, 2003).

\section{References}

ASTM D4525-90(1995) Standard Test Method for Permeability of Rocks by Flowing Air

API RP 40, Core Analysis, 2nd Ed. American Petroleum Institute, 1998.

Mann, R.L., E.L. Moffatt, and R.V. Quinn, Running and Cementing 10-3/4 Inch Casing at 6990 feet, CER Geonuclear Corporation/Equity Oil Company, Rio Blanco Project report on RB-E-01, 1972 (unpublished report from DOE Records, North Las Vegas, Nevada)

WELLS AND FAULTS WITHIN TEN MILES OF THE RIO BLANCO WELL LOCATION

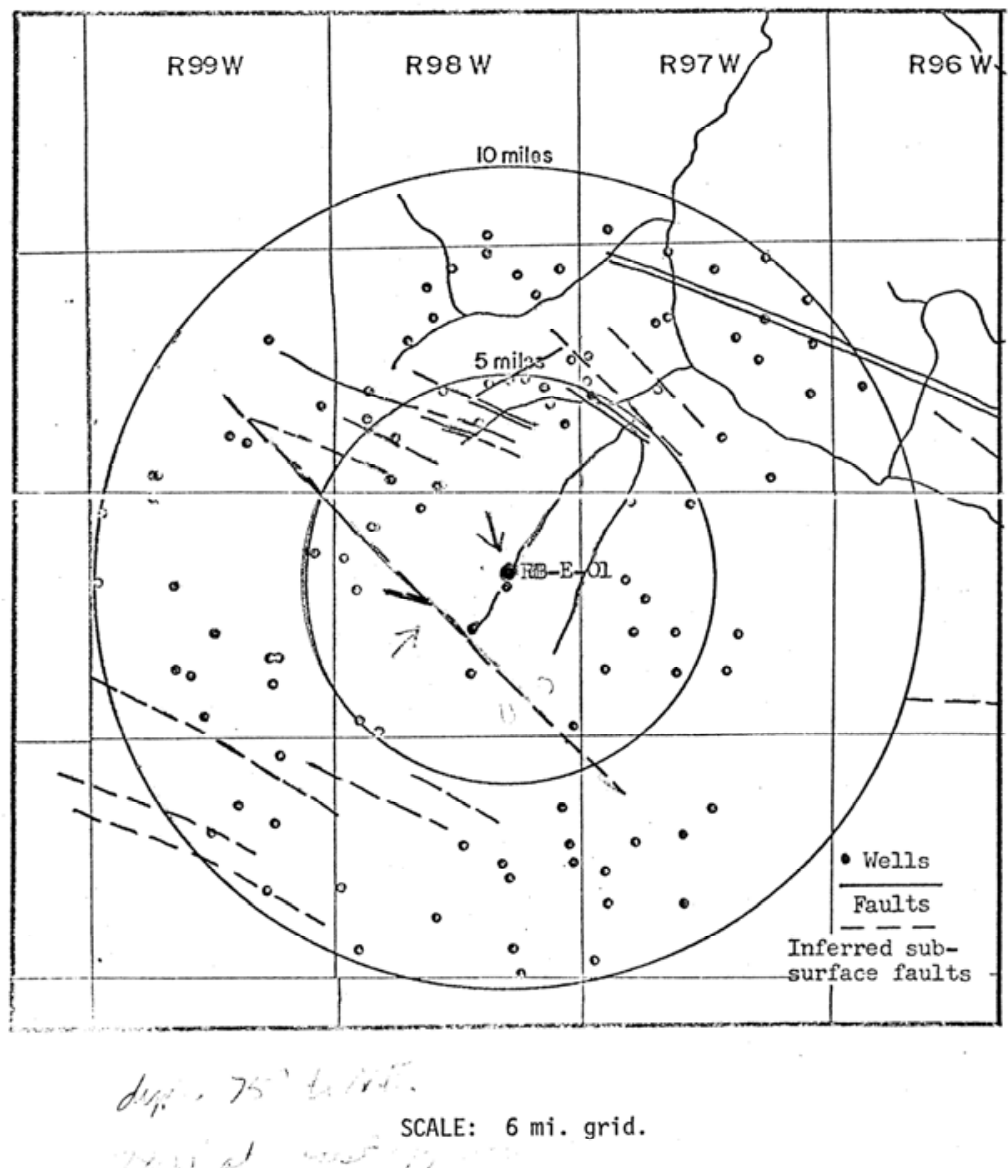

Figure B1. Faults within 10 miles of emplacement borehole (scanned copy from informal containment prospectus notebook at LLNL). 


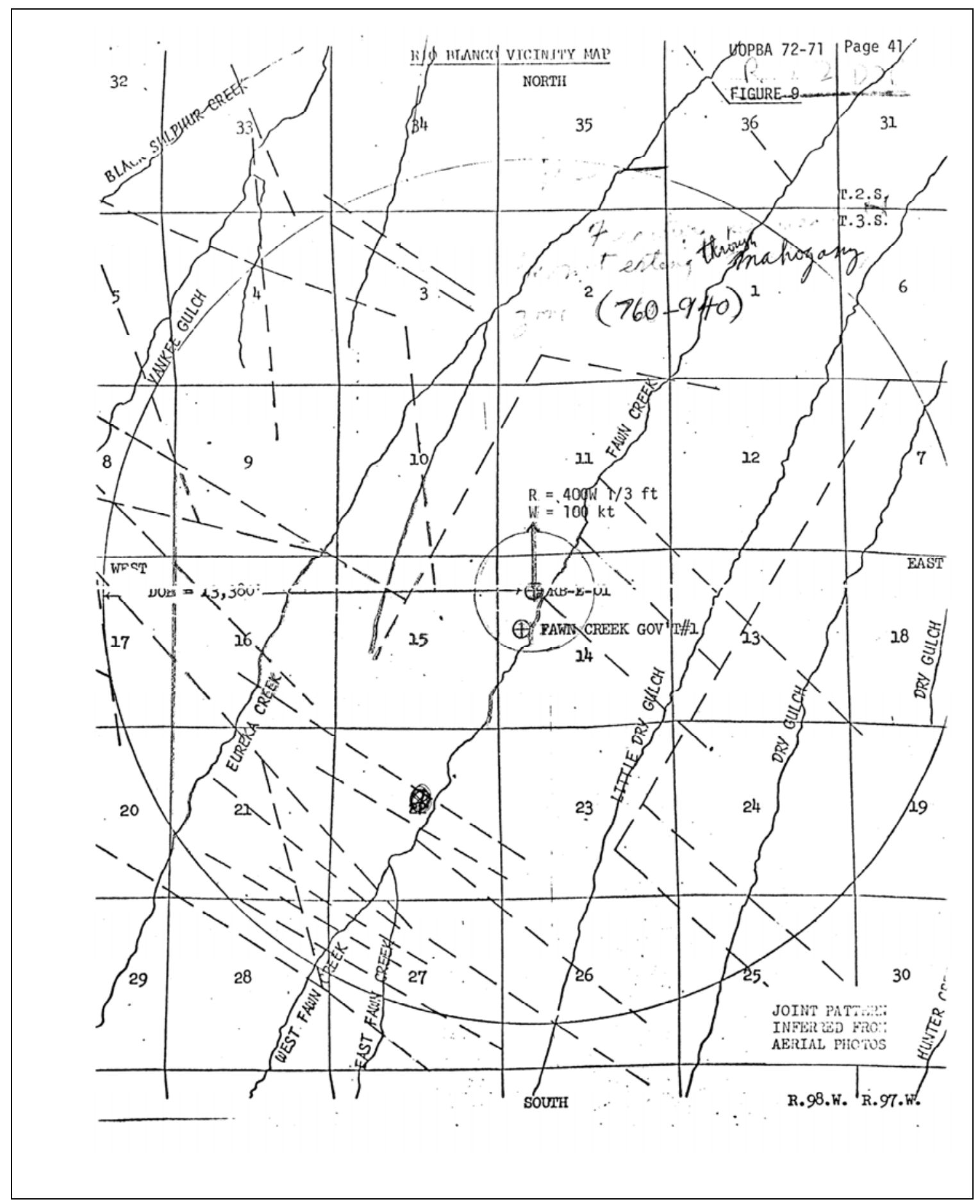

Figure B2. Joints within 23,360 feet of emplacement borehole (scanned copy from informal containment prospectus notebook at LLNL). 
Table B1. Circular statistics.

\begin{tabular}{|c|c|c|c|c|c|c|c|c|}
\hline Parameter & $\mathrm{n}$ & $\mathrm{R}$ & Mean & $\begin{array}{c}\text { Mean } \\
\text { Dispersion }\end{array}$ & $\begin{array}{l}\text { Circular } \\
\text { Variance }\end{array}$ & $\mathrm{K}$ & $\begin{array}{l}95 \% \\
\mathrm{CI}\end{array}$ & $\begin{array}{c}99 \% \\
\mathrm{CI} \\
\end{array}$ \\
\hline \multicolumn{9}{|l|}{ Dataset } \\
\hline Map 1 Raw frequency & 28 & 18.9641 & 128.380 & 0.6773 & 0.3227 & 2.9881 & 1.052 & 1.074 \\
\hline Map 2 Raw frequency & 56 & 37.0608 & 113.759 & 0.6618 & 0.3382 & 2.9040 & 0.763 & 0.779 \\
\hline Combined Trace 1 and 2 & 84 & 55.6172 & 118.697 & 0.6621 & 0.3379 & 2.943 & 0.621 & 0.634 \\
\hline Length Weighted Map 1 & 37,762 & $25,272.6527$ & 122.676 & 0.6693 & 0.3307 & 3.0235 & 0.029 & 0.029 \\
\hline Length Weighted Map 2 & 44,673 & $30,687.1621$ & 118.792 & 0.6867 & 0.3133 & 3.1920 & 0.025 & 0.026 \\
\hline Outcrop all observations & 86 & 76.9867 & 125.288 & 0.8952 & 0.1048 & 9.4305 & 0.294 & 0.300 \\
\hline Outcrop First Quartile & 21 & 20.3982 & 122.323 & 0.9713 & 0.0287 & 33.2352 & 0.304 & 0.310 \\
\hline Outcrop middle quartiles & 43 & 38.8699 & 124.872 & 0.9040 & 0.0960 & 10.1692 & 0.398 & 0.407 \\
\hline $\begin{array}{l}\text { Outcrop Last Quartile } \\
\text { Combined First and Last }\end{array}$ & 22 & 17.7972 & 129.595 & 0.8090 & 0.1910 & 4.9966 & 0.840 & 0.857 \\
\hline $\begin{array}{l}\text { Quartile } \\
\text { Outcrop Elongation }(\mathrm{L} / \mathrm{H})\end{array}$ & 43 & 38.1189 & 125.711 & 0.8865 & 0.1135 & 8.6046 & 0.437 & 0.446 \\
\hline Weighted & 17,726 & $3,393.8237$ & 356.780 & 0.1915 & 0.8085 & 1.2367 & 0.122 & 0.125 \\
\hline
\end{tabular}

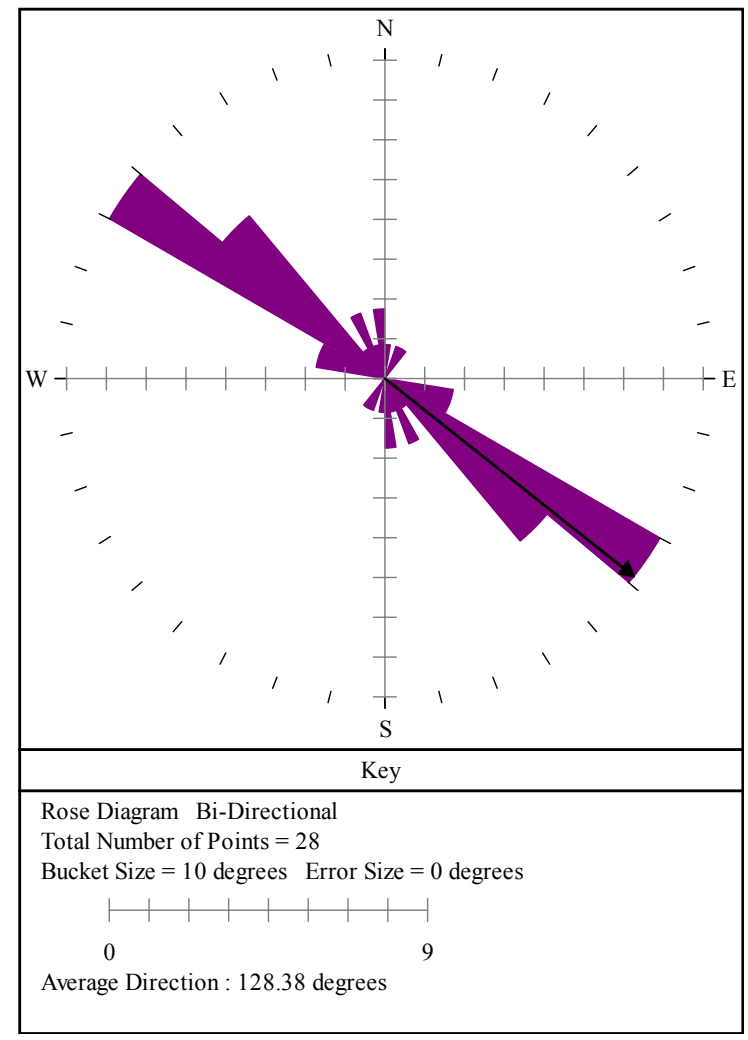

Figure B3. Map 1 data rose diagram 


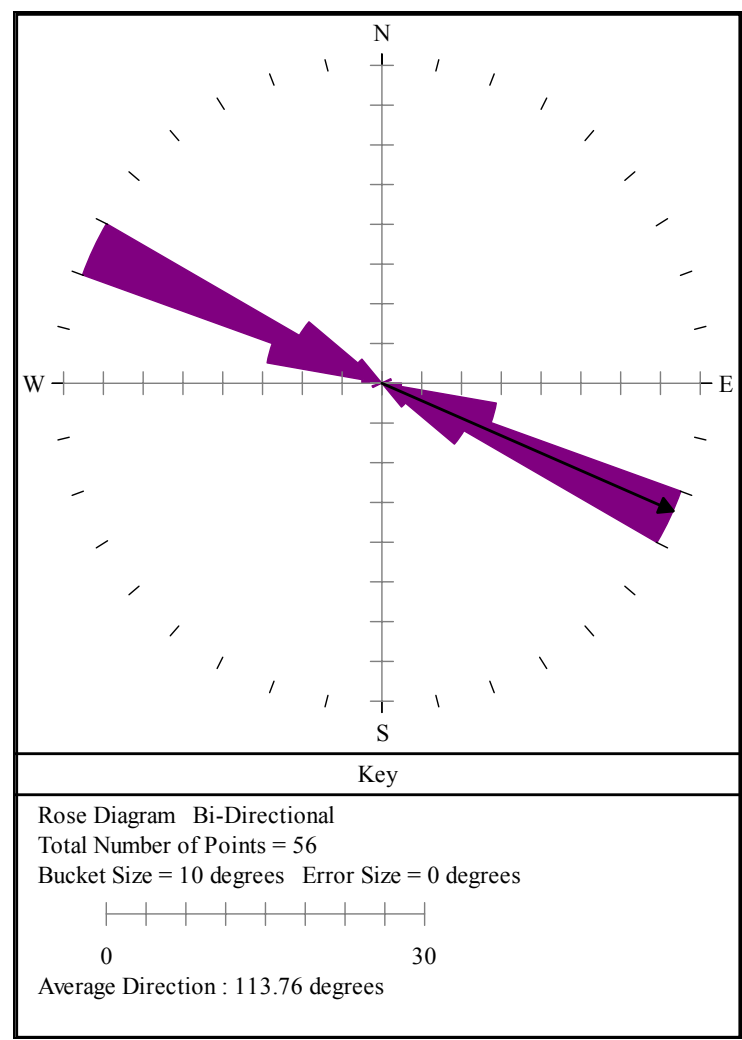

Figure B4. Map 2 data rose diagram.

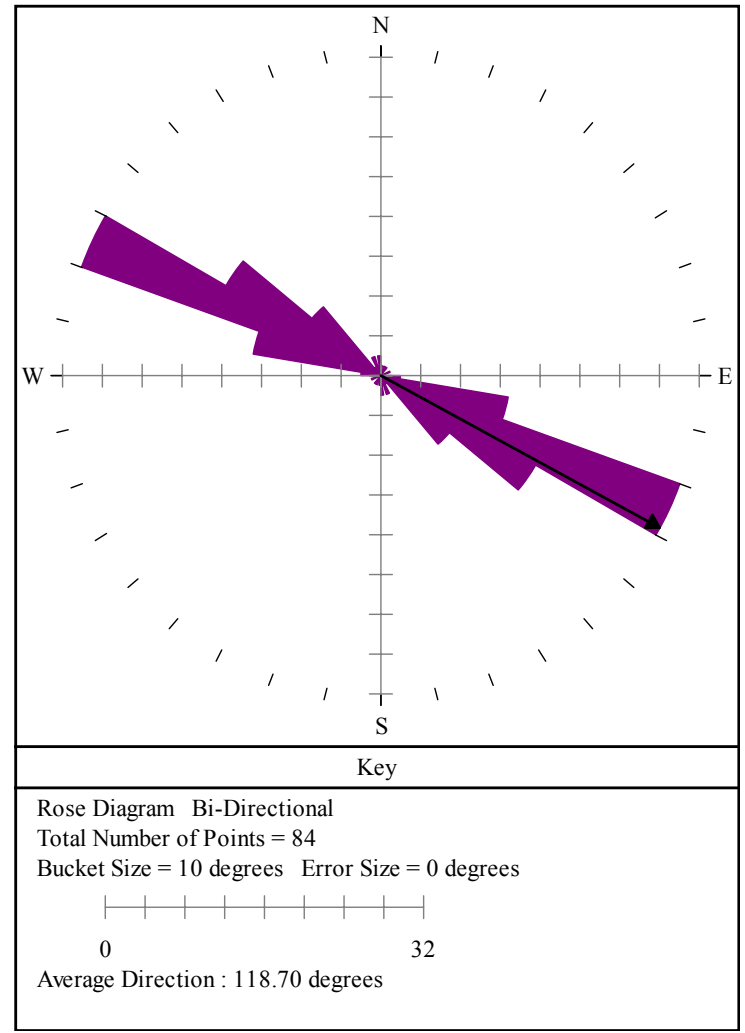

Figure B5. Combined fault and joint orientation. 
Table B2. Directional data from Map 1.

\begin{tabular}{|c|c|c|c|}
\hline Length & Bearing & Length & Bearing \\
\hline 0.99 & 89.01 & 1.11 & 88.89 \\
\hline 0.91 & 89.09 & 1.21 & 88.79 \\
\hline 0.89 & 89.11 & 0.96 & 89.04 \\
\hline 0.86 & 89.14 & 1.27 & 88.73 \\
\hline 1.46 & 88.54 & 1.30 & 88.70 \\
\hline 1.66 & 88.34 & 1.78 & 88.22 \\
\hline 1.51 & 88.49 & 1.40 & 88.60 \\
\hline 1.90 & 88.10 & 0.92 & 89.08 \\
\hline 1.26 & 88.74 & 1.88 & 88.12 \\
\hline 0.91 & 89.09 & 0.97 & 89.03 \\
\hline 2.50 & 87.50 & 1.21 & 88.79 \\
\hline 1.46 & 88.55 & 1.09 & 88.91 \\
\hline 0.67 & 89.33 & 1.38 & 88.62 \\
\hline 1.57 & 88.43 & 2.73 & 87.27 \\
\hline
\end{tabular}

Table B3. Directional data from Map 2.

\begin{tabular}{cccc}
\hline Length & Bearing & Length & Bearing \\
\hline 0.84 & 89.16 & 0.39 & 89.61 \\
0.32 & 89.68 & 0.39 & 89.61 \\
0.44 & 89.56 & 0.51 & 89.49 \\
0.58 & 89.42 & 0.44 & 89.56 \\
0.77 & 89.23 & 0.58 & 89.42 \\
0.84 & 89.17 & 1.18 & 88.82 \\
0.98 & 89.02 & 1.72 & 88.28 \\
0.58 & 89.42 & 6.28 & 83.72 \\
0.41 & 89.60 & 0.51 & 89.49 \\
1.19 & 88.81 & 0.95 & 89.06 \\
1.40 & 88.60 & 0.93 & 89.07 \\
0.88 & 89.12 & 0.79 & 89.21 \\
0.68 & 89.32 & 0.73 & 89.27 \\
1.49 & 88.51 & 0.75 & 89.25 \\
0.87 & 89.13 & 0.95 & 89.05 \\
2.02 & 87.98 & 0.56 & 89.44 \\
0.71 & 89.29 & 0.18 & 89.82 \\
1.09 & 88.92 & 0.64 & 89.36 \\
1.08 & 88.92 & 0.46 & 89.54 \\
0.61 & 89.39 & 0.72 & 89.28 \\
0.09 & 89.91 & 0.90 & 89.10 \\
0.34 & 89.66 & 0.76 & 89.24 \\
0.22 & 89.78 & 0.79 & 89.21 \\
0.23 & 89.77 & 0.70 & 89.30 \\
0.65 & 89.35 & 0.25 & 89.75 \\
0.10 & 89.90 & 0.23 & 89.77 \\
0.39 & 89.61 & 0.71 & 89.29 \\
0.58 & 89.43 & 0.34 &
\end{tabular}


Table B4. Outcrop geometric data (the data in this table are taken from Appendix 1 of the CER Geonuclear reservoir report, arithmetic errors in the original have been corrected).

\begin{tabular}{|c|c|c|c|}
\hline Orientation & Height & Length & L/H Ratio \\
\hline 145.00 & 20.00 & $2,700.00$ & 135.00 \\
\hline 140.00 & 20.00 & $2,300.00$ & 115.00 \\
\hline 135.00 & 20.00 & 800.00 & 40.00 \\
\hline 135.00 & 20.00 & 700.00 & 35.00 \\
\hline 135.00 & 20.00 & 700.00 & 35.00 \\
\hline 160.00 & 50.00 & $2,200.00$ & 44.00 \\
\hline 135.00 & 20.00 & $1,800.00$ & 90.00 \\
\hline 135.00 & 20.00 & $1,500.00$ & 75.00 \\
\hline 135.00 & 20.00 & 600.00 & 30.00 \\
\hline 135.00 & 20.00 & $1,500.00$ & 75.00 \\
\hline 120.00 & 20.00 & 500.00 & 25.00 \\
\hline 160.00 & 20.00 & $2,600.00$ & 130.00 \\
\hline 90.00 & 20.00 & $1,800.00$ & 90.00 \\
\hline 110.00 & 30.00 & 360.00 & 12.00 \\
\hline 11.00 & 20.00 & 400.00 & 20.00 \\
\hline 110.00 & 25.00 & 500.00 & 20.00 \\
\hline 110.00 & 30.00 & 270.00 & 9.00 \\
\hline 110.00 & 15.00 & 120.00 & 8.00 \\
\hline 110.00 & 20.00 & 400.00 & 20.00 \\
\hline 110.00 & 20.00 & 400.00 & 20.00 \\
\hline 110.00 & 25.00 & 500.00 & 20.00 \\
\hline 110.00 & 15.00 & 300.00 & 20.00 \\
\hline 110.00 & 2.00 & 24.00 & 12.00 \\
\hline 110.00 & 4.00 & 120.00 & 30.00 \\
\hline 110.00 & 2.00 & 10.00 & 5.00 \\
\hline 110.00 & 1.00 & 50.00 & 50.00 \\
\hline 110.00 & 1.00 & 20.00 & 20.00 \\
\hline 110.00 & 3.00 & 90.00 & 30.00 \\
\hline 110.00 & 2.00 & 20.00 & 10.00 \\
\hline 110.00 & 4.00 & 400.00 & 100.00 \\
\hline 110.00 & 1.00 & 40.00 & 40.00 \\
\hline 110.00 & 6.00 & 120.00 & 20.00 \\
\hline 110.00 & 3.00 & 42.00 & 14.00 \\
\hline 110.00 & 5.00 & 40.00 & 8.00 \\
\hline 110.00 & 1.00 & 5.00 & 5.00 \\
\hline 110.00 & 1.00 & 15.00 & 15.00 \\
\hline 110.00 & 1.00 & 12.00 & 12.00 \\
\hline 110.00 & 2.00 & 70.00 & 35.00 \\
\hline 130.00 & 20.00 & 300.00 & 15.00 \\
\hline 130.00 & 8.00 & 300.00 & 37.50 \\
\hline 130.00 & 4.00 & 80.00 & 20.00 \\
\hline 0.00 & 12.00 & $2,000.00$ & 166.67 \\
\hline 0.00 & 4.00 & $1,000.00$ & 250.00 \\
\hline 65.00 & 24.00 & 470.00 & 19.58 \\
\hline 65.00 & 26.00 & 510.00 & 19.62 \\
\hline 65.00 & 32.00 & 520.00 & 16.25 \\
\hline 130.00 & 6.00 & 180.00 & 30.00 \\
\hline 130.00 & 10.00 & 230.00 & 23.00 \\
\hline 130.00 & 4.00 & 160.00 & 40.00 \\
\hline 130.00 & 10.00 & 530.00 & 53.00 \\
\hline 130.00 & 8.00 & 90.00 & 11.25 \\
\hline
\end{tabular}

$\mathrm{nr}=$ no record 
Table B4. Outcrop geometric data (the data in this table are taken from Appendix 1 of the CER Geonuclear reservoir report, arithmetic errors in the original have been corrected) (continued).

\begin{tabular}{|c|c|c|c|}
\hline Orientation & Height & Length & L/H Ratio \\
\hline 130.00 & 9.00 & 90.00 & 10.00 \\
\hline 130.00 & 8.00 & 180.00 & 22.50 \\
\hline 130.00 & 5.00 & 210.00 & 42.00 \\
\hline 130.00 & 7.00 & 120.00 & 17.14 \\
\hline 130.00 & 15.00 & 250.00 & 16.67 \\
\hline 130.00 & 8.00 & 130.00 & 16.25 \\
\hline 130.00 & 6.00 & 120.00 & 20.00 \\
\hline 130.00 & 10.00 & 160.00 & 16.00 \\
\hline 130.00 & 10.00 & 300.00 & 30.00 \\
\hline 130.00 & 12.00 & 250.00 & 20.83 \\
\hline 135.00 & 7.00 & 130.00 & 18.57 \\
\hline 135.00 & 10.00 & 280.00 & 28.00 \\
\hline 135.00 & 20.00 & 300.00 & 15.00 \\
\hline 150.00 & 35.00 & $1,200.00$ & 34.29 \\
\hline 145.00 & 10.00 & 170.00 & 17.00 \\
\hline 145.00 & 4.00 & 50.00 & 12.50 \\
\hline 145.00 & 5.00 & 120.00 & 24.00 \\
\hline 145.00 & 12.00 & 240.00 & 20.00 \\
\hline 145.00 & 12.00 & 200.00 & 16.67 \\
\hline 145.00 & 30.00 & 680.00 & 22.67 \\
\hline 145.00 & 30.00 & 700.00 & 23.33 \\
\hline 145.00 & 20.00 & 680.00 & 34.00 \\
\hline 145.00 & 30.00 & 360.00 & 12.00 \\
\hline 140.00 & 45.00 & 900.00 & 20.00 \\
\hline 140.00 & 20.00 & 330.00 & 16.50 \\
\hline 140.00 & 20.00 & 170.00 & 8.50 \\
\hline $\mathrm{nr}$ & 12.00 & 210.00 & 17.50 \\
\hline $\mathrm{nr}$ & 8.00 & 230.00 & 28.75 \\
\hline $\mathrm{nr}$ & 8.00 & 92.00 & 11.50 \\
\hline $\mathrm{nr}$ & 13.00 & 170.00 & 13.08 \\
\hline $\mathrm{nr}$ & 20.00 & 480.00 & 24.00 \\
\hline $\mathrm{nr}$ & 15.00 & 420.00 & 28.00 \\
\hline $\mathrm{nr}$ & 14.00 & 334.00 & 23.86 \\
\hline $\mathrm{nr}$ & 6.00 & 100.00 & 16.67 \\
\hline $\mathrm{nr}$ & 4.00 & 60.00 & 15.00 \\
\hline $\mathrm{nr}$ & 4.00 & 80.00 & 20.00 \\
\hline 145.00 & 25.00 & $1,200.00$ & 48.00 \\
\hline 145.00 & 12.00 & 480.00 & 40.00 \\
\hline 145.00 & 7.00 & 230.00 & 32.86 \\
\hline 145.00 & 4.00 & 350.00 & 87.50 \\
\hline 145.00 & 4.00 & 190.00 & 47.50 \\
\hline 145.00 & 8.00 & 300.00 & 37.50 \\
\hline 145.00 & 12.00 & 600.00 & 50.00 \\
\hline 145.00 & 6.00 & 220.00 & 36.67 \\
\hline 145.00 & 20.00 & 280.00 & 14.00 \\
\hline
\end{tabular}

$\mathrm{nr}=$ no record 


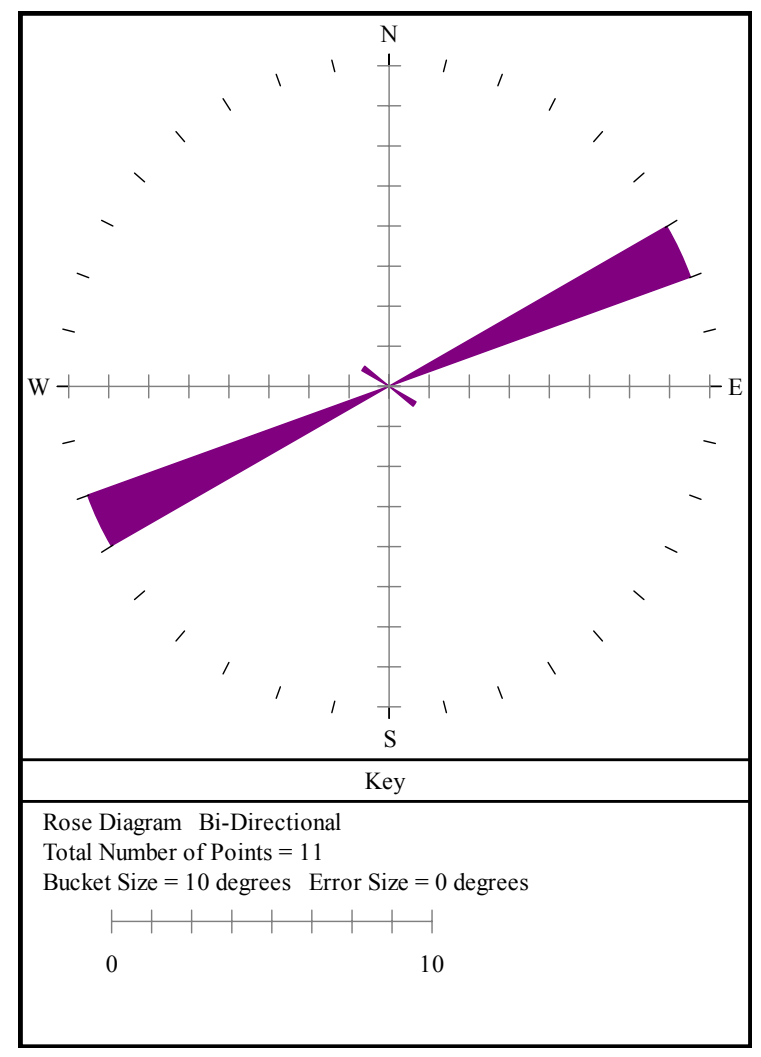

Figure B6. Unweighted rose diagram.

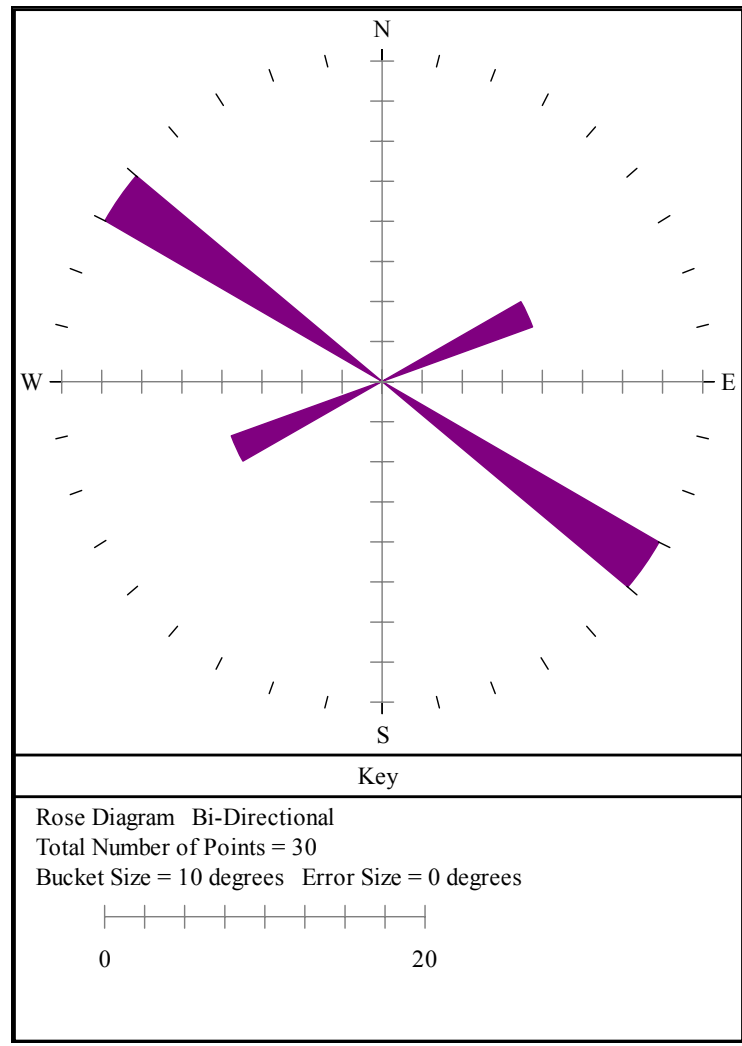

Figure B7. Length-weighted rose diagram. 


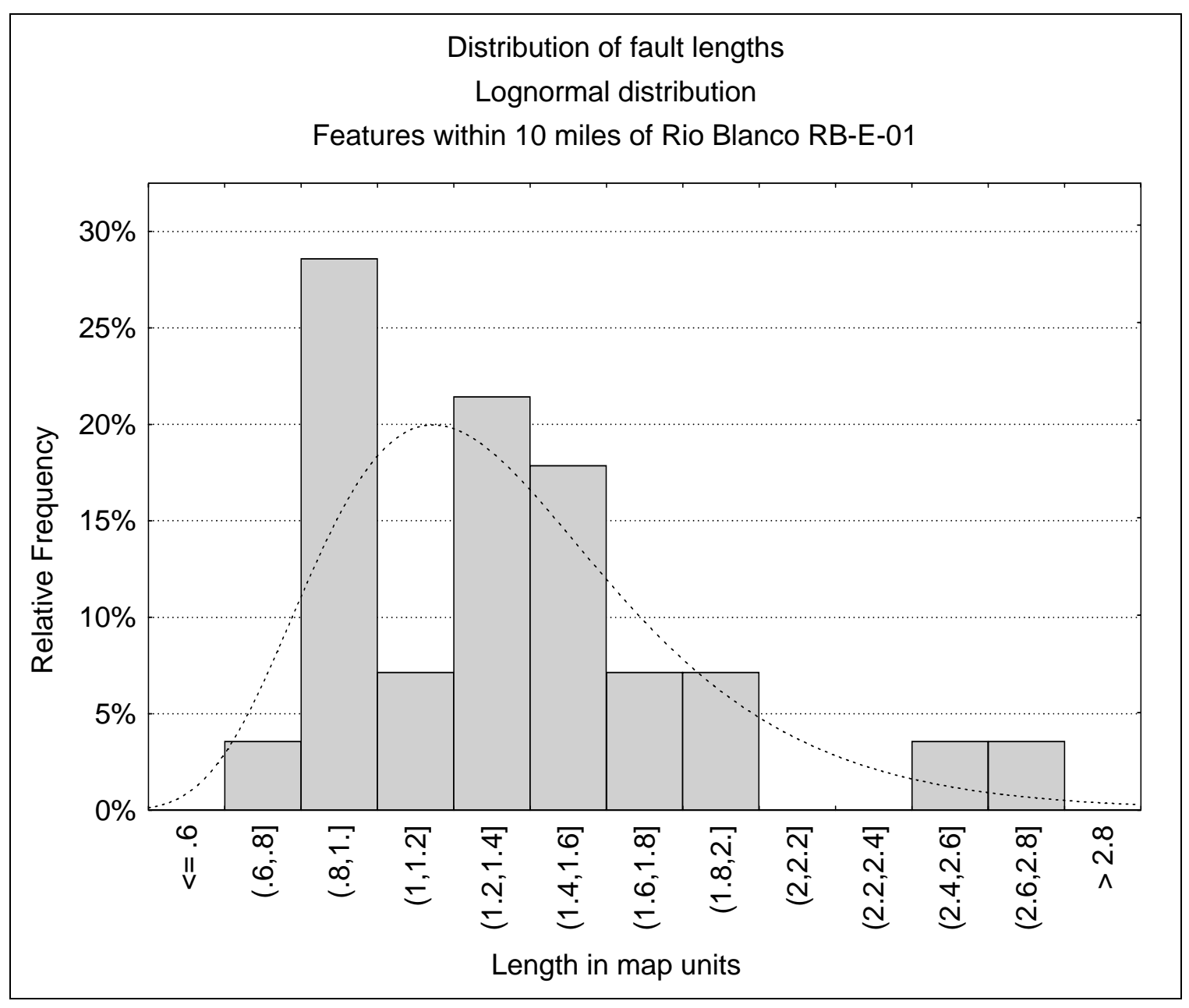

Figure B8. Fault-length distribution. 


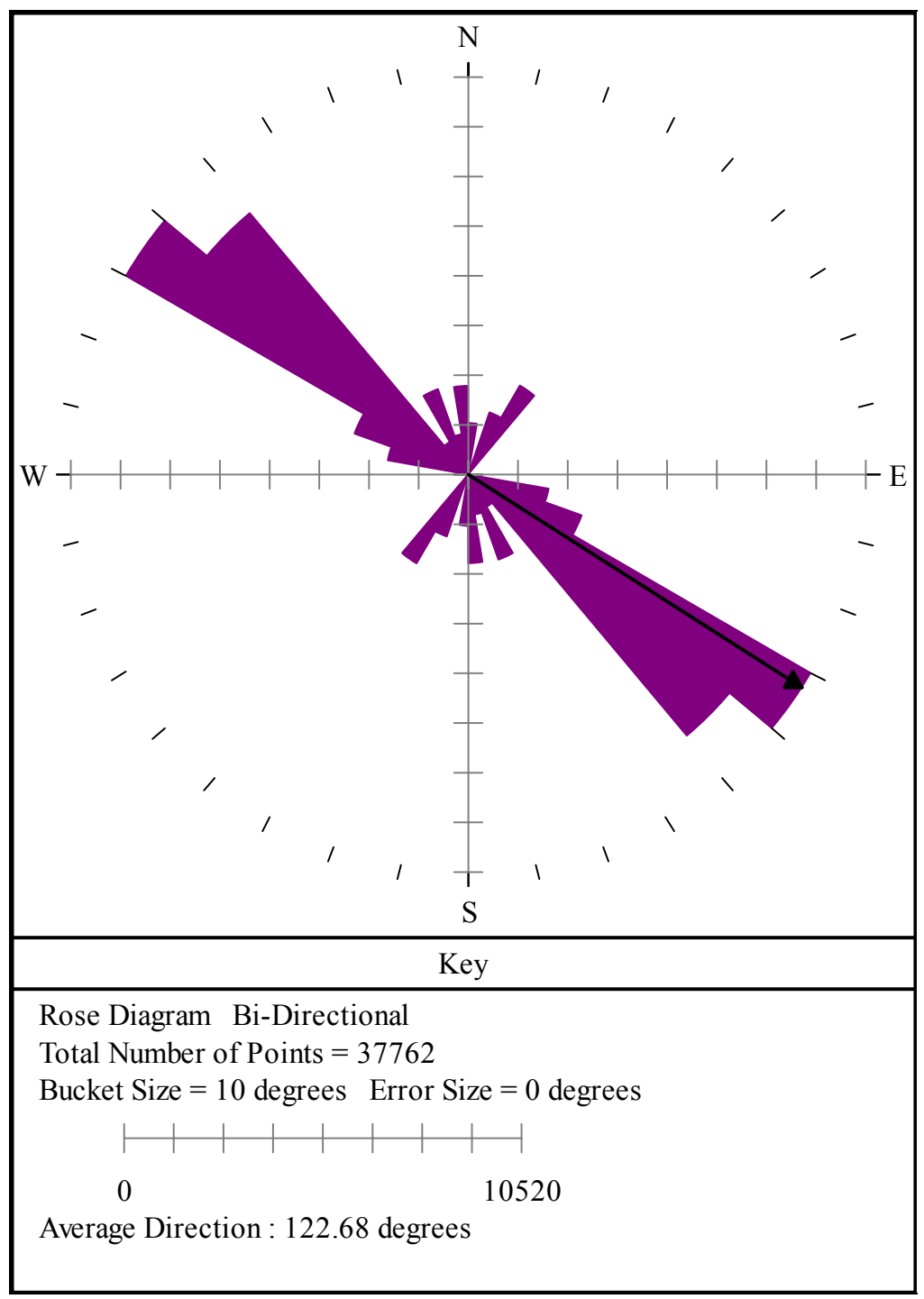

Figure B9. Length-weighted rose diagram, Map 1 data. 


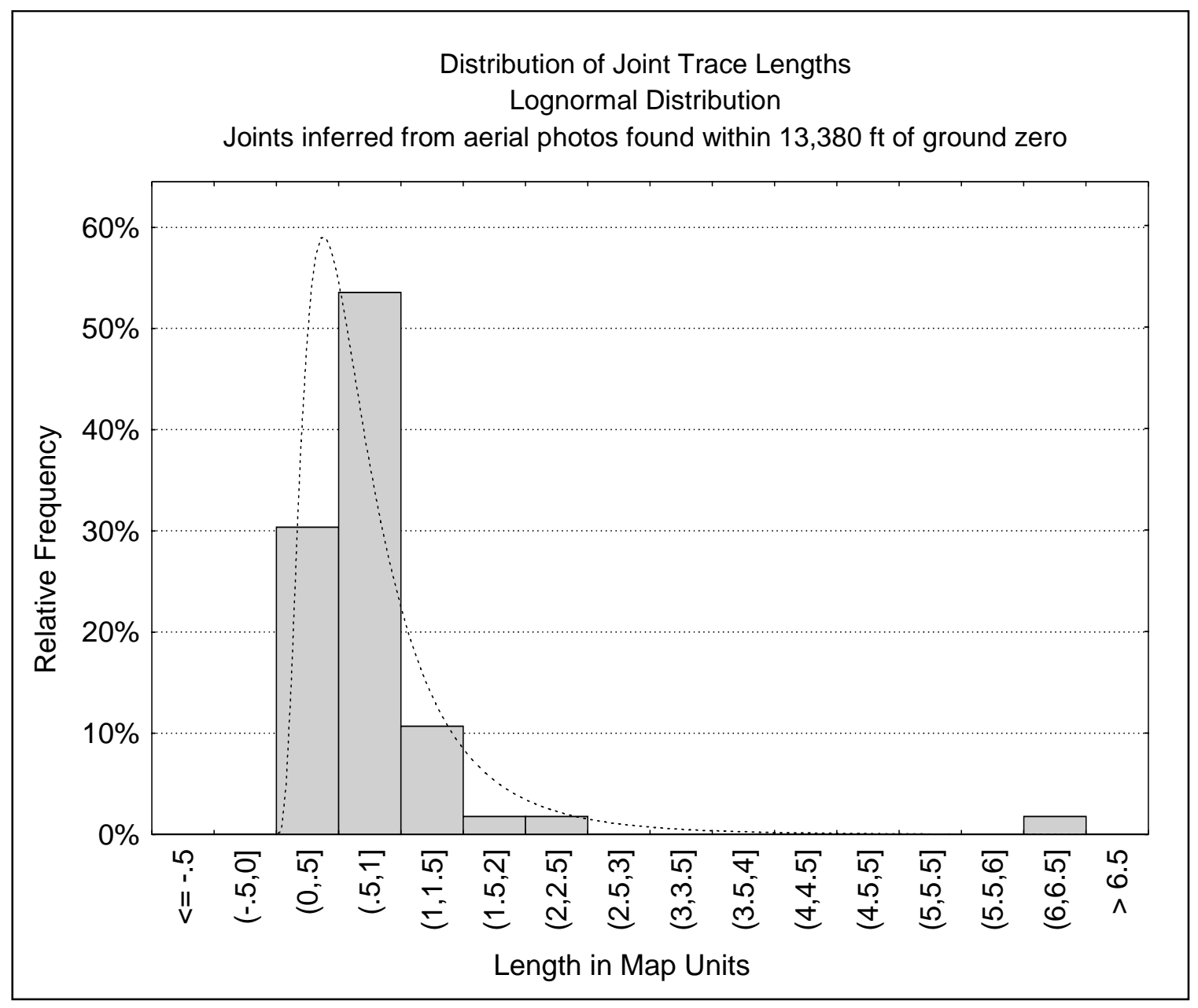

Figure B10. Distribution of proximate joint lengths. 


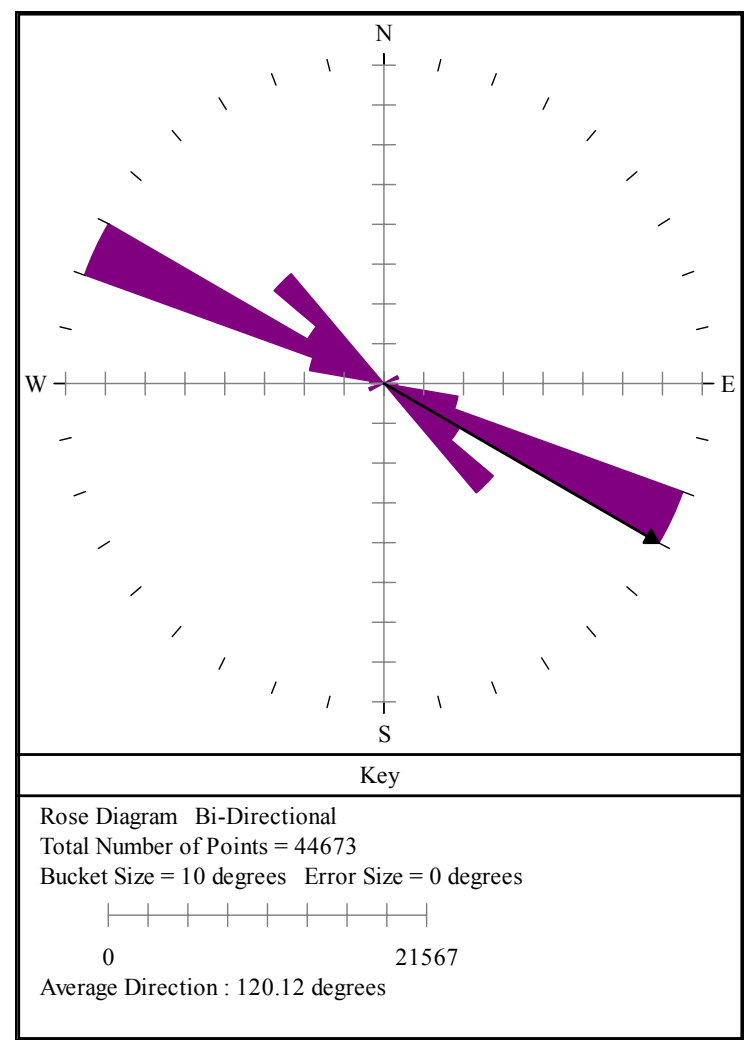

Figure B11.Length-weighted rose diagram, Map 2 data.

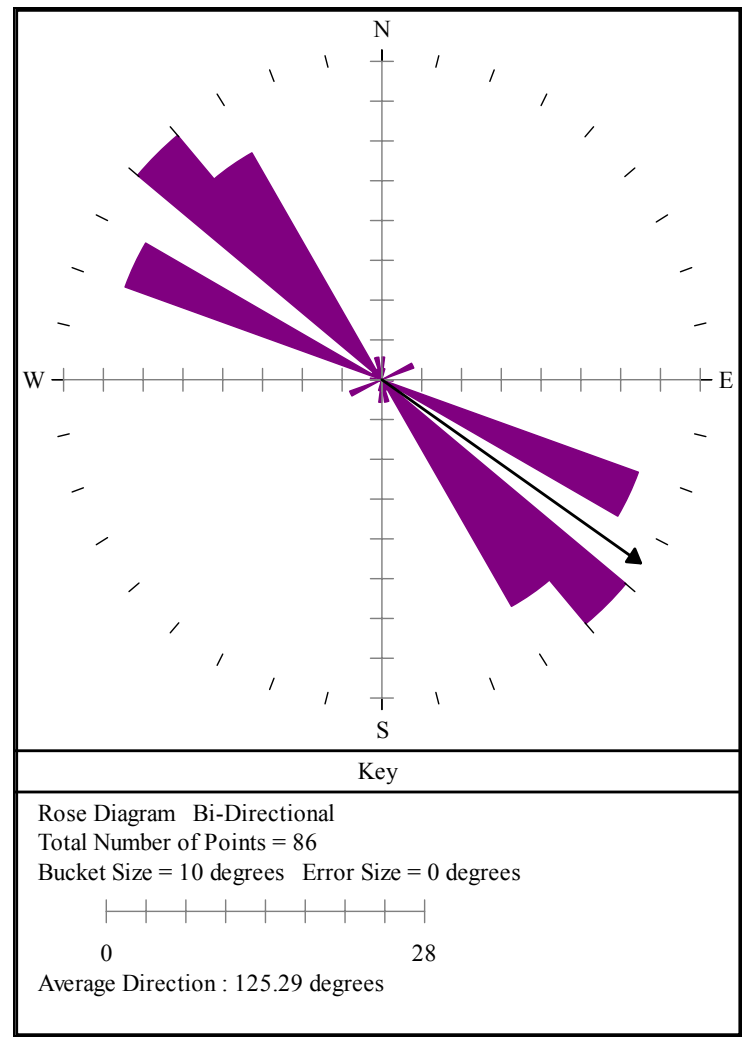

Figure B12. Outcrop orientation rose diagram. 


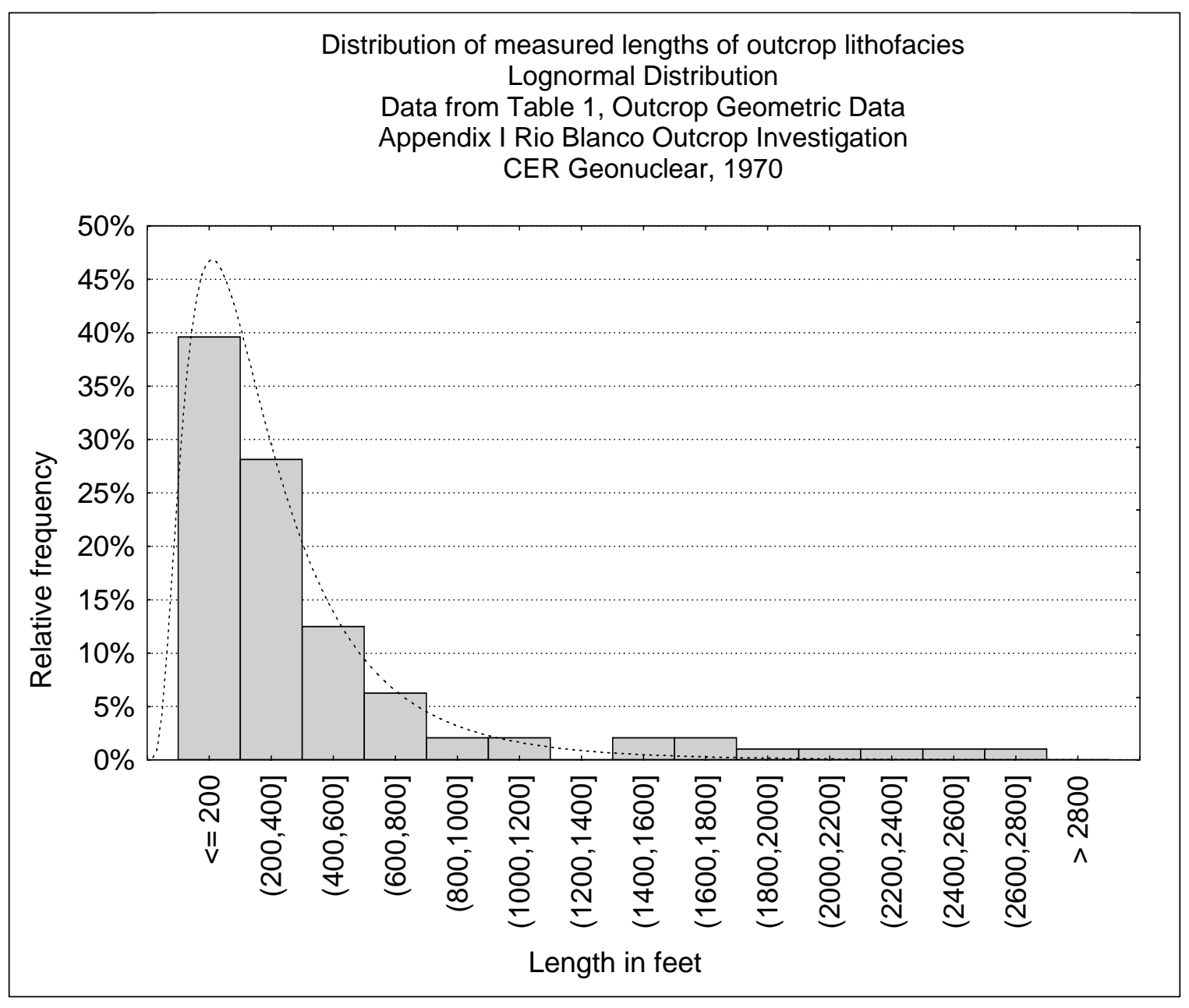

Figure B13. Distribution of outcrop lengths. 
Table B5. Observations of core.

\begin{tabular}{|c|c|c|c|c|}
\hline \multirow[b]{2}{*}{ Hole ID } & \multirow[b]{2}{*}{ Box } & \multicolumn{2}{|c|}{ Interval } & \multirow[b]{2}{*}{ Observations } \\
\hline & & Top & Bottom & \\
\hline RB E 01 & 1 & 5,710 & 5,726 & $\begin{array}{l}\text { Possible, but unlikely, fracture at } 5,716 \text {. Probably drilling related, } \\
\text { no weathering on faces noted, some drilling mud seen. Fracture at } \\
5,719,<1 \mathrm{~mm} \text { aperture. Otherwise core is massive, without } \\
\text { fractures. Core partings indicate that visible bedding does not } \\
\text { significantly effect orientation of parting, see top portion of core } \\
\text { in Figure B19. }\end{array}$ \\
\hline RB E 01 & 2 & 5,727 & 5,743 & $\begin{array}{l}\text { Possible vertical joint at } 5,728 \text { to } 5,729 \text {. Break at } 5,739 \text { cuts } \\
\text { visible lamina (see Figures B20 and B21), drilling related, no } \\
\text { weathering of crystal faces. Thin }(<2 \mathrm{~mm}) \text { carbonaceous lamina } \\
\text { at 5,740 with stated orientation. Other than vertical joint, no } \\
\text { evidence of natural fracturing. }\end{array}$ \\
\hline RB E 01 & 3 & 5,744 & 5,758 & $\begin{array}{l}\text { Uniform, massive, well-sorted sandstone without any visible } \\
\text { indication of fracturing (see Figure B22). }\end{array}$ \\
\hline RB E 01 & 4 & 5,759 & 5,761 & Massive, uniform, no visible evidence of fracturing. \\
\hline RB E 01 & 4 & 5,855 & 5,858 & $\begin{array}{l}\text { Darker gray, finer grained, only fragments of core. No evidence } \\
\text { of natural fracturing on fragment faces. No weathering or staining } \\
\text { detected. Material is lower strength than more massive units, but } \\
\text { appears to contain enough silt/clay to be prone to plastic } \\
\text { deformation rather brittle fracture. }\end{array}$ \\
\hline RB E 01 & 4 & 5,858 & 5,869 & Lighter gray, massive, uniform, unfractured. \\
\hline RB E 01 & 5 & 5,869 & 5,884 & $\begin{array}{l}\text { Thin }(<2 \mathrm{~mm}) \text {, horizontal, carbonaceous lamina at } 5,870 \text {. } \\
\text { Partings are generally coincident with visible change in grain size, } \\
\text { either abrupt coarsening or fining. Partings appear fresh, no } \\
\text { weathering or staining of faces. Probably drilling induced. }\end{array}$ \\
\hline RB E 01 & 6 & 5,885 & 5,899 & $\begin{array}{l}\text { Through 5,885 partings follow darker stringers (see Figures B24 } \\
\text { and B25). Stringers do represent potential fracturing path, } \\
\text { however, horizontal extent seems likely to be limited and small- } \\
\text { scale (on the order of } 1 \mathrm{~cm} \text { ) variation in orientation may limit } \\
\text { propagation. Darker material seems to have a high carbon } \\
\text { content, so plastic deformation may be a possibility. }\end{array}$ \\
\hline RB E 01 & 6 & 6,018 & 6,019 & $\begin{array}{l}\text { Finer-grained layer. Darker, more prone to breakage during } \\
\text { recovery. No evidence of naturally occurring fractures. }\end{array}$ \\
\hline RB E 01 & 7 & 6,019 & 6,038 & $\begin{array}{l}\text { Parting at subtle change in grain size, otherwise massive, uniform } \\
\text { (see Figures B25 and B26, depth 6,022). No natural fractures } \\
\text { detected. }\end{array}$ \\
\hline RB E 01 & 8 & 6,039 & 6,048 & $\begin{array}{l}\text { Light and dark gray layering in fine-grained, unfractured sand to } \\
\text { siltstone. No fractures detected. }\end{array}$ \\
\hline RB E 01 & 8 & 6,451 & 6,455 & $\begin{array}{l}\text { Massive, unfractured, light to medium gray, well-sorted } \\
\text { sandstone. }\end{array}$ \\
\hline RB E 01 & 8 & 6,455 & 6,465 & $\begin{array}{l}\text { Dark gray, fine-grained fragments. Arcuate faces without } \\
\text { preferential orientation. No complete core this interval. }\end{array}$ \\
\hline RB E 01 & 9 & 6,466 & 6,477 & $\begin{array}{l}\text { Vertical fracture } 8 \text { to } 10 \text { inches in length, }<1 \mathrm{~mm} \text { aperture, cuts } \\
\text { lamina without deflection, Fe staining visible when mud removed } \\
\text { Appears to be natural fracture (see Figure B28); otherwise } \\
\text { unfractured. }\end{array}$ \\
\hline RB E 01 & 9 & 6,900 & 6,907 & Massive, no fracturing, partings drilling induced. \\
\hline RB E 01 & 10 & 6,909 & 6,926 & $\begin{array}{l}\text { 8-inch high-angle fracture at } 6,913 \text {, in dark gray, fine-grained } \\
\text { material, calcite void filling noted around small }(<3 \mathrm{~mm}) \text { dark } \\
\text { inclusions at } 6,922 \text {. Near vertical } 6 \text { - to } 10 \text {-inch fracture at } 6,924 \text { to } \\
6,925 \text { (see Figure B28). }\end{array}$ \\
\hline
\end{tabular}


Table B5. Observations of core (continued).

\begin{tabular}{|c|c|c|c|c|}
\hline \multirow[b]{2}{*}{ Hole ID } & \multirow[b]{2}{*}{ Box } & \multicolumn{2}{|c|}{ Interval } & \multirow[b]{2}{*}{ Observations } \\
\hline & & Top & Bottom & \\
\hline RB E 01 & 11 & 6,927 & 6,943 & $\begin{array}{l}\text { Figure B29 shows a stringer of carbonaceous material at a depth } \\
\text { of } 6,940 \text {. No natural fractures were detected in the remaining } \\
\text { portion of core in this box. The core grades to finer-grained, } \\
\text { darker material with depth, which showed reduced recovery size, } \\
\text { being mainly cuttings by the depth of } 6,943 \text {. }\end{array}$ \\
\hline RB E 01 & 12 & 6,944 & 6,946 & $\begin{array}{l}\text { Fine-grained, dark gray, primarily fragments recovered. No } \\
\text { evidence of weathering detected on faces of fragments. Breaks } \\
\text { appear to be due to drilling process rather than pre-existing } \\
\text { fractures. }\end{array}$ \\
\hline RB E 01 & 12 & 7,096 & $7,7,03$ & $\begin{array}{l}\text { Uniform texture, massive, unfractured, light to medium gray } \\
\text { sandstone. Very well sorted. }\end{array}$ \\
\hline RB E 01 & 13 & 7,704 & 7,713 & $\begin{array}{l}\text { No fractures detected. Grades from uniform, massive, well-sorted, } \\
\text { light to medium gray sandstone to darker gray, finer-grained sand } \\
\text { to siltstone. Core pieces get smaller with grain size. }\end{array}$ \\
\hline RB E 01 & 14 & 7,714 & 7,724 & $\begin{array}{l}\text { Filled fracture at } 7,715,<1-\mathrm{mm} \text { aperture, minor Fe staining. Core } \\
\text { is medium-grained sandstone with thin }(<1 \mathrm{~mm}) \text { carbonaceous } \\
\text { lamina at roughly } 1-\mathrm{cm} \text { intervals. No preferential parting } \\
\text { orientation noted. Other than previously noted, no natural } \\
\text { fractures. }\end{array}$ \\
\hline RB E 01 & 15 & 7,725 & 7,735 & $\begin{array}{l}\text { Filled fracture at } 7,728 \text {. Fracture filling is black, shiny material, } \\
\text { apparently carbonaceous, no visible Fe staining. Cuts through } \\
\text { depositional layering. Remainder of material in box is dark gray, } \\
\text { finer-grained, fragments. No visible weathering of crystal edges, } \\
\text { faces appear fresh. No other fracturing detected. }\end{array}$ \\
\hline RB E 01 & 16 & 7,738 & 7,747 & $\begin{array}{l}\text { Fine-grained fragments coarsening with depth. Becomes } \\
\text { competent at } 7,743 \text { and massive by } 7,747 \text {. No evidence of } \\
\text { weathering on fragments. No natural fractures detected. }\end{array}$ \\
\hline RB E 01 & 17 & 7,748 & 7,754 & $\begin{array}{l}\text { Uniform texture, unfractured, massive, medium gray, well-sorted } \\
\text { sandstone. }\end{array}$ \\
\hline RB U-2 & 1 & 7,050 & 7,052 & $\begin{array}{l}\text { Small } 1 \text { - to } 1.5 \text {-in-long partings parallel to contacts where grain } \\
\text { texture and/or color changes. Orientation data apply to visible } \\
\text { striations and partings. Material becomes darker and finer grained } \\
\text { at bottom ( } 1 \text { in) of core. Note parting at bottom of core appears to } \\
\text { be drilling related. No natural fractures noted. }\end{array}$ \\
\hline RB U-2 & 1 & 7,052 & 7,053 & $\begin{array}{l}\text { Possible near-vertical fracture face on portion of core. Very minor } \\
\text { Fe staining on mafic/ultra-mafic grains. Fe halos }<1 \mathrm{~mm} \text { where } \\
\text { observed. Fe staining not seen on other portions of core. Not } \\
\text { fragment is approximately } 2 \text { inches long. }\end{array}$ \\
\hline RB U-2 & 1 & 7,053 & 7,054 & $\begin{array}{l}\text { Orientation measurements apply to thin }(<1 \mathrm{~mm}) \text { dark gray to } \\
\text { black lamina. No evidence of preferential parting at or parallel to } \\
\text { the lamina. Orientation grades to alpha }=20 \text { degrees, beta }=20 \\
\text { degrees at bottom of core, but lamina are becoming indistinct. } \\
\text { Two inch fragment with possible, very minor Fe staining on } \\
\text { vertical face found in box below this core. }\end{array}$ \\
\hline RB U-2 & 1 & 7,054 & 7,055 & $\begin{array}{l}\text { Break in core, parallel to dark, carbon-rich lamina. Appears to be } \\
\text { drilling related. Very minor Fe staining, may be related to } \\
\text { handling, did not seem a natural occurrence. }\end{array}$ \\
\hline RB U-2 & 1 & 7,055 & 7,056 & $\begin{array}{l}\text { Core ends with lithology change, break follows contact, with } \\
\text { approximately } 1 \mathrm{~mm} \text { of dark gray to black, possibly micaceous or } \\
\text { carbonaceous material on face. Appears to be drilling related. }\end{array}$ \\
\hline
\end{tabular}


Table B5. Observations of core (continued).

\begin{tabular}{|c|c|c|c|c|}
\hline \multirow[b]{2}{*}{ Hole ID } & \multirow[b]{2}{*}{ Box } & \multicolumn{2}{|c|}{ Interval } & \multirow[b]{2}{*}{ Observations } \\
\hline & & Top & Bottom & \\
\hline RB U-2 & 1 & 7,056 & 7,057 & $\begin{array}{l}\text { Small }(<1 \mathrm{~cm} \text { in length) randomly oriented fractures in dark gray, } \\
\text { fine-grained material. Fractures are healed with light gray calcite } \\
\text { cement. Orientation measures are best visual estimate of } \\
\text { predominate direction. Plug was drilled from core, not change in } \\
\text { nature or orientation of fractures observable in plug walls, } \\
\text { material showed no cracking due to plug drilling or cutting. }\end{array}$ \\
\hline RB U-2 & 1 & 7,057 & 7,061 & $\begin{array}{l}\text { The remainder of this box to a depth of } 7,061 \text { consists of small } \\
(<8 \mathrm{~cm}) \text { fragments of darker gray, fine-grained material. No } \\
\text { distinct orientation of breakage could be discerned from those } \\
\text { fragments where the borehole/core wall could be identified. } \\
\text { Breakage appears to be drilling related, no weathering was } \\
\text { detected on fragment faces. The finer-grained material seems } \\
\text { more prone to breakage than the coarser layers. }\end{array}$ \\
\hline RB U-2 & 2 & 7,709 & 7,710 & $\begin{array}{l}\text { Dark gray to black lamina measured at orientations of alpha }=10 \text {, } \\
\text { beta }=15, \text { alpha }=4, \text { beta }=2 \text {, alpha }=7, \text { beta }=18, \text { and alpha }=5 \text {, } \\
\text { beta }=2 \text {. Core parts along these laminae, no evidence of pre- } \\
\text { drilling parting, mineral grain edges are fresh, with water soluble } \\
\text { mud film (assumed to be drilling related). }\end{array}$ \\
\hline RB U-2 & 2 & 7,710 & 7,712 & $\begin{array}{l}\text { Very small linear openings parallel to dark laminae, may be } \\
\text { erosion resulting from when core was sawn. Length is typically } \\
<1 \mathrm{~cm} \text {. Overall orientation is plus or minus } 5 \text { degrees of } \\
\text { horizontal. }\end{array}$ \\
\hline RB U-2 & 2 & 7,713 & 7,715 & $\begin{array}{l}\text { Partings along black lamina, carbonaceous material which marks } \\
\text { paper, presumably coal. Spacing is roughly } 2 \mathrm{~cm} \text { between lamina. } \\
\text { Intervening material is friable, only small fragments recovered. }\end{array}$ \\
\hline RB U-2 & 2 & 7,715 & 7,717 & $\begin{array}{l}\text { No lamina or partings, very minor Fe staining on vertical face, } \\
\text { may be related to core handling }\end{array}$ \\
\hline RB U-2 & 2 & 7,717 & 7,718 & $\begin{array}{l}\text { Numerous finer-grained clasts in coarser grained matrix. Clasts } \\
\text { have healed/filled fractures showing variable, but generally sub- } \\
\text { horizontal orientation. No evidence of open, natural fractures. } \\
\text { Parting is coincident with dark, carbonaceous lamina. }\end{array}$ \\
\hline RB U-2 & 3 & 7,698 & 7,708 & $\begin{array}{l}\text { Massive, well-sorted gray sandstone through } 7,708 \text {, all partings } \\
\text { appear drilling related, no weathering of crystal faces noted. } \\
\text { Some partings coincident with darker lamina, but other cut } \\
\text { lamina. Very limited anisotropy of competence }\end{array}$ \\
\hline RB U-2 & 3 & 7,719 & 7,721 & $\begin{array}{l}\text { No natural fractures, partings cut through visible lamina without } \\
\text { preferential direction. }\end{array}$ \\
\hline RB U-2 & 3 & 7,722 & 7,725 & $\begin{array}{l}\text { Fine-grained, massive, no visible fractures, no preferred } \\
\text { orientation to partings. All partings appear to be drilling related. } \\
\text { No weathering noted on crystal edges. }\end{array}$ \\
\hline RB-MHF & 1 & 5958 & 6852 & $\begin{array}{l}\text { Widely spaced cuttings, no core. Lithologically indistinguishable } \\
\text { from RB U-2 and RB-E01 Ranges from dark fine-grained to light } \\
\text { coarser grained. Carbonaceous lamina appear to be plane of } \\
\text { weakness when laterally continuous and when thicker than } 0.5 \\
\mathrm{~mm} \text {. }\end{array}$ \\
\hline RB-MHF & 2 & 7,031 & 7,082 & $\begin{array}{l}\text { Widely spaced cuttings, no core. Lithologically indistinguishable } \\
\text { from RB U-2 and RB-E01 and previous box from RB-MHF. } \\
\text { Fragments are generally smaller than in box 1. Ranges from dark } \\
\text { fine-grained to light coarser grained. }\end{array}$ \\
\hline
\end{tabular}




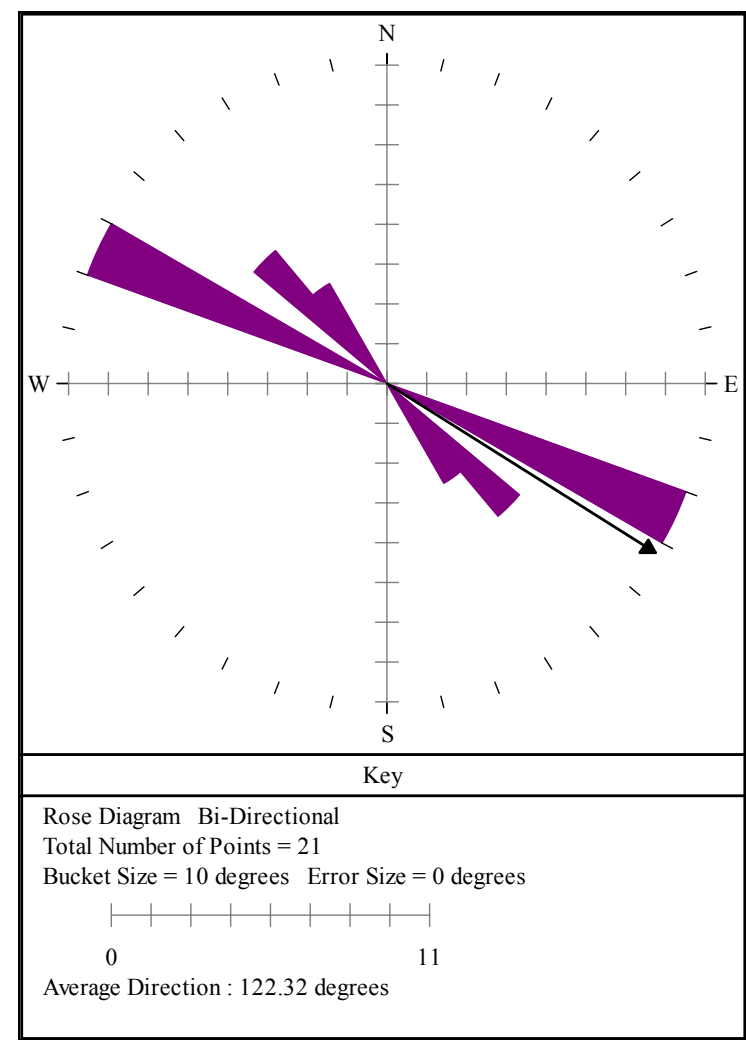

Figure B14. First quartile (elongation ranking) of outcrop orientation.

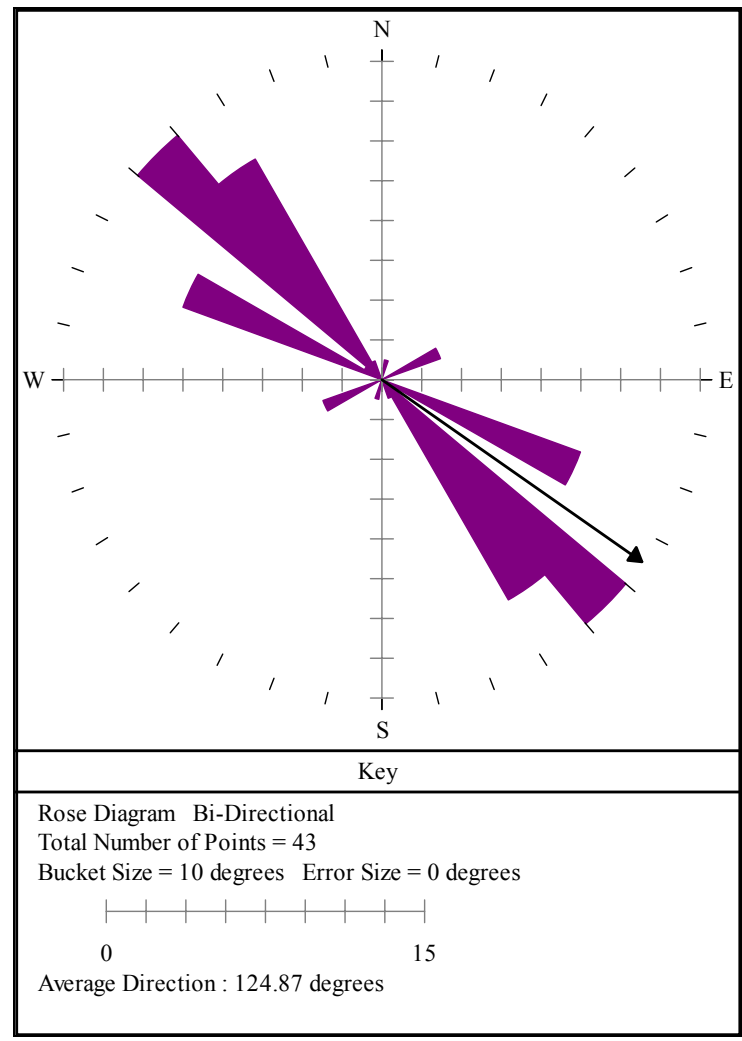

Figure B15. Middle (25\% to $75 \%$ ) quartiles (elongation ranking) of outcrop orientation. 


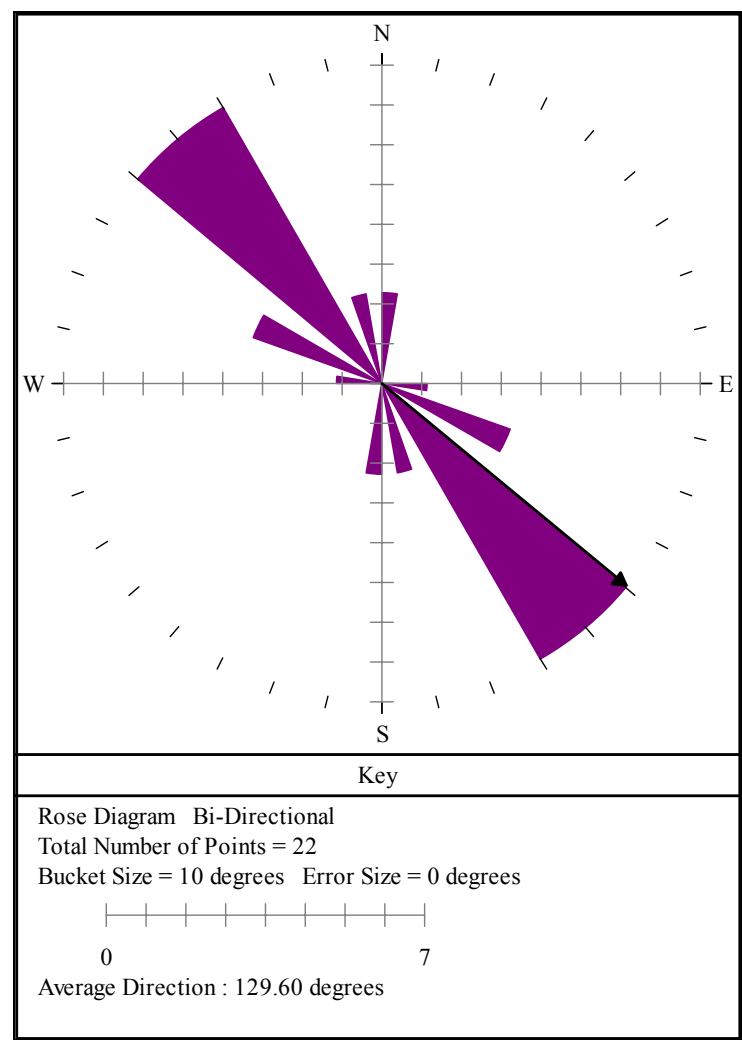

Figure B16. Last quartile (elongation ranking) of outcrop orientation.

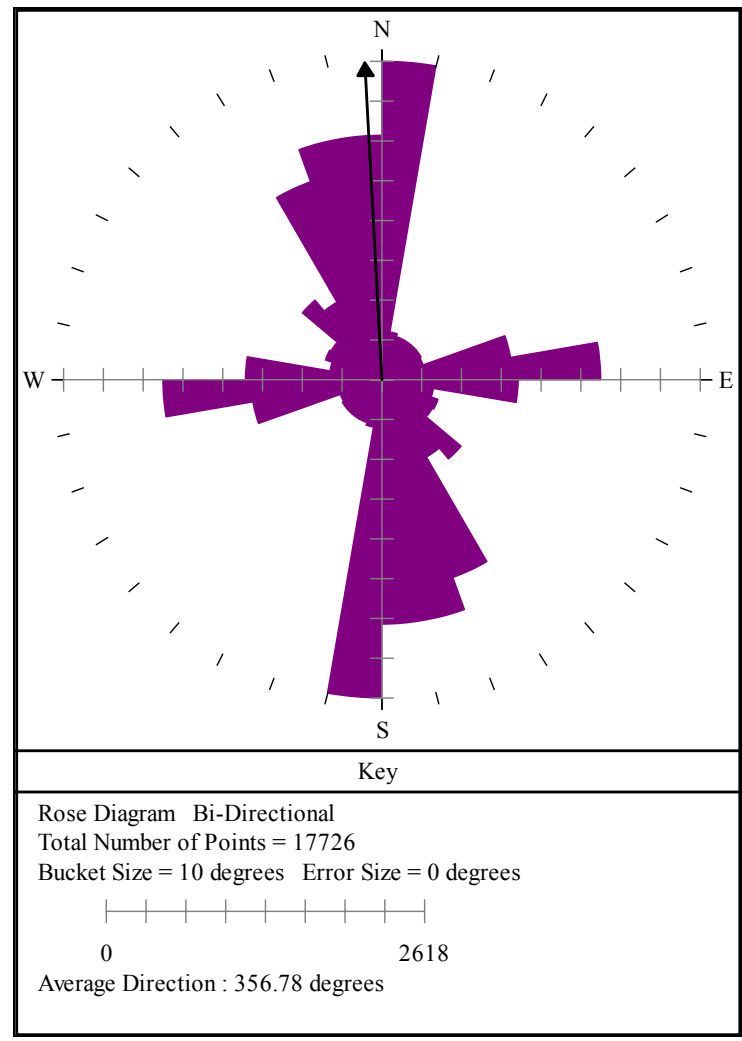

Figure B17. Elongation weighted rose diagram of outcrop orientation. 


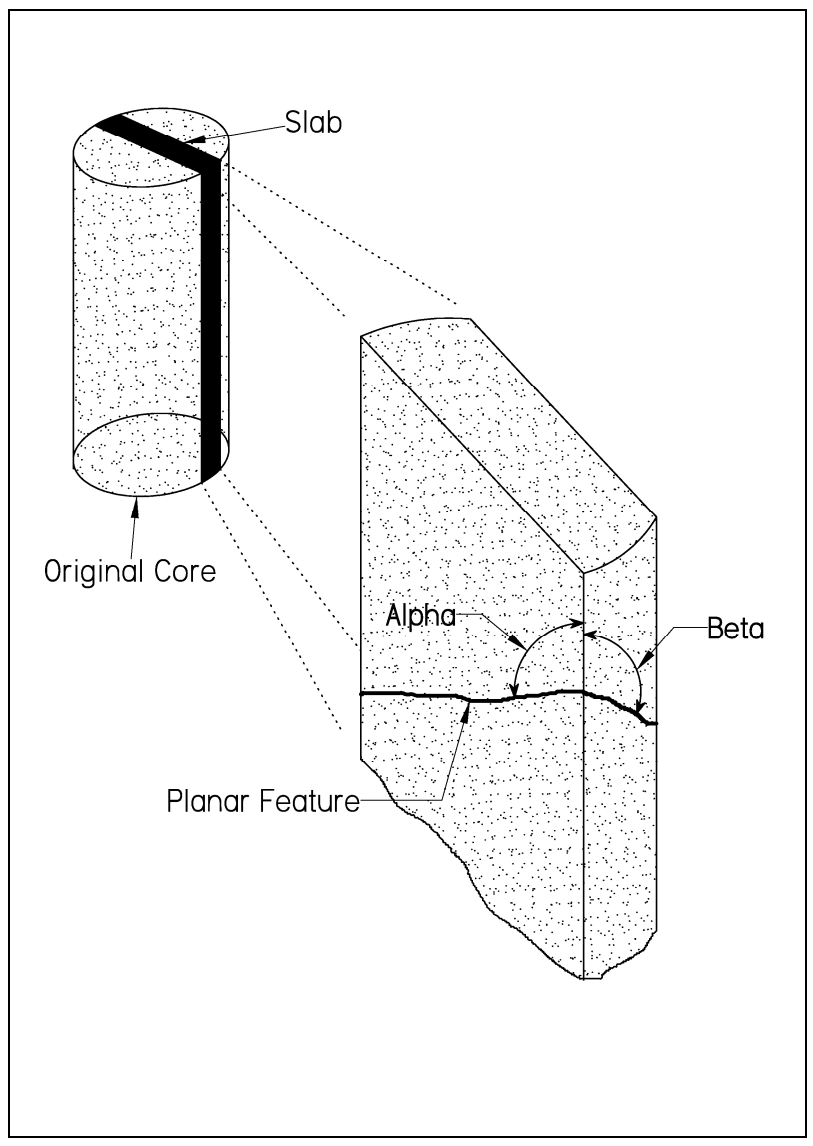

Figure B18. Method used to measure orientation of planar features in core slabs.

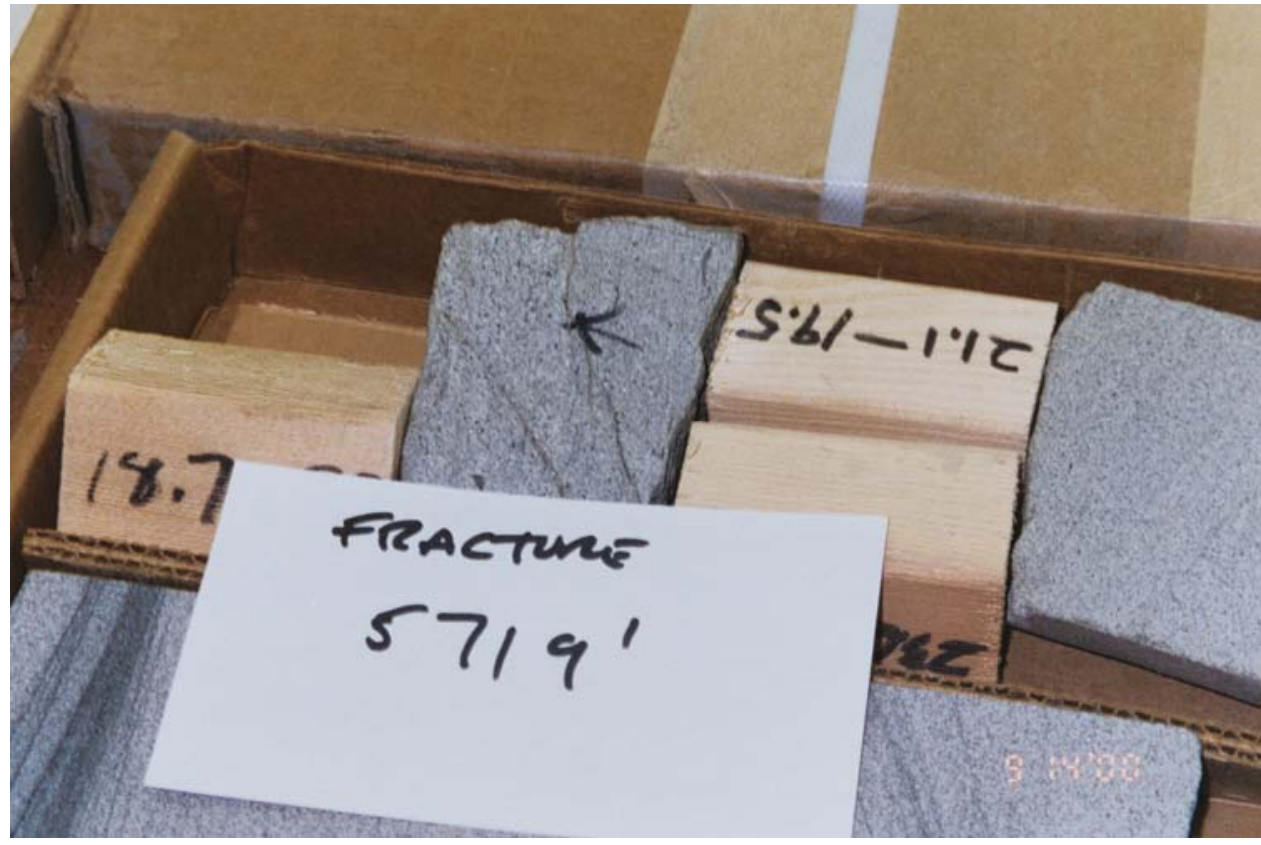

Figure B19. RB E 01 Fracture, less than $1 \mathrm{~mm}$ aperture (image by Clay Cooper). 


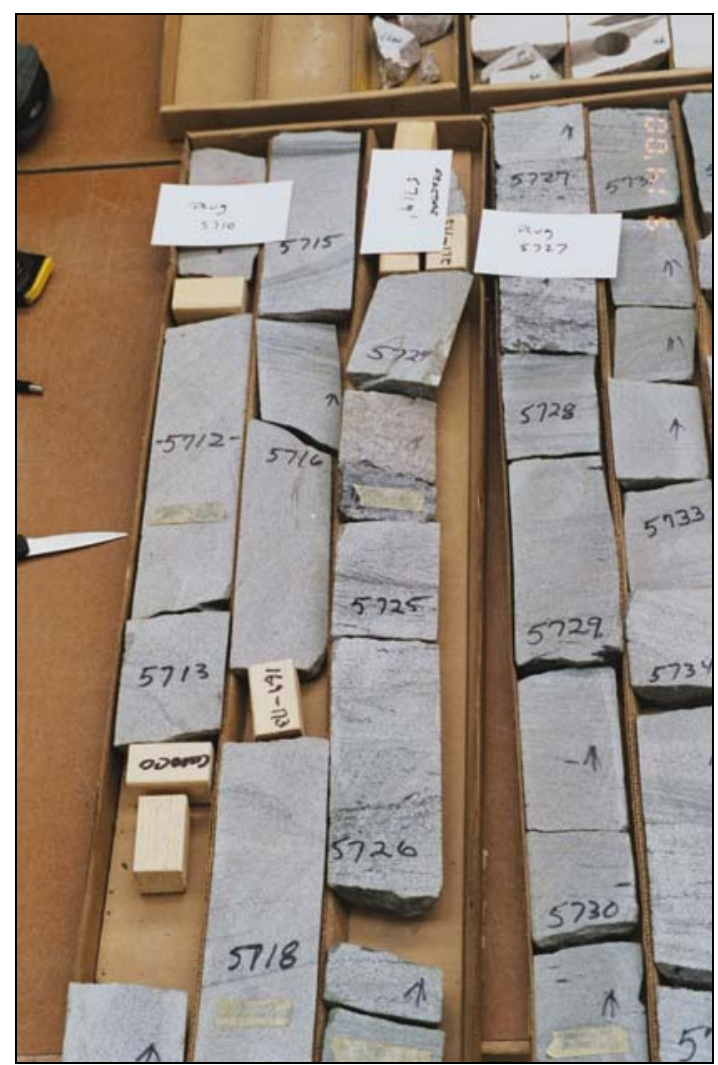

Figure B20. RB E 01 core. Numbers refer to feet below land surface (image by Clay Cooper).

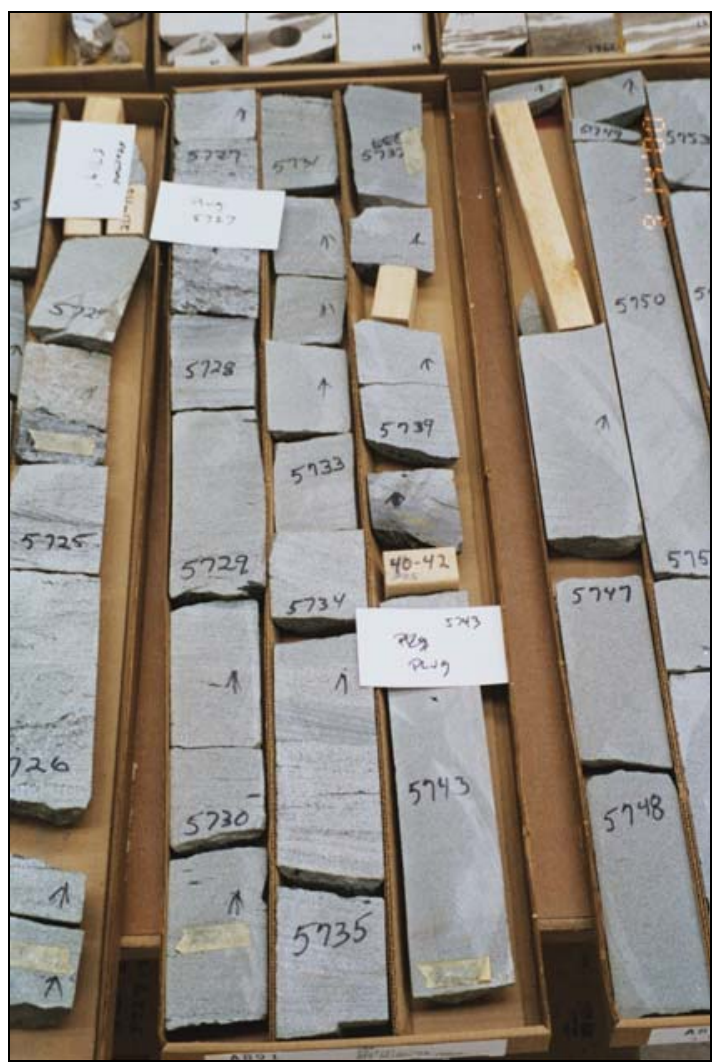

Figure B21. RB E 01 core. Numbers refer to feet below land surface (image by Clay Cooper). 


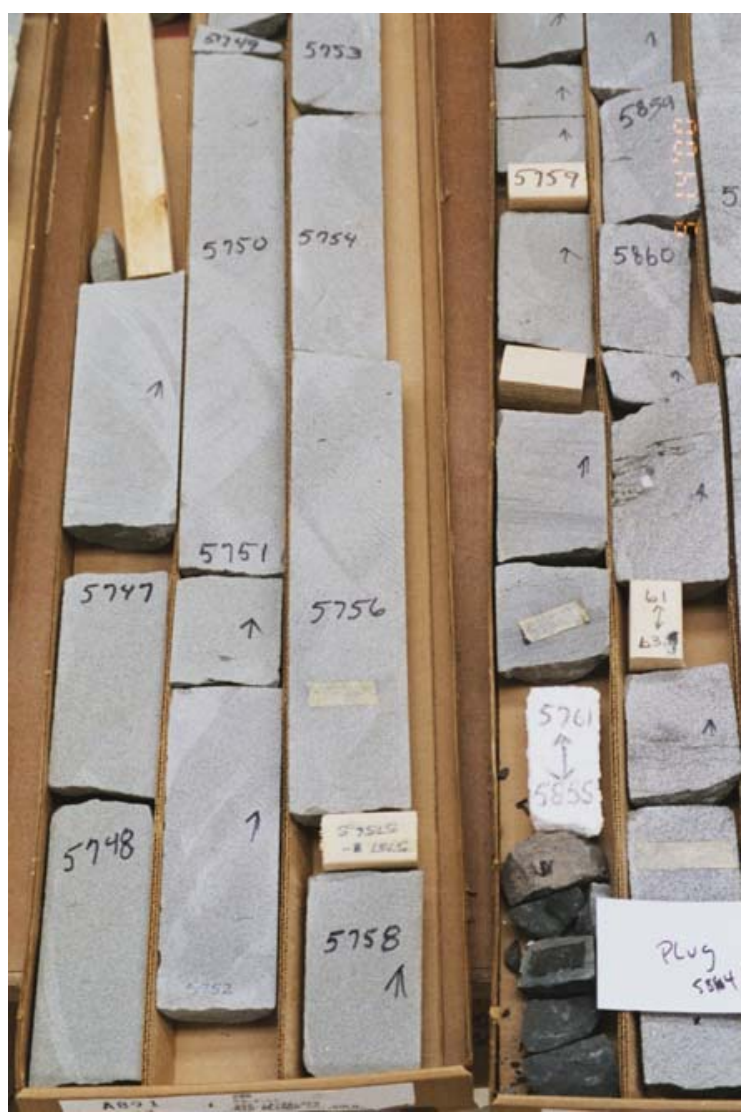

Figure B22. RB E 01 core. Numbers refer to feet below land surface (image by Clay Cooper).

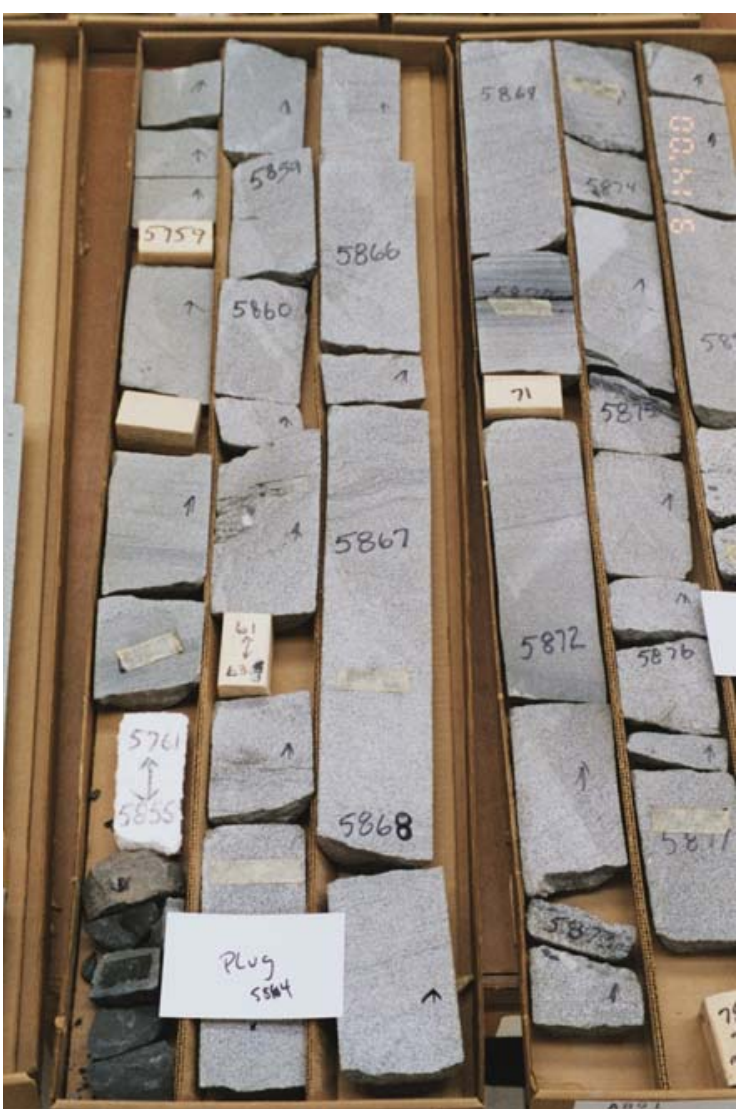

Figure B23. RB E 01 core (image. Numbers refer to feet below land surface by Clay Cooper). 


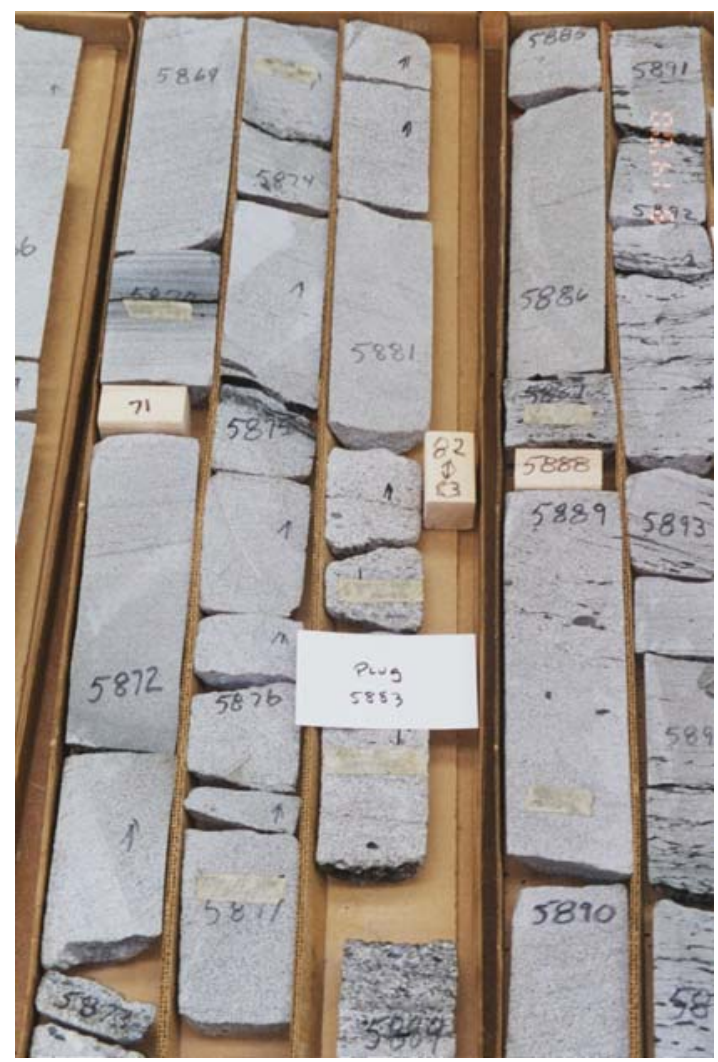

Figure B24. RB E 01. Numbers refer to feet below land surface (image by Clay Cooper).

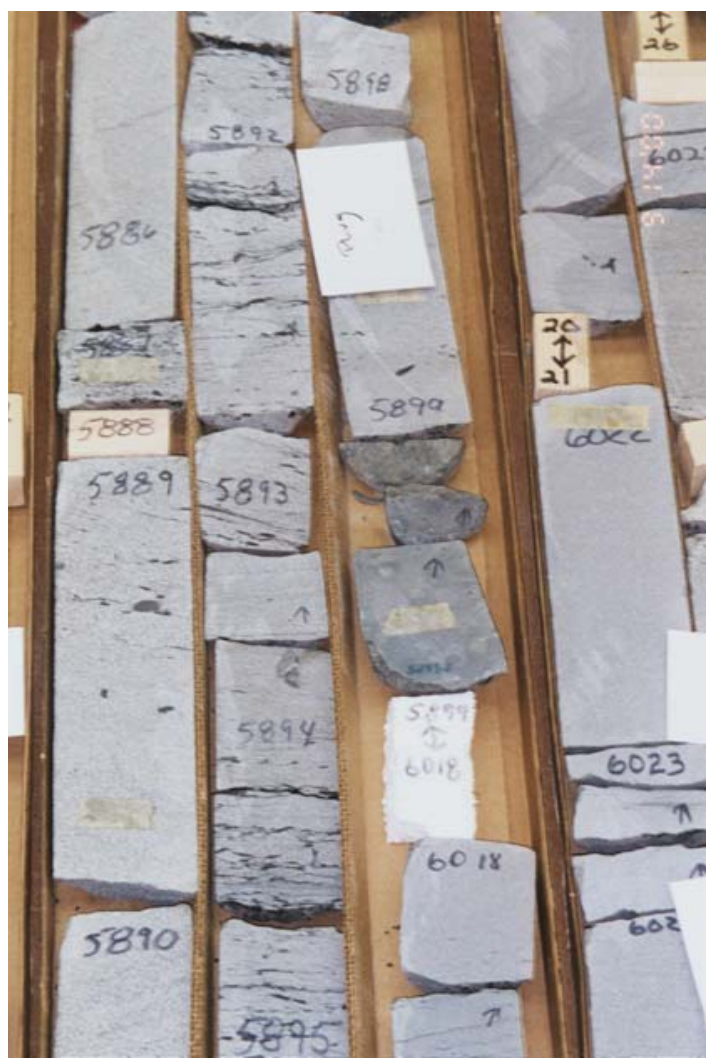

Figure B25. RB E 01. Numbers refer to feet below land surface (image by Clay Cooper). 


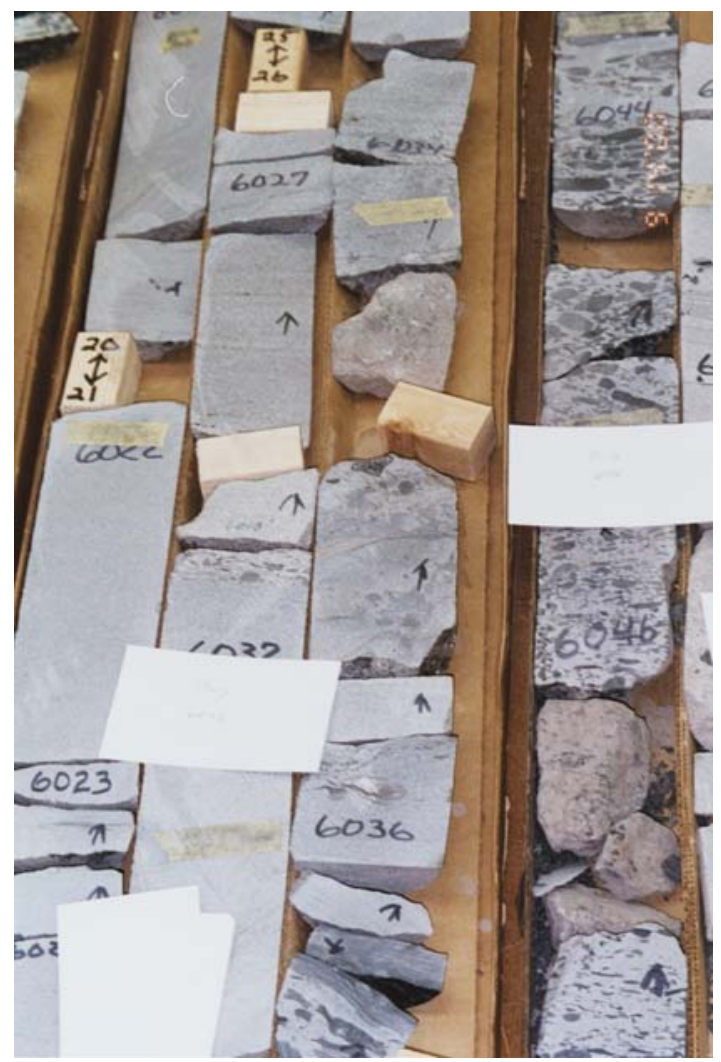

Figure B26. RB E 01. Numbers refer to feet below land surface (image by Clay Cooper).

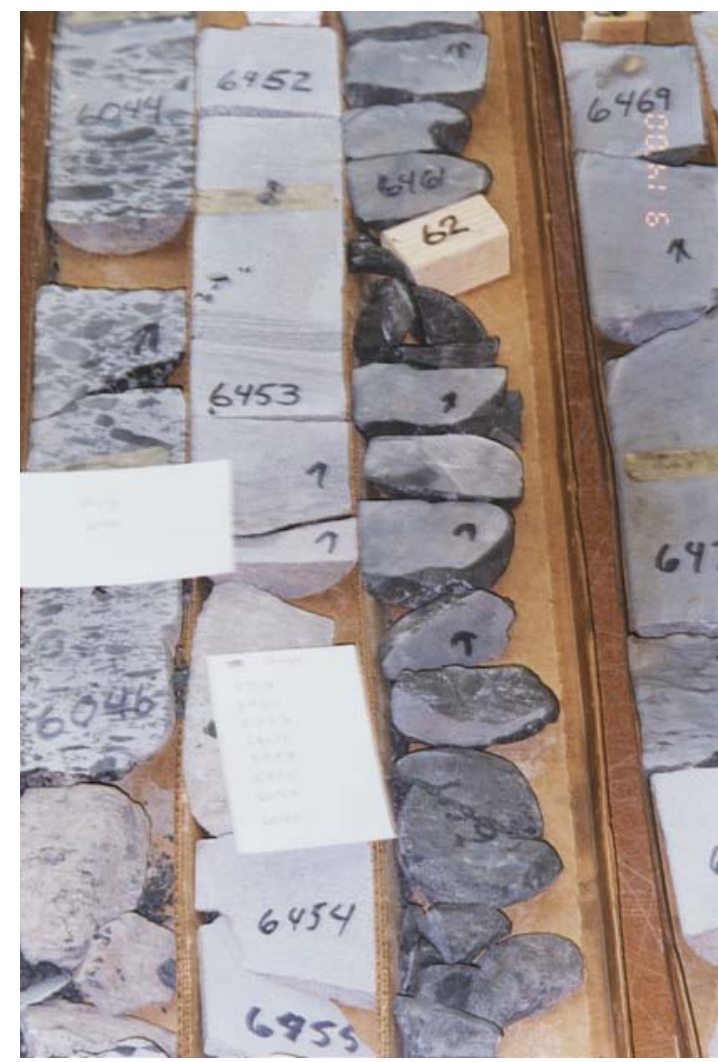

Figure B27. RB E 01. Numbers refer to feet below land surface (image by Clay Cooper). 


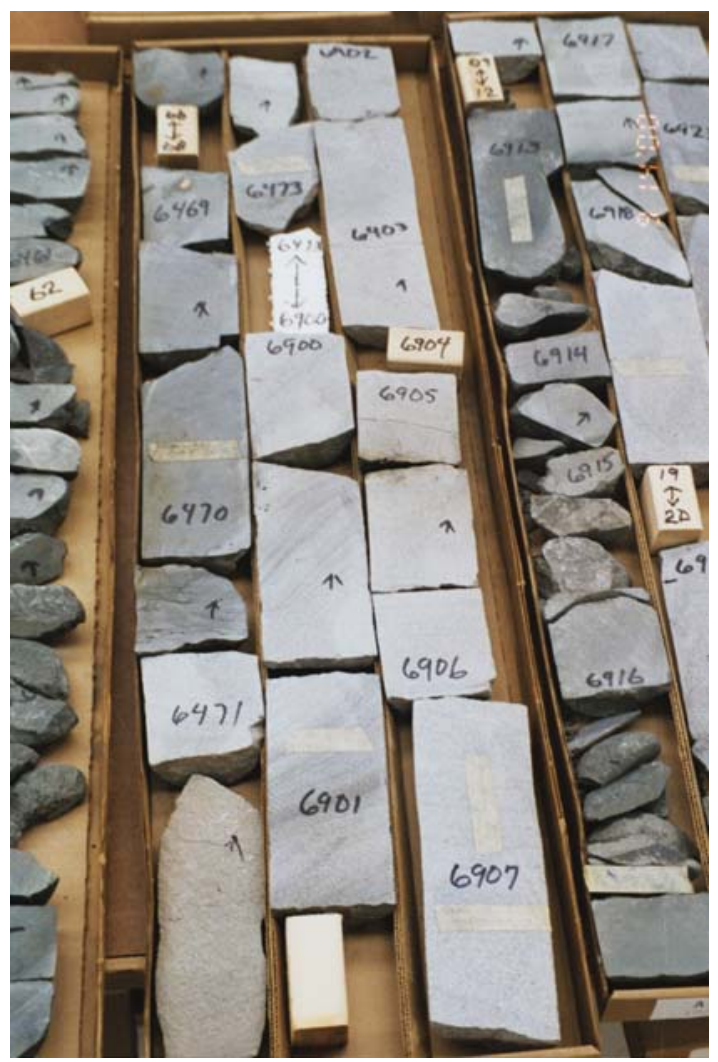

Figure B28. RB E 01. Numbers refer to feet below land surface (image by Clay Cooper).

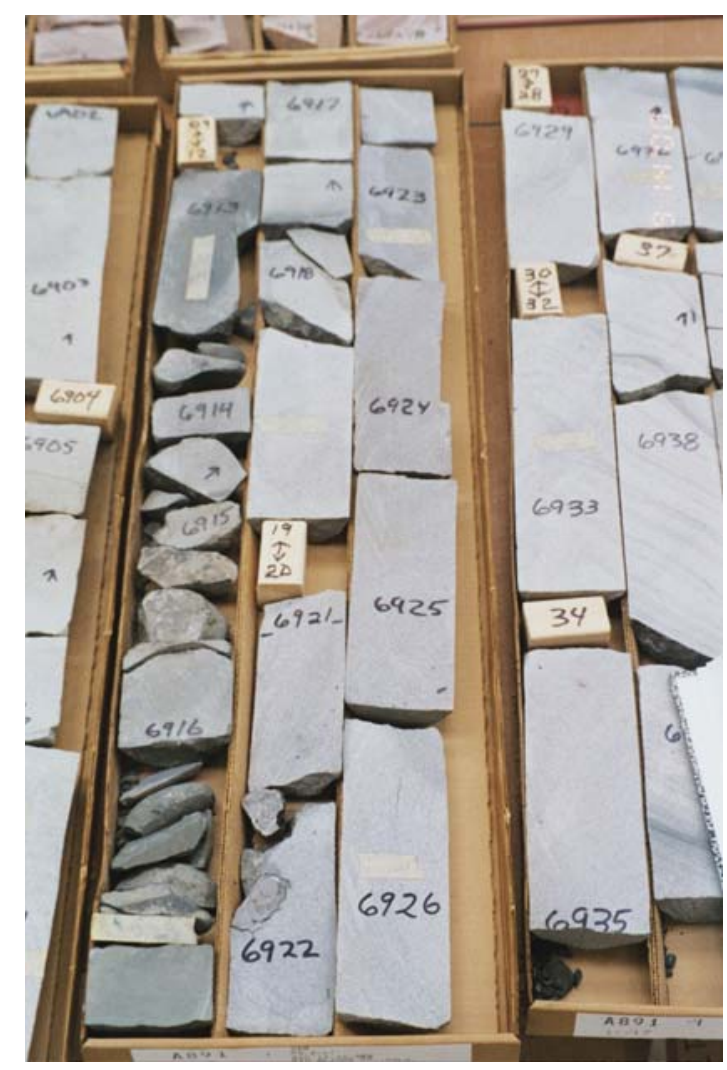

Figure B29. RB E 01. Numbers refer to feet below land surface (image by Clay Cooper). 


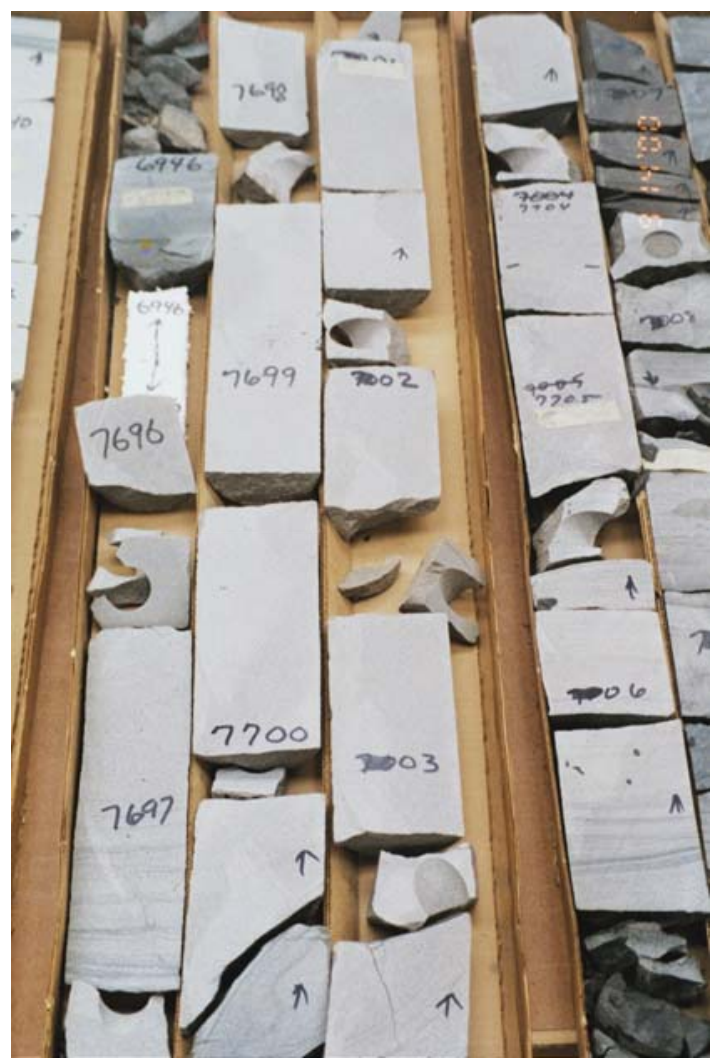

Figure B30. RB E 01. Numbers refer to feet below land surface (image by Clay Cooper).

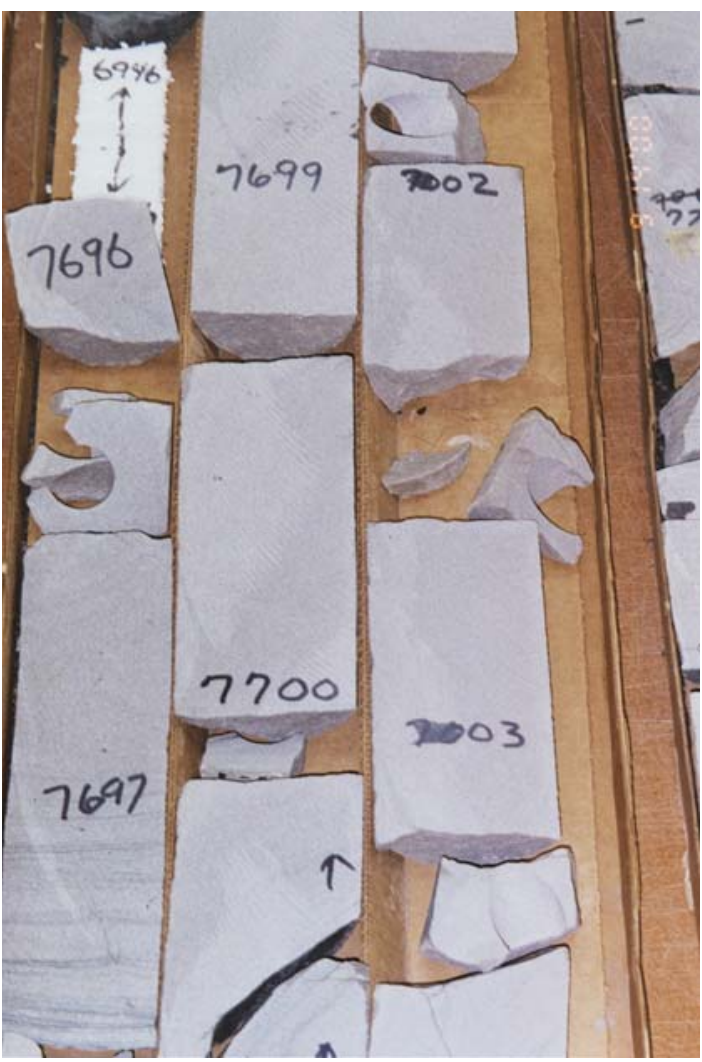

Figure B31. RB E 01. Numbers refer to feet below land surface (image by Clay Cooper). 


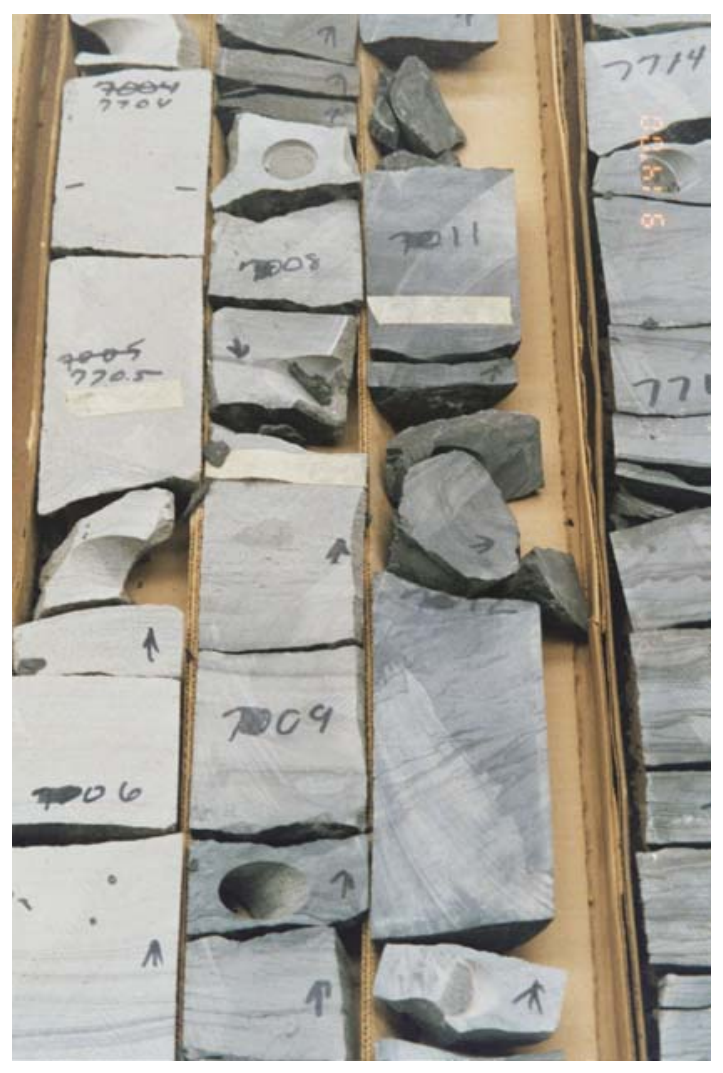

Figure B32. RB E 01. Numbers refer to feet below land surface (image by Clay Cooper). 


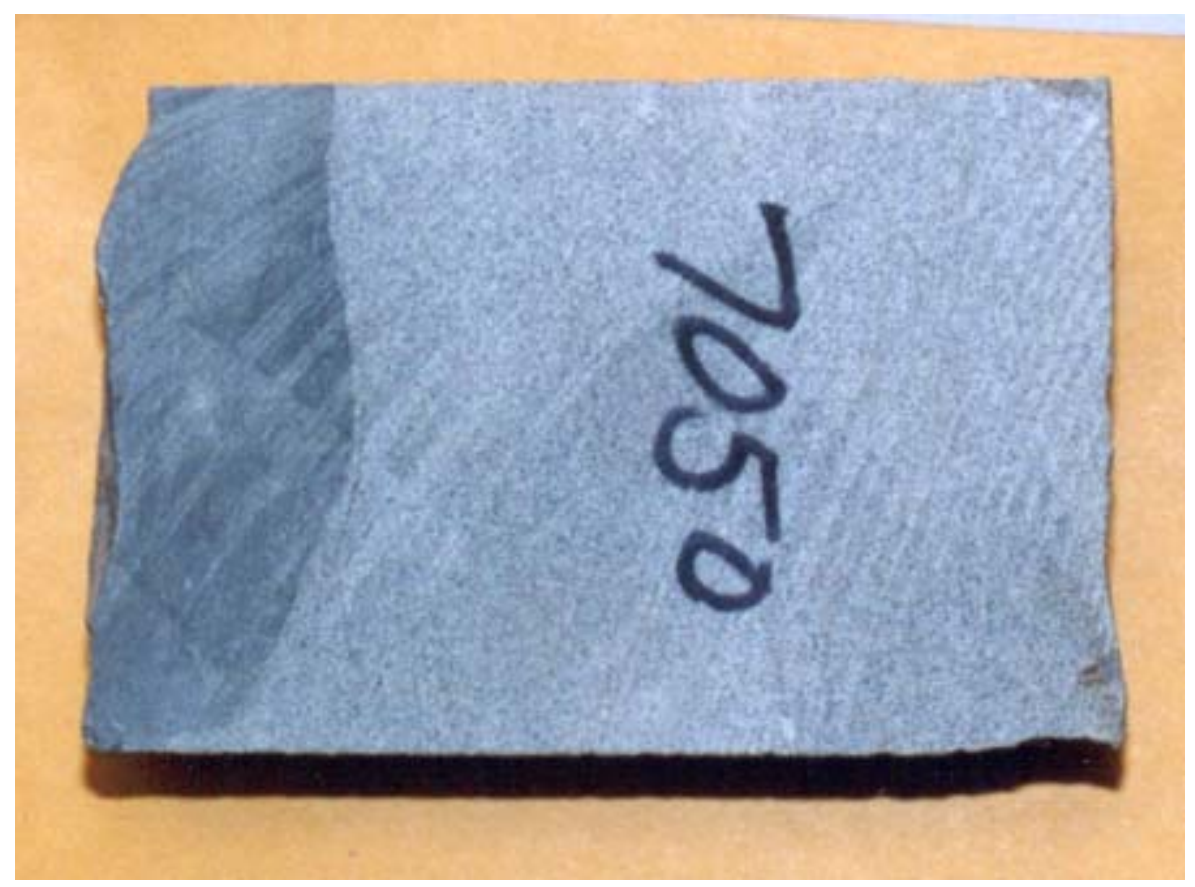

Figure B33. RB U-2 core at depth of 7,050 ft showing visible contact (image by Craig Shirley).

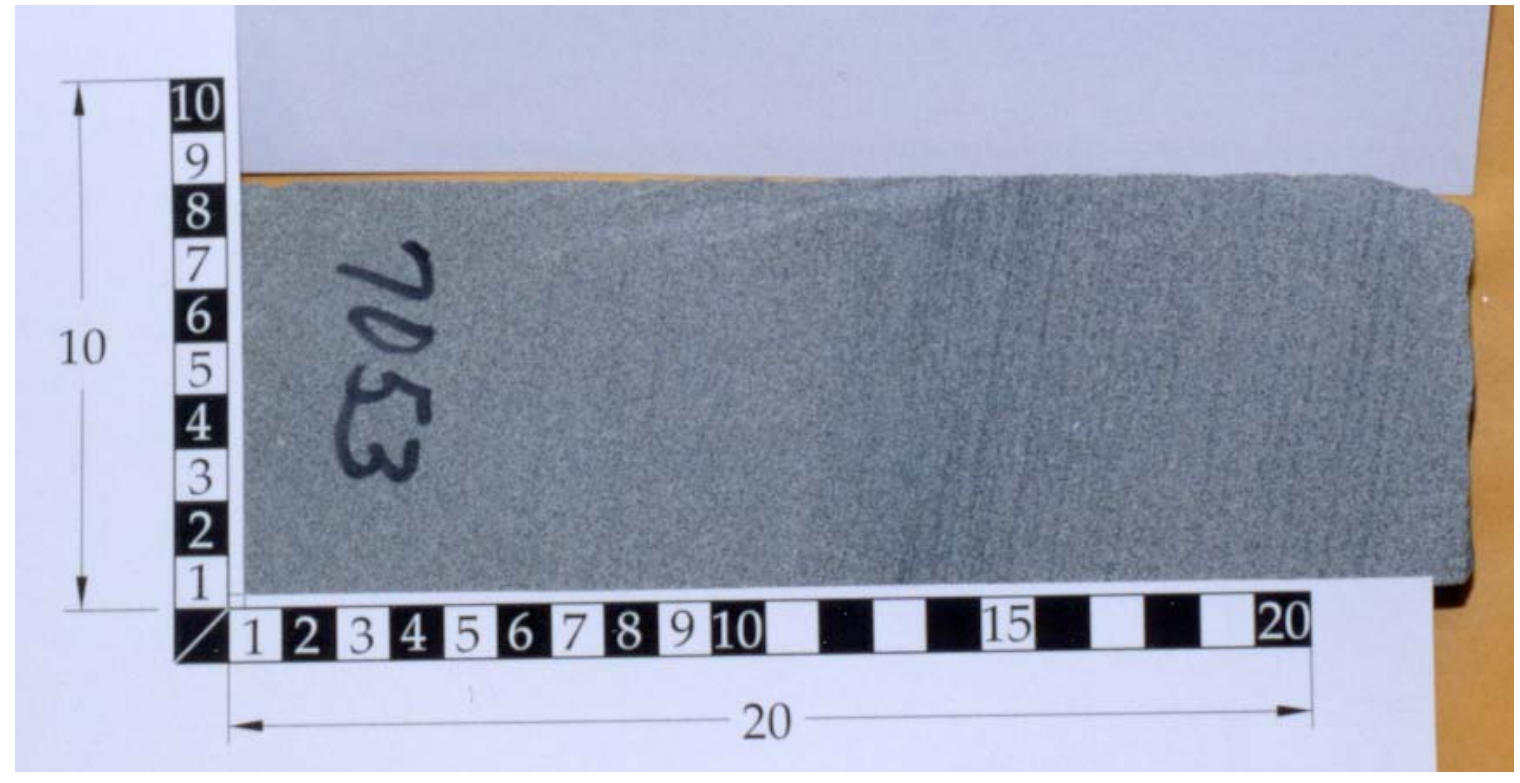

Figure B34. RB U-2 core at 7,053 ft with visible laminae (image by Craig Shirley). 


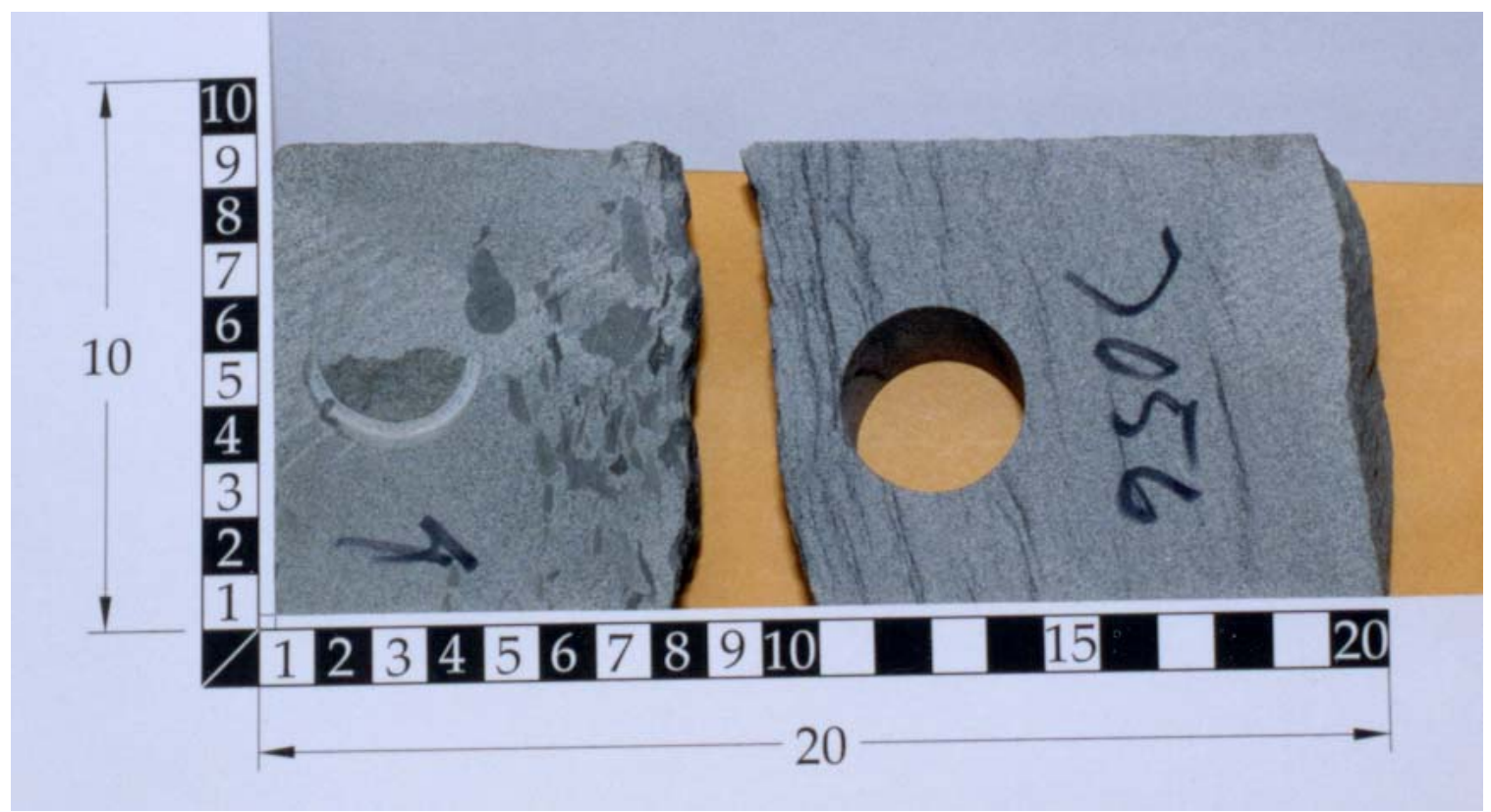

Figure B35. RB U-2 Core at 7,056 ft with laminae and fine-grained inclusions (image by Craig Shirley).

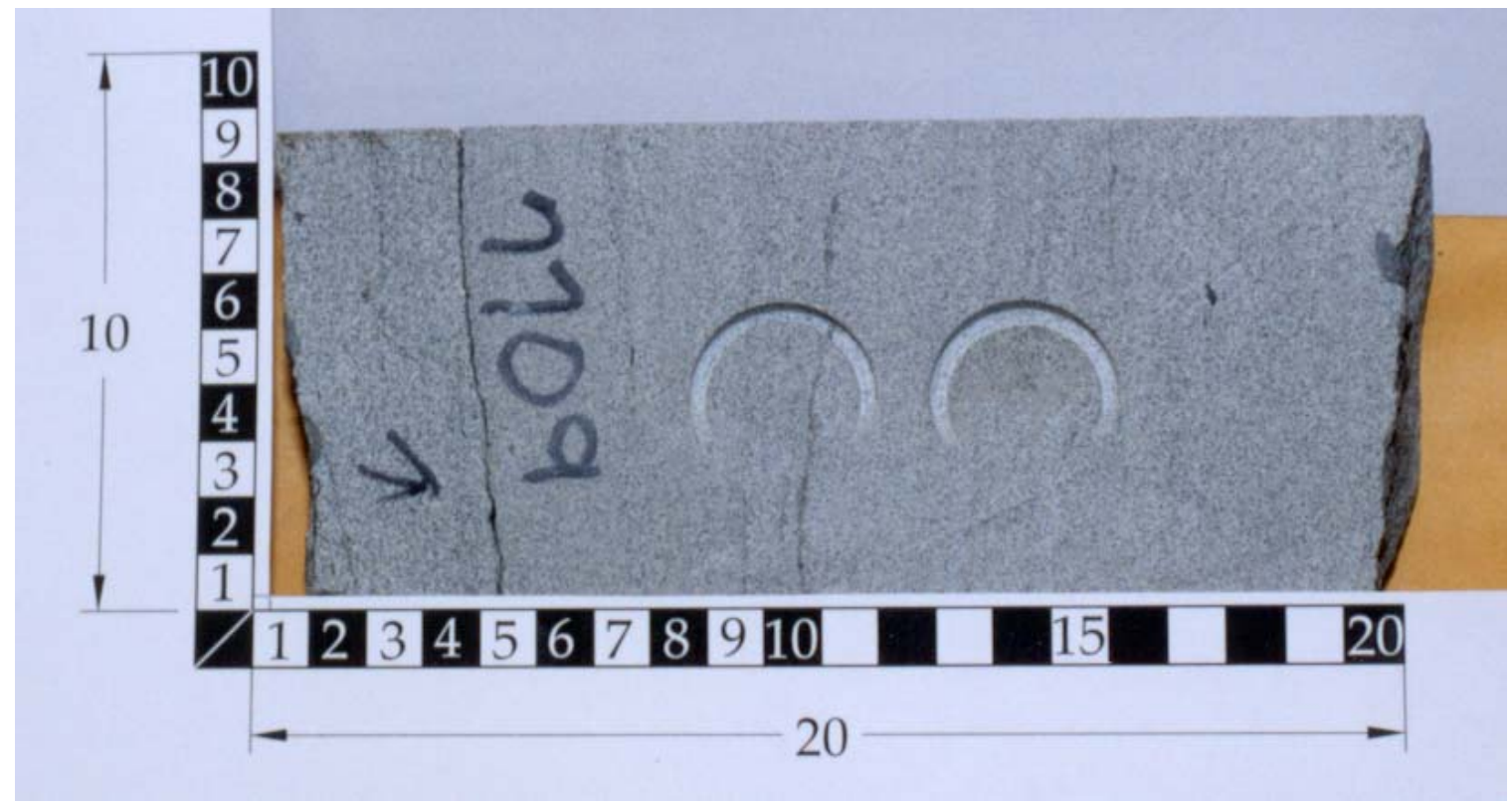

Figure B36. RB U-2 core at 7,709 ft with carbonaceous laminae (image by Craig Shirley). 


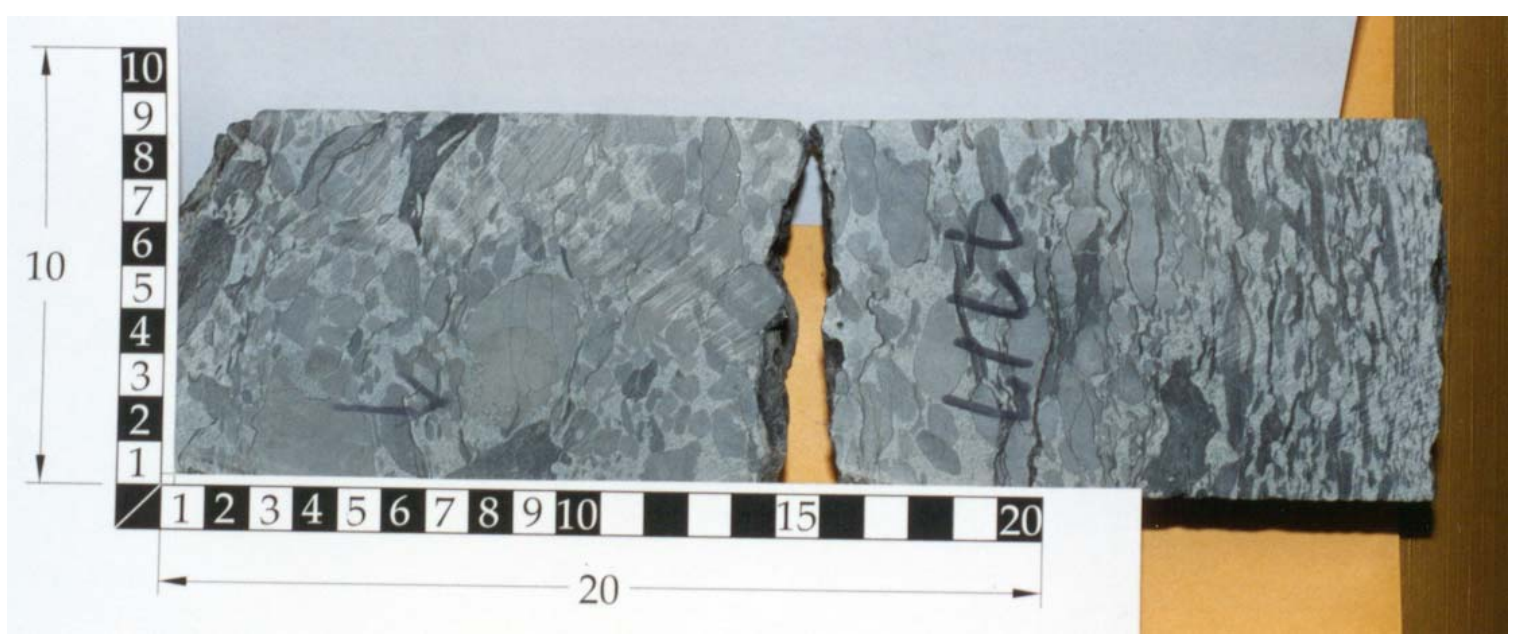

Figure B37. RB U-2 core at 7,717 to 7, $718 \mathrm{ft}$ with numerous clasts and laminae (image by Craig Shirley).

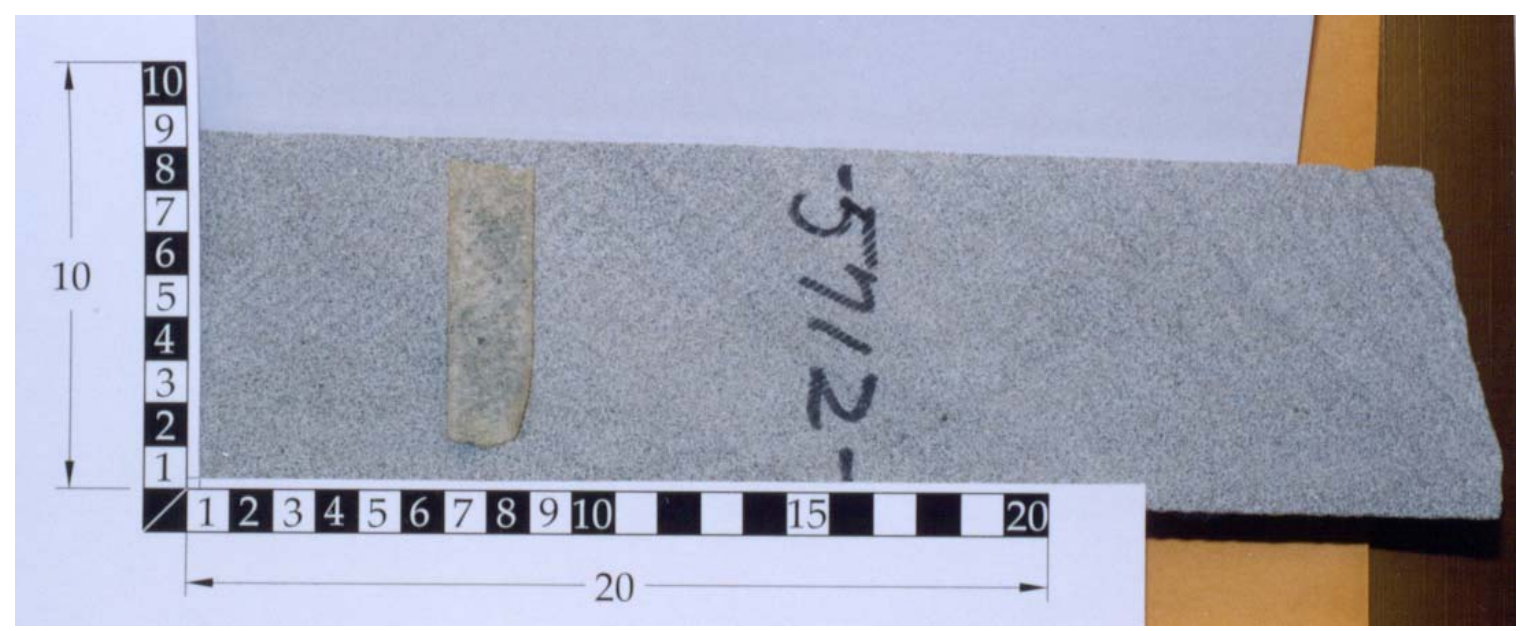

Figure B38. RB E 01 core at 5,712 ft showing core parting not coincident with lamina (image by Craig Shirley). 


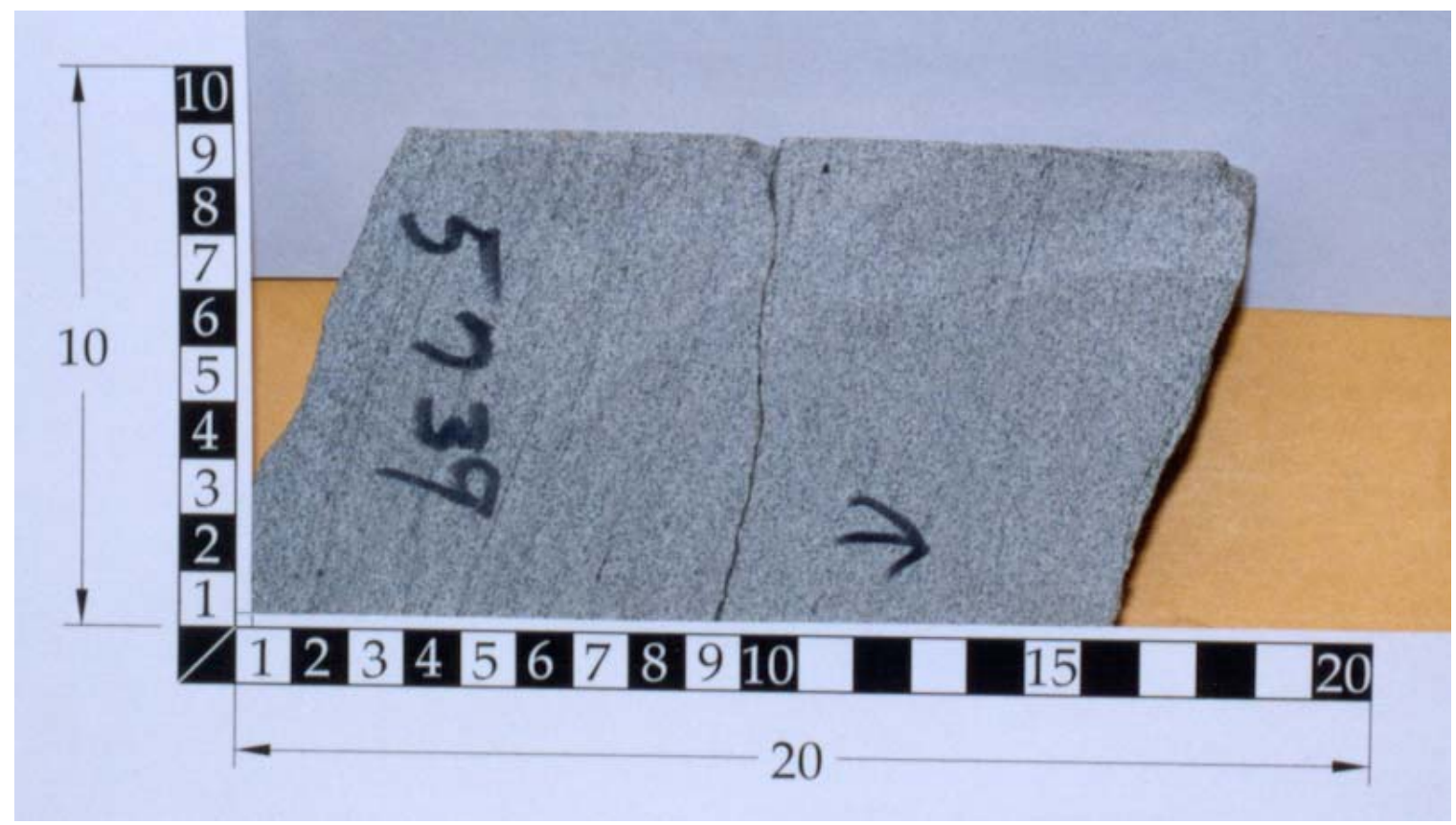

Figure B39. RB E 01 at 5,739 ft with drilling-induced parting cutting visible laminae (image by Craig Shirley).

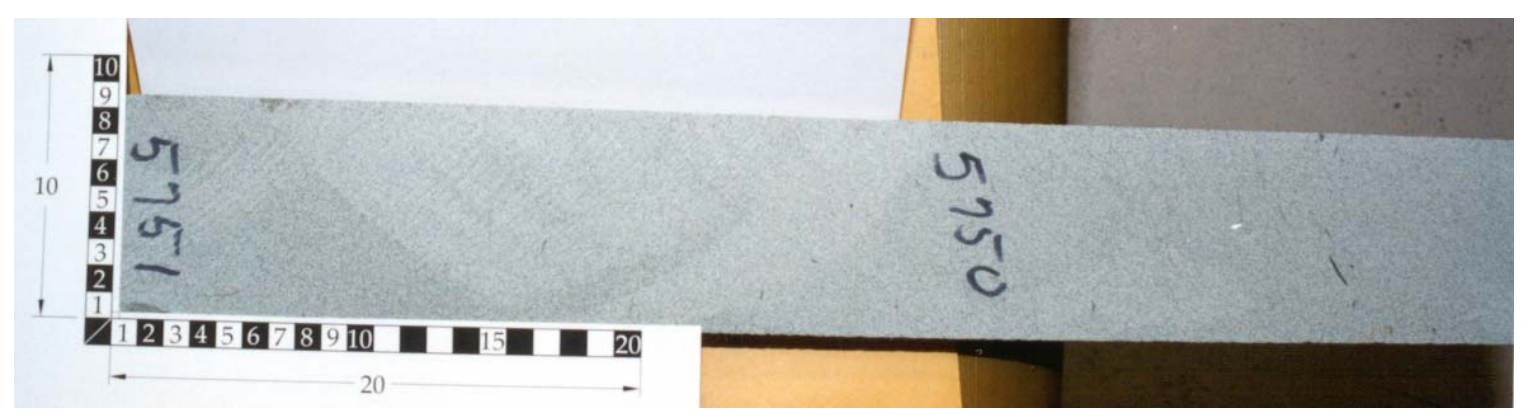

Figure B40. RB E 01 at 5,749 to 5,751 ft massive well-sorted sandstone (image by Craig Shirley). 


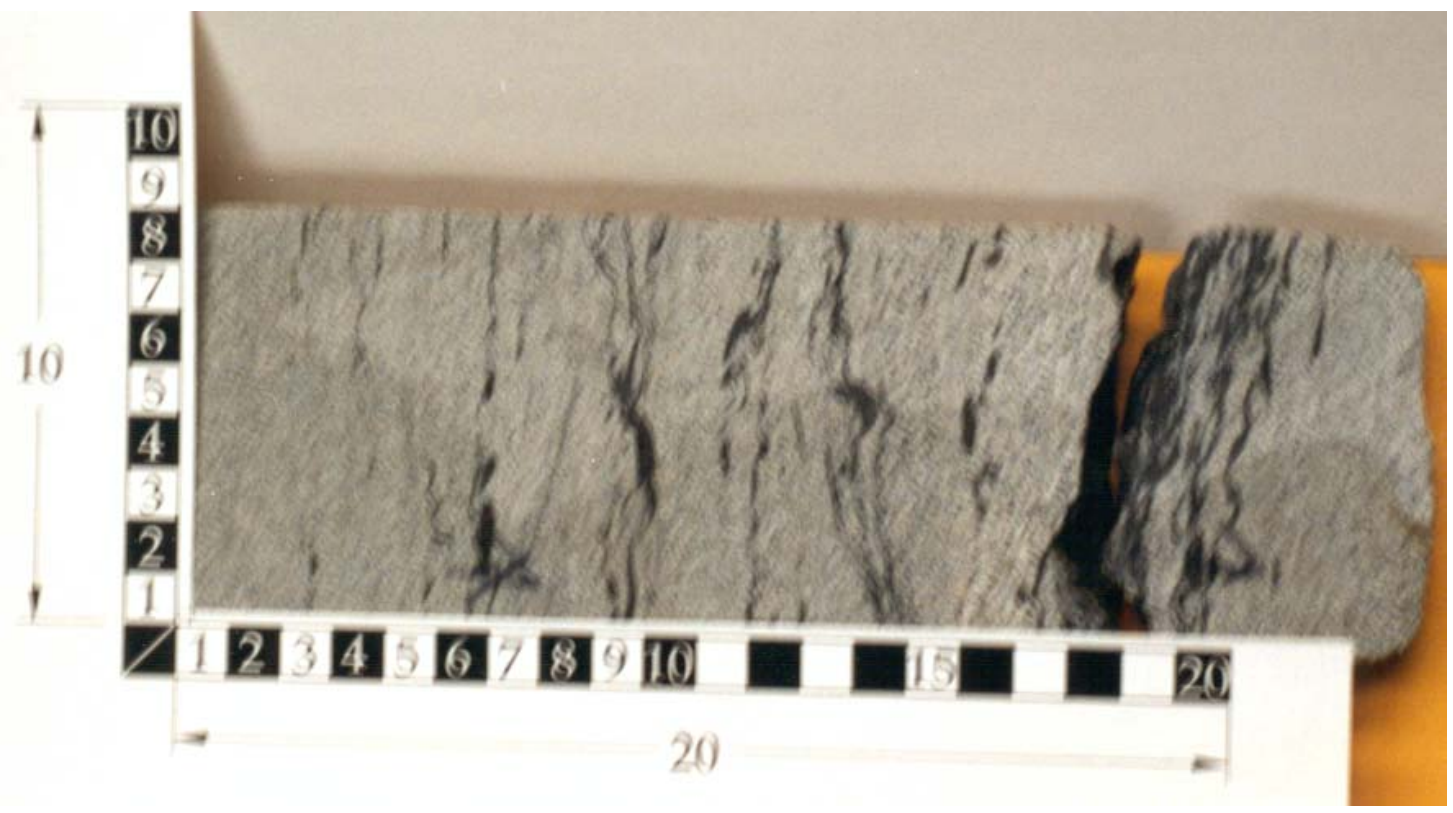

Figure B41. RB E 01 at 5,885 $\mathrm{ft}$ with numerous carbonaceous laminae and stringers. Image is not clear (image by Craig Shirley).

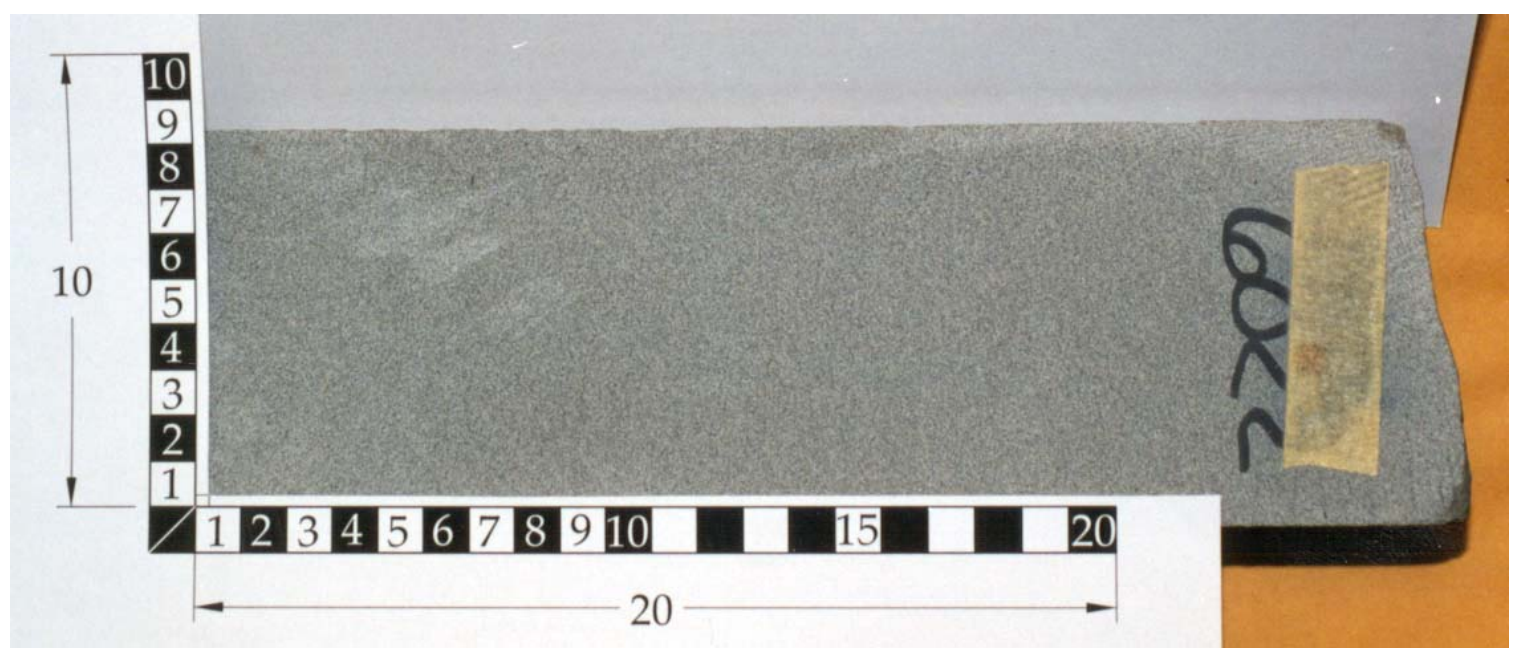

Figure B42. RB E 01 at 6,022 ft core parting at subtle shift in grain size (image by Craig Shirley). 


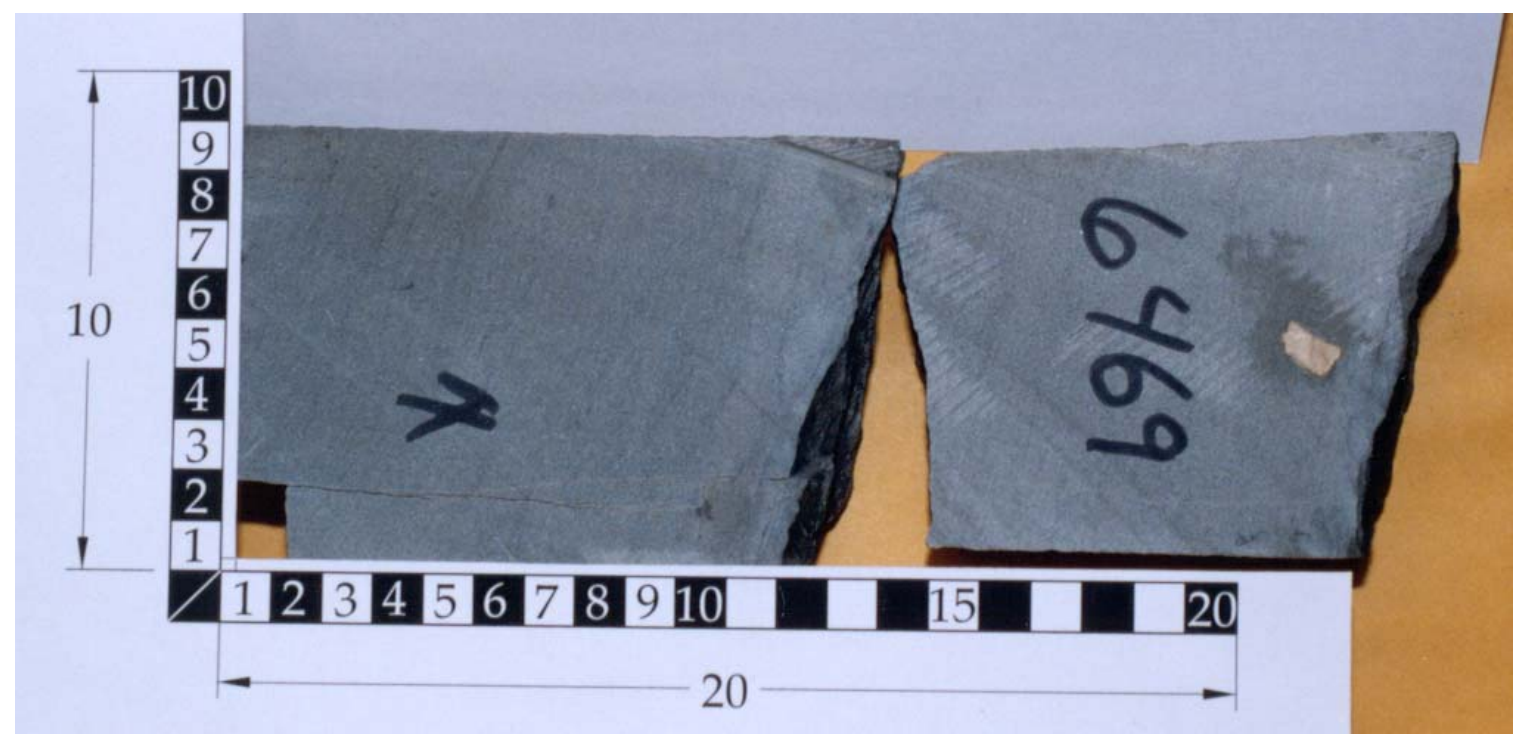

Figure B43. RB E 01 at 6,469 ft showing near-vertical fracture in lower left portion of photograph (image by Craig Shirley).

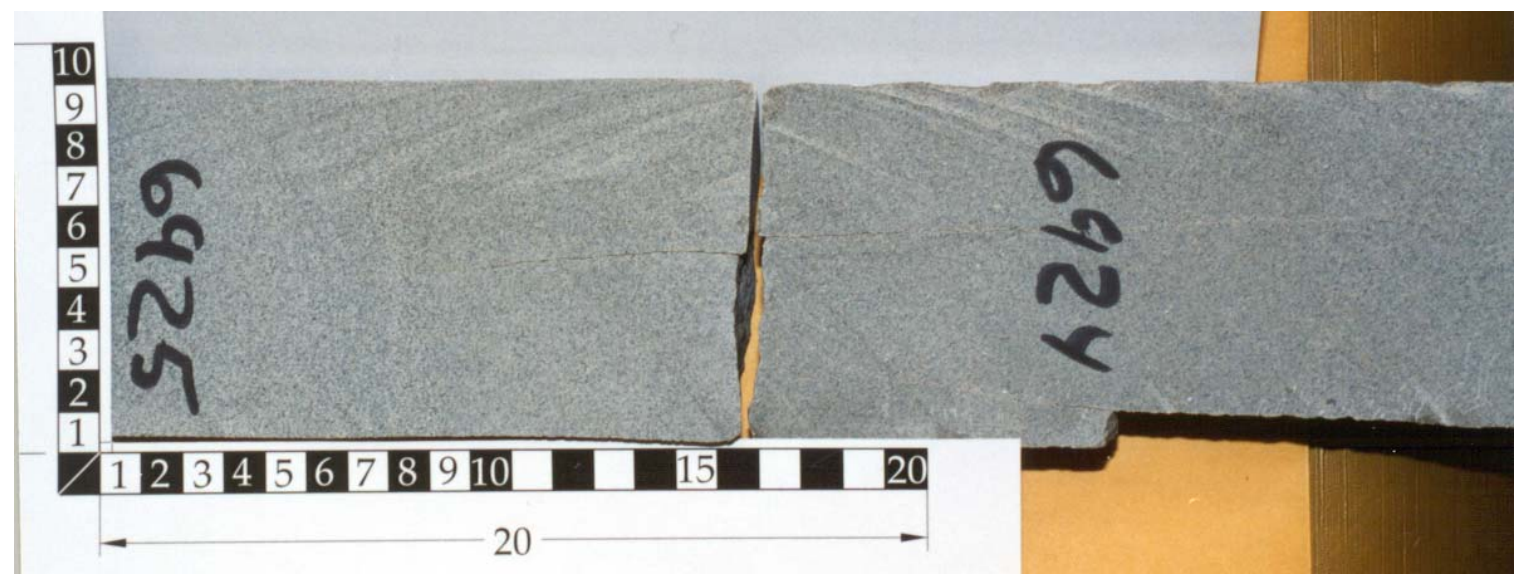

Figure B44. RB E 01 at 6,924 to 6,925 with high-angle fracture (image by Craig Shirley). 


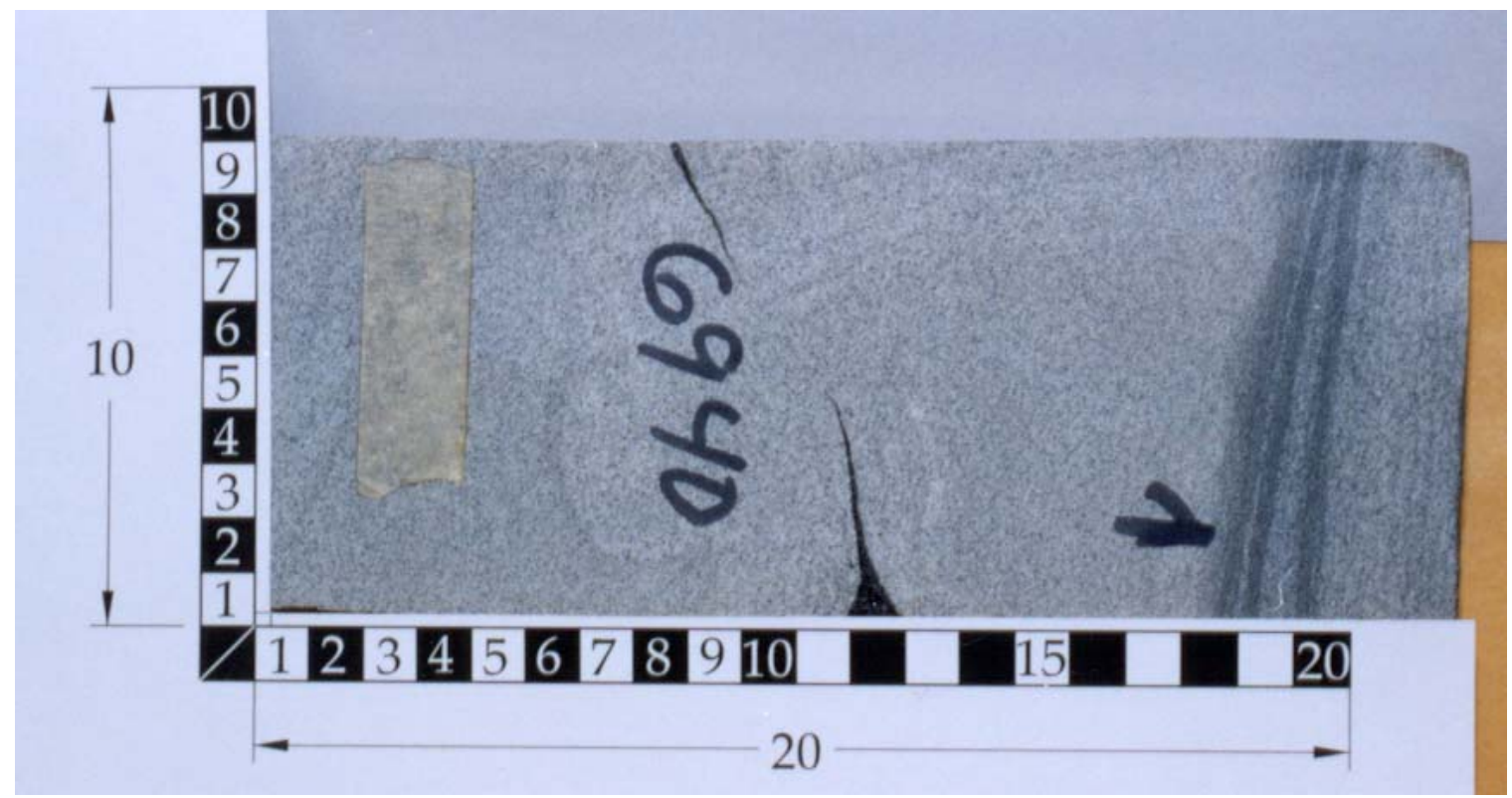

Figure B45. RB E 01 at 6,940 ft showing carbonaceous stringer and laminae (image by Craig Shirley).

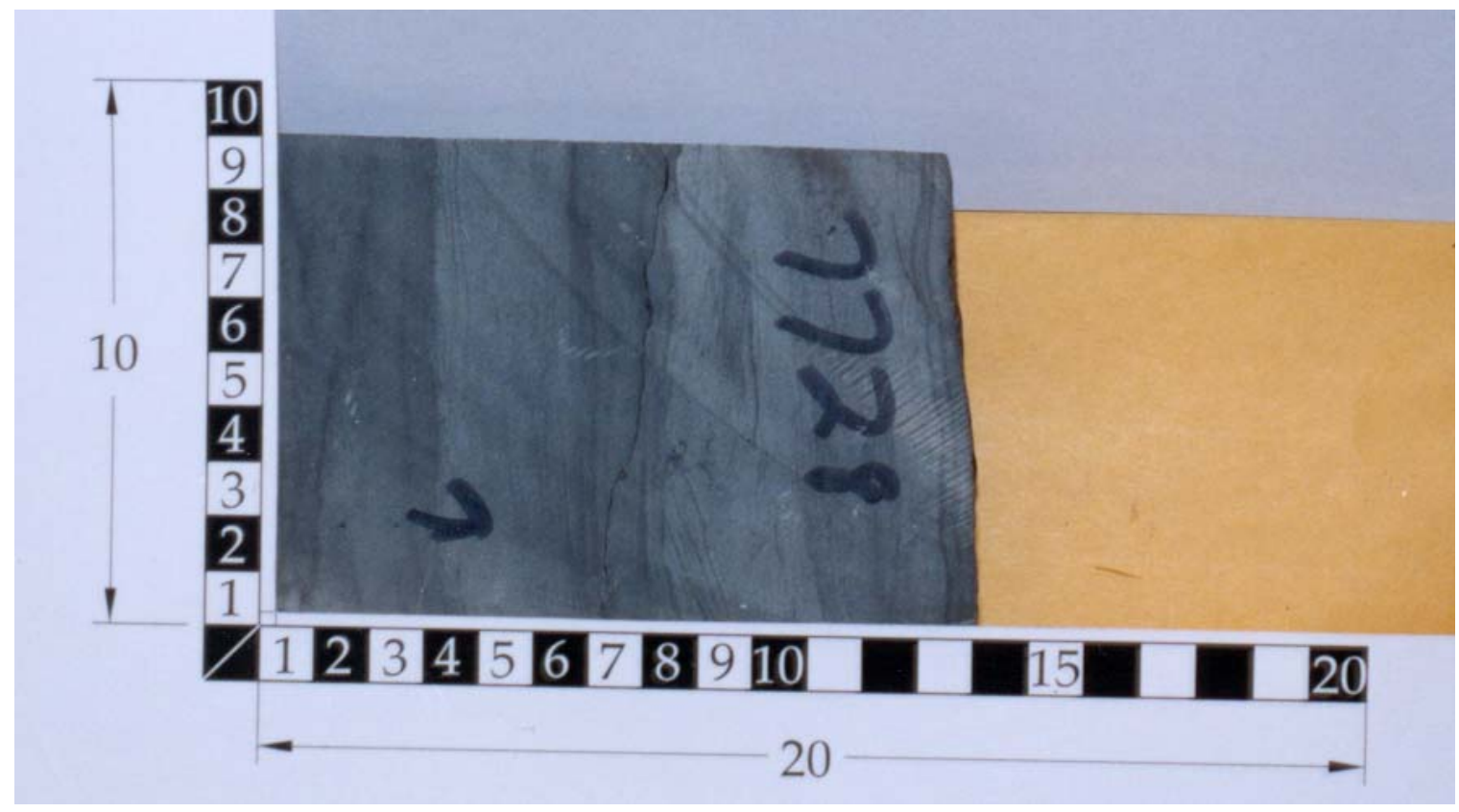

Figure B46. RB E 01 at 7,728 ft showing stratification in darker, fine-grained material (image by Craig Shirley). 
Distribution of fault lengths

Lognormal distribution

Features within 10 miles of Rio Blanco RB-E-01

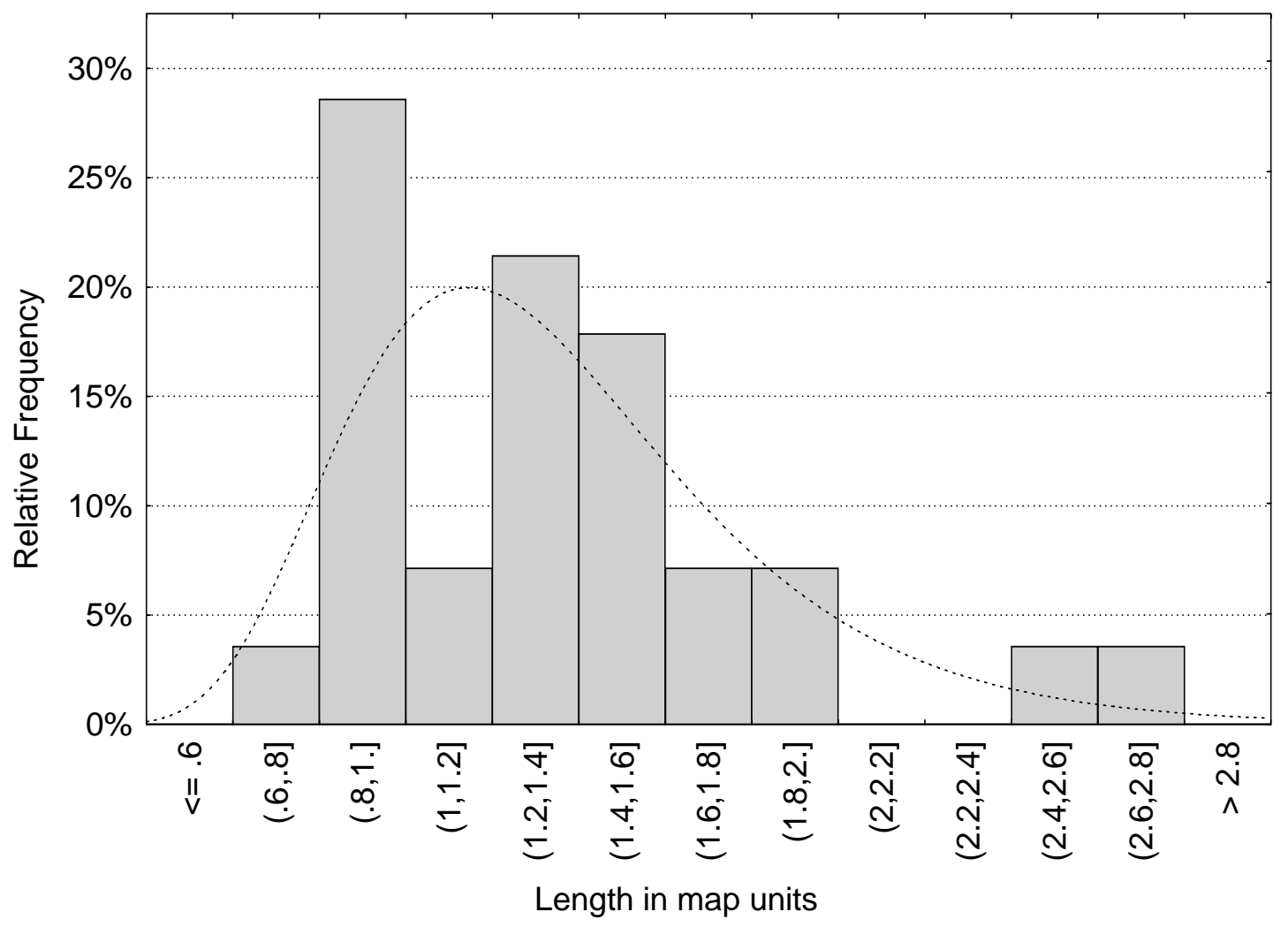

Figure B47. Fault-length distribution. 


\section{Discussion of Saraband Log Errors}

The tabular listing of the Saraband ${ }^{\odot} \log$ for borehole RB-AR-2 showed anomalously high permeabilities of 50 millidarcies at 5,440 and 100 millidarcies at 5,827 ft below ground surface. These two observations were an order of magnitude greater than the next largest observation. The supporting logs (see Figure B48 through Figure B55) used to create the Saraband ${ }^{\odot}$ permeability estimates were examined for those two intervals and it was determined that these values are outliers. Subsequent statistical analysis did not include the two excluded measurements.
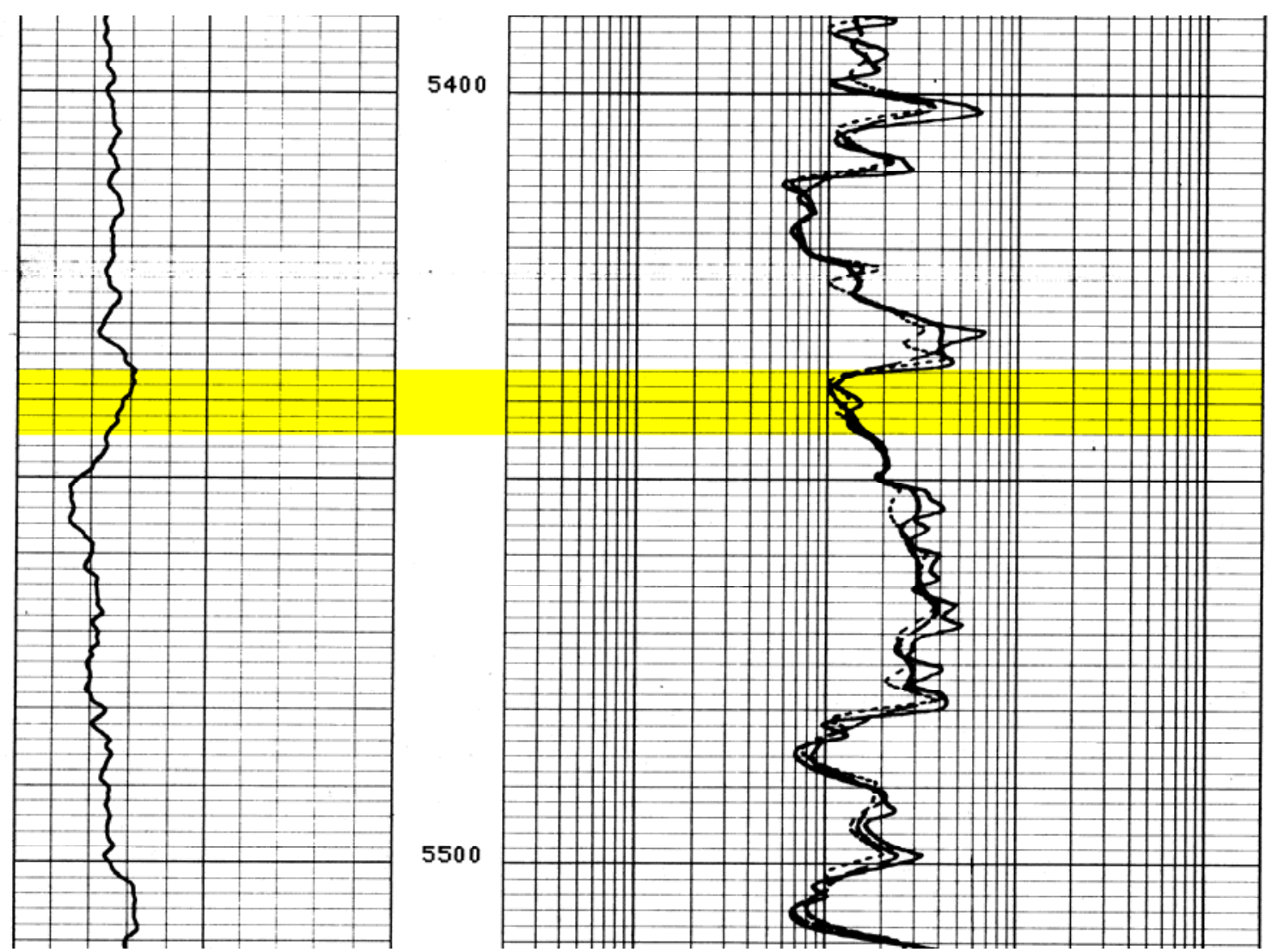

Figure B48. Resistivity log tracks for RB-AR-2 for 5,400 to $5,500 \mathrm{ft}$. 

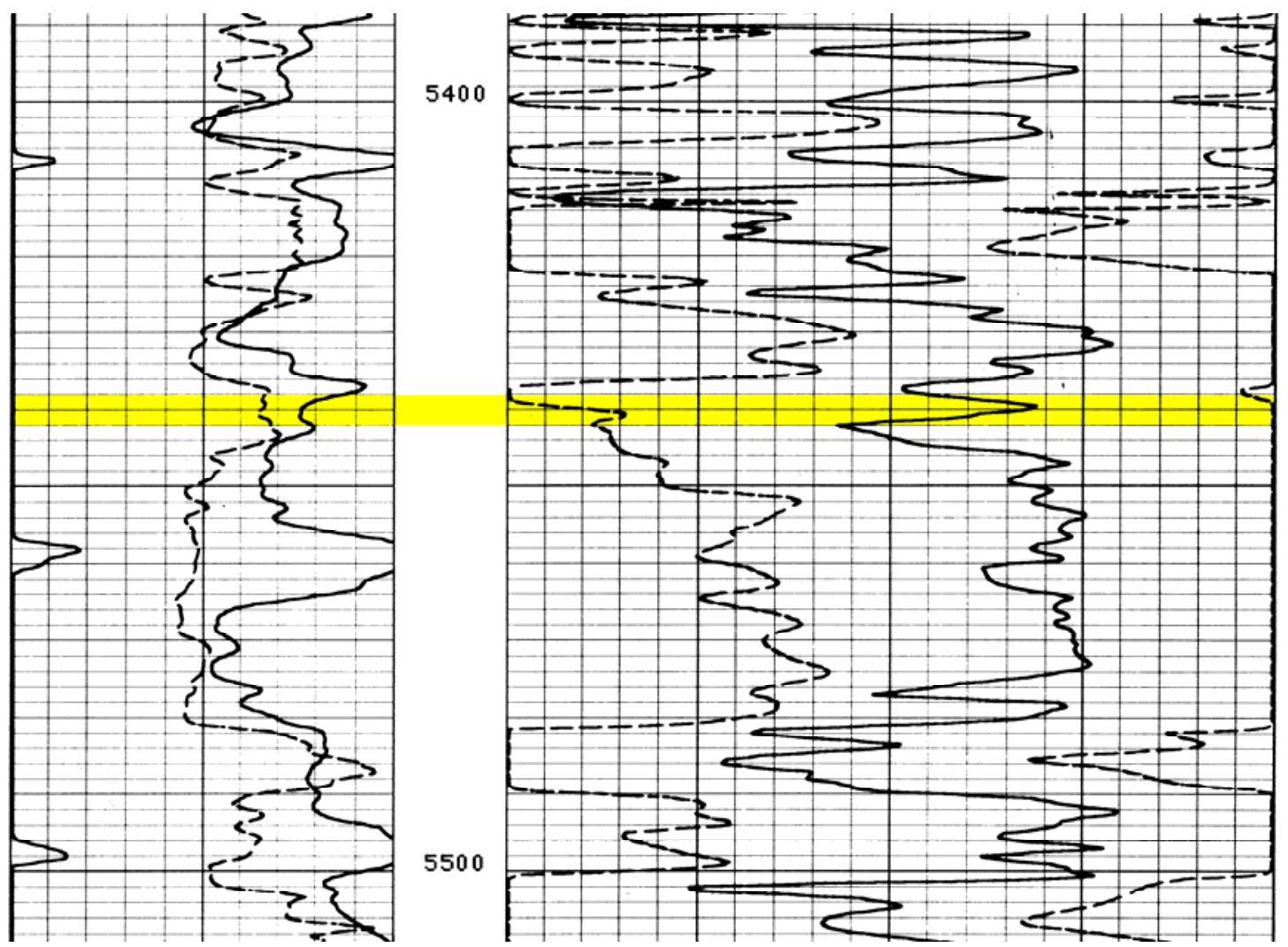

Figure B49. Density log tracks for RB-AR-2 for 5,400 to 5,500 ft.
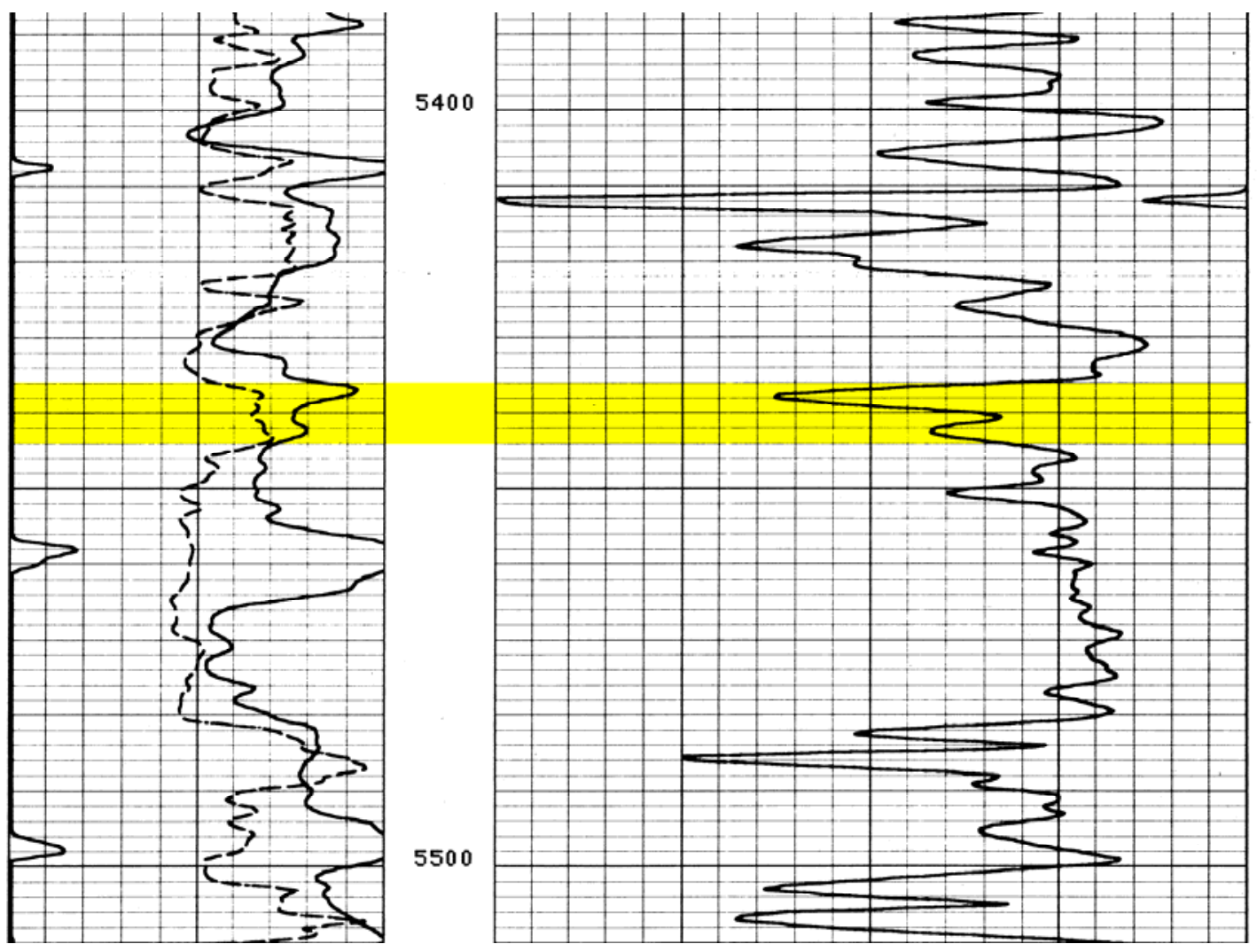

Figure B50. Transit time log tracks for RB-AR-2 for 5,400 to 5,500 ft. 


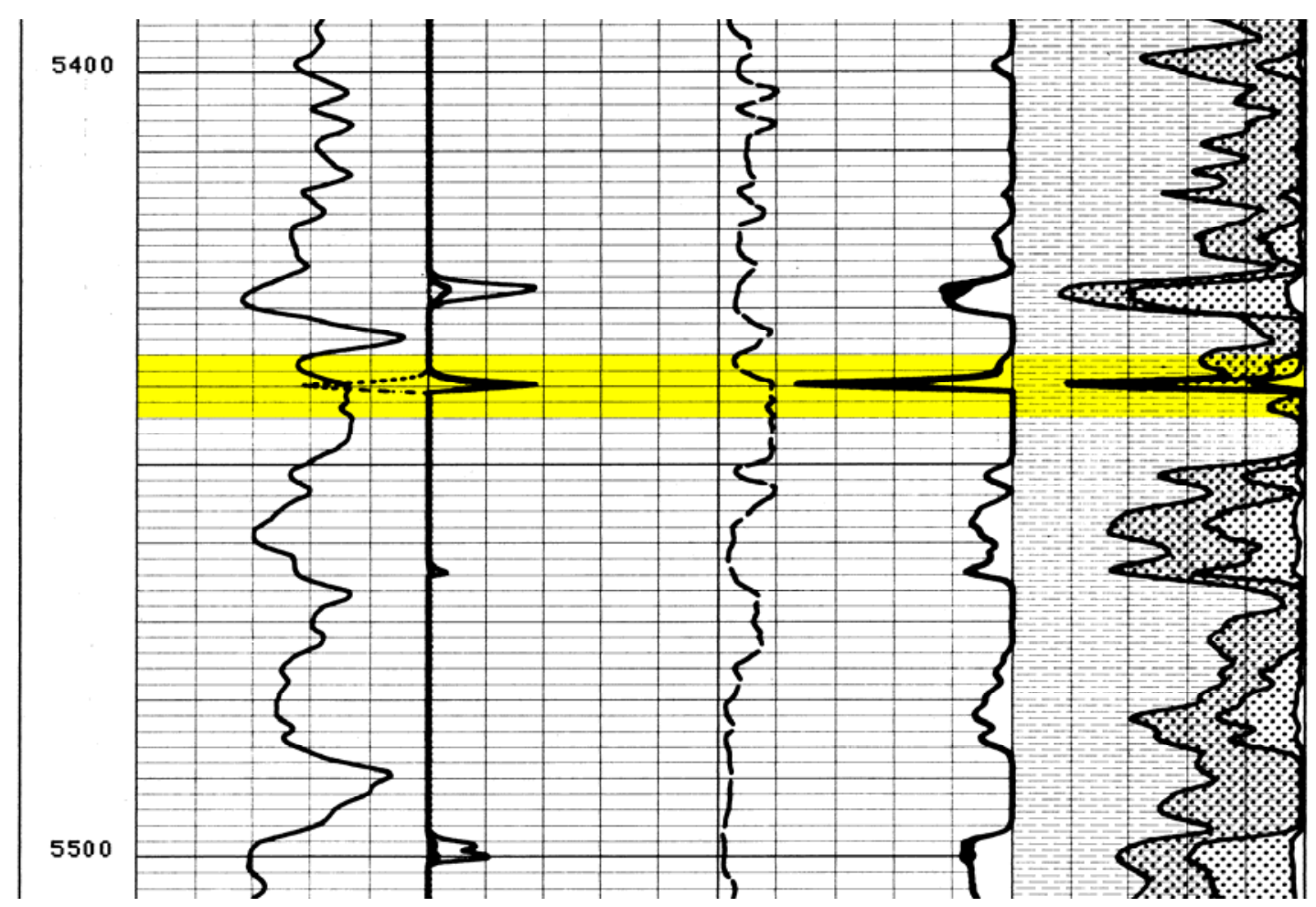

Figure B51. Saraband log tracks for RB-AR-2 for 5,400 to 5,500 ft.
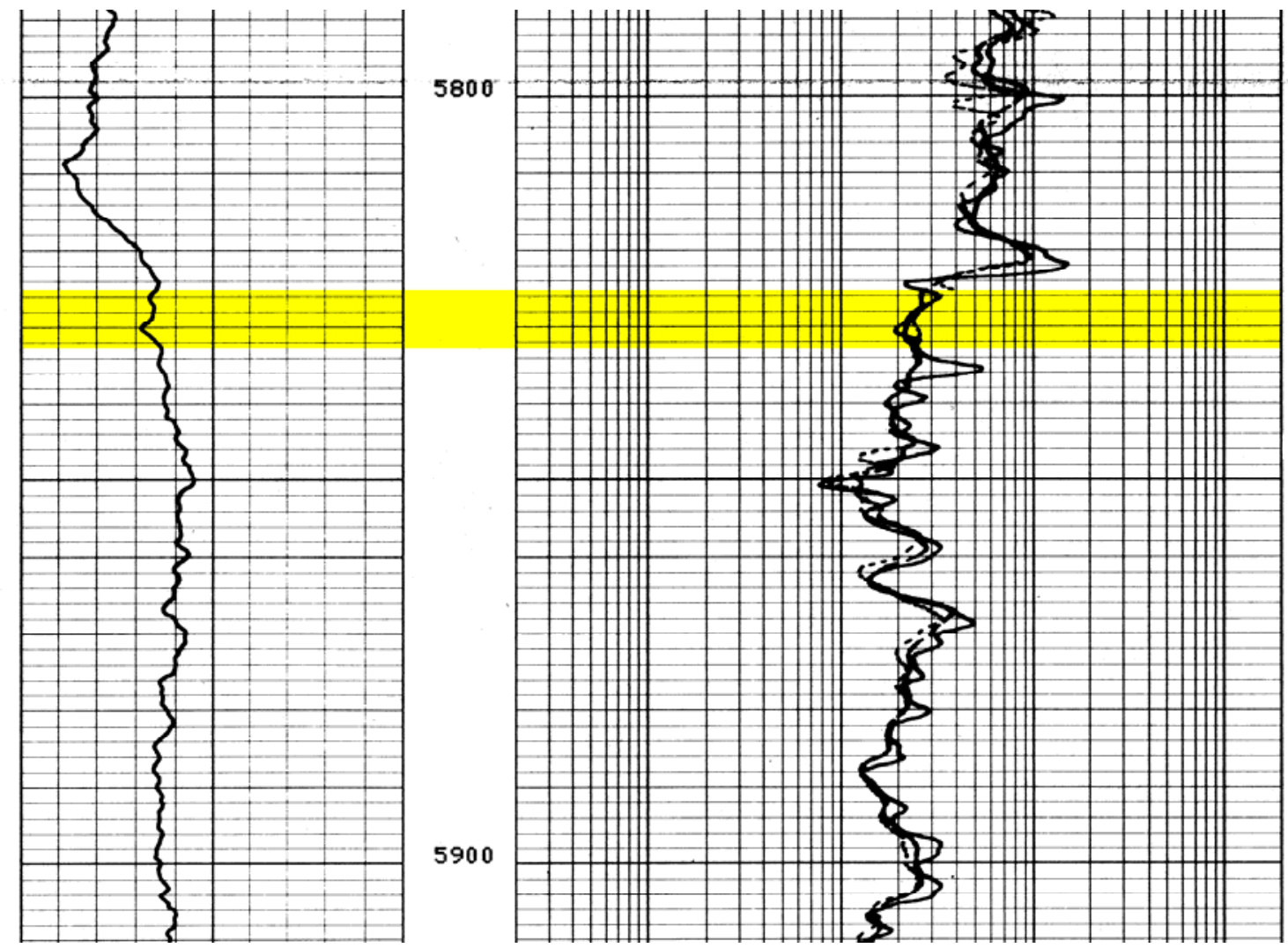

Figure B52. Resistivity log tracks for RB-AR-2 5,800 to 5,900 ft. 

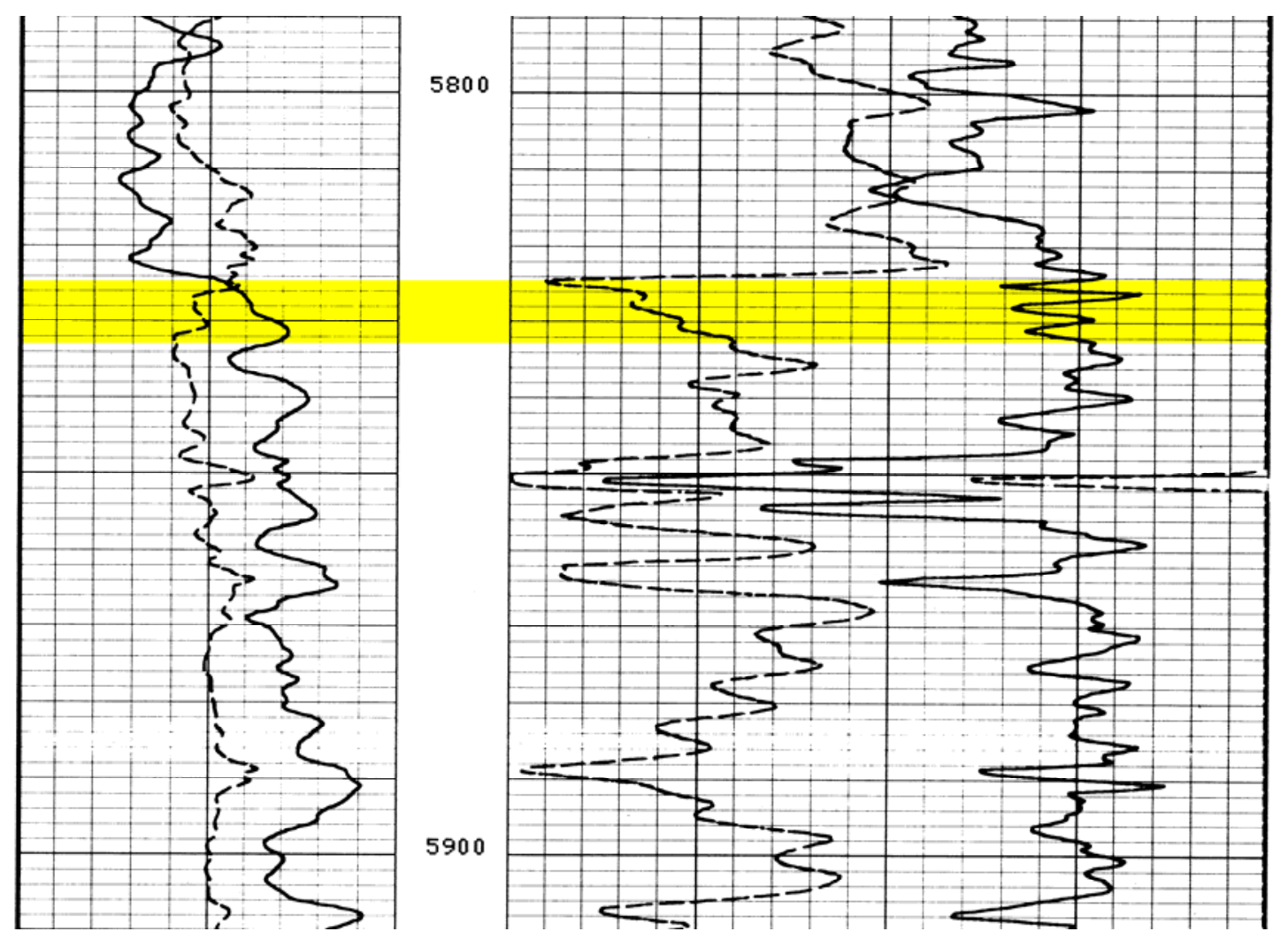

Figure B53. Density logs for RB-AR-2, 5,800 to 5,900 ft.
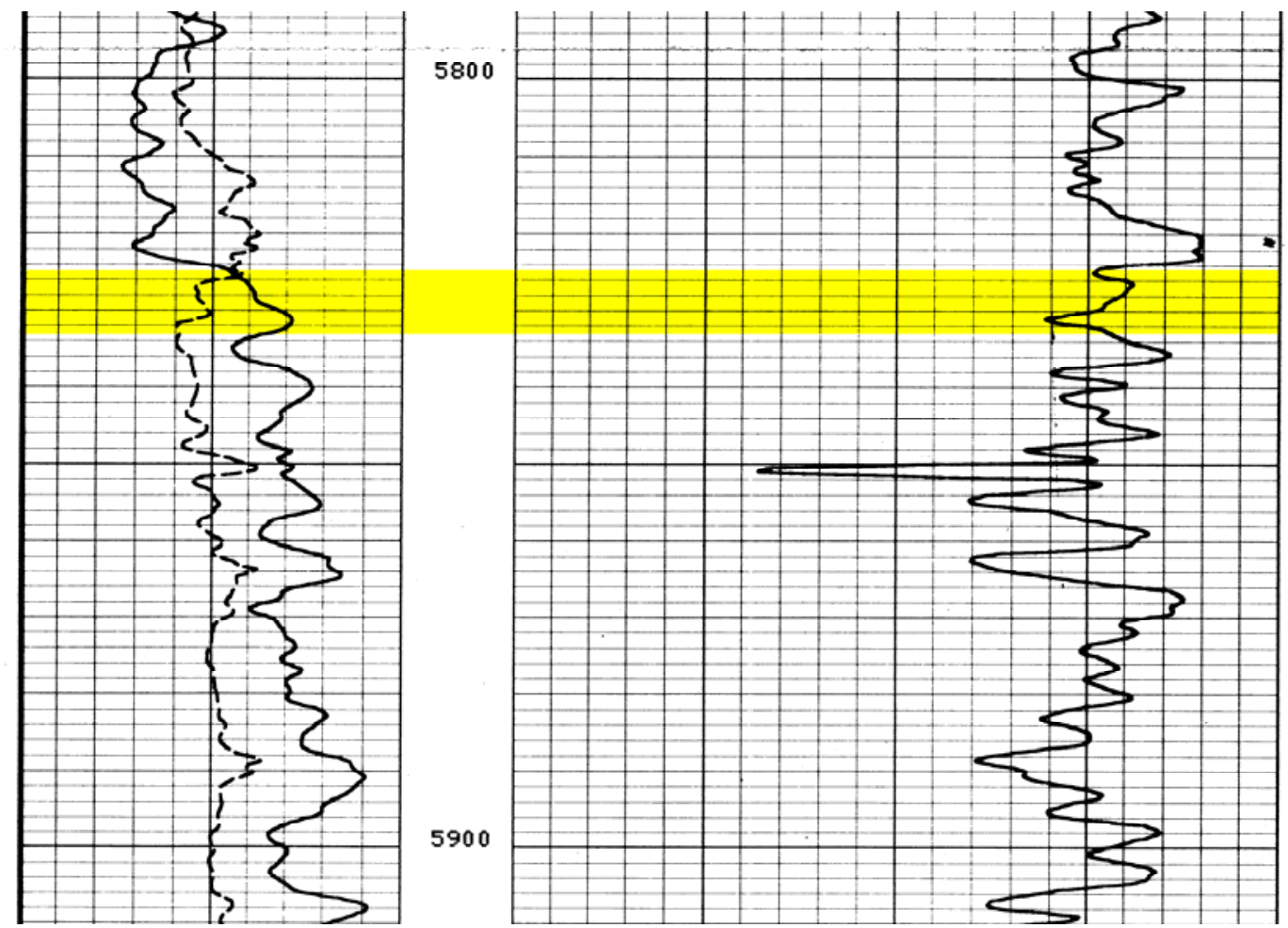

Figure B54. Acoustic velocity transit time tracks for RB-AR-2, 5,800 to 5,900 ft. 


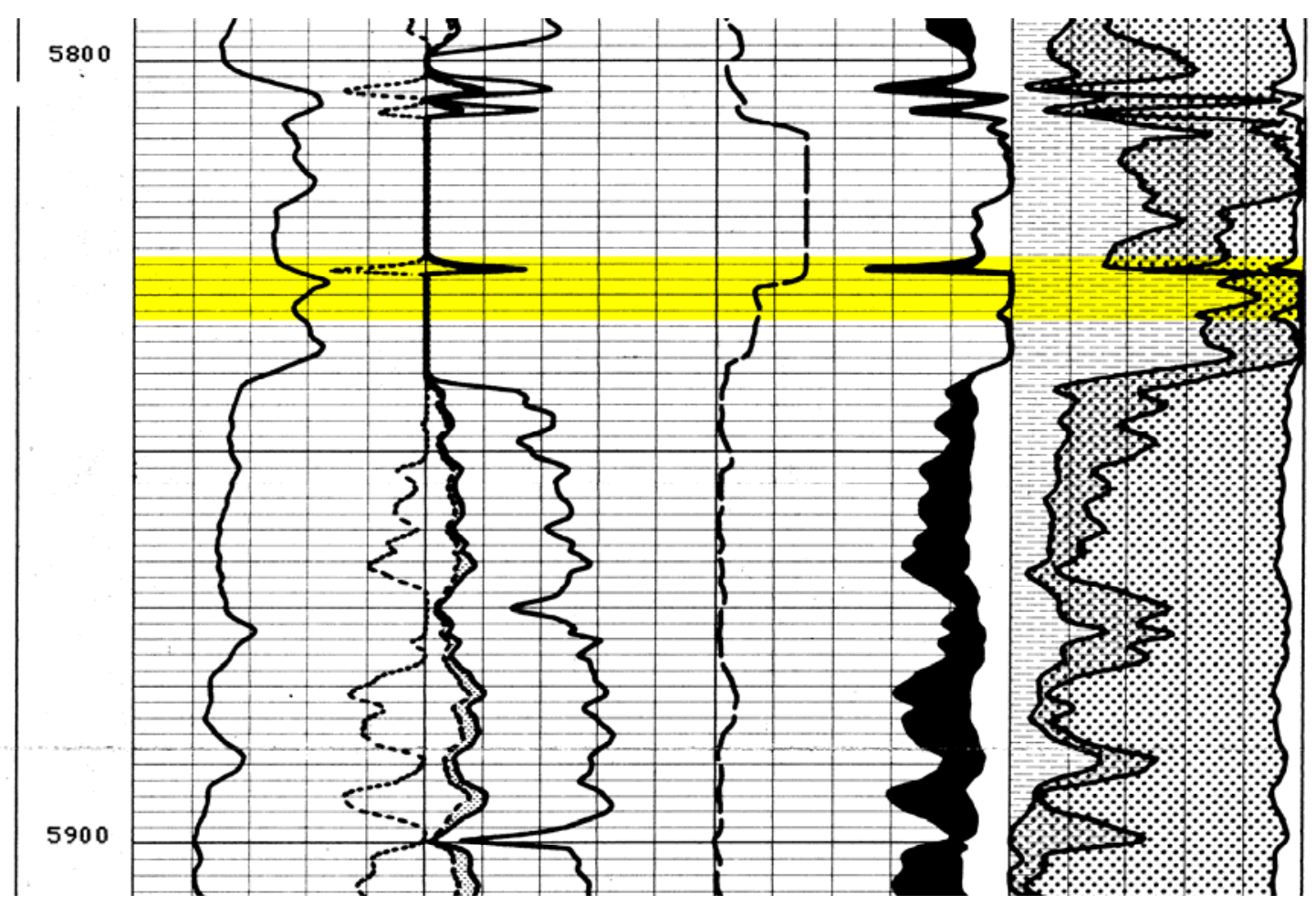

Figure B55. Saraband log for RB-AR-2, 5,800 to 5,900 ft. 
THIS PAGE INTENTIONALLY LEFT BLANK 


\section{APPENDIX C. TOUGH2 V2.0 Governing Equations}

\section{Governing Equations}

The two fluid phases are gas (water vapor and air) and liquid water. As little is known of the thermodynamic properties of the gas mixtures at the three nuclear-stimulation sites, the gas phase was left as air instead of replacing it with methane properties. The governing mass and heat transport equations are

$$
\frac{d}{d t} \int_{V_{n}} M^{\kappa} d V_{n}=\int_{\Gamma_{n}} \mathbf{F}^{\kappa} \cdot \mathbf{n} d \Gamma_{n}+\int_{V_{n}} q^{\kappa} d V_{n}
$$

where the integration is over the domain of the flow system, $V_{n}$, which is bounded by the closed surface $\Gamma_{n}$. The quantity $M$ that appears in the accumulation term represents mass or energy per unit volume, where the components (mass and/or heat) are labeled by $\kappa(\kappa=1$ water, $\kappa=2$ air, $\kappa=3$ heat). $\mathbf{F}$ denotes mass or heat flux, and $q$ denotes sources and sinks. The normal vector $\mathbf{n}$ on the surface $d \Gamma_{n}$ points inward into $V_{n}$.

The mass accumulation term is

$$
M^{\kappa}=\phi \sum_{\beta} S_{\beta} \rho_{\beta} X_{\beta}{ }^{\kappa}
$$

The total mass of component $\kappa$ is obtained by summing over the fluid phases $\beta$ (liquid, gas). $\varphi$ is porosity, $S_{\beta}$ is saturation of phase $\beta, \rho_{\beta}$ is the density of phase $\beta$, and $X_{\beta}{ }^{\kappa}$ is the mass fraction of component $\kappa$ in phase $\beta$. The heat accumulation term is

$$
M^{3}=(1-\phi) \rho_{r} C_{r} T+\phi \sum_{\beta} S_{\beta} \rho_{\beta} u_{\beta}
$$

where $\rho_{r}$ is the grain density of the porous medium, $C_{r}$ is the specific heat of the rock, $T$ is temperature, and $u_{\beta}$ is the internal energy of phase $\beta$.

Mass flux terms are summed over the two mobile phases,

$$
\mathbf{F}^{\kappa}=\sum_{\beta} X_{\beta}{ }^{\kappa} \mathbf{F}_{\beta}{ }^{\kappa}
$$

and the flux of each phase is modeled by the multiphase version of Darcy's law

$$
\mathbf{F}_{\beta}=\rho_{\beta} \mathbf{u}_{\beta}=-k \frac{k_{r \beta} \rho_{\beta}}{\mu_{\beta}}\left(\nabla P_{\beta}+\rho_{\beta} \mathbf{g}\right)
$$

Here, $\mathbf{u}_{\beta}$ is the Darcy velocity of phase $\beta, k$ is absolute permeability, $k_{r \beta}$ is the relative permeability to phase $\beta, \mu_{\beta}$ is the dynamic viscosity of phase $\beta$, and $\nabla P_{\beta}$ is the pressure gradient across phase $\beta$. 
Heat flux (conduction and convection) is

$$
\mathbf{F}^{3}=-\lambda \nabla T+\sum_{\beta} h_{\beta} \mathbf{F}_{\beta}
$$

where $\lambda$ is thermal conductivity, and $h_{\beta}$ is the specific enthalpy of phase $\beta$.

Mass diffusion for both solutes and gases is modeled with Fick's law,

$$
\mathbf{f}_{\beta}{ }^{\kappa}=-\phi \tau_{0} \tau_{\beta} \rho_{\beta} D_{\beta}{ }^{\kappa} \nabla X_{\beta}{ }^{\kappa}
$$

where $\mathbf{f}_{\beta}{ }^{\kappa}$ is the mass flux of component $\kappa$ in phase $\beta, \phi$ is porosity, $\tau_{0}$ is a tortuosity parameter dependent upon pore geometry, $\tau_{\beta}$ is a tortuosity parameter dependent upon phase saturation, $D_{\beta}{ }^{\kappa}$ is the diffusion coefficient of component $\kappa$ in phase $\beta$, and $X_{\beta}{ }^{\kappa}$ is the mass fraction of component $\kappa$ in phase $\beta$. The hydrodynamic dispersion module available in TOUGH2 was not implemented in these simulations; there are no data on dispersivities, and since properties of the fractures themselves are largely unknown, dispersion would only contribute to uncertainty. Fortunately, the primary interest is in radionuclide transport in the gas phase, and unlike the case for liquids, mass flux due to gas diffusion in porous media and fractures is more important than gas dispersion. This is explained in the text using a scale analysis. 


\section{DISTRIBUTION}

Jenny Chapman

Division of Hydrologic Sciences

Desert Research Institute

755 East Flamingo Road

Las Vegas, NV 89119-7363

Jacqueline Van Lier

Stoller-Navarro Joint Venture

7710 W. Cheyenne

Las Vegas, NV 89128

Director

Environmental Restoration Division

Nevada Site Office

National Nuclear Security Administration

U.S. Department of Energy

P.O. Box 98518

Las Vegas, NV 89193-8518

Bruce Hurley

Hydrology Program Manager

Environment, Safety and Health Division

Nevada Site Office

National Nuclear Security Administration

U.S. Department of Energy

P.O. Box 98518

Las Vegas, NV 89193-8518

Tim Echelard

Stoller-Navarro Joint Venture

P.O. Box 93838, M/S 439

Las Vegas, NV 89193-3838

Erwin Faqua, Contracting Officer

Acquisition and Financial Assistance

Department

Office of Business Services

NNSA Albuquerque Office

P.O. Box 5400

Albuquerque, NM 87185-5400
Kenneth A. Hoar, Director

Environment, Safety and Health Division

Nevada Site Office

National Nuclear Security Administration

U.S. Department of Energy

P.O. Box 98518

Las Vegas, NV 89193-8518

Richard Hopper

Deputy Laboratory Director

U.S. Environmental Protection Agency

Radiation and Indoor Environments

National Laboratory

4220 S. Maryland Parkway, Bldg. C

Las Vegas, NV 89119

Rick Hutton

Stoller Grand Junction

2597 B 3 / 4 Road

Grand Junction, CO 81503

John Jones

Environmental Restoration Division

Nevada Site Office

National Nuclear Security Administration

U.S. Department of Energy

P.O. Box 98518

Las Vegas, NV 89193-8518

Marjory Jones

Division of Hydrologic Sciences

Desert Research Institute

2215 Raggio Parkway

Reno, NV 89512-1095

Randy Laczniak

U.S. Geological Survey

Water Resources Division

160 N. Stephanie St.

Henderson, NV 89074-8829 
Tom Pauling

Office of Land and Site Management

Office of Legacy Management

U.S. Department of Energy

25973 / 4 Road

Grand Junction, CO 81503

Peter Sanders

Environmental Restoration Division

Nevada Site Office

National Nuclear Security Administration

U.S. Department of Energy

P.O. Box 98518

Las Vegas, NV 89193-8518

David Shafer

Division of Hydrologic Sciences

Desert Research Institute

755 E. Flamingo Road

Las Vegas, NV 89119-7363

Nevada State Library and Archives

State Publications

100 North Stewart Street

Carson City, NV 89710-4285

Archives

Getchell Library

University of Nevada, Reno

DeLaMare Library/262

University of Nevada, Reno

Document Section, Library

University of Nevada, Las Vegas

4505 Maryland Parkway

Las Vegas, NV 89154

Library

Stoller-Navarro Joint Venture

7710 W. Cheyenne, Bldg. 3

Las Vegas, NV 89128
Library

Southern Nevada Science Center

Desert Research Institute

755 E. Flamingo Road

Las Vegas, NV 89119-7363

Technical Library

Nevada Site Office

National Nuclear Security Administration

U.S. Department of Energy

P.O. Box 98518

Las Vegas, NV 89193-8518

Public Reading Facility

c/o Nuclear Testing Archive

Nevada Site Office

National Nuclear Security Administration

U.S. Department of Energy

P.O. Box 98521, M/S 400

Las Vegas, NV 89193-8521

Office of Scientific and Technical Information

U.S. Department of Energy

P.O. Box 62

Oak Ridge, TN 37831-9939

(electronic copy) 